\begin{tabular}{|c|c|c|}
\hline \multicolumn{2}{|c|}{$\begin{array}{l}\text { OFFICE OF CIVILIAN RADIOACTIVE WASTE MANAGEMENT } \\
\text { SPECIAL INSTRUCTION SHEET }\end{array}$} & $\begin{array}{l}\text { QA: } \mathbf{N} \\
\text { Page: } 1 \text { of: } 1\end{array}$ \\
\hline \multicolumn{3}{|c|}{ This is a placeholder page for records that cannot be scanned or microfilmed } \\
\hline $\begin{array}{l}1 . \text { Record Date } \\
08 / 01 / 97\end{array}$ & $\begin{array}{l}\text { 10. Accession Number } \\
\text { MOL. } 19980107.0365\end{array}$ & \\
\hline $\begin{array}{l}\text { 2. Author Name(s) } \\
\text { WILDER DG }\end{array}$ & $\begin{array}{l}\text { 3. Author Organization } \\
\text { N/A }\end{array}$ & \\
\hline \multicolumn{3}{|c|}{$\begin{array}{l}\text { 4. Title } \\
\text { NEARRIELD AND ALTERED-ZONE ENVIRONMENT REPORT VOLUME 1: TECHNICAL BASES FOR EBS DESIGN, } \\
\text { REVISION } 1\end{array}$} \\
\hline $\begin{array}{l}\text { 5. Document Number(s) } \\
\text { UCRL-LR-107476 }\end{array}$ & &  \\
\hline \begin{tabular}{|l|} 
7. Document Type \\
PUBLICATION \\
\end{tabular} & $\begin{array}{l}\text { 8. Medium } \\
\text { PAPER } \\
\text { PPTIC }\end{array}$ & \\
\hline \multicolumn{3}{|l|}{$\begin{array}{l}\text { 9. Access Control Code } \\
\text { MGDS }\end{array}$} \\
\hline $\begin{array}{l}11 \text { Traceability Designator } \\
\mathrm{N} / \mathrm{A}\end{array}$ & $\cdots$ & \\
\hline \multicolumn{3}{|c|}{$\begin{array}{l}\text { 12. Comments } \\
\text { ONE OF A KIND COLOR PUBLICATION CAN BE LOCATED THROUGH THE RPC }\end{array}$} \\
\hline
\end{tabular}




\title{
Near-Field and Altered-Zone Environment Report Volume 1: Technical Bases for EBS Design Revision 1
}

\author{
Dale G. Wilder
}

Publication Date: August 1997 


\section{Table of Contents}

List of Figures ..............................................................................................................................................

List of Tables............................................................................................................................................

Acronyms and Abbreviations ................................................................................................... vii

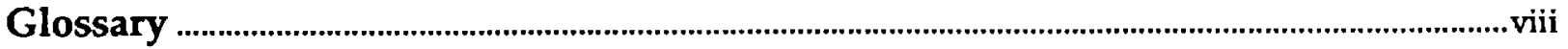



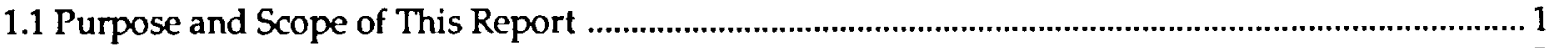

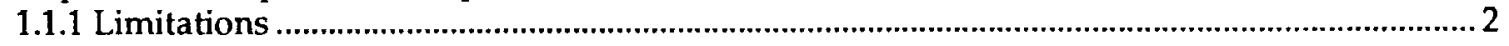

1.1.2 Emphasis on Processes......................................................................................................... 2

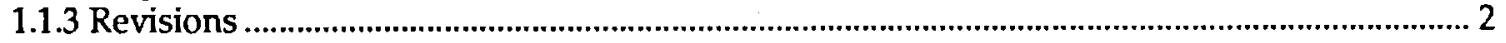

1.1.4 Quality Assurance Controls .................................................................................................... 3

1.1.5 Importance of NFE/AZ to Waste Isolation ................................................................................ 3

1.1.6 Importance to Performance Assessment ................................................................................... 5

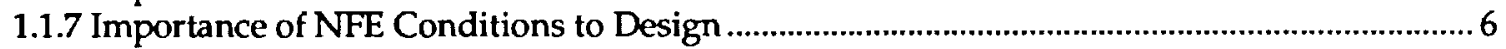

1.2 Changes Since Publication of the.Preliminary NFER ....................................................................... 7

1.2.1 Definitions of Near-Field versus Altered-Zone Environments ................................................. 7

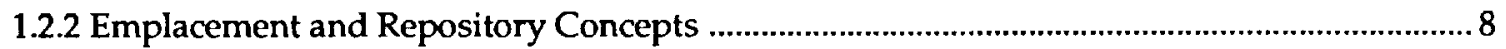

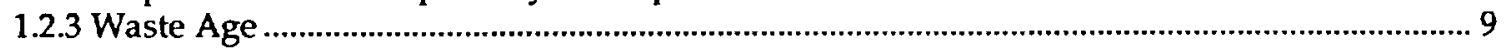

1.2.4 Prioritization of Variables and Parameters .............................................................................. 9

1.2.5 Single versus Multiple Repository Design Efforts ................................................................... 12

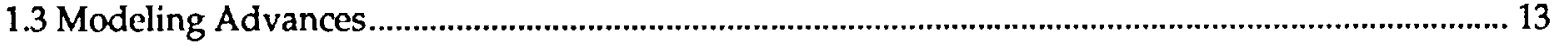

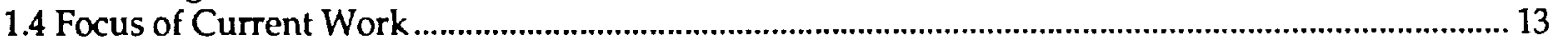

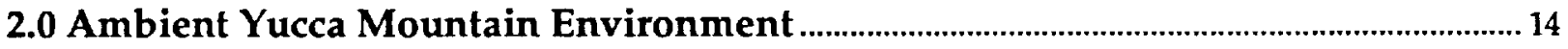



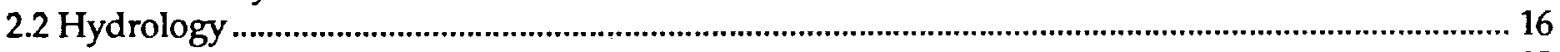

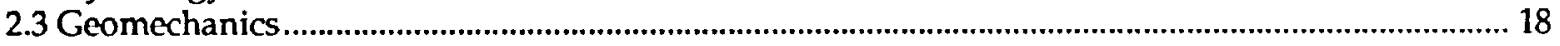

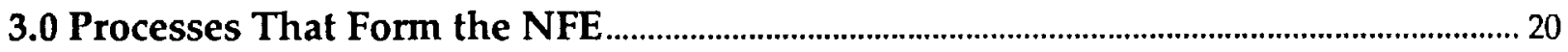

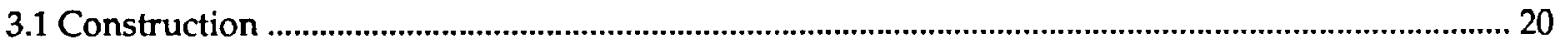

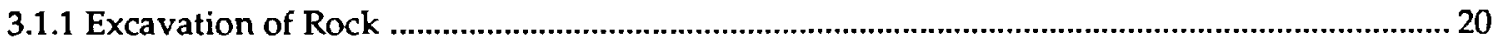

3.1.2 Fluids Introduced during Drilling and Mining ..................................................................... 20



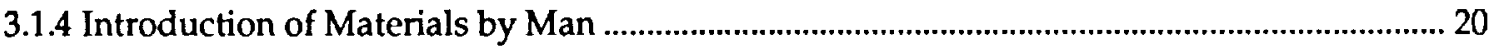

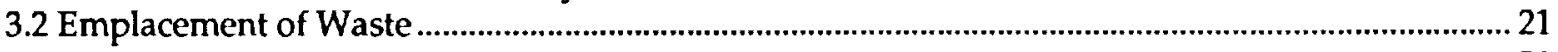

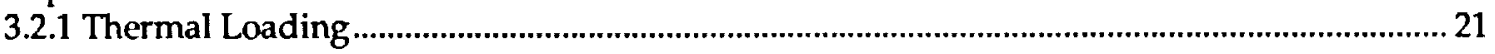

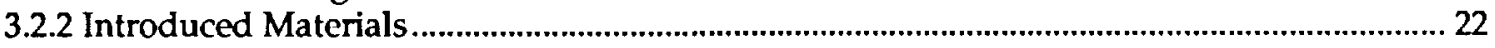

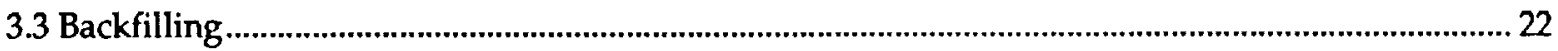

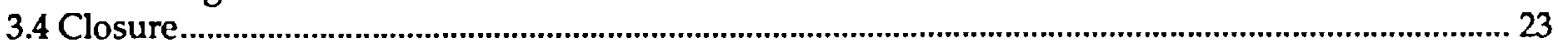

3.5 Climate or Site Environment Changes with Geologic Time ............................................................... 23

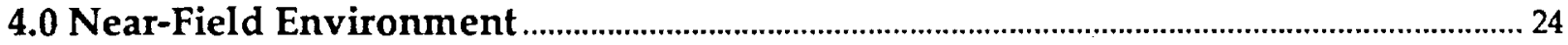

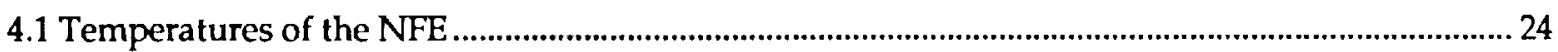

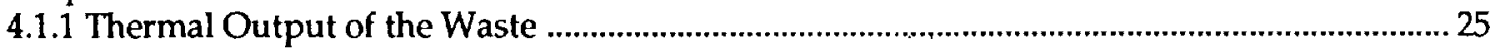

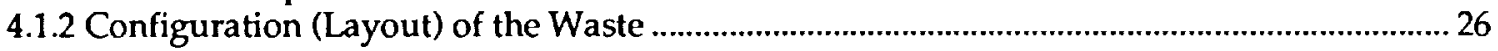

4.1.3 Thermal Conductivity of the Rock ......................................................................................... 26

4.1.4 Heat Redistribution by Moisture and Vapor ............................................................................... 26

4.1.5 Results: Temperatures in the NFE.......................................................................................... 27

4.2 Water (Liquid/Vapor) Fluxes in the NFE .................................................................................... 30 
4.3 Relative Humidity Conditions in the Drift/NFE .................................................................................32



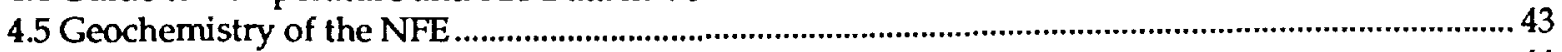

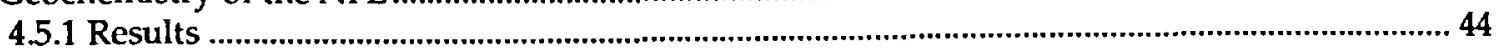

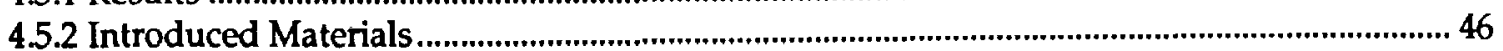

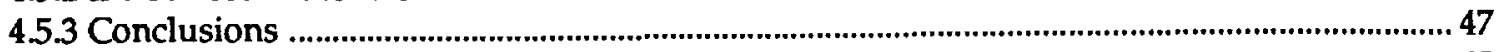

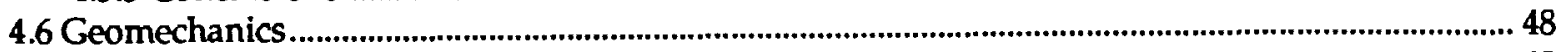

4.6.1 Ambient Mechanical Rock Properties ................................................................................... 48

4.6.2 Ambient Joint/Fracture Properties ............................................................................................. 48

4.6.3 Ambient Rock Mass Properties.............................................................................................. 49

4.6.4 Temperature-Dependent Rock Properties ................................................................................... 49

4.6.5 Time-Dependent Joint/Rock Mass Properties …................................................................... 50

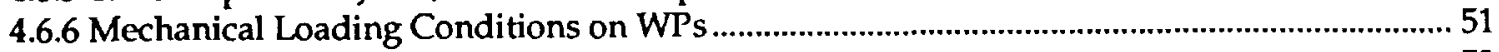

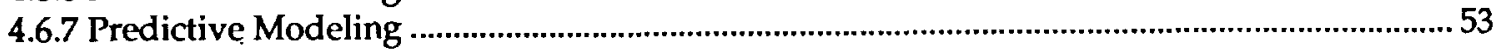

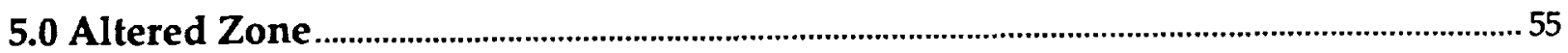

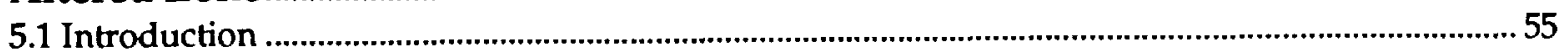

5.1.1 Definitions and Organization ........................................................................................... 55



5.2 Thermal-Hydrology in the Unsaturated Zone ............................................................................. 57

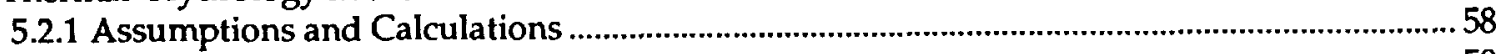

5.2.2 Influence of Fracture Permeability Distribution .................................................................... 59

5.2.3 Influence of Water Vapor and Relative Humidity ................................................................6 63

5.2.4 Overburden Thickness ................................................................................................................64

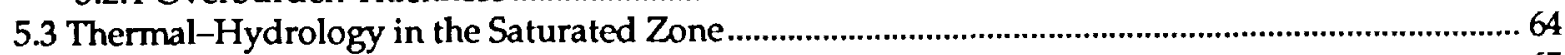

5.4 Altered Zone Geochemistry and Mineralogy ................................................................................... 65

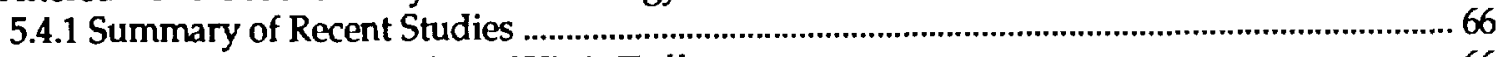

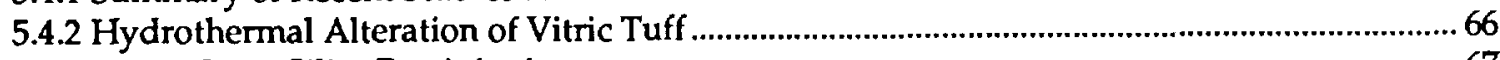

5.4.3 Amorphous Silica Precipitation.............................................................................................67

5.4.4 Bounds on Water Consumption and Secondary Mineral Development in the AZ ...............68

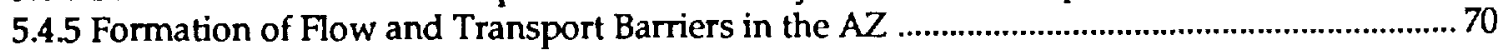

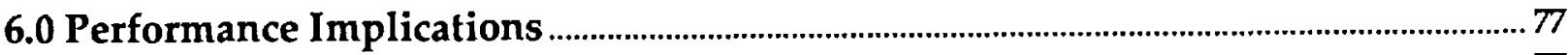

6.1 Impacts on Waste Container Performance.................................................................................... 77

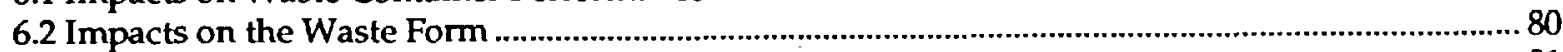

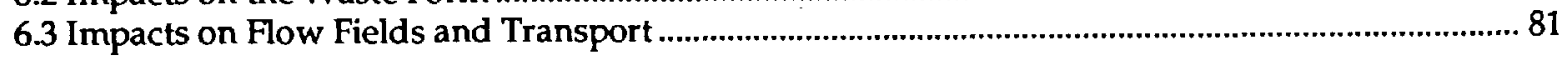

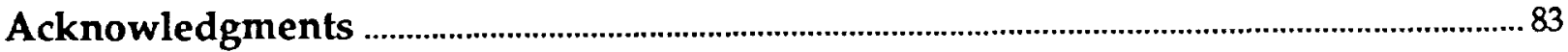

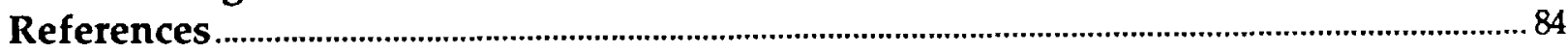




\section{List of Figures}

Figure 1-1. Figure 1-2.

Figure 1-3. Figure 1-4. Figure 1-5.

Figure 2-1. Figure 2-2.

Figure 2-3. Figure 2-4. Figure 2-5. Figure 2-6. Figure 2-7.

Figure 2-8.

Figure 4-1. Figure 4-2. Figure 4-3. Figure 4-4. Figure 4-5. Figure 4-6. Figure 4-7. Figure 4-8. Figure 4-9. Figure 4-10. Figure 4-11. Figure 4-12. Figure 4-13. Figure 4-14. Figure 4-15. Figure 4-16. Figure 4-17. Figure 4-18. Figure 4-19. Figure 4-20. Figure 4-21. Figure 4-22.

Figure 5-1. Figure 5-2. Figure 5-3. Figure 5-4. Figure 5-5.

Figure 5-6.

Figure 5-7.
Location of the Yucca Mountain site 1 Plan view of the WP layout for ACD point-load and line-load (LL) designs ...................... 8 Plan view of the WP layout for the 1997 modified repository design .................................... 8 Simplified matrix showing coupled processes in the NFE .................................................. 10 Forward and back coupling processes in the NFE ........................................................... 10

Distribution of fractures by azimuth in the main drift 14 Fracture-density histograms of fractures, cooling joints, and vapor-phase partings per meter along the main drift .......................................................................... 15 General stratigraphic column at Yucca Mountain ................................................................ 15 East-west cross section through the repository siting volume ........................................... 15 Suction potential and matric potential as a function of saturation ..................................... 16 Suction potential as a function of water saturation for Topopah Spring tuff..................... 16 Axial stress vs axial strain for uniaxial measurements on Topopah Spring tuff samples 19 Ultimate strength vs sample diameter for uniaxial measurements on Topopah Spring tuff samples

Matrix of coupled processes in the NFE 24

Calculated temperatures around the drifts for the ACD and LL designs..........................2 27

Calculated temperatures on the WP surface for the ACD and LL designs ....................... 27

Temperature on WP surface and in drift wall rock for TSPA95 reference case ..................2 29

Temperature distribution for ACD vs LL designs at 100 and $500 \mathrm{yr}$.................................30

Liquid-phase flux at the repository horizon .......................................................................... 31

Calculated relative humidities around drifts for the ACD and LL designs ......................34

Calculated relative humidities on the WP surface for the ACD and LL designs ............. 35

Matrix of coupled processes in the NFE related to water chemistry ..................................4 43

Evolving $\mathrm{pH}$ as a function of temperature ...............................................................................4 44

$\mathrm{Eh}$, in volts, as a function of temperature .............................................................................4

Total $\mathrm{Na}$ in solution, in $\mathrm{mg} / \mathrm{kg}$, as a function of temperature ...........................................4.

Total $\mathrm{S}$ in solution, in $\mathrm{mg} / \mathrm{kg}$, as a function of temperature ................................................44

Total $\mathrm{Cl}$ in solution, in $\mathrm{mg} / \mathrm{kg}$, as a function of temperature ..............................................44

Total $\mathrm{F}$ in solution, in $\mathrm{mg} / \mathrm{kg}$, as a function of temperature ...............................................4.4.

Total $\mathrm{Ca}$ in solution, in $\mathrm{mg} / \mathrm{kg}$, as a function of temperature ..........................................4 44

Total $P$ in solution, in $\mathrm{mg} / \mathrm{kg}$, as a function of temperature ............................................4 44

Total $\mathrm{Si}$ in solution, in $\mathrm{mg} / \mathrm{kg}$, as a function of temperature .............................................4

Log moles of calcite precipitated as a function of temperature ..........................................45

Log moles of dolomite precipitated as a function of temperature .......................................45

Log moles of saponite precipitated as a function of temperature ........................................ 45

Log moles of stilbite precipitated as a function of temperature .........................................45

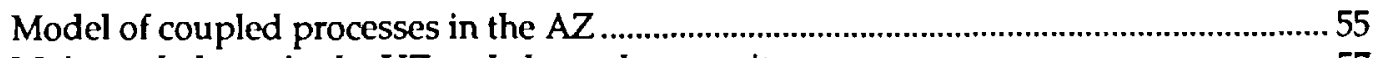

Moisture balance in the UZ and above the repository .....................................................5 57

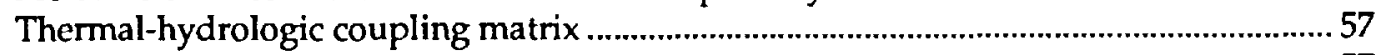

Schematic of hydrothermal flow near the emplacement drift ........................................... 57

Various time and length scales involved in how decay heat influences

the three major sources of liquid water flow...

Vertical temperature profiles and vertical liquid saturation profiles

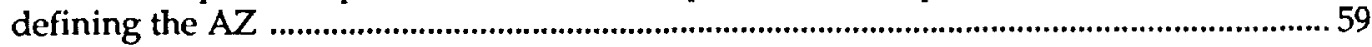

Model calculations of repository-heat-driven vapor and condensate flow. 
Figure 5-8. Duration of boiling period versus percentage of repository area enclosed for different bulk permeabilities....

Figure 5-9. Net buildup of liquid water above the repository vs time for various $k_{b}$ values

Figure 5-10. Maximum net buildup of liquid water above the repository as a function of bulk permeability

Figure 5-11. Liquid-phase flux above the emplacement drift for an AML of $83.4 \mathrm{MTU} / \mathrm{acre}$.

Figure 5-12. Liquid-phase flux above the repository horizon and relative humidity in rock at the upper drift wall for the LL design ..

Figure 5-13. Temperature history at locations below the center of the repository for an AML of 83.4 MTU/acre.

Figure 5-14. Contours of temperature rise above ambient and velocity vectors for liquid-phase flow in fractures in the SZ at 5000 and 20,000 yr

Figure 5-15. Matrix of coupled geochemical and mineralogical processes

Figure 5-16.

Estimates of sanidine abundance over time

Figure 5-17.

Matrix of coupled processes

Figure 5-18.

Mineral saturation indices vs time at the inlet node of

a GIMRT simulation at $90^{\circ} \mathrm{C}$.

Figure 5-19. Mineral saturation indices vs time at the outlet node of

a GIMRT simulation at $90^{\circ} \mathrm{C}$.

Figure 5-20.

Porosity and volume fractions of primary and secondary minerals

as a function of distance at six months for a GIMRT simulation at $90^{\circ} \mathrm{C}$

Figure 5-21.

Porosity and volume fractions of trace secondary minerals as a function

of distance after six months for a GIMRT simulation at $90^{\circ} \mathrm{C}$

Figure 5-22. Porosity and volume fractions of primary and secondary minerals as a function of time at the inlet node of a GIMRT simulation at $250^{\circ} \mathrm{C}$

Figure 5-23. Mineral saturation indices vs time at the inlet node of a

GIMRT simulation at $250^{\circ} \mathrm{C}$

Figure 5-24.

Mineral saturation indices vs time at the outlet node of a

GIMRT simulation at $250^{\circ} \mathrm{C}$

Figure 5-25.

Porosity and volume fractions of primary and secondary minerals

as a function of time at the outlet node of a GIMRT simulation at $250^{\circ} \mathrm{C}$

Figure 5-26.

Mineral saturation indices as a function of distance after six months

for a GIMRT simulation at $250^{\circ} \mathrm{C}$

Figure 5-27.

Porosity and volume fractions of primary and secondary minerals

as a function of distance after six months for a GIMRT simulation at $250^{\circ} \mathrm{C}$

Figure 5-28.

Mineral saturation indices as a function of time at the inlet node

of a GIMRT simulation at $95^{\circ} \mathrm{C}$

Figure 5-29. Mineral saturation indices as a function of time at the center node of a GIMRT simulation at $95^{\circ} \mathrm{C}$

Figure 5-30. Mineral saturation indices as a function of time at the outlet node of a GIMRT simulation at $95^{\circ} \mathrm{C}$

Figure 5-31.

Porosity and volume fractions of primary and secondary minerals

as a function of time at the inlet node of a GIMRT simulation at $95^{\circ} \mathrm{C}$.

Figure 5-32

Porosity and volume fractions of primary and secondary minerals

as a function of distance after $100 \mathrm{yr}$ for a GIMRT simulation

Figure 5-33.

Porosity and volume fractions of primary and secondary minerals

as a function of distance after $1000 \mathrm{yr}$ for a GIMRT simulation

Figure 5-34.

Porosity and volume fractions of primary and secondary minerals

as a function of distance after $5000 \mathrm{yr}$ for a GIMRT simulation.

Figure 5-35.

Porosity and volume fractions of primary and secondary minerals

as a function of distance after $10,000 \mathrm{yr}$ for a GIMRT simulation. 
Figure 6-1. Location of individual waste packages for the modified design ......................................79

Figure 6-2. Heat output as a function of the location (axial position) of individual waste packages for various averaging lengths..................................................... 79

Figure 6-3. Corrosion rate of the outer WP barrier at ambient conditions compared with the rate predicted for a 24-MTU/acre repository ......................................... 79

Figure 6-4. Cumulative corrosion depth of the outer WP barrier at ambient conditions compared with the values predicted for a 24-MTU/acre repository ................................... 80

Figure 6-5. WP relative humidity versus surface temperature for the ACD design with no backfill

Figure 6-6. WP relative humidity versus surface temperature for the $0.1-\mathrm{m}$ LL design with sand backfill

\section{List of Tables}

Table 1-1. Near-field and altered-zone environmental parameters ................................................ 12

Table 1-2. Factors that influence the near-field and altered-zone environment ............................. 12

Table 2-1. Percentages of major constituents in Topopah Spring tuff .............................................. 16

Table 2-2. Matrix properties of Yucca Mountain tuff .............................................................................. 17

Table 2-3. Physical and thermal properties of rock in the potential repository horizon .................. 18

Table 2-4. Values and ranges of principal stresses in the potential repository horizon .................... 19

Table 4-1. Peak temperatures in rock at the upper drift wall and on the WP surface for ACD and LL designs

Table 4-2 Temperature on the upper WP surface by waste type for the $A C D$ versus $L L$ design

Table 4-3. Relative humidity in rock at the upper drift wall and on the WP surface for ACD and LL designs

Table 4-4. Relative humidity on the upper WP surface by waste type for the $A C D$ versus $L L$ designs

Table 4-5. Guide to temperature and relative humidity data in

Volume II, Rev. 1 by section number 36

Table 4-6. Guide to Figures and Tables in Volume II, Rev. 1, Section 1-10 ....................................... 37

Table 5-1. Summary of infiltrating fluid composition used in simulations ...................................... 71 


\section{Acronyms and Abbreviations}

\begin{tabular}{|c|c|}
\hline ACD & advanced conceptual design \\
\hline AML & areal mass loading \\
\hline APD & areal power density \\
\hline $\mathrm{AZ}$ & altered zone \\
\hline BWR & boiling water reactor \\
\hline DHLW & defense high-level waste \\
\hline DOE & U.S. Department of Energy \\
\hline$\Delta T_{\text {drift }}$ & temperature difference between WP and drift wall \\
\hline EBS & engineered barrier system \\
\hline ECM & equivalent continuum model \\
\hline ESF & Exploratory Studies Facility \\
\hline$k_{\mathrm{b}}$ & bulk permeability \\
\hline$K_{\text {th }}$ & thermal conductivity (of WP, backfill, or invert) \\
\hline LA & license application \\
\hline LAD & license application design \\
\hline LLNL & Lawrence Livermore National Laboratory \\
\hline LML & lineal mass loading \\
\hline LPL & lineal power loading \\
\hline MTU & metric tons of uranium \\
\hline NF & near field \\
\hline NFE & near-field environment \\
\hline NFER & Near-Field Environment Report \\
\hline NTS & Nevada Test Site \\
\hline PTn & Paintbrush vitric nonwelded tuff unit at YM \\
\hline$P_{\mathbf{v}}$ & partial pressure of water vapor \\
\hline PWR & pressurized water reactor \\
\hline QA & quality assurance \\
\hline QARD & Quality Assurance Requirements and Description (DOE, 1997) \\
\hline $\overrightarrow{R H}$ & relative humidity \\
\hline RIB & Reference Information Base (DOE, 1995) \\
\hline SCP & Site Characterization Plan (DOE, 1988) \\
\hline SNF & spent nuclear fuel \\
\hline SHT & Single Heater Test \\
\hline SZ & saturated zone \\
\hline$T$ & temperature \\
\hline TBM & tunnel boring machine \\
\hline TDIF & Technical Data Information Form \\
\hline $\mathrm{T}-\mathrm{H}$ & thermal-hydrological \\
\hline $\mathrm{T}-\mathrm{H}-\mathrm{M}-\mathrm{C}$ & thermal-hydrological-geomechanical-geochemical \\
\hline Tpt & Topopah Spring Member of the Paintbrush tuff \\
\hline UNE & underground nuclear explosion \\
\hline UZ & unsaturated zone \\
\hline WP & waste package \\
\hline WPP & Waste Package Plan (Harrison-Giesler, 1991) \\
\hline YM & Yucca Mountain \\
\hline YMP & Yucca Mountain Site Characterization Project \\
\hline YMSCO & Yucca Mountain Site Characterization Project Office \\
\hline
\end{tabular}




\section{Glossary}

ACD rev 00 design

Altered Zone (AZ)

Areal mass loading

Axial WP spacing

Drift diameter

$\Delta T_{\text {drift }}$

EBS performance

Emissivity of WP

Lineal mass loading

Line-load design
This report uses the Advanced Conceptual Design (ACD) from TRW, 1996, as the Reference Design for the repository. The geometry of the $A C D$ has a spacing between drift centerlines roughly the same as axial spacing between WPs. The drift spacing is $22.5 \mathrm{~m}$, and the areal mass loading AML is $83.4 \mathrm{MTU} / \mathrm{acre}$.

In general, the region extending from tens to hundreds of meters outward from the repository, where temperatures are sufficiently low to allow liquid water to exist in pores and fractures. In this region, fundamental changes to hydrologic, mineralogic, or chemical conditions may take place, but these conditions do not interact directly with the waste packages. Rather, they interact with the near-field environment.

AML is expressed as metric tons of uranium emplaced per acre of drift (MTU/acre).

The spacing of waste packages along the emplacement drift axis, expressed as center-to-center spacing.

Diameter of drift excavation, but does not account for ground support or other engineered structures.

Temperature difference between the WP and drift wall.

The extent to which the engineered barrier system contributes to isolation of radionuclides, either by containment or limits to release from the waste package. Although the EBS may also contribute to performance by physical/chemical inclusion of radionuclides into its components, this is not normally considered as part of isolation performance.

Determines how efficiently heat is transferred by thermal radiation between a WP and the drift floor, drift wall, or adjacent WPs.

LML is expressed as metric tons of uranium emplaced per meter of drift (MTU/m).

One of several possible alternative WP arrangements in a repository at $Y M$, which lineally concentrates decay heat by placing WPs nearly end to end along drifts, i.e., tight axial spacing. For this report, the line-load design has the same AML (83.4 MTU/acre) as the ACD rev 00 design, although the AML could vary depending on drift spacing. Two line-load (LL) designs are considered:

- The 0.1-m spacing, 1.11-MTU/m line-load design, which assumes a $0.1-\mathrm{m}$ gap between WPs, resulting in an LML of $1.11 \mathrm{MTU} / \mathrm{m}$ and drift spacing of $53.8 \mathrm{~m}$.

- The 1.0-m spacing, 0.94-MTU/m line-load design, which assumes a 1.0-m gap between WPs, resulting in an LML of $0.94 \mathrm{MTU} / \mathrm{m}$ and drift spacing of $46.1 \mathrm{~m}$. 
Near-field environment (NFE)

Percolation flux

Point-load design

Reference Design

Thermal conductivity of invert or backfill

Thermal conductivity of rock

Thermal conductivity of WP

WP layout
Encompasses the region of rock and drift that is proximal to the waste packages and interacts with them; sometimes called the waste package environment (WPE). In general, the NFE or WPE is where temperatures reach above the boiling point and where resulting changes in environmental conditions dominate. These changes may be reversible.

Generally applied to the amount of water that moves through the rock mass below the zone where infiltration and evapo-transpiration can remove water. For this report, the term focuses on the liquid-phase flux in host rock (TSw2 unit at Yucca Mountain).

A repository design wherein waste is placed with sufficient spacing that environmental conditions of temperature and moisture do not reflect the influence of adjacent waste packages. To a large extent, the ACD rev 00 design is a point-load design.

See $A C D$ rev 00 design.

The measure of how effectively heat is conducted through introduced invert or backfill materials.

The measure of how effectively heat is conducted through the repository rock.

The measure of how effectively heat is conducted through the waste package.

The geometric configuration of waste emplacement. For this study, the layout consists of axial spacing along a drift between waste package (WP) centers and lateral spacing between drift centers (called drift spacing). Although other design options exist (e.g., two parallel rows of WPs in a drift or WPs placed off-center in a drift), this report is limited to layouts of WPs centered within drifts. 


\section{Near-Field and Altered-Zone Environment Report Volume 1: Technical Bases for EBS Design \\ Rev. 1}

\subsection{Overview}

The United States Department of Energy (DOE) is investigating the suitability of Yucca Mountain as a potential site for the nation's first high-level nuclear waste repository. As shown in Fig. 1-1, the site is located about $120 \mathrm{~km}$ northwest of Las Vegas, Nevada, in an area of uninhabited desert.

Figure 1-1. Location of the Yucca Mountain site.

Favorable aspects of Yucca Mountain (YM) as a potential repository site include its arid nature and the sorptive properties of the rock materials. The arid environment results in unsaturated conditions at the potential emplacement horizon, which is the Topopah Spring Member of the Paintbrush tuff (Tpt). The major advantages of unsaturated conditions are that container corrosion, waste-form leaching, and radionuclide transport mechanisms are minimized because of the lack of contact between liquid water and the waste package (WP). Although recent studies indicate that percolation fluxes may be higher than originally anticipated, the major advantages should still apply, but their significance must be evaluated.

Lawrence Livermore National Laboratory (LLNL) is a Yucca Mountain Site Characterization Project (YMP) participant and is responsible for WP and engineered barrier system (EBS) evaluations, including materials testing, waste-form characterization, EBS performance assessments, and near-field environment (NFE) characterization. Materials testing, design criteria and concept development, and waste-form characterization all require an understanding of the environmental conditions that will interact with the WP and EBS. The Near-Field Environment Report (NFER) was identified in the Waste Package Plan (WPP) (Harrison-Giesler, 1991) as the formal means for transmitting and documenting this information.

\subsection{Purpose and Scope of This Report}

The first NFER was published in April, 1993 as a preliminary report (Wilder, 1993) because the design and characterization studies were not mature. Since publication of the Preliminary NFER, information regarding the environment of the potential repository site has progressed considerably. This new report is Revision 1 of the NFER. The term "Preliminary" has been dropped from the title to reflect the greater maturity of both design and characterization efforts. In addition, at the time the Preliminary NFER was published, a companion report was intended that would focus on the altered zone (AZ) environment-that is, the environment that develops away from the WPs and impacts the waste and its containers only in terms of its influences on the WP environment. Subsequently, a decision was made to combine both WP and AZ reports into the NFER. This decision recognizes the interdependence of the WP and AZ environments and the fact that the studies documented in the companion volume (Volume II of this report) apply to both of these zones of the environment.

The purpose of this new Near-Field and Altered-Zone Environment Report is to update the Preliminary NFER, to convey current understanding of environmental conditions, and to provide 


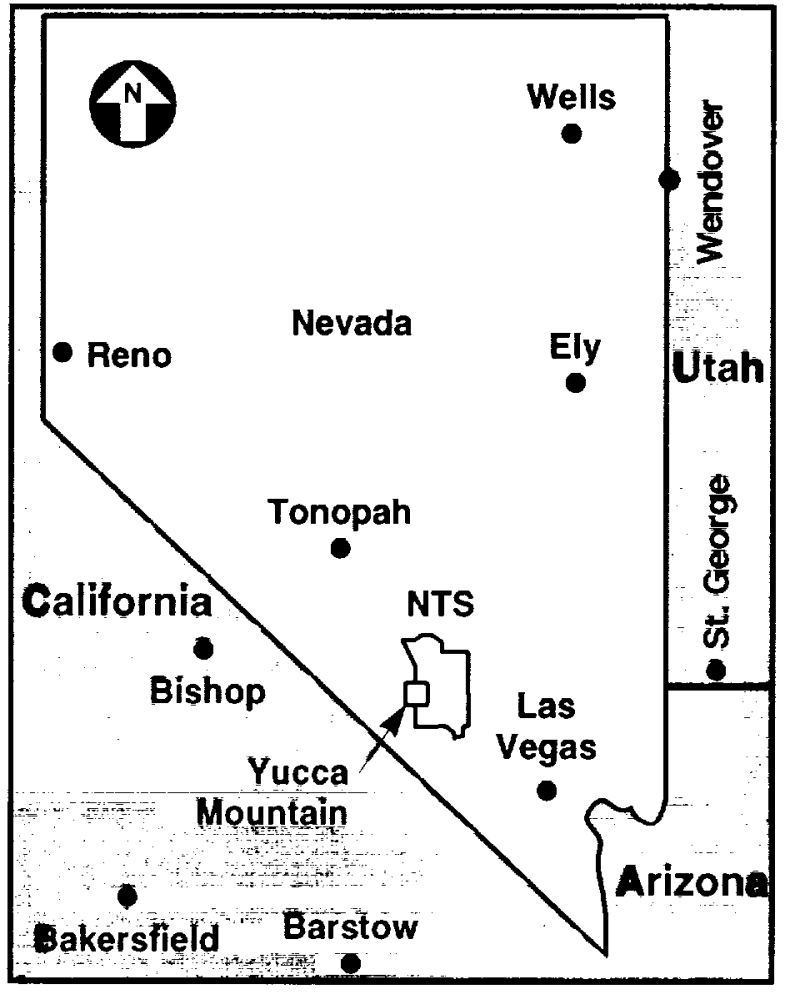

Figure 1-1. 
technical information needed for repository design decisions and performance analyses. Volume I provides the technical bases for design of the EBS, which is derived from our current knowledge of the waste-package and altered-zone environment. Volume I also discusses the $A Z$ as it might impact performance analyses; however, Volume II is the principal source of information regarding the $\mathrm{AZ}$.

Volume II consists of 11 sections providing much more detailed discussion of the topics in Volume I as they pertain to particular fields of study. Volume II includes information on many different design options, property values, and sensitivity analyses. Volume I focuses on the ACD (reference) design and on project reference property values. To allow scientists and engineers to determine the validity of information in Volume I, Volume II documents the scientific and engineering data, models, and approaches used to gather information. Of particular relevance in Volume II are an extended and updated description of hydrothermal modeling (Sec. 1) and new discussions of the AZ environment (Sec. 10) and thermodynamic data determination of radionuclides (Sec. 11).

\subsubsection{Limitations}

Evaluations of the expected environment are based on currently available understanding of properties, parameters, analyses, and assumptions, as well as reference designs, and on prototype or scoping tests and analyses. In some cases, information from similar rock type or formations as well as from specific mineral or chemical conditions is used. Field tests needed to characterize the responses of $\mathrm{YM}$ and to test the model conceptualizations have not been completed at the time of this report. Thus, although the information in this report is considered accurate vis-a-vis modeling approximations, the validation exercises have not been completed. Future assessments will be required to determine if the environment as described here is appropriate for conditions at YM.

\subsubsection{Emphasis on Processes}

The design and performance of the WP and EBS will depend on the hydrological, geochemical, and geomechanical conditions that develop over time in the rock extending for considerable distances into the mountain. For that reason, emphasis in this report is placed not only on the conditions that will result and their associated parameter values, but also on the processes that will change the environmental conditions. That is, it is necessary to understand not just the statistical distribution of environment conditions, but also the physical processes themselves.

A mechanistic understanding of processes and events as they unfold over time is essential for several reasons. For example, the degree of rock saturation is one important aspect of the repository environment. However, what the initial saturation happens to be is insufficient information for design and decisions. It is the amount, timing, and temporal distribution (steadystate or episodic) of water contacting the waste that are pertinent to design. To estimate the amount of water expected to contact waste at or over a given time, we must integrate saturation data with other factors, including, (1) percolation flux, (2) fracture-matrix flow models, (3) fracture distribution, (4) emplacement configuration, (5) areal mass loading, (6) projected WP thermal characteristics, and (7) repository design. Similarly, events as wide ranging as construction activities, microbial processes, climate change, and many others may modify repository conditions. For these reasons, the report focuses not only on detailed technical information but also on the interaction of processes and the integration of values.

\subsubsection{Revisions}

This Near-Field and Altered-Zone Environment Report is the first of the scheduled NFER revisions identified in the WPP. However, the WPP has been superseded by the Annual Planning 
process. Although the process does not have the same revision points as those specified in the WPP, it includes updating the NFER at major milestones, such as at completion of field testing, and at times needed for major decisions or documents, such as viability assessment and license application. This revision (Rev 1 of the NFER) will support the viability assessment and associated design and performance assessment. A second revision of the NFER will be based on the Large Block Test at Fran Ridge and the single heater test (SHT) in the Exploratory Studies Facility (ESF). The second revision will support the license application design (LAD) phase. A third revision based on ESF test results will support defense of the license application (LA) and the LA amendment to emplace waste. Additional reports are likely, and they will cover subsequent work related to the performance confirmation phase.

\subsubsection{Quality Assurance (QA) Controls}

At the time of the Preliminary NFER, a distinction was made between quality-affecting work and work that was not quality-affecting. Subsequently, changes have been made in the QA program. All of the work or activities reported in this Near-Field and Altered-Zone Environment Report comes under the control of the Quality Assurance Requirements and Description (QARD; DOE, 1997). All data included in this report, except for referenced information from other sources not collected under YMP controls, were collected under controls of the QARD and are therefore qualified for use. The specific controls are noted for each activity in Scientific Notebooks. However, the material presented in this report is a synthesis of data and other information that have been collected under other activities and reported elsewhere. Therefore, no new data are transmitted in this report that were not already transmitted to YMP by Technical Data Information Form (TDIF). Most of the data appear in Volume II, and the QA status of the data is determined by the activities and reports from which they were synthesized.

\subsubsection{Importance of NFE/AZ to Waste Isolation}

The emphasis of the safety argument has changed over the years, both in response to changing understanding of the regulations as well as of the repository and natural system. When the Site Characterization Plan (SCP) was prepared, it was understood that the containers must contribute to satisfy requirements of the regulations by substantially complete containment of the waste for 300 to 1000 years. The waste form was required to release no more than 1 in $10^{5}$ of the 1000 -year radionuclide specific inventory for up to 10,000 years. Because the container was assumed to perform for 1,000 years - as opposed to the waste form for 10,000 years - the stress on the NFE was to provide an environment that was compatible with waste form performance by keeping the $\mathrm{pH}$ close to neutral and avoiding higher $\mathrm{pH}$. This was the reason for the requirement in the SCP to limit the use of concrete or cementitious materials in the repository. There were also SCP requirements to prevent water contact by maintaining a capillary barrier (gap between WP and borehole rock) and limiting rock sloughing into boreholes. The natural system was then relied on to provide a ground water travel time that exceeded 1000 years and also to retard the transport of the radionuclides by sorption and similar processes. The natural system was assumed to provide this function for times that extended up to 1,000,000 years under some regulatory interpretations. Because of the emphasis on long times and on retardation of radionuclides, it was deemed important to keep from destroying the sorptive minerals (zeolites). To protect the sorptive minerals as well as other components of both natural and engineered systems a series of constraints were placed on temperatures. In the case of sorptive minerals, these temperature limits were placed because dehydration of zeolites would impact their sorptive capacities. These limits are reflected in the SCP.

At the time of the Preliminary NFER, the greatest emphasis for isolation continued to be on the unperturbed natural system, although credit for lifetimes of the container beyond 1000 years was being considered, and thus concepts to maintain a very dry NFE (extended dryout) were being stressed. Because of the possibly conflicting goals of high temperatures to keep packages 
dry and lower temperatures to prevent dehydration or alteration of sorptive minerals (as well as thermal performance issues of other components of the repository/waste disposal system), a series of thermal goals was formalized. During this time, the requirement for $\mathrm{pH}$ control or limit on use of concrete was relaxed.

The current strategy has placed more reliance on the Engineered Barrier System, specifically the container. This emphasis is illustrated by several draft Waste Isolation Strategies. Although none have been formally accepted by the DOE, they place increased emphasis on the EBS with either greatly reduced emphasis on the natural system or at least equal emphasis on the EBS. The strategy is in transition, and the thermal goals have remained largely as they were during the time of the Preliminary NFER. Current information indicates that geochemical processes that result from the coupling of heat and fluids generated from waste emplacement will form large volumes of sorptive minerals within the AZ. Furthermore, there will likely be a significant change in the hydrologic system. However, there are large uncertainties in our understanding of the natural system, and recent evidence suggests much higher percolation fluxes than originally anticipated. As a result, there has been a tendency to place greater emphasis on very robust WPs (e.g., ceramics) that will be able to last for times that exceed 10,000 years regardless of the water and water chemistry to which they are exposed. The much greater emphasis on very robust containers occurred since publication of Volume II of this report. This evolving strategy has not fully addressed performance issues beyond the 10,000 year time frame. Because the strategy has not been officially adopted and is evolving, this report will not focus on it but recognizes and addresses the implications.

The impact of the NFE on the evolving waste isolation strategy depends, to a large degree, on the portion of the waste isolation system being considered. The three main aspects of the system that will contribute to isolate waste from the accessible environment are:

- The waste form itself.

- The container in which the waste is placed.

- The natural system (rock mass).

In addition, many engineering options (such as drip shield or backfill) can enhance the performance of these three components. However, the actual isolation of waste as required by regulations (e.g., 10 CFR 60) depends only on the functioning of these three components. For instance, a drip shield will not contain the waste or control the rate of release, except as it impacts water contact. Thus, a drip shield is more a determinant of the NFE that a component of the isolation system. Whereas other components can contribute to isolation, it is the author's contention that they can be covered as part of the NFE rather than the isolation system. Perhaps the distinction is not as clear for backfill because such material can provide performance similar to that of the natural system, although at a much smaller geometric scale. As discussed below, the NFE impacts the three major components listed above in different ways, but is a very important factor in the performance of each of them.

The waste form contributes to isolation of radionuclides mainly by limiting the rate at which the waste can be released. The NFE factors that influence the rate of release are the amount, temperature, and chemical content of water that is able to contact the waste. The properties of the waste that determine this rate are discussed in the Waste Form Characteristics Report (Stout and Leider, 1997). Note that this does not address the gaseous radionuclide releases (e.g., ${ }^{14} \mathrm{C}$ ), which are not expected to be the major releases. The NFE will be a major factor in the release rates from the waste form because the quantity, temperature, and chemistry of water contacting the waste are all parts of the NFE. Water chemistry contacting the waste will likely be dominated by introduced materials (including potentially significant amounts of corrosion products), and the quantity of water will certainly be influenced by the mobilization of water due to waste 
emplacement. Microbial activities as well as the presence of colloids from corrosion products and microbes can have a major impact on the mobilization of radionuclides from the waste form.

Container performance depends on the container design and materials selected, and on their interaction with the NFE, specifically the quantity, temperature, and chemical content of both liquid water and water vapor as well as drift gaseous makeup (i.e., presence or absence of oxygen and $\mathrm{CO}_{2}$ ). The mode of contact of water (dripping, continuous contact, condensation) also is an important factor in the performance of the container, or more specifically, on corrosion kinetics. Once again, these factors are all components of the NFE, and the processes noted for the waste form will be important to the container performance, although the influence of corrosion products and colloids will not be as significant. Even if a ceramic waste container is selected, it will be impossible to guarantee $100 \%$ performance of the ceramic because of undetected manufacturing flaws, damage, and other issues. Thus, the NFE becomes critical, and given the trend toward increased reliance on the container, it will be the most critical portion of the environment.

The natural system contributes to isolation in three ways. First, it limits the amount of water that can contact the waste and WPs. Factors that limit the amount of water include the unsaturated rock mass and the tight rock matrix. Second, the natural system can prevent radionuclide migration through chemical exchange or sorptive processes with the rock minerals and pore water. Third, the natural system contributes to isolation by delay in transport, which will either allow shorter-lived radionuclides to decay or will allow for delayed releases and dilution processes to lower the dose rates. Of course, there are also processes within the natural system that can concentrate radionuclides by allowing them to accumulate over time.

Processes within the NFE/AZ can impact the water distribution, specifically the redistribution of water due to waste heat. Processes that occur in the AZ can also contribute to significant changes in porosity and permeability, which can have dramatic impacts on the water contact issues. These processes can also result in significant modifications of the mineralogy of the system, resulting in vastly different sorptive capacities of the system (not all of which are detrimental). In addition, if dryout occurs within the AZ, there is increased capacity for imbibition so that radionuclides in any water that is imbibed from the fractures into the pores would tend to be physically held by capillary forces for very long times. Thus, the AZ can have potentially positive impacts on performance.

\subsubsection{Importance to Performance Assessment}

The rate of radionuclide release (and dose rate) at the accessible environment depends on the time that release from the EBS begins, the magnitude and duration of the release, and decrease in magnitude (attenuation) of radionuclide concentration resulting from radioactive decay and dilution during the time required for radionuclides to move through the natural system from the repository to the accessible environment.

Radionuclide release from the EBS requires two conditions:

- A breach, or failure, of the WP, including the outer corrosion-allowance barrier, inner corrosion-resistance barrier, and cladding.

- Contact of the waste form by liquid water, which can dissolve or suspend radionuclides and transport them through the failed WP and other elements of the EBS to the unexcavated rock host. (Once again, this does not address release of gaseous radionuclides, such as ${ }^{14} \mathrm{C}$. However, these radionuclides are not identified by the TSPA or Waste Isolation Strategies as major concerns and are not included in NFE discussions.) 
Postemplacement cladding failure will be controlled primarily by the temperature within the WP. An additional factor is the amount of oxygen that is able to contact the cladding. If temperatures are high at the time $\mathrm{O}_{2}$ contacts cladding, the cladding will oxidize rapidly. In addition, if temperatures are high and $\mathrm{O}_{2}$ can contact the waste (penetrate the cladding) it will oxidize with significant volume increase thereby bursting the cladding. Furthermore, oxidized fuel is much more soluble than non-oxidized fuel. WP temperature depends on the rate of heat transfer between the WP and its surroundings. Heat transfer rate, in turn, depends on whether or not backfill is used, the spacing between drifts and between WPs, the thermal output of waste, and other factors. The heat transfer rate from WPs is not expected to be particularly sensitive to the presence within the repository of liquid water or its chemistry. The mode of heat transfer may be impacted, as well as distributed along the drift, but overall transfer will be fairly insensitive.

Breach of the outer barrier is determined by its corrosion rate, particularly the localized rate of attack or "pitting rate." Current analysis suggests that the depth of pits in the corrosionallowance material can be modeled statistically by a random pitting factor times the general corrosion depth. The general corrosion rate is a function of NFE conditions (humid air or aqueous surroundings). For humid air conditions, the corrosion rate is much more sensitive to relative humidity than to temperature. Some of the rate parameters also depend strongly on the chemical composition of solids on the WP surface, because the composition of salts can control the humidity at which a liquid film can form. These solids could be manufacturing residues or salts left by the evaporation of water.

Breach of the inner corrosion-resistant barrier will be controlled almost entirely by the internal environment until the outer barrier is breached. At that time, the NFE could affect corrosion. The materials being considered have extremely slow general corrosion rates under anticipated repository conditions. The highly localized forms of corrosion depend on the chemistry of water entering the drift and on microbiological attack. The main considerations are halide ions entering the drift, which can substantially increase pitting, and nutrients for microbes, which can accelerate corrosion by creating a more aggressive microenvironment.

Even if a container fails, negligible amounts of radioactive material will be released from the repository unless liquid water is advected into the drift, into the breached WP, into the waste form, out of the WP, and into the repository horizon rock. Hence, the timing of advected water entry, flux of liquid water, and its chemistry will be the most important NFE variables for performance assessment after failure of WPs. All of these issues may be dominated by changes within the NFE from processes involving:

- Introduced materials, such as corrosion products, backfill, and altered drift liner materials.

- Mineralogical changes that can influence the hydrologic properties and water chemistry.

- Coupled thermal-mechanical-hydrological processes within the AZ, which may completely change the flow fields above and below the repository.

Such processes could alter the physical and geochemical processes in the NFE that control WP performance as well as the transport of radionuclides in both the unsaturated zone and in the saturated zone below the repository.

\subsubsection{Importance of NFE Conditions to Design}

The Performance Assessment implications of NFE conditions suggest that design goals should include the development of an EBS that, in concert with the natural system, will provide a long delay between emplacement and the first contact of waste by water. The overall design goal is to prevent water from contacting the waste form as long as possible and to limit the amount of waste contacted by water after contact begins. The NFE that develops above the repository may change the amount, chemistry, and mechanisms (location, timing, and duration) of water seeping 
into drifts and ultimately contacting the waste form. Calculated fluxes around the drifts during the first few hundred years, driven by decay heat, are in the range of hundreds of millimeters per year. Thus, depending on the design, percolation flux into the drifts from condensed water may far exceed that of meteoric water.

Survival of the WP can be greatly increased if the relative humidity at the WP surface is kept low. Current calculations suggest that a thermal loading strategy can be used to reduce humid air corrosion during the thermal pulse to rates below those under ambient conditions. The duration and magnitudes of this reduction depend on many factors, including percolation flux. Uncertainty exists in the validity of the models used in the calculations. Thus, it is important to experimentally test the thermohydrological model calculations that predict the ability to maintain low relative humidity for thousands of years. If the model results are correct, then design decisions can be made to use heat constructively for increasing WP life.

The importance of NFE conditions to design can be seen by current discussions of design modifications. Recent results of site investigations indicate that the ambient infiltration flux could average as high as 5 to $10 \mathrm{~mm}$ per year, with large temporal and spatial variations above and below those averages. If these ambient fluxes were allowed to contact a significant fraction of the waste inventory, such contact could lead to releases larger than some of the proposed dose standards. Hence, conceptual designs are being developed, including measures such as drip shields and ceramic coatings, to divert water from failed packages or to lengthen the package lifetimes, respectively.

\subsection{Changes Since Publication of the Preliminary NFER}

\subsubsection{Definitions of Near-Field versus Altered-Zone Environments}

The Preliminary NFER focused on environmental conditions that will have a direct impact on the WP container materials and on the waste form. From work that supported the Preliminary NFER, it was recognized that interactions between the environment and waste could potentially cause important property changes that could extend for considerable distances into the rock mass or natural system. Although the same suite of processes exist in all zones of the perturbed environment, those that dominate the NFE or even the far-field environment (FFE) (essentially, the unperturbed environment) are not necessarily the same as those that dominate in the region between them. Therefore, an altered zone (AZ) was defined and is now the focus of considerable attention. As noted earlier, information on the $\mathrm{AZ}$ is included in this report to provide a complete description of all aspects of the perturbed environment.

This report defines the near-field environment (NFE) as encompassing the region of rock and drift that is proximal to the WPs and interacts with them. The NFE has sometimes been called the WP environment (WPE). In general, the NFE or WPE is where temperatures reach above the boiling point. This environment evolves over time in response to waste emplacement. Some of the resulting changes in environmental conditions may be reversible.

The $\mathrm{AZ}$ refers to those regions where the rock mass undergoes changes due to coupled processes again related to emplaced waste. These changes may also be reversible over long times but are typically long-lived or permanent. In general, the $A Z$ is a region where temperatures are sufficiently low to allow liquid water to exist in pores and fractures, al though it may include vapor-dominated regions as well. The $A Z$ is the region where rates of geochemical interactions with the environmental parameters are a maximum. Conditions in the $\mathrm{AZ}$ do not interact directly with the waste packages but, rather, interact with the NFE. Furthermore, changes in the AZ are more significant than those in the FFE, where ambient conditions prevail. The distinction between the NFE and FFE is based on processes and resultant changes rather than on a single 
geometric scale. The AZ may extend considerably farther for some processes than for others, ranging from tens to hundreds of meters outward from the repository.

\subsubsection{Emplacement and Repository Concepts}

An important development since publication of the Preliminary NFER is that major changes in the disposal concept have taken place. Emplacement is no longer planned in open boreholes and thin-walled containers. Rather, emplacement is currently envisioned in large, multi-barrier WPs within emplacement drifts (horizontal tunnels).

Three repository design options are evaluated in this Near-Field and Altered-Zone Environment Report. The three designs are all based on an areal mass loading (AML) of $83.4 \mathrm{MTU} / \mathrm{acre}$. The designs are:

- The Advanced Conceptual Rev 00 Design (ACD) (CRWMS M\&O, 1996), as shown in Fig. 12(a). In the ACD design, the axial center-to-center spacing of WPs varies from 10.3 to $14.6 \mathrm{~m}$, and the drift-to-drift spacing is $22.5 \mathrm{~m}$. Because WP spacing is large in comparison to their length and is from 46 to $65 \%$ as large as the drift spacing, the WP heat tends to be point (or isolated) sources. The waste types are indicated in the figure.

- An alternative design has been suggested by LLNL in which the WPs are placed nearly endto-end, as shown in Fig. 1-2(b). Two versions of WP spacings are analyzed: one with $1.0-\mathrm{m}$, end-to-end WP spacing; and one with 0.1-m, end-to-end WP spacing (or gaps). This results in center-to-center spacings of 5.68 to $6.68 \mathrm{~m}$. The drift spacing to maintain an AML of 83.4 MTU/acre is $53.8 \mathrm{~m}$, Thus, the WP spacing is roughly 10 to $12 \%$ of the drift spacing, and the WP heat tends to be a line source (conduction between packages of different waste types evens out the differences in heat output). This alternative design is referred to as the line-load (LL) design.

- The 1997 modified design, as shown in Fig. 1-3 wherein a slightly larger drift spacing (28 m versus $22.5 \mathrm{~m}$ for the ACD design) is used, together with closer WP spacing (6.6 to $14.23 \mathrm{~m}$ versus 10.3 to $14.6 \mathrm{~m}$ for the ACD design). The end-to-end gap or spacing for this design is 1 to $8.5 \mathrm{~m}$ versus 5 to $10 \mathrm{~m}$ for the ACD design, so that there is somewhat less isolation of the heat output. In addition, the WP spacing is a slightly smaller percent of the drift spacing (20 to $51 \%$ versus 46 to $65 \%$ for $A C D$ ). Thus, the difference between drift and pillar thermal conditions is greater than that for the ACD design.

Figure 1-2. Plan view of the WP layout for (a) the ACD point-load design and (b) the LLNLproposed line-load (LL) design. Both designs result in an AML of 83.4 MTU/acre.

Figure 1-3. Plan view of the WP layout for the 1997 modified repository design. The AML is 85 MTU/acre, and drift spacing $=28 \mathrm{~m}$.

The first two designs are the basis for analysis in Volume II. Because the 1997 modified design falls somewhere between the ACD and line-load cases in terms of WP spacing and ratio of WP to drift spacing, the ACD and line-load designs can be viewed as the bounding cases for designs currently under consideration. Where the modified design includes 1- to 2-m end-to-end spacing, the line-load analysis is more pertinent; where that spacing is closer to $8.5 \mathrm{~m}$, the ACD analysis is more germane. Nevertheless, the ACD and line-load designs bound the conditions.

Whereas the ACD and line-load designs bound the average conditions, the actual distribution of waste types can impact specific conditions associated with individual WPs. The ACD and lineload designs use the same distribution of waste types; the only difference is the spacing of WPs and drifts. However, the 1997 modified design not only varies the spacing, but also the way the waste types are distributed. Therefore, the environmental conditions given in this report for individual waste types should not be used to necessarily bound the conditions that could be 
(a) ACD design

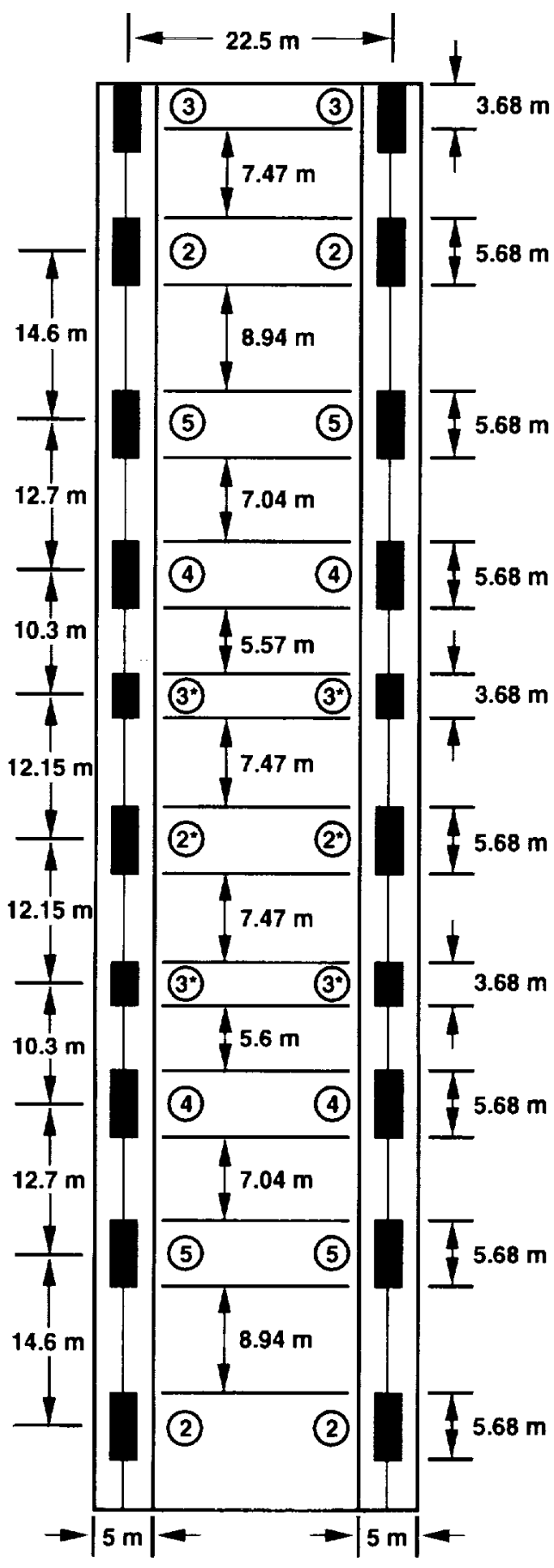

(b) Line-load (LL) design

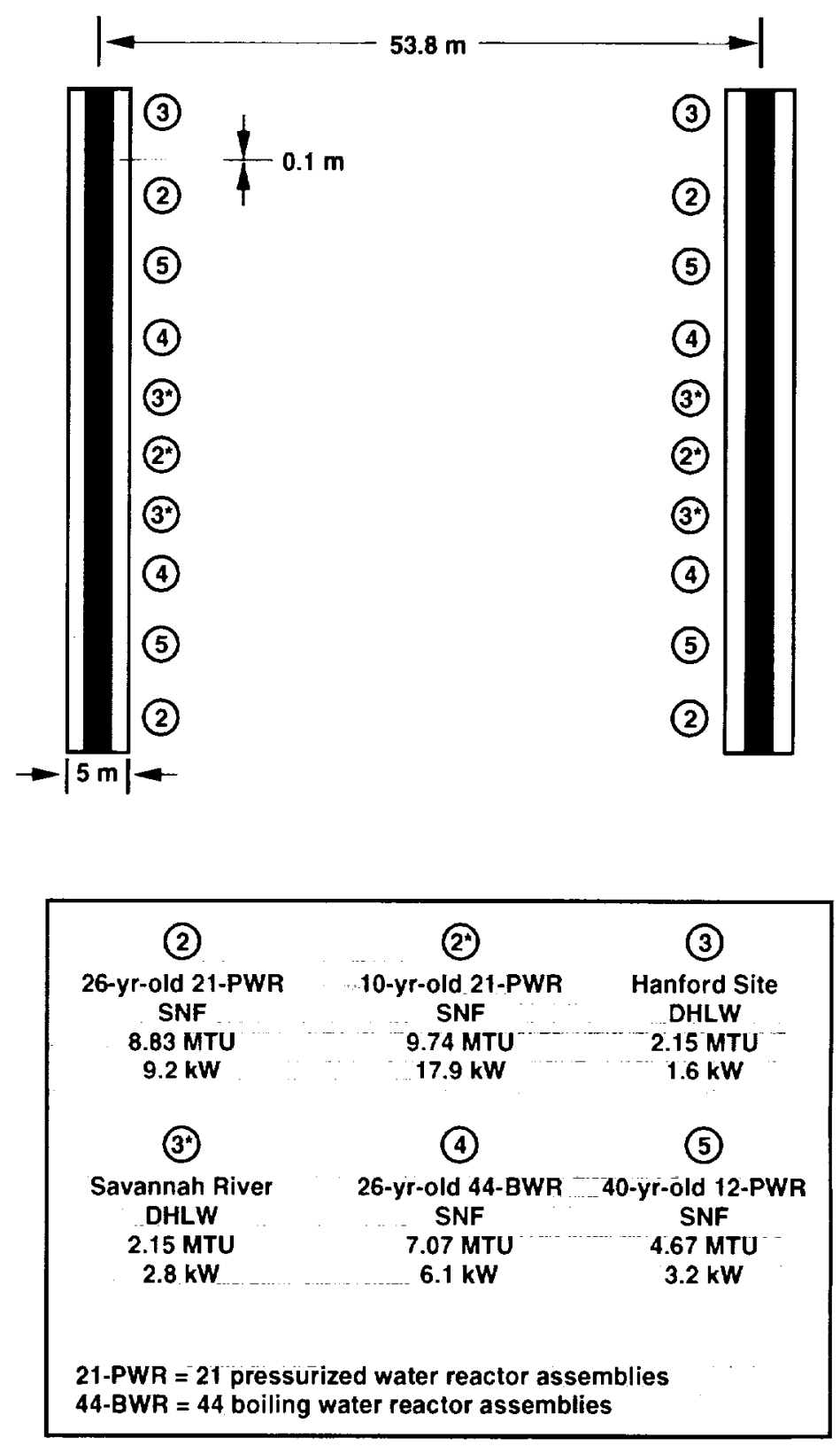

Note: heat outputs are at time of emplacement

Fig 1-2. 

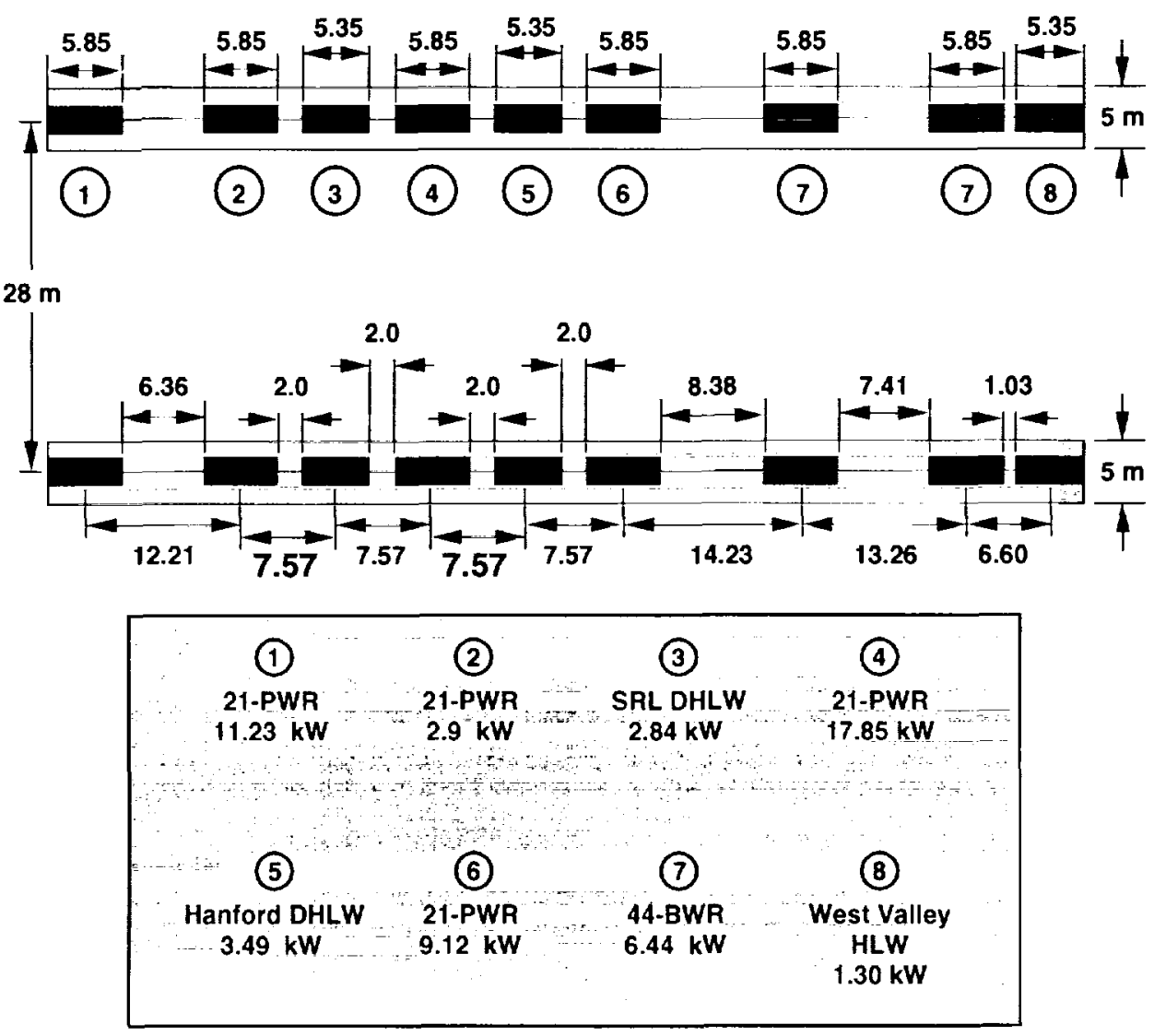

Figure 1-3. 
expected for individual waste containers under the modified design. The analysis of these environmental conditions will be included in future versions of this report, if the modified design remains pertinent.

\subsubsection{Waste Age}

At the time the Preliminary NFER was published, many of the analyses were based on the hottest or youngest waste that was considered likely to be emplaced. The age for that waste was approximately 10 years out of core. No detailed information on what the actual emplacement age will be is available (some young waste could be emplaced first, depending on how waste is delivered from utilities). However, the age of the overall inventory has increased, and 10-yr-old waste is probably an unrealistic value.

The ACD design specifies a mix of 10-, 26-, and 40-yr-old SNF, with 26-yr-old as the most prevalent. This represents the typical waste age discussed in Rev 1 . As was the case at the time of the Preliminary NFER, several issues continue to make the age of SNF subject to great uncertainty. Current discussions are considering interim storage, which could result in considerably older waste at the time of emplacement. Waste age has the greatest impact on peak WP and rock temperatures and on the time that the peak occurs. In general, older waste results in a lower peak, which occurs at later times.

\subsubsection{Prioritization of Variables and Parameters}

Another distinction between the Preliminary NFER and this report is in the organization of information according to environmental priorities. The Preliminary NFER was organized by following a temporal sequence, from preemplacement activities and conditions to postemplacement conditions and performance implications. A primary purpose of that report was to inform the reader about the complexity of changing conditions and interactions over time, and it remains a valuable reference tool for that reason. However, the earlier report made no attempt to prioritize processes that may change the environment or the most relevant environmental parameters themselves.

This report includes an attempt to rank order, or at least focus on, the factors or conditions that are important for design decisions and Performance Assessment. The purpose of prioritizing the most germane factors and focusing on a few design options is to facilitate design decisions and to center attention on which of the myriad variables may be the most important for overall repository design considerations and performance of the EBS.

A key consideration in the ranking is the interactions between the WPs/repository and the NFE. These interactions are not separable; that is, the WP/repository impacts the NFE, but the NFE also impacts performance of the WP/repository. For example, we know that areal mass loading (AML) defines the repository environment to a larger extent than does a host of other factors, ranging from drilling and ventilation to radiation field from WPs, although they are also relevant. Furthermore, we now know that the way WPs are configured in the repository has a far greater role in determining whether near-field thermal-hydrological (T-H) behavior is beneficial (versus deleterious) than the areal mass loading of the repository itself. Indeed, WP layout may be more consequential than variability or uncertainty in the natural system parameters. However, the processes within the NFE that are triggered by the waste loading can modify the thermal regime and locally impact the heat distribution so that it is more typical of other AMLs.

An overriding characteristic of the interaction between the WPs/repository and the NFE is that it results from coupled processes. The significance and magnitude of the coupling varies both spatially and temporally. To assist in the prioritization, the dominant processes were considered. 
The forward and back coupling of processes makes the NFE an environment typified by interrelated interactions. This idea can be shown conceptually by using an interaction matrix of the type proposed by Hudson(1989). Figure 1-4 is an interaction matrix for the NFE, where the key components of the NFE are shown along the diagonal, and the interaction of processes is shown off diagonal. Rather than showing all components and all coupling, which can be very complex, it is the objective of this matrix to focus on the key parameters or components and on the key processes. The matrix reflects, in general, the organization of this report.

\section{Figure 1-4. Simplified matrix showing coupled processes in the NFE.}

Figure 1-5 shows two examples of forward and back-coupling that are typical of both NFE and $A Z$ environments. The first example is the coupling between temperatures and moisture conditions. Temperature regimes are directly coupled to moisture conditions through processes of evaporation/dryout. Many more processes are discussed in greater detail in the hydrology section (Sec. 4 of this report), but in a simplistic view, the moisture conditions are determined by the forward coupling shown on the matrix as the short arrow (A) to the right. However, the changes to moisture conditions will back-couple to the temperatures by processes involving moisture/heat transfer. Vaporization of water and its condensation and return to the vaporization zone (heat pipe) can strongly alter the heat regime. This is shown by the short arrow (a) to the left of moisture, indicating back-coupling. Another example is the interaction of temperature and moisture conditions through rock-water interactions to change hydrologic properties (see the B-b loops in Fig. 1-5). This is a multiply coupled process: both temperature and moisture conditions couple to change hydrologic properties, which, in turn, back-couple to the temperature field in modification to convection, water flow pathways, and potential coefficient of conductivity changes, and also potentially to the moisture conditions by modifications of flow pathways.

The boxes shown here on the diagonal are generalized topics that identify the major subject areas discussed in this report. As Jiao and Hudson (1995) point out, a matrix such as this actually represents one part of a hierarchy of interaction matrices. In this report, the general matrix is either expanded as details are required, or a lower-level (more refined) matrix is used to explain the concepts and processes germane to a specific topic.

Figure 1-5. Forward and back coupling processes in the NFE.

1.2.4.1 Dominant Processes in the NFE. In the NFE, the dominant processes can be grouped into two categories: those occurring during the heating phase and those occurring after the waste cools.

During the heating phase, the processes will include:

- Relative humidity reductions due to strong thermal gradients.

- Removal of water from the system, slowing or shutting off many of the processes and resulting in weaker coupling between the geochemistry of system components.

- Thermal expansion under spatially varying thermal gradients, which will change rock and rock-support-system stresses.

- Potential microcracking of both rock and rock-support and invert systems.

- Potential precipitation of salts by water removal from vaporization.

- Dormancy or sporation of microbial colonies.

- Potential carbonation, depending on $\mathrm{CO}_{2}$ availability, of concrete portions of the EBS.

- Displacement of $\mathrm{O}_{2}$ by water vapor.

The rates and significance of coupling will depend on the balance between two factors that have opposite effects. At elevated temperature, kinetics are increased, which will increase the 


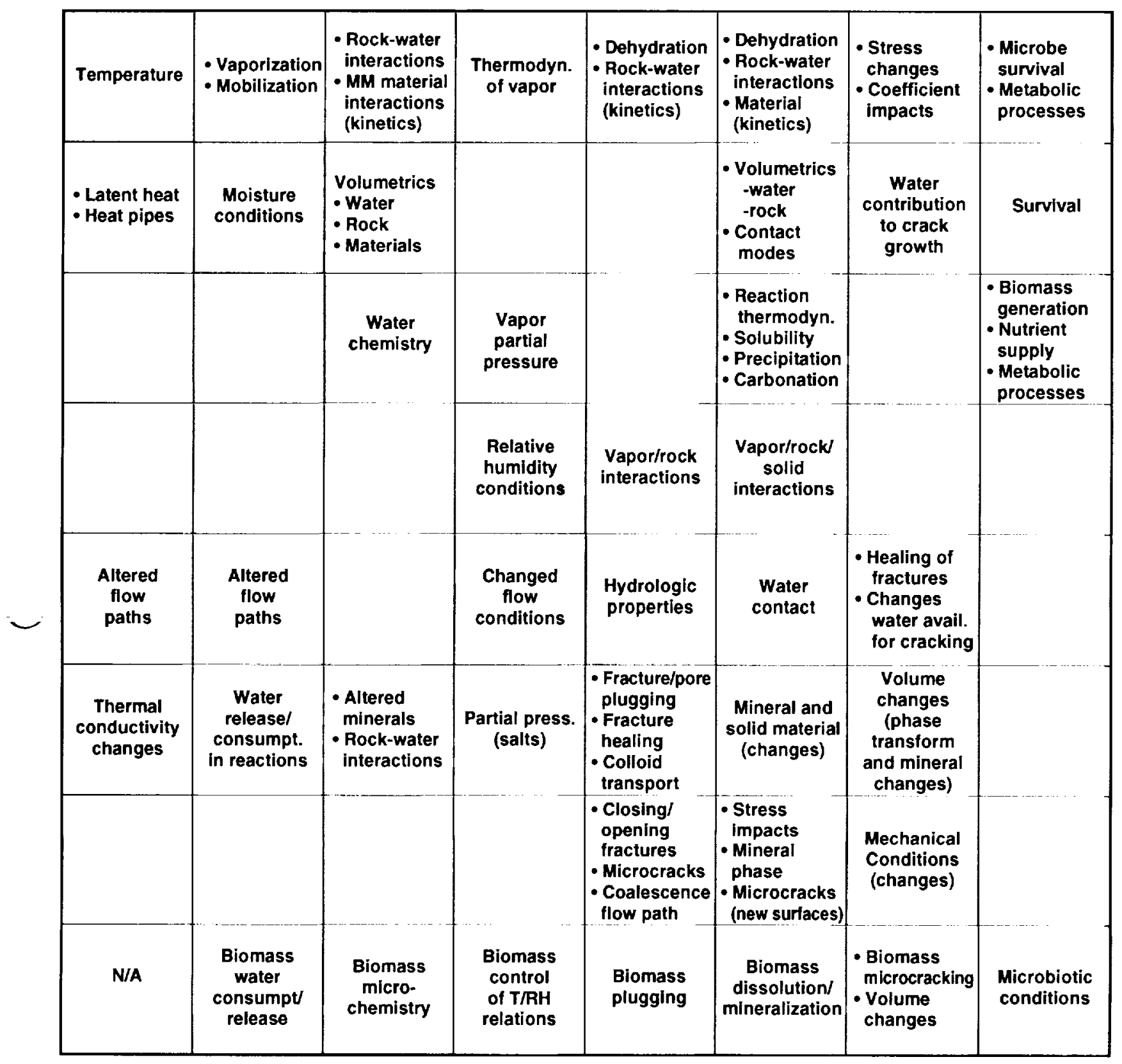

Figure 1-4 


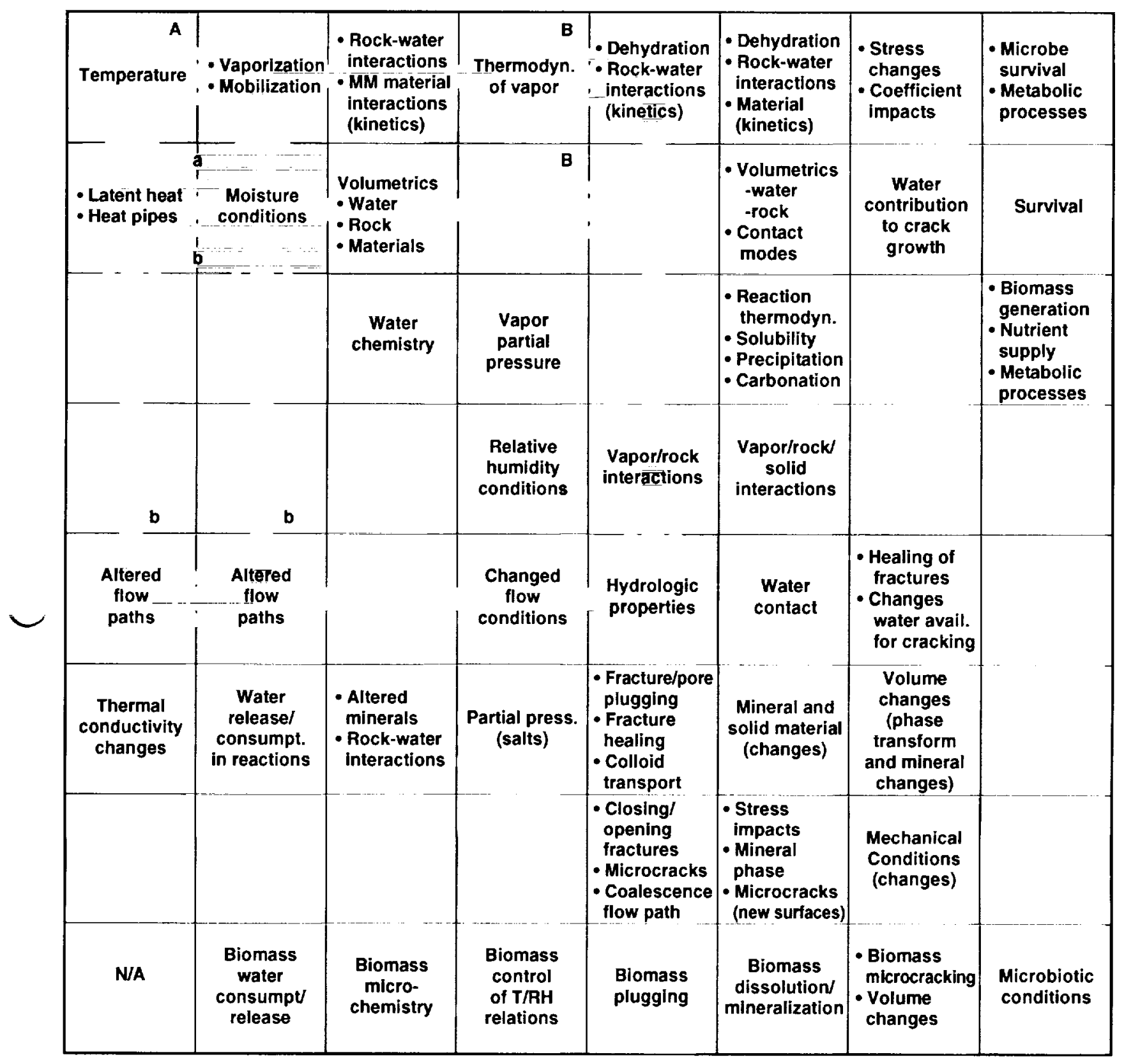

Figure 1-5 
rates and significance of coupling with introduced materials and microbial communities. However, when temperatures approach or reach the boiling point, evaporation and boiling will remove water from the system. Without water, microbial processes become minimal or are eliminated, many geochemical processes are minimized or eliminated (except vapor processes, which can be increased), and aqueous corrosion or interactions with man-made materials are shut down. If water removal is significant, many of the coupled thermal-hydrologicalgeomechanical-geochemical processes are eliminated.

After cooldown, water will return to the NFE mainly by relatively rapid fracture flow and by very slow movement of moisture and resaturation through the matrix. The amount of water that can return through fractures will depend on how much of the condensate from water driven out of the NFE during the thermal phase can be stored in fractures and on percolation flux at the time.

Once water returns, the NFE will be dominated by strongly coupled processes. Depending on how effectively the thermal field prevents water return during heating and on how far the water removal extends, the coupling will be re-established, but with lower kinetics because of lower temperatures. The NFE will likely be strongly influenced by the effects of processes that took place during the thermal phase. Water chemistry will mainly depend on interactions with introduced materials, precipitated salts left by the water that was removed, and, to some extent, on changes in mineralogy of the NFE rock. Interactions with introduced materials, particularly concretes, will depend on modifications to the concretes that resulted during the thermal pulse. Some effects, such as precipitated salts, may decrease with time. Because the time frames considered can be lengthy (hundreds to thousands of years), the significance of these processes must be based on the specific time of concern.

1.2.4.2 Dominant Processes in the AZ Environment. In the AZ, hydrological processes will be dominated by increased water availability and saturation associated with vapor condensation at elevated temperatures. Geochemical processes will be dominated by rock-fluid interactions, vapor contact at elevated temperatures, and reactive transport. The $A Z$ will be less transient or dynamic than the WPE in that residence times for water will be much longer. Because of the durations, the processes will tend to go toward completion, and the changes will tend to be more dramatic.

Many of the geochemical processes in the regions of the NFE and AZ will be the same (for example, recrystallization, dissolution and precipitation, cation exchange, sorption, etc.). However, their impact on rock properties will be different because of contrasts in heating and cooling rate and in the abundance and temperature of liquid water. The difference will be in the magnitude and nature of chemical and mineralogical changes, and in the duration of specific processes. As a result, performance of the overall repository system will be affected differently in the two regions because of mineral-water interactions. In addition to mineral-water interactions, there will be a significant difference due to introduced material interactions. This is true not only because the introduced materials are located mainly in the drifts or NFE but also because of the higher temperatures, dynamic or transient water conditions, and the very large volume percent of introduced materials that occurs in the NFE as opposed to the AZ. Thus, introduced materials will be a significant, if not dominant, factor in determining the NFE, whereas mineral-water interactions will be one of the principal factors that determines the $\mathrm{AZ}$ environment.

1.2.4.3 Summary of Prioritization. Although the dominant processes vary for the NFE and $\mathrm{AZ}$, evaluations have shown the overriding importance of hydrology and geochemistry, and the strong influence of heat on those processes. Thus, we can begin to prioritize the most essential issues related to EBS design and performance. It is logical to break down the parameters and processes into two lists. Table 1-1 identifies the most important NFE and AZ parameters, that is, the environmental parameters shown to have the greatest effects on the EBS and WPs. Table 1-2 
identifies, in approximate order, the factors show to have the greatest influence on the NFE and AZ. Subsequent sections of this report discuss these parameters in more detail and some of the complex processes and interactions among them.

Table 1-1. Near-field and altered-zone environmental parameters.

I. Parameters shown to have the greatest effects on the EBS and WP

Amount of water contacting the WPs

Water chemistry

Relative humidity

II. Parameters expected to have moderate or variable effects on the EBS and WP

Native microbial species

III. Parameters expected to have minimal (little or controllable) effects on the EBS and WP.

(These factors could have secondary effects through coupling with more significant parameters.)

Rock fall physically damaging metal waste containers (different priority if ceramic)

Geomechanics

Table 1-2. Factors that influence the near-field and altered-zone environment.

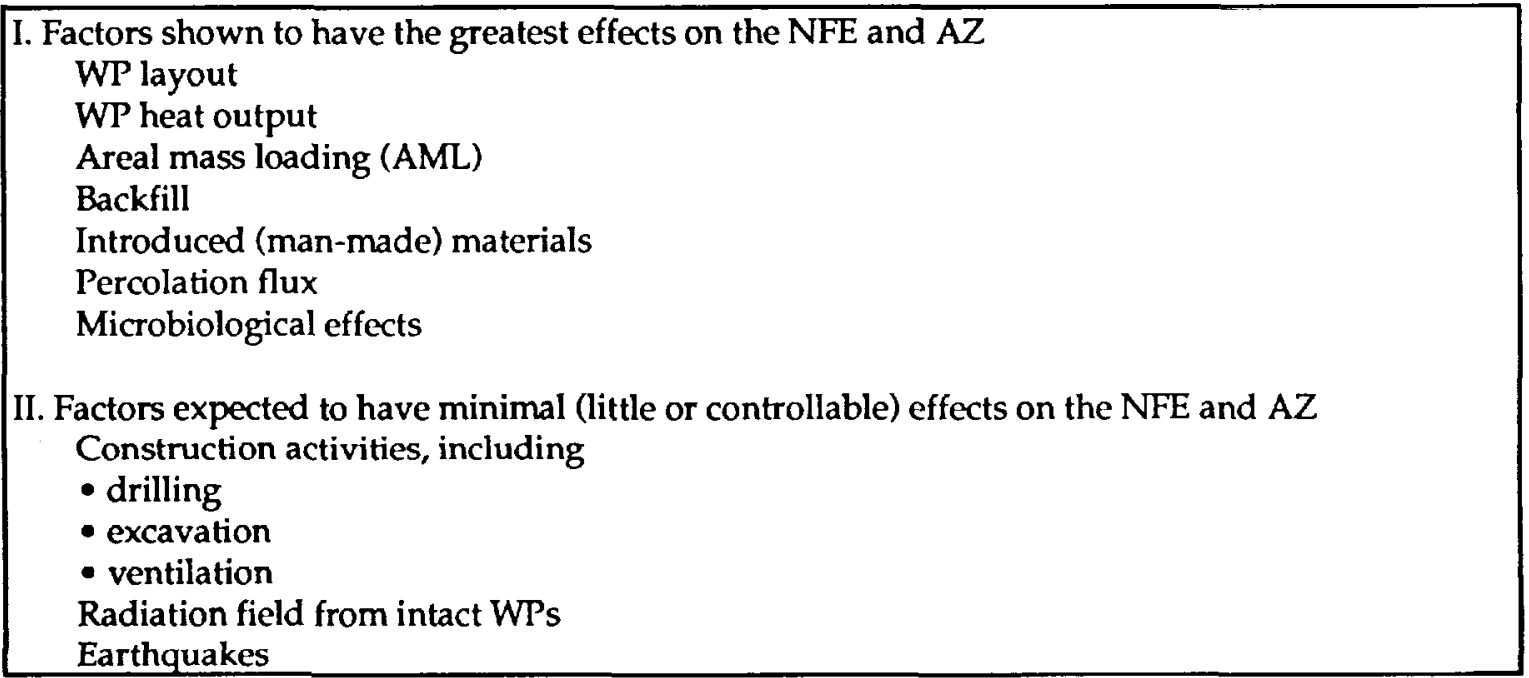

\subsubsection{Single versus Multiple Repository Design Efforts}

Repository design must not only consider what the NFE is, but once design decisions are made, it must also consider how those decisions will affect the NFE. This is an iterative process. It involves a determination of the design that will function within the given environment, a consideration of the environment that will then develop as a result of that design, and revision of the design, as necessary, for the newly developed environment.

An alternative to such an iterative approach is to assume different designs and then to assess the NFE for those design alternatives. This is akin to a sensitivity study - which has the advantage of a shorter schedule because the second assessment is eliminated-and it is the approach taken in this report. However, a disadvantage is that many different cases must be 
assessed and reported. The Preliminary NFER included sensitivity analyses; however, it was more focused on the iterative approach. In contrast, Rev. 1 evaluates multiple designs and sensitivity. To minimize the cumbersome nature of reporting all cases that have been considered, Volume I focuses on a few design assumptions that represent the most likely ones, or reference designs (ones that bound the 1997 modification). We refer the reader to Volume $I$ for information on the many other design options that were evaluated.

\subsection{Modeling Advances}

Whereas considerable progress has been made since publication of the Preliminary NFER in the characterization of $Y M$, particularly in the availability of the underground drifts and ESF facilities for sampling and mapping, perhaps even more progress has been made in the conceptual understanding and models of coupling and in the codes available to assist in the analyses of those conceptualizations. Of course, there have also been significant improvements in the capabilities of computers to handle the computationally intensive requirements of these models and codes. This report is not focused on discussions of those advances. The reader can find more detailed discussion in Hardin and Chesnut (1997) and in Glassley (1997).

\subsection{Focus of Current Work}

As stated, interactions between the EBS components and the NFE are, to a large extent, dominated by the possible presence of liquid water and elevated humidity. For example, leaching of most of the radionuclides from the waste forms is almost exclusively aqueous, and corrosion of most candidate container materials is either dominated by liquid water contact or by relative humidity that is sufficiently high to allow water films to form on the containers. The transport of radionuclides through the rock mass depends exclusively on aqueous mechanisms (except for gaseous radionuclides associated with spent fuel and those generated slowly by radioactive decay from the glass waste form). Thus, an assessment of EBS performance can focus on hydrological aspects and associated geochemistry. Fracture flow is a key issue. As noted in the Preliminary NFER, "if radionuclide transport does occur, it will most likely involve fracture flow" (Wilder, 1993).

We are now focusing almost entirely on the following processes as priorities:

1. Understanding how and when water will contact the WPs, especially during the first several thousand years. This work includes determining the amount of fluids, as well as vapor or gases, that contact the container or waste forms, and optimizing ways to keep water away from the WPs.

2. Determining the chemical composition of fluids and gases that contact the container or waste forms. Introduced man-made materials, such as the containers, invert material, cement grout, concrete, and rock-support system, will be a dominant factor in water chemistry. The chemistry of water contacting the WPs will also depend on whether water drains quickly down fractures or migrates slowly in the matrix and on process such as refluxing.

3. Understanding what happens in the $\mathrm{AZ}$ at distances that can extend more than hundreds of meters away from the repository. This focus arises because conditions in the $A Z$ set the initial water chemistry as well as changes in hydrological properties.

4. Determining how geomechanics couples to the hydrology and geochemistry. Issues include:

- Microfracturing to create new flow paths and reactive surfaces.

- Fracture closing or changed hydrologic pathways.

- Altered pore spaces. 


\subsection{Ambient Yucca Mountain Environment}

Yucca Mountain (YM) consists of a series of variably fractured, nonwelded to densely welded tuff units with an eastward tilt of about 5 to $30^{\circ}$ (Montazer and Wilson, 1984). At YM, the thickness of the unsaturated zone varies from 500 to $750 \mathrm{~m}$. The potential repository is located within this unsaturated zone, lying approximately $350 \mathrm{~m}$ below the ground surface and $225 \mathrm{~m}$ above the water table (Klavetter and Peters, 1988). Montazer and Wilson (1984) also report the absence of perennial streams at YM. Therefore, recharge due to rainfall occurs episodically. Flint (1991) reports that the mean annual precipitation at YM varies (areally) from 150 to $240 \mathrm{~mm} / \mathrm{yr}$.

At the time of preparation of the Preliminary NFER in 1993, it was reported that overall infiltration was expected to be very low. Flux estimates based on equivalent continuum model (ECM) analysis for the repository horizon ranged from 0.05 to $1.0 \mathrm{~mm} / \mathrm{yr}$, possibly upward due to vapor transport from the underlying saturated zone (see Vol. II, Sec. 1.0) (Montazer and Wilson, 1984). More recent estimates based on infiltration studies, ${ }^{36} \mathrm{Cl}$, calcite, and other evidence, have been revised upward to a range from 1.0 to $15 \mathrm{~mm} / \mathrm{yr}$ (Bodvarsson and Bandurraga, 1996). It is judged that $5 \mathrm{~mm} / \mathrm{yr}$ is the most likely value. However this revision of Volume I, focuses on $0.3 \mathrm{~mm} / \mathrm{yr}$ to be consistent with values used in Vol II.

The geologic unit being considered as the host rock is in the Topopah Spring Member of the Paintbrush tuff (Tpt). The welding within the Topopah Spring tuff (Tpt) results in a highly fractured rock mass. The Preliminary NFER reported estimates of fracture density ranging from 20 to 42 fractures per cubic meter based on information available at that time, which was obtained from surface outcrops and from boreholes (MacIntyre et al., 1990; Scott and Castellanos, 1984; Dudley et al., 1990; Wilder, 1990). These data did not distinguish fracture spacing along any direction, although attempts to estimate fracture spacing in terms of fractures per meter were representative (see Volume $1, \operatorname{Rev} 0$ ). Since the Preliminary NFER, the main drift of the Exploratory Studies Facility (ESF) has been excavated and mapped. Results of mapping (Albin et al., 1997) more than 10,000 fractures within the middle nonlithophysal and lower lithophysal zones (upper repository horizon strata) indicate that there are four sets of fractures. The first set is oriented at $120^{\circ} / 80^{\circ}$ (strike/dip). The second set is oriented $220^{\circ} / 80^{\circ}$. A third set is oriented approximately $310^{\circ} / 30^{\circ}$. A fourth set was identified that has strike similar to sets 1 and 3 , ranging between $270^{\circ}$ and $330^{\circ}\left(90^{\circ}\right.$ to $\left.150^{\circ}\right)$, and dips intermediate between these sets at $40^{\circ}$ to $60^{\circ}$.

The relative prominence of the sets depends on location within the drift; however Set 1 is always, by far, the most prominent (from 47 to $74 \%$ of total fractures). Set 2 is the next most dominant of those sets that are associated with a particular orientation (as opposed to random) and varies from 5 to $22 \%$ of the fracture population. These two sets comprise 61 to $79 \%$ of the fractures observed in the drift, as is clearly shown by the azimuth distribution histogram (Fig. 21). A correction for orientation bias from drift orientation was made to evaluate Set 2 . However, in the author's view, the drift and fracture Set 2 orientations were too similar (only $17^{\circ}$ from the edge of the distribution that starts at $200^{\circ}$ ), and the correction can be misleading (Yow and Wilder, 1983). Albin et al. (1997) recognized this problem and used an averaging method to moderate the effect. Albin et. al. (1997) interpreted four fracture domains within the drift. These domains occur in separate intervals of the drift, as shown in Fig. 2-2. As can be observed, the fracture frequency average - except in Domain 3, which was defined as a fracture zone-is about 2.5 fractures per meter. In the fracture zone, the average is about 5 fractures per meter.

Figure 2-1. Distribution of fractures by azimuth in the main drift. Modified from Albin et al., (1997). 


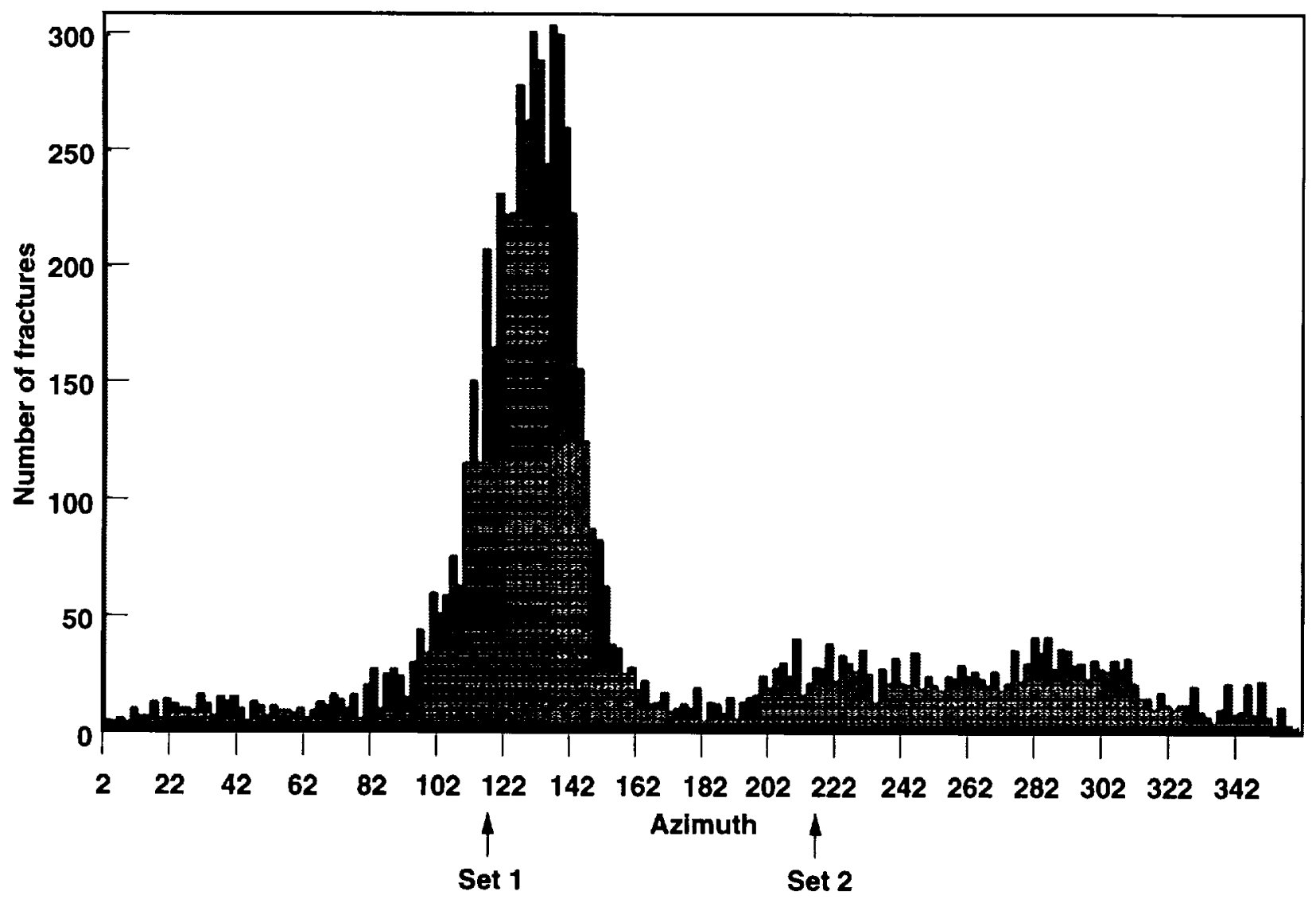

Figure 2-1. 
Figure 2-2. Fracture-density histogram plots of the number of fractures, cooling joints, and vapor-phase partings per meter in each 2-meter interval along the main drift. Modified from Albin et al., (1997).

One of the critical NFE aspects of the fractures is the way the fractures are distributed. Set 1 is dominant, and its spacing becomes critical, as will be discussed in Section 4 of this report. The average spacing of Set 1 is 0.89 fractures per meter for domain $1,1.1$ fractures per meter for domain 2, 3.1 fractures per meter for domain 3, and 1.2 fractures per meter for domain 4 . Fracture aperture estimates range from 43 to $127 \mu \mathrm{m}$ (Buscheck, 1990). As discussed in greater detail in Volume II, this fracturing has a major impact on the NFE.

The Tpt is a formal stratigraphic unit and has been subdivided into more specific thermal/mechanical units, which are particularly useful for hydrologic analyses. Both the formal and thermal/mechanical stratigraphic columns are shown in Fig. 2-3. Figure 2-4 shows an eastwest cross section through the repository site. The potential repository horizon is in the thermal/mechanical TSw2 unit (Ortiz et al., 1985). This unit is a devitrified, welded, rhyolitic tuff that is moderately to densely welded tuff. It appears to consist of a mass of intact blocks separated by ubiquitous planar cooling fractures, which tend to be strata-bound, and by discrete tectonic fractures, which may not be planar but tend to be more extensive. Price, Connolly, and Keil (1987) report that the majority of the rock is a fine-grained matrix containing gray-colored regions of vapor-phase-altered material that vary in size and are quite common. In addition to these main components, the rock contains small (open and closed) lithophysal and "healed" fractures filled with quartz or calcite.

Figure 2-3. General stratigraphic column at Yucca Mountain. Modified from Elayer (1997).

Figure 2-4. East-west cross section through the repository siting volume. Modified from Elayer (1997).

\subsection{Geochemistry}

Petrographic analysis shows that the repository horizon tuff consists of primary minerals, such as sanidine, plagioclase, quartz, biotite, iron-titanium oxides, allanite and zircon, that formed at temperatures in excess of $600^{\circ} \mathrm{C}$ in a magma chamber prior to eruption of the tuff. It also contains secondary minerals, such as cristobalite, quartz, alkali feldspars, and smectite clays, that formed during cooling and later alteration of the tuff at temperatures less than $500^{\circ} \mathrm{C}$. The chemical composition of the rock is shown in Table 2-1. Because these values were determined from cores, they may not be representative of the composition of mineral coatings along fractures.

Distinguished from the primary and secondary minerals are the minerals that formed on fracture surfaces [e.g., calcite, smectite, quartz, cristobalite, alkali feldspar, and the zeolites mordenite, chabazite, clinoptilolite, and heulandite (Carlos, 1985, 1989; Lin and Daily, 1989)]. These minerals form layers that possess physical properties distinct from those minerals in the rock matrix and are estimated to be a maximum of $5 \%$ of the total rock mass. The mineral assemblage along a fracture surface varies from one location to another, and appears to reflect, at least in part, the previous location of the saturated zone (Carlos, 1989). Based on $x$-ray diffraction (XRD) analyses, the mineral assemblage of a typical fracture surface within the repository horizon might consist of $7 \%$ smectite, $7 \%$ cristobalite, $12 \%$ quartz, $29 \%$ clinoptilolite, and $45 \%$ alkali feldspar (Carlos, 1985).

See Glassley (1986) for a more detailed discussion and a description of the mineralogic and chemical properties of the preemplacement environment. 


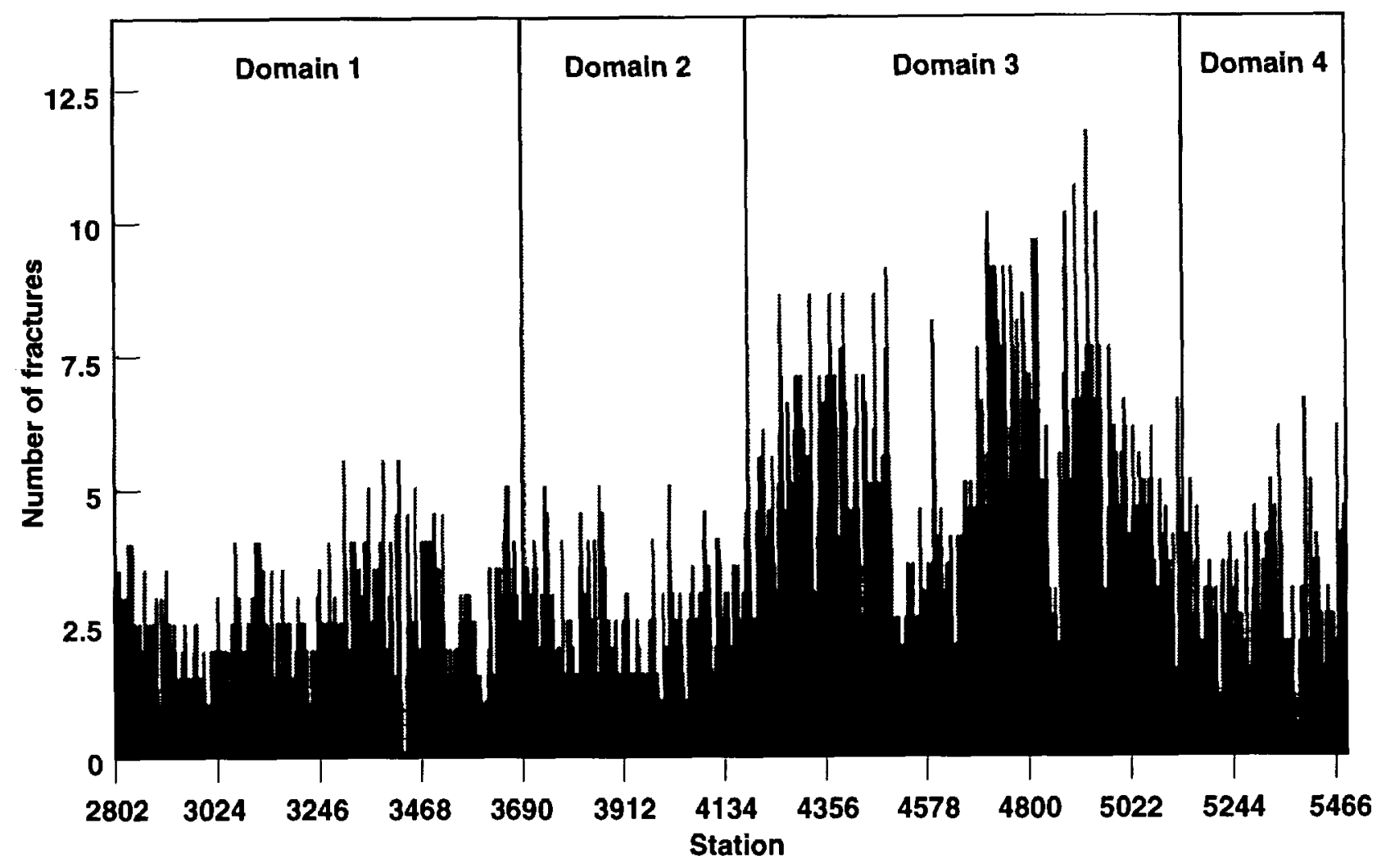

Figure 2-2. 


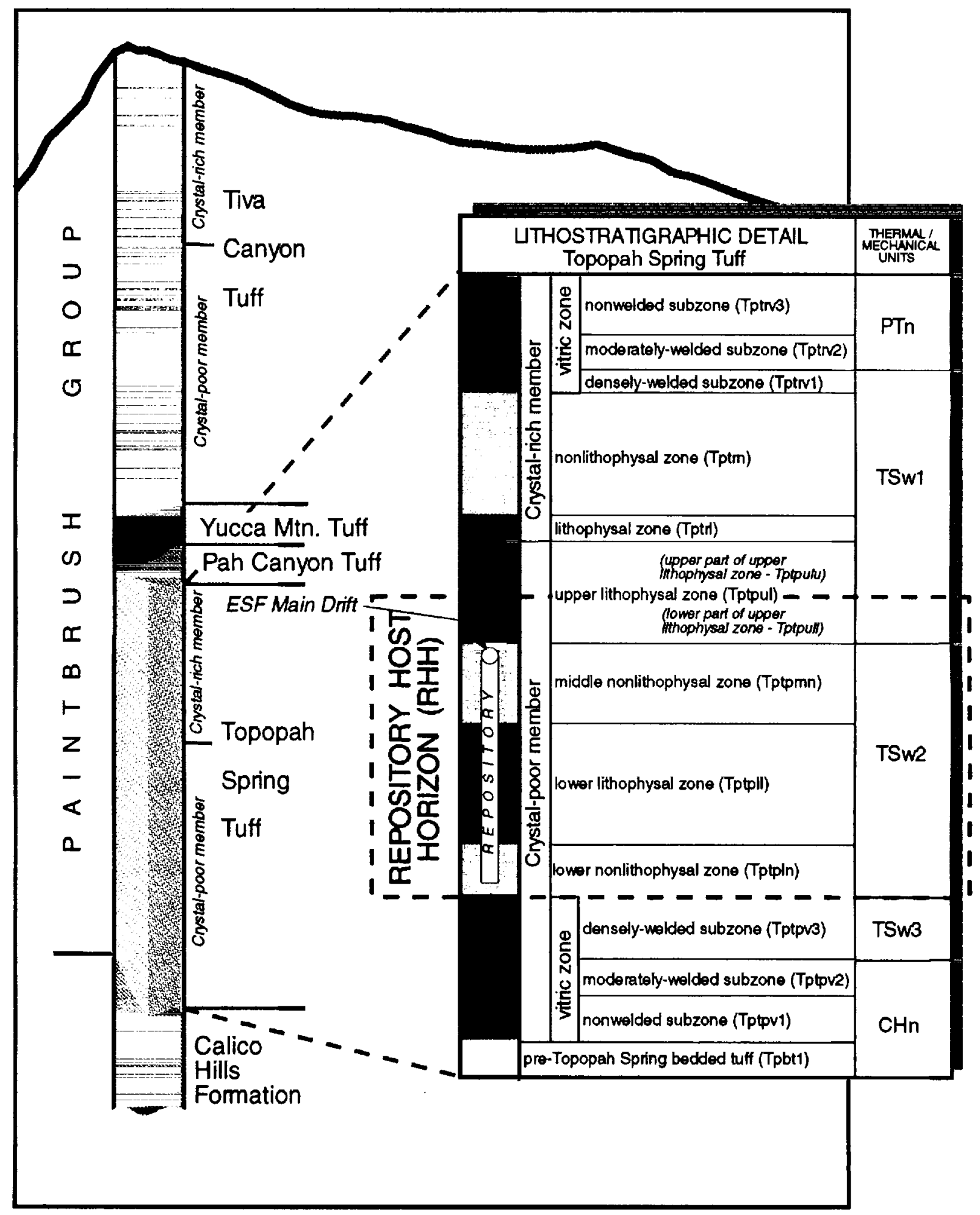

Figure 2-3 


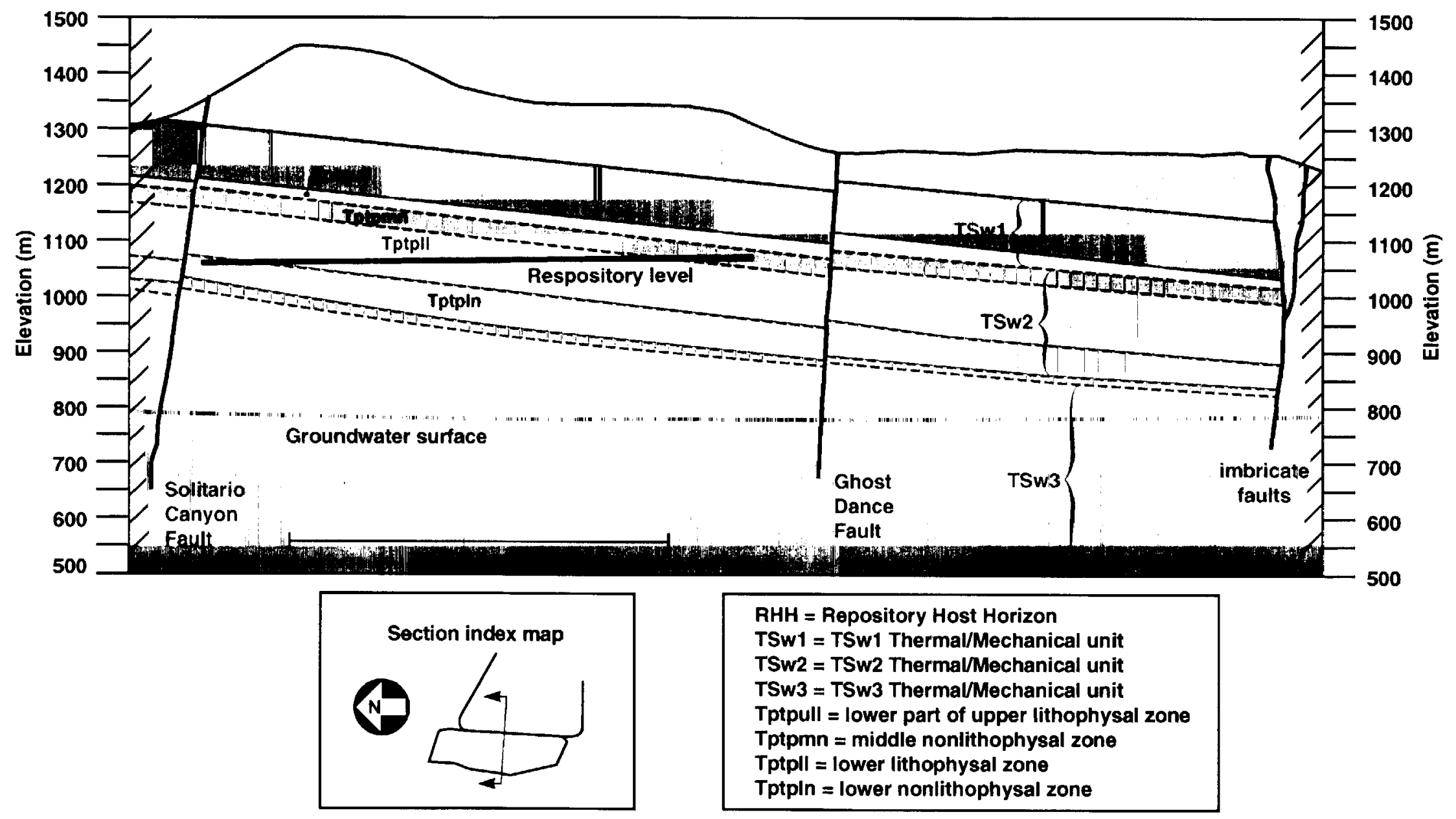

Figure 2-4. 
Table 2-1. Percentages of major constituents in Topopah Spring tuff (core samples 60, 61, and 62 from drill hole USW G-3). $\mathrm{Fe}_{2} \mathrm{O}_{3}$ represents total iron. Data from Schuraytz et al. (1986).

\begin{tabular}{|l|c|c|c|c|c|}
\hline \multicolumn{5}{|c|}{ Constituent } & \multicolumn{6}{c}{60} & 61 & \multicolumn{2}{c|}{ Average } & $\begin{array}{c}\text { Standard } \\
\text { deviation }\end{array}$ \\
\hline $\mathrm{SiO}_{2}$ & 78.4 & 78.9 & 78.9 & 78.73 & 0.24 \\
\hline $\mathrm{Al}_{2} \mathrm{O}_{3}$ & 12.0 & 12.3 & 12.2 & 12.17 & 0.12 \\
\hline $\mathrm{Fe}_{2} \mathrm{O}_{3}$ & 1.016 & 0.973 & 1.000 & 0.996 & 0.018 \\
\hline $\mathrm{CaO}^{\mathrm{MgO}}$ & 0.492 & 0.451 & 0.480 & 0.474 & 0.017 \\
\hline $\mathrm{TiO}_{2}$ & 0.1217 & 0.1281 & 0.1126 & 0.123 & 0.007 \\
\hline $\mathrm{Na}_{2} \mathrm{O}$ & 0.1108 & 0.0927 & 0.0984 & 0.101 & 0.008 \\
\hline $\mathrm{K}_{2} \mathrm{O}$ & 4.07 & 3.92 & 4.25 & 4.08 & 0.13 \\
\hline $\mathrm{P}_{2} \mathrm{O}_{5}$ & 3.71 & 3.18 & 2.94 & 3.28 & 0.32 \\
\hline $\mathrm{MnO}$ & 0.01 & 0.01 & 0.03 & 0.02 & 0.01 \\
\hline
\end{tabular}

\subsection{Hydrology}

Because of the small pore size and the unsaturated conditions, a significant suction potential (matrix potential, capillary force, or suction) develops in the rock. Recent measurements of saturation indicate higher saturations than originally estimated. Samples from the ESF Single Heater Test indicate saturation ranges from 80.5 to $99.0 \%$, which compare with saturation values of $85 \pm 12 \%$ for the same interval from surface boreholes (CRWMS M\&O, 1996). LLNL evaluation of the Lawrence Berkeley Laboratory site scale model (Bodvarsson and Bandurraga, 1996) yields saturations ranging from 88.6 to $96 \%$. Thus, the suction potential may be less than previously anticipated.

As noted in the Preliminary NFER, LLNL performed suction potential tests at room temperature and at elevated temperatures. The results are shown in Figs. 2-5(a) and 2-6. Tests performed more recently have filled in the data gaps. Based on these recent results, shown in Fig. 2-5(b), the matric potential at the best current estimate for saturation (i.e., about $90 \%$ ) is not greatly different than that for the assumed $65 \%$ saturation; both values are less than 100 bars (10 MPa).

Figure 2-5. (a) Suction potential as a function of water saturation at $20^{\circ} \mathrm{C}$ for Topopah Spring tuff. (b) Matric potential as a function of saturation from the Single Heater Test. Drying refers to the portion of the test cycle when moisture was being removed. Wetting refers to the portion of the test cycle when moisture was being added.

Figure 2-6. Suction potential as a function of water saturation at $70^{\circ} \mathrm{C}$ for Topopah Spring tuff.

Current data are significantly different from data reported in the Preliminary NFER. Current data show the suction potential $>500$ bar up to 20 to $25 \%$ saturation compared to about $10 \%$ saturation in the Preliminary NFER. This result probably reflects variability of rock properties. The current tests were performed on samples from the ESF, whereas earlier tests relied on samples from surface boreholes. It was noted in the Preliminary NFER that considerable variability was shown among these samples, implying a heterogeneity of suction properties in the Topopah Spring tuff. The earlier data showed approximately a factor of 3 difference in suction potential between samples 1 and 3 at 15\% saturation. Nevertheless, the room-temperature drying data of the earlier measurements were within the spread of corresponding psychrometer results of Klavetter and Peters (1987). The current data have not been analyzed sufficiently to determine how they compare with results from other tests. 



Figure 2-5(a \& b) 


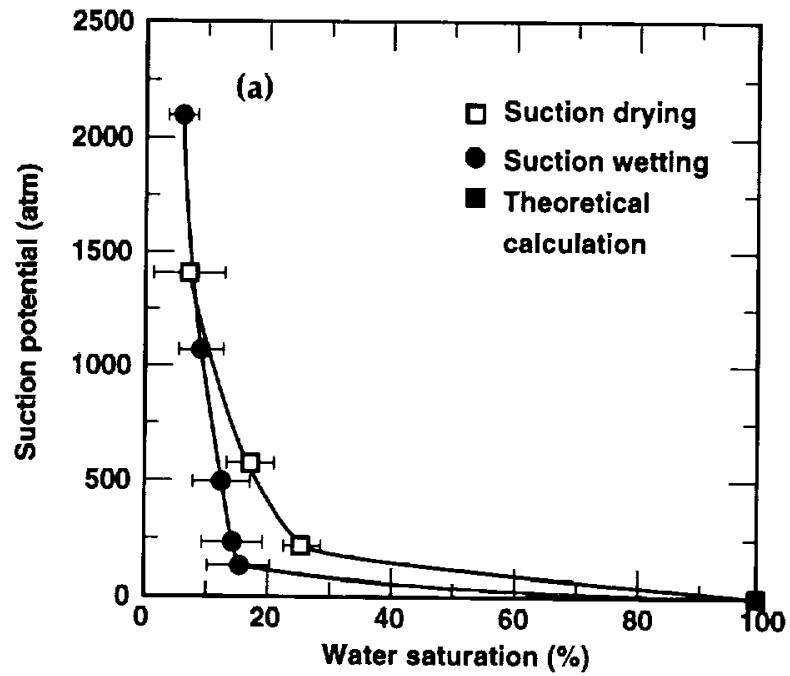

Figure 2-6. 
The saturated water permeability of an intact Topopah Spring tuff sample at room temperature measured by LLNL is about $0.3 \mu \mathrm{D}$, although measurements by others (Moore et al., 1986) at room temperature ranged from 0.85 to $64 \mu \mathrm{D}$. The saturated water permeability of fractured Topopah Spring tuff is at least 3 orders of magnitude greater than that of intact tuff. At room temperature, cylindrical tuff samples containing a single natural hairline through-fracture have apparent water permeabilities ranging from 0.85 to $13 \mathrm{mD}$ (Daily et al., 1987). The water permeability of an intact Topopah Spring tuff sample is virtually independent of temperature, time, and the dehydration and rehydration processes.

The matrix properties of the hydrostratigraphic units at Yucca Mountain are summarized in Table 2-2 (Klavetter and Peters, 1988). The units generally fall into two categories: (1) welded tuffs of very low permeability and low porosity (TCw, TSw1, TSw2, and TSw3), and (2) nonwelded vitric tuffs of high permeability and high porosity (PTn and $\mathrm{CHnv}$ ). The zeolitized nonwelded CHnz has low permeability and intermediate porosity, and the welded PPw has intermediate permeability and porosity. The permeabilities of the nonwelded vitric tuffs are 4 to 5 orders of magnitude greater than those of the welded tuffs and the zeolitized nonwelded CHnz.

Physical properties including porosity, grain density, bulk density at in situ saturation, and dry bulk density have been determined from core samples, and values of these parameters are summarized in Table 2-3. Additional discussion can be found in Vol. II, Sec. 4.0.

On the basis of samples taken from surface coring, the TSw2 was expected to have $65 \%$ saturation $( \pm 19 \%)$ (although, as noted, measurements on ESF samples show saturations of approximately $90 \%$ ) and a porosity of $11 \%$ (DOE, 1990; Klavetter and Peters, 1986). Air in the unfilled voids is expected to be moist, although not always at $100 \%$ humidity. For further discussion, see Vol. II, Sec. 1.0.

Table 2-2. Matrix properties of Yucca Mountain tuff (Klavetter and Peters, 1988).

\begin{tabular}{|l|c|c|c|c|c|c|}
\hline \multicolumn{2}{|c}{} & \multicolumn{1}{c}{$\begin{array}{c}\text { Sample } \\
\text { code }\end{array}$} & \multicolumn{5}{c|}{$\begin{array}{c}\text { Permeability } \\
\text { Unit }\end{array}$} & Gorosity & \multicolumn{4}{c|}{$\begin{array}{c}\alpha^{\mathbf{c}} \\
\left(\mathbf{1 0}^{-2} \mathbf{m}^{-1}\right)\end{array}$} & $\beta^{\mathbf{c}}$ \\
\hline TCw & 0.08 & $9.7 \times 10^{-19}$ & 0.002 & 0.821 & 1.558 \\
\hline PTn & GU3-7 & 0.40 & $3.9 \times 10^{-14}$ & 0.100 & 1.500 & 6.872 \\
\hline TSw1 & G4-6 & 0.11 & $1.9 \times 10^{-18}$ & 0.080 & 0.567 & 1.798 \\
\hline TSw2 & G4-6 & 0.11 & $1.9 \times 10^{-18}$ & 0.080 & 0.567 & 1.798 \\
\hline TSw3 & GU3-11 & 0.07 & $1.5 \times 10^{-19}$ & 0.080 & 0.411 & 2.058 \\
\hline CHnv & GU3-14 & 0.46 & $2.7 \times 10^{-14}$ & 0.041 & 1.60 & 3.872 \\
\hline CHnz & G4-11 & 0.28 & $2.0 \times 10^{-18}$ & 0.110 & 0.308 & 1.602 \\
\hline PPw & G4-18 & 0.24 & $4.5 \times 10^{-16}$ & 0.066 & 1.41 & 2.639 \\
\hline
\end{tabular}

"Unit designations: $\mathrm{TC}=$ Tiva Canyon, $\mathrm{PT}=$ Paintbrush, $\mathrm{TS}=$ Topopah Spring, $\mathrm{CH}=$ Calico Hills, $\mathrm{PP}=$ Prow

Pass, $\mathbf{w}=$ welded, $\mathbf{n}=$ nonwelded, $\mathbf{v}=$ vitric, $\mathbf{z}=$ zeolitized.

${ }^{b} \mathrm{~S}_{\mathrm{r}}$ is the residual liquid saturation (not in situ saturation).

${ }^{c} \alpha$ and $\beta$ are fitting parameters for capillary pressure and relative permeability curves, respectively. 
Table 2-3. Physical and thermal properties of rock in the potential repository horizon.

\begin{tabular}{l|c|}
\hline Parameter & Value \\
\hline Physical properties & $12 \pm 4^{\mathrm{a}}$ \\
\hline Porosity $(\%)$ & $2.55 \pm 0.03^{\mathrm{a}}$ \\
\hline Grain density $\left(\mathrm{g} / \mathrm{cm}^{3}\right)$ & $2.30 \pm 0.09^{\mathrm{a}}$ \\
\hline Bulk density at in situ saturation $\left(\mathrm{g} / \mathrm{cm}^{3}\right)$ & $2.22 \pm 0.10^{\mathrm{a}}$ \\
\hline Dry bulk density $\left(\mathrm{g} / \mathrm{cm}^{3}\right)$ & \\
\hline & \\
\hline Thermal properties & $2.51 \pm 0.17^{\mathrm{b}}$ \\
\hline Dry matrix thermal conductivity $\left(\mathrm{W} / \mathrm{m}^{\circ} \mathrm{K}\right)$ & $2.1 \pm 0.2^{\mathrm{b}}$ \\
\hline Dry in situ thermal conductivity $\left(\mathrm{W} / \mathrm{m}^{\circ} \mathrm{K}\right)$ & $2.1 \pm 0.2^{\mathrm{b}, c}$ \\
\hline Saturated in situ thermal conductivity $\left(\mathrm{W} / \mathrm{m}^{\circ} \mathrm{K}\right)$ & \\
\hline aDOE $(1995)$. & \\
bNimick $(1990)$. & \\
c.65 \pm 0.19 in situ saturation with lithophysical cavities and fractures assumed dry.
\end{tabular}

\subsection{Geomechanics}

A substantial number of laboratory measurements have been made to determine the mechanical strength of intact samples from the proposed repository horizon. These data indicate that the intact rock is quite strong with a uniaxial strength of $155 \mathrm{MPa}( \pm 59 \mathrm{MPa})$ and a high Young's modulus. Uncracked samples have stress-strain curves that show nearly linearly elastic behavior until failure. Samples with cracks exhibit nonlinear stress-strain behavior as expected when stress is above $50 \%$ of the failure stress. Typical stress-strain curves for 50.8 -mm-diam saturated samples tested under drained conditions are shown in Fig. 2-7. Most of the tests for compressive strength have been conducted on samples that were saturated with water and tested under drained conditions. This represents a minimum value as rocks are generally weaker when saturated with water. Furthermore, as noted by Biotnott (1997) the uniaxial stress path commonly used to infer elastic constants is strongly influenced by nonlinearities. This becomes more critical when coupled to thermal and other processes, as will be discussed in the Section 4.

The dynamic properties of the rock are also important, especially in the area of seismic design. These properties include the compressional-wave ( $P$-wave) velocity $\left(C_{p}\right)$, the shear-wave ( $S$-wave) velocity $\left(C_{\mathrm{s}}\right)$, the dynamic deformation (Young's) modulus $\left(E_{\mathrm{d}}\right)$, and the dynamic Poisson's ratio $\left(v_{\mathrm{d}}\right)$. Recommended values of these parameters are given in item 2.2.2 of the RIB as $C_{\mathrm{p}}=3400 \mathrm{~m} / \mathrm{s}, C_{\mathrm{s}}=2040 \mathrm{~m} / \mathrm{s}, E_{\mathrm{d}}=23.5 \mathrm{GPa}$, and $v_{\mathrm{d}}=0.22$.

Price (1986) studied the effect of sample size on mechanical properties of Topopah Spring tuff (Tpt) and found that both the ultimate strength and axial strain at failure are inversely related to sample diameter, whereas Young's modulus and Poisson's ratio are independent of sample diameter. The effect of sample size on ultimate strength is illustrated in Fig. 2-8.

Estimates of rock-mass strength are based on (1) the known behavior of intact rock, (2) the known joint characteristics, and (3) the presence of applied or confining stresses. A rock-mass strength criterion of

$\left(\sigma_{1}\right)_{\text {ultimate }}=16.0+10.2\left(\sigma_{3}\right)^{0.602}$,

where $0<\sigma_{3}<25 \mathrm{MPa}$, is presented in item 1.2.6 of the RIB. Equation (1) is based on an assumed rock-mass rating (RMR) of 61 and an unconfined compressive strength of $16.0 \mathrm{MPa}$. 
In situ stress values for the potential repository horizon have been determined from measurements in drill holes USW G-1, USW G-2, and USW G-3 (Stock et al., 1984, 1985). Table 24 shows the average mean value and range for vertical stress, which is the maximum principal stress and is due to the overburden rock at the site, in addition to the ratios of minimum and maximum horizontal stresses to vertical stress, and the bearings of minimum and maximum horizontal stresses.

A stress profile for the in situ stress near the ESF has been estimated using two-dimensional finite-element analysis similar to those presented in Bauer et al. (1985). The stress profile can be found in Vol. II, Sec. 4.0.

Figure 2-7. Plots of axial stress vs axial strain for uniaxial measurements on 50.8-mm saturated Topopah Spring tuff samples at $22^{\circ} \mathrm{C}$. Measurements were taken at a strain rate of $10^{-5} \mathrm{~s}^{-1}$. Adapted from Price (1986).

Figure 2-8. Plot of ultimate strength vs sample diameter for uniaxial measurements on saturated Topopah Spring tuff samples at $22^{\circ} \mathrm{C}$. Measurements were taken at a strain rate of $10^{-5} \mathrm{~s}^{-1}$. Adapted from Price (1986).

Table 2-4. Values and ranges of principal stresses in the potential repository horizon at Yucca Mountain (Stock et al., 1984, 1985).

\begin{tabular}{|l|c|c|}
\hline \multicolumn{1}{|c|}{ Parameter } & Average value & Range \\
\hline Maximum principal stress (vertical) & $7.0 \mathrm{MPa}(1015 \mathrm{psi})$ & 5.0 to 10 \\
\hline $\begin{array}{l}\text { Ratio of minimum horizontal stress to vertical } \\
\text { stress }\end{array}$ & 0.5 & 0.3 to 0.8 \\
$\begin{array}{l}\text { Ratio of maximum horizontal stress to vertical } \\
\text { stress }\end{array}$ & 0.6 & 0.3 to 1.0 \\
\hline Bearing of minimum horizontal stress & $\mathrm{N} 57^{\circ} \mathrm{W}$ & $\mathrm{N} 50^{\circ} \mathrm{W}$ to $\mathrm{N} 65^{\circ} \mathrm{W}$ \\
\hline Bearing of maximum horizontal stress & $\mathrm{N} 32^{\circ} \mathrm{E}$ & $\mathrm{N} 25^{\circ} \mathrm{E}$ to $\mathrm{N} 40^{\circ} \mathrm{E}$ \\
\hline
\end{tabular}

Average value for a depth of about $0.3 \mathrm{~km}(1000 \mathrm{ft})$. 




Figure 2-7 


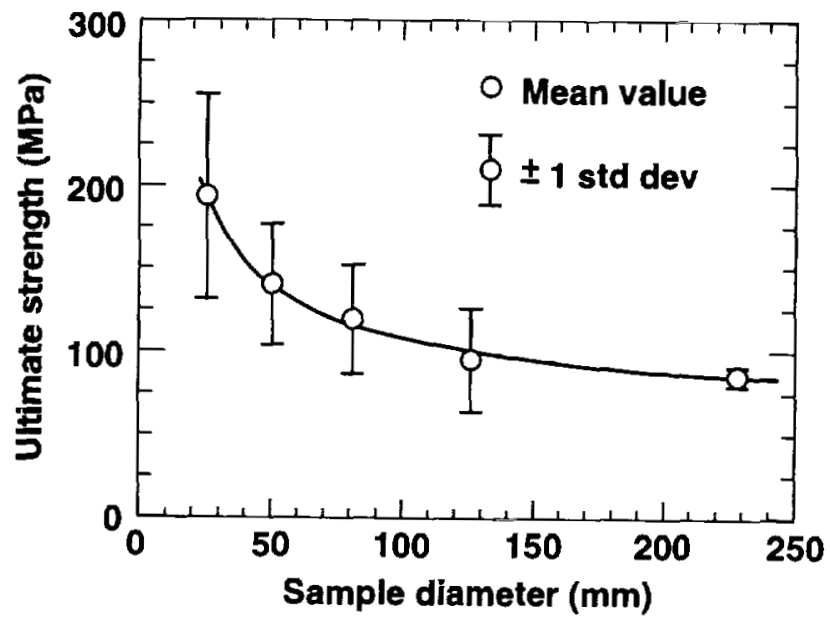

Figure 2-8 


\subsection{Processes That Form the NFE}

As discussed in Section 1, waste packages will interact with a near-field environment that will be altered from the original Yucca Mountain conditions. The NFE changes arise from several factors, including construction of the repository, emplacement of waste, and the possible backfilling of drifts. All of these activities can cause chemical changes, possible mineralogical or basic rock-mass property changes, as well as hydrologic and thermal changes. These alterations may be significant relative to the EBS design and performance. Because NFE development is driven by coupled $\mathrm{T}-\mathrm{H}-\mathrm{M}-\mathrm{C}$ processes that are initiated by repository-related activities, the processes leading to the NFE related to those activities are discussed in this section. The specific NFE conditions that may result are summarized in Section 4 . The intention of this report is not to give all possible scenarios but, rather, to indicate the types of processes that can alter the environment so that the reader can consider the impacts on design options.

\subsection{Construction}

The following discussion includes all activities involved in construction of the facilities that take place prior to emplacement of waste. It does not include construction activities that will take place subsequent to waste emplacement (including closure activities).

\subsubsection{Excavation of Rock}

The most significant impacts assessed for excavation are the alteration of the stress field in the rock near drifts and changes in moisture due to exposure of surfaces to air. Moisture changes are discussed in Section 3.1.3, below. The changes in stress will result in an overall increase in hoop stresses, which will tend to close fractures, particularly during the period of increased temperature. For further discussion, refer to the Preliminary NFER.

\subsubsection{Fluids Introduced during Drilling and Mining}

As explained in the Preliminary NFER, the introduction of mining and drilling fluids may increase the matrix saturation surrounding the openings. However, no evidence was found of significant moisture increases during construction of the 5-mile-long access drift, which should be representative of construction and emplacement drifts. The Preliminary NFER contains discussions of possible impacts of drilling and mining, if they should occur.

\subsubsection{Mine Ventilation}

The Preliminary NFER noted that mine ventilation may lead to drying of the matrix surrounding emplacement drifts, where ventilation of the shafts, ramps, and drifts will remove moisture from the rock via evaporation. This appears to have been the case within the access drift. No water has been observed to drip into the tunnels, except when the ventilation is shut off or when rock is isolated from ventilation. Ions dissolved in the affected pore water will leave behind a small residue of soluble and insoluble salts as the pore water evaporates. No samples of such residue have been taken.

\subsubsection{Introduction of Materials by Man}

Materials will be introduced, both intentionally and unintentionally, during construction of the facilities. These materials may include such things as material added in the form of crushed rock, granular minerals, engine exhaust, rubber products and other polymers, metals, and 
concretes. The major potential for perturbations of the environment due to man-made materials will exist after emplacement.

\subsection{Emplacement of Waste}

When waste is emplaced, heat from the radioactive decay of the waste will cause changes in the environment, which will likely dominate the geochemical-hydrological-mechanical conditions. Heat has the potential to drive water away from the WPs, to control the relative humidity, and to change the relative hydraulic conductivity, gas permeability, imbibition characteristics, and other properties of the rock mass.

\subsubsection{Thermal Loading}

3.2.1.1 Dry Out. As reported in the Preliminary NFER, after waste emplacement, thermal loading will drive moisture away from waste emplacement openings. Because of the large increase in vapor pressure, nearly all of the air will be driven away from the boiling zone (leaving the gas phase with $100 \%$ water vapor). Tests and analyses of matrix drying show that vapor transport preferentially occurs into openings and along fracture faces. Upon reaching the fractures, most of the vapor is driven away from the boiling zone toward a condensation zone where it condenses and drains down fractures until it is either (1) entirely imbibed by the matrix, (2) enters the saturated zone, or (3) flows back into the boiling zone where it boils again forming a "heat pipe" by refluxing. Low wetting sorptivity of TSw 2 appears to facilitate drainage to great depths below the repository. The extent to which condensate drains away from the emplacement zone depends on the competition between gravity drainage and imbibition by the rock matrix. Results of field tests at G-Tunnel (Ramirez, et al., 1991; Nitao and Buscheck, 1995) and at the ESF Single Heater Test (Finley et al., 1997) indicate that condensate drainage can be significant.

3.2.1.2 Rewetting. As the rock cools below boiling conditions, vapor and liquid will flow back into the dried region toward the drifts. The flow will be dominantly along fractures. Saturation gradients will also cause water redistribution in the matrix; however, the very low permeabilities will cause matrix flow to be slow. Thus, flow along fractures will dominate rewetting of the dried-out zone.

Studies show that rewetting occurs at a much slower rate than drying. The details of emplacement configurations, fuel age, AMLs, and percolation flux will have profound effects on the time of dryout and return of moisture to the WP areas. Design development must take these phenomena into account.

3.2.1.3 Dissolution and Precipitation of Minerals. Strong coupling will take place between thermo-hydrologic and geochemical processes. Within the NFE/AZ in the regions where rock is dried, the processes will be dominated by vapor flow and chemical exchanges associated with vapor flow. In the portions of this region where temperatures are very near boiling, the rock will undergo drying with dissolved minerals left in the pores of the rock. This zone may be fairly limited in extent, but the zone will move outward with time so that much of the rock mass may be in this zone at some time. As water is removed, dissolved minerals will be deposited in the throats of pores, particularly the smaller ones. This may result in fundamental changes of the matrix hydrologic properties. Studies have shown that, in addition to salt deposition, considerable mineral changes can result from rock-water interactions at elevated temperatures. This topic is discussed in detail in Sec. 10.4.4, Volume II.

The zone of rock where temperatures are elevated, but are below the boiling point, will be very active both hydrologically and geochemically with potential for very active dissolution and precipitation of minerals. Numerous experiments have demonstrated that the chemical 
composition of the water is likely controlled by the solubility of mineral phases present in the rock (Knauss, 1987; Knauss and Peifer, 1986; Knauss et al., 1986). See Sec. 10.4.3, Volume II.

3.2.1.4 Increased Stress. The largest effect on the geomechanical behavior of the NFE is expected to be due to the thermal cycle in which the rock will be heated and then allowed to slowly cool. Thermal loading of the NFE will alter the stress in the rock near the emplacement drift as a function of time. During the period of temperature increase, stress in the near-field rock will increase as the rock tries to expand. However, due to geometry of the excavated drifts, the stress fields in the NFE will be complex, and some zones may even be put in tension for an extended period of time. As the temperature decreases, the overall stress levels will decrease, and the entire stress will again be compressive.

Deformations within the rock mass can impact the hydrologic flow system. Many laboratory studies (Bandis et al., 1983; Barton et al., 1985) have documented that greater impact often results from shear rather than normal deformations. This is especially true once stresses are removed, as would be the case for the repository once the thermal pulse has decayed. Permanent changes in hydrologic properties or flow paths can result from stresses normal to fractures, but they tend to be smaller than those caused by shear displacements. This has also been observed in field studies (Wilder, 1987). A "qualitative evaluation of the coupling complexity between mechanical behavior and void space evolution between the joint walls during shear displacement..." has been suggested by Archambault et al. (1997).

\subsubsection{Introduced Materials}

In addition to material introduced as part of construction, significant volumes of material will be brought in at the time of emplacement, including the container materials and EBS packing materials. The significance of such materials (except for dust, coatings, lubricants, and so forth) is long-term once they interact (corrode) with the NFE. As noted, the major potential for perturbations of the environment due to man-made materials will exist after emplacement, when heat and microbial activity will increase the chances for impact on geochemistry of the water. It is anticipated that introduced material will dominate the WP or NFE chemistry, particularly if microbial activity becomes significant.

\subsection{Backfilling}

Environmental conditions most likely to be impacted by backfilling include the hydrologic characteristics and an early, transient thermal effect of different heat conduction in the backfill compared with that of the rock mass. Backfilling will also influence opening stability, but that is a design-related issue, not an environmental characteristic. As is discussed in Section 4, backfill can have a significant effect on WP temperatures, on humidity, and on the potential for water to contact the WPs.

As discussed in the Preliminary NFER, it is likely that backfill materials will be the tuff removed during excavation. Excavated materials will either be temporarily stored in drifts, where it is assumed there would be some sort of dust control by ventilation, or on the surface. The moisture in the excavated materials would be reduced because ventilation air and surface conditions are expected to be considerably drier than the in situ rock saturation conditions. With handling and breaking of rock, this drying process would be facilitated. Thus, backfill will likely have lower saturation than the original rock-mass saturation. However, backfill will possibly have greater saturation than the dried-out rock mass that develops as a function of waste heat, unless the backfill materials have been stored in areas of drifts that were above the boiling point of the rock. Once emplaced, the backfill will act as a porous media that, depending on the material chosen, could disperse any episodic fracture-dominated flow. 


\begin{abstract}
Although crushed tuff is the most likely backfill material (it is readily available), significant advantages are associated with using backfill consisting of impervious grains (Wilder, 1990; Sec. 1.10.14, Vol. II) rather than crushed tuff. If such a granular backfill is used, there will be longterm flow diversion without wicking. The thermal conduction of granular backfill will be lower than that of the rock mass because of its granular nature. This will not only modify thermal conditions, but because of that modification, will also have dramatic impacts on relative humidity as well as evaporation and deposition of salt and its location.
\end{abstract}

\title{
3.4 Closure
}

Major activities associated with closure that might impact the environmental conditions include (1) ceasing of ventilation, (2) emplacement of seals in openings, and (3) the introduction of construction materials. Because the details of closure are yet to be determined, and further field studies of hydrothermal-chemical-mechanical coupling will be conducted prior to those details being developed, closure effects will be discussed in subsequent revisions of this report.

\subsection{Climate or Site Environment Changes with Geologic Time}

Hydrologic discussions for the NFE included in this report assume that conditions will remain unsaturated for the 10,000-yr performance period. The discussions do not address changes (e.g., climatic) that might take place during the 10,000-yr time frame. However, preliminary information is included that addresses how sensitive the hydrologic response might be to differing flux conditions. The flux at the depths of the NFE depends on the response of the overlying units.

Current estimates suggest that the flux is considerably greater than values used at the time of the Preliminary NFER, and they are higher than those values addressed in Volume II, Rev. 1. The information available at the time of preparing this report has not been updated to address the higher flux estimates - namely, in the range of $10 \mathrm{~mm} / \mathrm{yr}$. The highest flux values evaluated in this report are in the range of 0.3 to $5 \mathrm{~mm} / \mathrm{yr}$. We are in the process of evaluating the hydrologic properties used in the higher flux estimates so that these analyses can be performed using internally consistent parameters. In addition, analyses of whether the higher flux $(10 \mathrm{~mm} / \mathrm{yr})$ is representative of actual conditions are in progress. Field measurements are likely to be available prior to the next update of the this report, and these values will allow an assessment to be made of the appropriate upper value of flux. Regardless of what value is deemed appropriate for upper ranges, the analysis contained in this report should be representative of the lower flux ranges. If it is determined that the upper ranges are higher than those reported here, that information will be incorporated in subsequent revisions. 


\subsection{Near-Field Environment}

Because the NFE is the environment that interacts with emplaced waste, it is, by definition, the post-emplacement environment that develops through process interactions with the waste. The interactions that develop the NFE (as well as the AZ) are highly coupled processes. To facilitate discussion in this report, the coupled processes are broken down either into singly coupled processes (see, for example, loop A-a in Fig. 1-5) or into multiply coupled processes (see, for example, loop B-b in Fig. 1-5), but with a limit on the number of processes analyzed separately.

Figure 4-1 is a simplified model of the coupled-process interactions that will develop the NFE. Recall from Section 1 that entries on the diagonal of this matrix are the principal components-in this case, of the NFE. Other entries on the matrix represent the processes. Those interactions located to the right of the diagonal are the ones that are forward coupled; those to the left are back coupled.

Figure 4-1. Matrix of coupled processes in the NFE.

For example, waste emplacement generates heat that will mobilize water by boiling or evaporation. Thus, to the right of the environmental parameter of temperature is the process of boiling, as indicated by the arrow. Below this process is the changed moisture conditions of the NFE, shown on the diagonal. The forward coupling indicates that the heat drives a change in moisture. However, the changed moisture conditions may also result in changes in thermal conductivity and in removal of heat by convection. These changes would result in a changed thermal regime. Therefore, back-coupling from moisture conditions to temperature is shown by the arrow to the left from moisture conditions to the process box of latent heat and then up to the environmental condition of heat (temperature). The coupling matix shown in Fig. 4-1 is neither comprehensive nor definitive of all of the interactions that must be considered for the NFE. It is simply provided to help understand the organization of technical discussions in this report and the coupling, which can be quite complex.

Volume I of this report focuses only on those issues that are deemed to have direct impact on the design of the repository, or on the Total System Performance Analysis (TSPA). Many additional issues associated with the NFE and coupled processes must be considered when assessing the NFE, but they are not deemed critical to the design or to the PA abstraction. These issues are discussed in Volume II of this report. For example, one of the issues important to PA is changes in hydrologic properties. Such changes are considered in the results reported in this volume, but the details of how those changes occur are of less direct interest and therefore are not specifically discussed in Volume I. Volume I, Rev 0, of the Preliminary NFER discussed changes that can occur in rock properties (see Sec. 4.2.1 of that report). Volume I, Rev 0 also discussed changes that can occur in hydrologic and geochemical properties (see Sec. 4.2.2). Volume II, Rev. 1 (Sec. 1.7 and 2.0) discussed these effects in detail. No attempt is made here to repeat that information, only to summarize results for design and TSPA purposes.

To aid the reader in locating a variety of issues discussed in greater detail in Volume II, Rev. 1 , see the tables in Section 4.4, below.

\subsection{Temperatures of the NFE}

The major contributor to development of the NFE is the coupling of heat to the hydrologic, chemical, and mechanical conditions of the ambient YM environment. Thus, it is critical to determine temperature distributions within the NFE/AZ to address the prioritized 


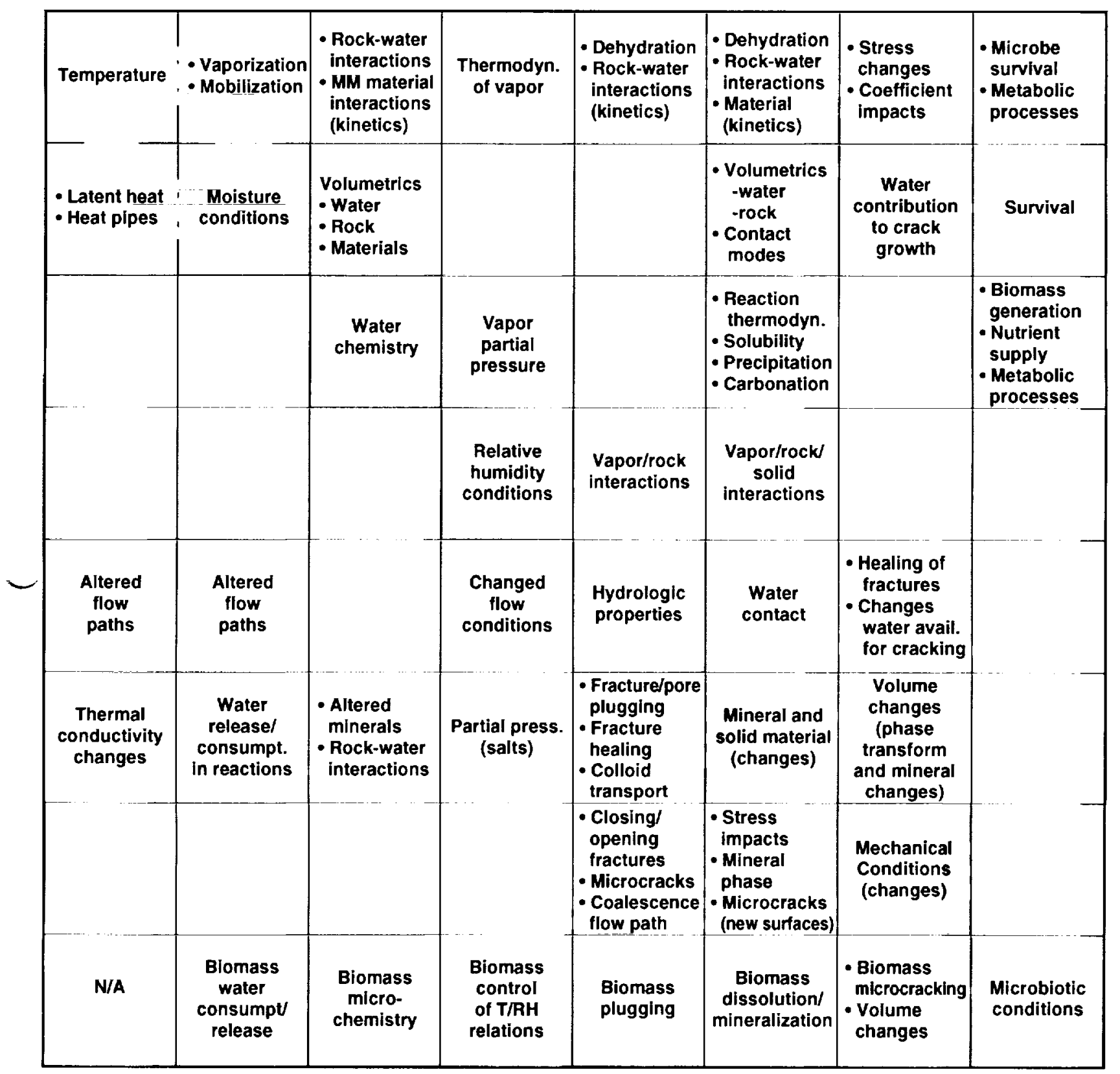

Figure 4-1 
design/performance parameters of water, water chemistry, and many others. This section begins with temperature regimes and then proceeds to the other prioritized topics that were identified in Tables 1-1 and 1-2.

For this revision of the NFER, no effort has been made to back-couple geochemistry etc. to the temperature fields, although it is recognized that such back-coupling could alter the temperature fields, possibly in fundamental ways. This will require an iteration of the alteration impacts back into the thermal conductivities. Such an iteration will be included in subsequent revisions of the NFER, once the design is more mature and laboratory and field test data are available on impact of mineral changes and microfracturing on thermal conductivities and hydrologic properties.

Temperatures of the NFE are mainly determined by:

- Thermal output of the waste.

- Configuration of the waste.

- Thermal conductivity of the rock.

- Heat redistribution by moisture/vapor.

First, each of these parameters or processes is discussed, then the results of analyses that consider these factors is presented.

\subsubsection{Thermal Output of the Waste}

The WPs being considered for emplacement have, for design analyses, been divided into six different classes based on heat outputs. Heat output is a function of waste type, waste age, and amount of waste in any given package. The WP types, in descending order of heat output, are:

1. WPs with 21 PWR assemblies of 10-yr-old spent nuclear fuel (SNF), 17.9-kW heat output.

2. WPs with 21 assemblies of 26-yr-old PWR SNF with a total heat output of $9.2 \mathrm{~kW}$.

3. WPs with 44 assemblies of 26-yr-old BWR SNF with $6.1-\mathrm{kW}$ heat output.

4. WPs with 12 PWR assemblies of 40-yr-old SNF with 3.2-kW heat output.

5. WPs with Defense High Level Waste (DHLW) from Savannah River, 2.8-kW heat output.

6. WPs with DHLW from Hanford with 1.6-kW heat output.

Approximately $38 \%$ of the waste inventory consists of the 21 assembly PWRs. The heat output will depend on the age of the SNF (as noted by comparing output of type 1 and 2 listed above). The 26-yr-old waste is considered to be more typical of the likely age of emplaced PWR waste than 10-yr-old SNF (see waste age discussion in Sec. 1.2.3 of this report). Whereas the DHLW packages are the next most prevalent waste type, their heat output does not contribute significant amounts of heat. The BWR SNF is the next most numerous WP type (about 26\%). The 12 PWR assemblies only represent about $6 \%$ of the WPs.

Even though the U.S. has other waste types, those listed are the ones that are currently being considered for disposal at YM if it were to become a repository. If other waste types are later considered, the analyses that follow would need to take such wastes into account.

Analyses of temperatures in the NFE/AZ have taken into account the heat outputs for the WP types, including their percentages and possible locations or distributions. However, the details of WP distribution are of greater interest for individual WP temperatures and local NFE temperatures. The $A Z$ and average NFE temperatures are influenced more by the total AML and drift spacing than by details of emplacement distribution by WP type. This is important because the distribution of the WPs shown on the design assumptions (see Figs. 1-2 and 1-3) may not be the actual distribution of emplaced waste. Final distributions will depend on several operational constraints. 


\subsubsection{Configuration (Layout) of the Waste}

This report only discusses the results in Volume II that are focused on two design cases, ACD and LL, both of which were performed for approximately $84 \mathrm{MTU} /$ acre loading. These two cases should bound the conditions for those designs options currently being considered.

One of the options common to all of the design cases is the incorporation (or lack thereof) of backfill. From an NFE perspective, properly chosen backfill can have very positive performance aspects that derive from:

1. Extending the duration of elevated WP temperatures.

2. Establishment of strong thermal gradients that result in significant $R H$ reductions (near the WPs) and lengthened duration of those reductions.

3. Diversion of seepage flow that might enter drifts, thus moderating impacts of higher flux.

4. Evaporation/boiling of any water that enters drifts during the thermal regime within the backfill rather than on WPs. This has the significant benefit of preventing salts on WPs, which can lower the magnitude of the $R H$ at which corrosion becomes active.

Backfill is addressed in Volume I for the two reference design cases, the ACD and LL designs.

Volume II considers many other design options, including variations in drift diameter, various AMLs, and various waste ages. Refer to Volume II for information on designs that may fall beyond the scope of those considered in the bounding calculations. Tables 4-5 and 4-6 later in this section are provided to assist in locating the appropriate sections in Volume II for the various design options.

\subsubsection{Thermal Conductivity of the Rock}

Theoretically, the conductivity of the rock should be a strong function of its moisture conditions, although other factors such as microcracking and mineralogic changes can contribute to changes in conductivity. As reported in the Preliminary NFER, the dry matrix thermal conductivity is $2.51 \pm 0.17 \mathrm{~W} / \mathrm{m}^{\circ} \mathrm{K}$. The in situ measurements of thermal conductivity, both dry $\left(2.1 \pm 0.2 \mathrm{w} / \mathrm{m} \cdot{ }^{\circ} \mathrm{K}\right)$ and at a saturation of $0.65\left(2.1 \pm 0.2 \mathrm{~W} / \mathrm{m} \cdot{ }^{\circ} \mathrm{K}\right)$, showed that the thermal conductivity may not vary significantly. That the dry and $65 \%$ saturation conductivities measured in situ are the same is not consistent with understanding based on intact sample measurements and may indicate that the presence of fractures has a more significant or masking influence on conductivity than does saturation. Recent measurements on intact TSw2 samples show that the thermal conductivity for dry samples is $1.50 \pm 0.44 \mathrm{~W} / \mathrm{m} \cdot{ }^{\circ} \mathrm{K}$ and for saturated samples is $2.29 \pm 0.42 \mathrm{~W} / \mathrm{m} \cdot{ }^{\circ} \mathrm{K}$. The calculations presented in this report use the Reference Information Base (RIB, Version 4) value of $2.1 \mathrm{~W} / \mathrm{m} \cdot{ }^{\circ} \mathrm{K}$.

\subsubsection{Heat Redistribution by Moisture and Vapor}

Hydrological conditions are the strongest coupled-process determinants of temperatures that develop within the system, particularly where temperatures reach the boiling point. Therefore, the coupling between heat output and hydrology is used to determine the temperature field of the NFE. The calculations that will be presented consider these changes as well as the chianges from convection/conduction to merely conduction as moisture is removed from rock zones. Other processes (e.g., geochemical and mineralogical) will then be coupled to the thermal and hydrological conditions. Thus, coupling is discussed, first, based on an analysis of single coupling of hydrological conditions to the thermal output of the waste considering the design layout, configuration, and characteristics of the waste to determine the temperature field of the system. 
Following that discussion, we describe the coupling of geochemistry and geomechanics to the coupled hydrothermal results.

\subsubsection{Results: Temperatures in the NFE}

Temperatures that are of greatest interest for the NFE are those on the WP surfaces and on the surface of the rock. For the AZ, the temperature distributions within the entire rock mass-at least to the point that they approach ambient temperatures-are important. Because much of the information presented for the two regions comes from the same calculations, there is some overlap between the information in this section and in Section 5 , which considers the AZ.

Several different analyses have been performed for temperatures in the NFE. For consistency, the analyses reported in Volume II are the focus of this report. More recent calculations are included in a Materials Research Society paper (Buscheck, 1996), which used a finer gridding as well as other model refinements. Those results show peak temperatures that are 5 to $10 \%$ higher than the ones reported in Volume II. Because this difference is well within the variation expected due to uncertainties in assumptions, it was decided that consistency between Volumes I and II is of greater value than incorporating more up-to-date information that was not as complete (less sensitivity analyses of other design options and of assumptions).

Another set of calculations sometimes referred to are those of TSPA95. These analyses assume that heat generated by WPs could be modeled as a line load. As noted earlier, this is only appropriate for the LL design option. For the point loading typified by ACD and for the modified design, this is not as appropriate as the analyses reported in Volume II that account for a large number of WP distributions/layouts. Finally, several analyses have been performed using models that only account for heat flow by conduction. These analyses are appropriate in a limited number of applications and are particularly useful for details within the drifts or WPs; however, they are not generally appropriate to the NFE or AZE because they do not account for the potentially significant coupling with water. For this reason, the analyses reported here will again be limited to those in Volume II, which include this coupling.

Figures 4-2 and 4-3 show the calculated temperatures around the drifts and on the WP surface to illustrate the difference between the ACD and line-load approaches, respectively. Two line-load options were considered: one in which WPs are placed with only $0.1-\mathrm{m}$ spacing between them, and one in which WPs are placed with $1.0-\mathrm{m}$ spacing. In each scenario considered, the drift spacing was determined by equating the spacing of waste and drifts to the AML and then calculating the drift spacing for the given waste spacing that would yield $83.4 \mathrm{MTU} /$ acre.

Figure 4-2. Calculated temperatures around the drifts for the ACD design, the LL design with 1.0-m spacing, and the LL design with 0.1-m spacing. The calculations shown here are specific to WP placement and use WPs with 21 assemblies of 26-yr-old PWR SNF.

Figure 4-3. Calculated temperatures on the WP surface for the ACD design, the LL design with 1.0-m spacing, and the LL design with 0.1-m spacing. The calculations shown here are specific to WP placement and use WPs with 21 assemblies of 26-yr-old PWR SNF.

Drift-wall and waste package surface temperatures are critical parameters of the NFE. The peak temperatures are shown in Table 4-1, whereas the temperatures over time extending to 10,000 years are shown in Figs. 4-2 and 4-3. The very early time responses are not well defined in these plots, and those beyond 10,000 years are not shown. The temperature data for these times can be found in Volume II (see Figs. 1.10.5.1.3, 1.10.5.1.6, 1.10.5.1.9, and 1.10.5.1.13). 


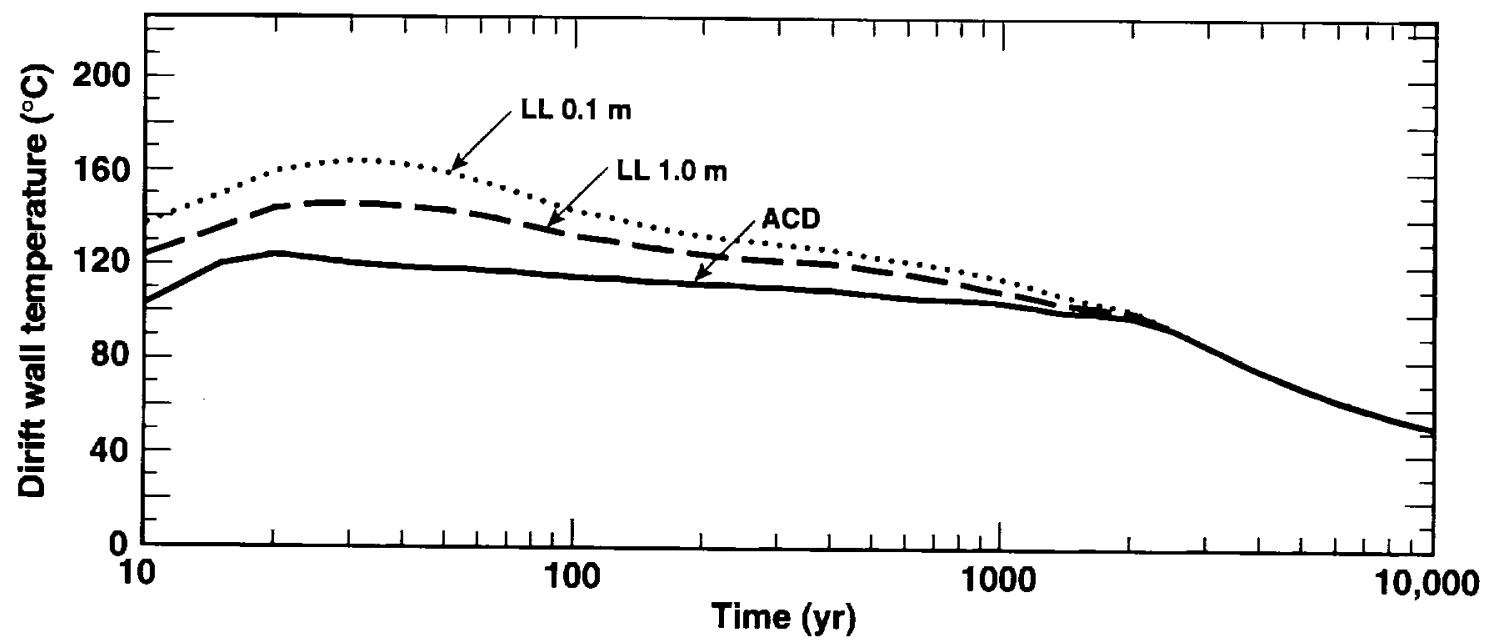

Figure 4-2. 


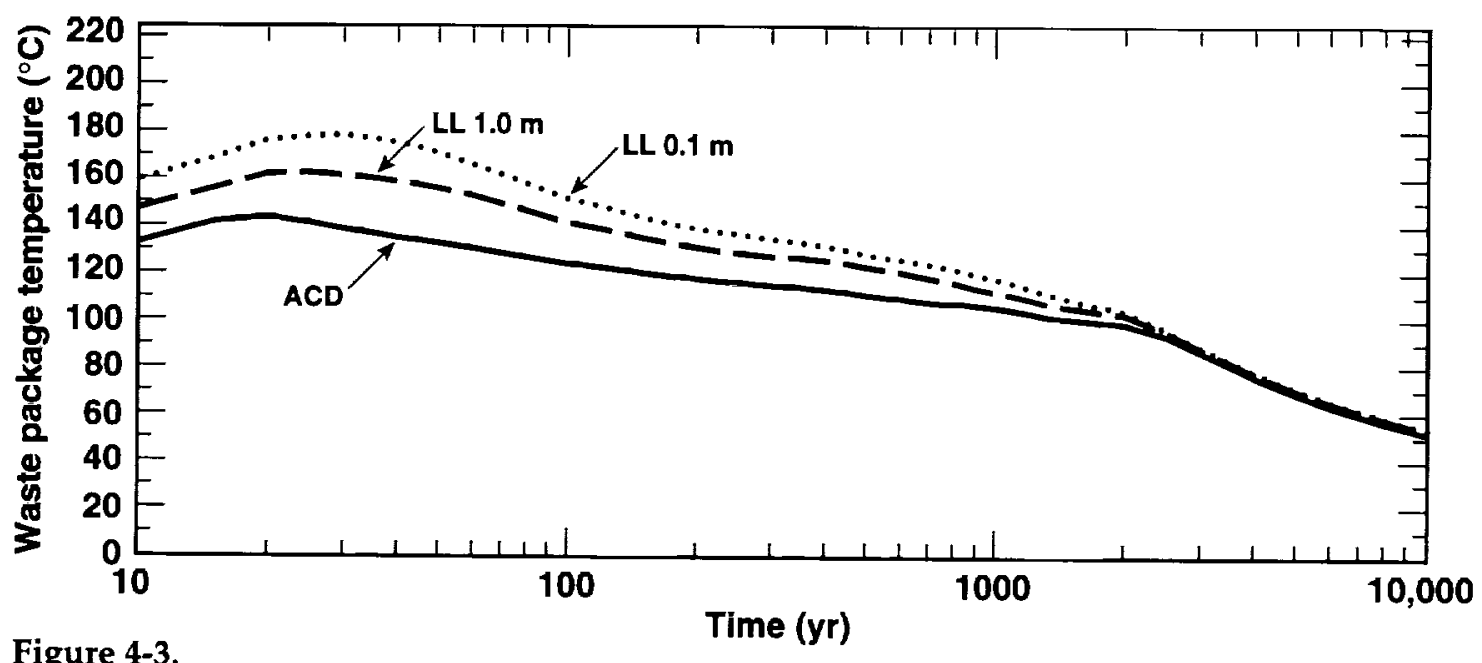

Figure 4-3. 
Table 4-1. Peak temperatures in rock at the upper drift wall and on the WP surface for ACD and line-load designs; percolation flux $=0.3 \mathrm{~mm} / \mathrm{yr}$.

\begin{tabular}{|l|l|l|l|l|}
\hline & \multicolumn{2}{|c|}{ ACD Rev 00 } & \multicolumn{2}{c|}{ Line-load design, 0.1m gap } \\
\hline Waste Package & $\begin{array}{l}\text { Without } \\
\text { backfill }\end{array}$ & With backfill & $\begin{array}{l}\text { Without } \\
\text { backfill }\end{array}$ & With backfill \\
\hline$T_{\text {peak }}(t<100 \mathrm{yr})$ & $107-192^{\circ} \mathrm{C}$ & $\begin{array}{l}\text { same, no } \\
\text { backfill yet }\end{array}$ & $172-203^{\circ} \mathrm{C}$ & $\begin{array}{l}\text { same, no } \\
\text { backfill yet }^{\mathrm{a}}\end{array}$ \\
\hline$T_{\text {peak }}(t>100 \mathrm{yr})$ & $104-144^{\circ} \mathrm{C}$ & $117-353^{\circ} \mathrm{C}$ & $147-158^{\circ} \mathrm{C}$ & $231-314^{\circ} \mathrm{C}$ \\
\hline Wall Rock & & & & \\
\hline$T_{\text {peak }}(t<100 \mathrm{yr})$ & $100-165^{\circ} \mathrm{C}$ & $\begin{array}{l}\text { same, no } \\
\text { backfill yet }^{\mathrm{a}}\end{array}$ & $161-184^{\circ} \mathrm{C}$ & $\begin{array}{l}\text { same, no } \\
\text { backfill yet }^{\mathrm{a}}\end{array}$ \\
\hline$T_{\text {peak }}(t>100 \mathrm{yr})$ & $100-129^{\circ} \mathrm{C}$ & $104-144^{\circ} \mathrm{C}$ & $142-148^{\circ} \mathrm{C}$ & $135-137^{\circ} \mathrm{C}$ \\
\hline
\end{tabular}

a Backfill is emplaced at $100 \mathrm{yr}$; therefore, there is no difference at $t<100 \mathrm{yr}$ between the backfilled and nobackfilled cases.

The temperature responses of the ACD and LL designs are markedly different. The axial WP spacing in the ACD design is large enough to thermally isolate. WPs from each other, which results in a broader range of temperatures. For the ACD case without backfill, peak drift-wall temperatures range from $100^{\circ}$ to $165^{\circ} \mathrm{C}$. (As shown in Table 4-1, the peak WP temperatures range from $107^{\circ}$ to $192^{\circ} \mathrm{C}$ ). The average peak wall rock temperature (at $t<100 \mathrm{yr}$ ) is $132.5^{\circ} \mathrm{C}$, and the average WP temperature is $149.5^{\circ} \mathrm{C}$. There is a range of $65^{\circ}$ in wall rock temperatures and $85^{\circ}$ in WP temperatures. This represents a range of $\pm 25 \%$ and $\pm 28 \%$ of the average wall rock and WP temperatures, respectively. In contrast, the wall rock temperatures for the LL range from $161^{\circ}$ to $184^{\circ} \mathrm{C}$, and for the WPs the temperatures range from $172^{\circ}$ to $203^{\circ} \mathrm{C}$. This range represents $\pm 6.7 \%$ and $\pm 8.3 \%$ of the average temperature of $172.5^{\circ}$ and $187.5^{\circ} \mathrm{C}$ for wall rock and WPs respectively. As is apparent, the temperatures are much more uniform for the LL than for ACD case.

The design option of backfilling the drifts was evaluated for the ACD and LL cases. It was assumed that backfilling was not emplaced until 100 yr after waste emplacement. The impact on WP and wall rock temperatures is also shown in Table 4-1. These analyses assumed complete backfilling around the WPs, including the gap between WPs. In the LL case, leaving the gap open facilitates thermal communication between WPs and therefore would have performance advantages. However, additional design features would be required to prevent backfill materials from filling (at least partially) the gap, and for that reason, the analyses reported are for the gap being filled. A more complete analysis of impacts of gap filling is discussed in Volume II, Sec. 1.10.5.2, and temperature information for the open gap can be found in Table 1.10.5.2.2 of Volume II. As can be seen, the peak temperature of the wall rock for backfilled versus nonbackfilled drifts are not significantly different (no change for ACD and 7 to $11^{\circ} \mathrm{C}$ greater temperatures for backfilled LL case). The greatest difference is for WP temperatures, where backfill increases temperature by 13 to $209^{\circ} \mathrm{C}$ for $\mathrm{ACD}$ and 84 to $156^{\circ} \mathrm{C}$ for the LL design. As a result, when backfilled, the uniformity of the LL case compared to the ACD remains pronounced. The average WP peak temperature after backfilling is $235^{\circ} \mathrm{C}$ with a range of $\pm 50 \%$ of the average for the ACD case, and is $272.5^{\circ} \mathrm{C}$ with a range of $\pm 15 \%$ of the average for the LL design.

Analyses of the current or modified design have been based on a modified ACD with 1.0-m spacing for significant portions of the drifts. Therefore, Figs. 4-2 and 4-3 showing the line-load design with $1.0-\mathrm{m}$ spacing are more representative of portions of the current design than is the ACD design.

As seen in Figs. 4-2 and 4-3, the distinction between temperatures resulting from different designs is reduced with time. This is also true for the distinction between wall rock and WP temperatures. As can be seen in Fig. 4-4, for times that extend beyond about 3000 years, there are 
only minor differences (about $5^{\circ} \mathrm{C}$ ) between the temperature on the WP surface and in the rock at the drift wall. This plot was based on the TSPA95 reference case with AML $=83.4 \mathrm{MTU} / \mathrm{acre}$. The plot is included merely to illustrate that, at longer times, the temperature differences between WP and rock decrease. Thus, the impacts of temperature differences between WPs and drift walls will be greatest during the first few thousand years after emplacement. The TSPA95 case was essentially a line load, but it was judged sufficiently representative of the average response of the design cases to illustrate this point. Therefore, the calculations were not redone to be more directly comparable with the ACD or LL cases.

Figure 4-4. Temperature on the WP surface and in rock at the drift wall for the TSPA95 reference case with $A M L=83.4 \mathrm{MTU} / \mathrm{acre}, \mathrm{LML}=0.47 \mathrm{MTU} / \mathrm{m}$, and drift spacing $=22.5 \mathrm{~m}$.

The preceding discussions were for average conditions. Table 4-2 shows the temperature conditions for individual WPs by waste type based on the ACD and LL cases. This table shows that there is considerably more variability in peak WP temperatures for the ACD design than for the LL design. For the first 100 years, the average WP temperature for the ACD design is $134^{\circ} \mathrm{C}$, and the range of temperatures is equivalent to $64 \%$ of the average. In contrast, the LL design has a higher average temperature of $180^{\circ} \mathrm{C}$ and much less variability, with a range of temperatures equivalent to $18 \%$ of the average. The difference is even more pronounced for times beyond 100 years. For $t>100 \mathrm{yr}$, the average ACD WP temperature is $212^{\circ} \mathrm{C}$, and the range is $111 \%$ of that value. The average LL WP temperature is $256^{\circ} \mathrm{C}$, and the range is only $6 \%$ of the average value.

Table 4-2 Temperature on the upper WP surface by waste type for the ACD versus $L L$ design with $0.1-\mathrm{m}$ spacing. Full sand backfill is used with $K_{\mathrm{th}}=0.6 \mathrm{~W} / \mathrm{m}^{\circ} \mathrm{C}$, and percolation flux $=0.3$ $\mathrm{mm} / \mathbf{y r}$.

\begin{tabular}{|l|l|l|l|l|l|l|}
\hline Parameter & $\begin{array}{l}\text { Hanford } \\
\text { DHLW }\end{array}$ & $\begin{array}{l}\text { Savannah } \\
\text { DHLW }\end{array}$ & $\begin{array}{l}\text { 40-yr-old } \\
\text { PWR MPC }\end{array}$ & $\begin{array}{l}\text { 26-yr-old } \\
\text { BWR MPC }\end{array}$ & $\begin{array}{l}\text { 26-yr-old } \\
\text { PWR MPC }\end{array}$ & $\begin{array}{l}\text { 10-yr-old } \\
\text { PWR MPC }\end{array}$ \\
\hline $\begin{array}{l}\text { ACD } \\
\begin{array}{l}T_{\text {peak }} \\
(t<100 \mathrm{yr})\end{array}\end{array}$ & $106^{\circ} \mathrm{C}$ & $121^{\circ} \mathrm{C}$ & $112^{\circ} \mathrm{C}$ & $127^{\circ} \mathrm{C}$ & $145^{\circ} \mathrm{C}$ & $192^{\circ} \mathrm{C}$ \\
\hline $\begin{array}{l}T_{\text {peak }} \\
(t>100 \mathrm{yr})\end{array}$ & $117^{\circ} \mathrm{C}$ & $136^{\circ} \mathrm{C}$ & $172^{\circ} \mathrm{C}$ & $222^{\circ} \mathrm{C}$ & $272^{\circ} \mathrm{C}$ & $353^{\circ} \mathrm{C}$ \\
\hline $\begin{array}{l}\text { Line load } \\
\begin{array}{l}T_{\text {peak }} \\
(t<100 \text { yr })\end{array}\end{array}$ & $171^{\circ} \mathrm{C}$ & $184^{\circ} \mathrm{C}$ & $171^{\circ} \mathrm{C}$ & $174^{\circ} \mathrm{C}$ & $178^{\circ} \mathrm{C}$ & $203^{\circ} \mathrm{C}$ \\
\hline $\begin{array}{l}T_{\text {peak }}(t>100 \mathrm{yr}) \\
\left(t>152^{\circ} \mathrm{C}\right.\end{array}$ & $258^{\circ} \mathrm{C}$ & $250^{\circ} \mathrm{C}$ & $251^{\circ} \mathrm{C}$ & $256^{\circ} \mathrm{C}$ & $266^{\circ} \mathrm{C}$ \\
\hline
\end{tabular}

Figure 4-5 shows the three-dimensional temperature distribution for the same amount of waste per acre (83.4 MTU/acre) at 100 and $500 \mathrm{yr}$ for the ACD and the line-load designs with 0.1 $\mathrm{m}$ spacing and full sand backfill at $100 \mathrm{yr}$. Temperatures less than $112^{\circ} \mathrm{C}$ are transparent to emphasize the relatively hot regions in the NFE. (For an ambient percolation flux of $0.3 \mathrm{~mm} / \mathrm{yr}$, rock temperatures above $105^{\circ} \mathrm{C}$ correspond to a reduction in relative humidity. Therefore, the colored regions in the illustration are zones of superheated conditions where temperatures are hotter than the nominal boiling point $\left(96^{\circ} \mathrm{C}\right)$, and moisture conditions are drier than ambient. Condensate drainage will generally occur around the colored regions.)

The large axial spacing in the ACD design thermally isolates WPs from one another, causing rock dryout and condensate shedding to occur in a spherical fashion. The size of any spherically shaped superheated zone is directly correlated with the heat output of the WP in that zone. Only half of the WPs generate enough decay heat to develop a superheated zone at $100 \mathrm{yr}$. In addition, 


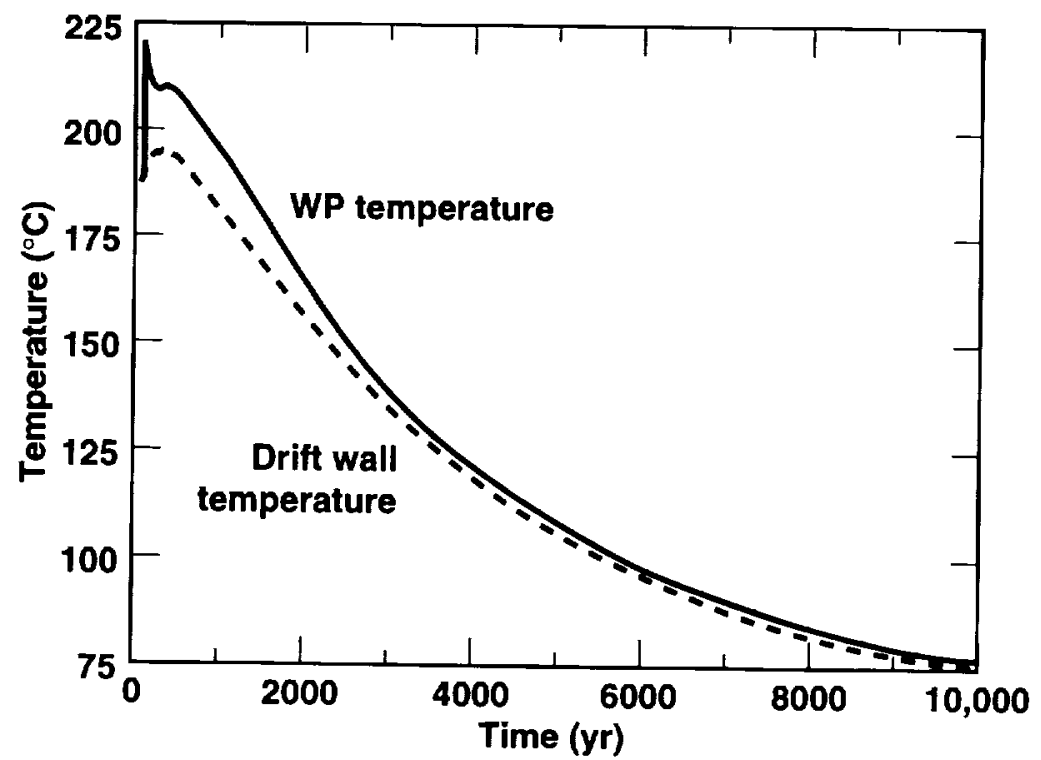

Figure 4-4. 
only a very small portion of the repository can be considered to be in a marginally superheated state at $500 \mathrm{yr}$ for the ACD design.

In contrast, for the line-load design, condensate shedding occurs in a cylindrical fashion, and condensate flux at the repository horizon only occurs in the rock pillars separating the emplacement drifts. Consequently, the line-load design is associated with a much larger superheated volume that the ACD design, even though the two designs share the same AML.

Figure 4-5. Temperature distribution for ( $a$ and c) ACD versus ( $b$ and d) line-load design with 0.1-m spacing between WPs. Temperatures are shown at ( $a$ and $b$ ) $100 \mathrm{yr}$ and at (c and d) $500 \mathrm{yr}$. For all cases shown, AML $=83.4 \mathrm{MTU} / \mathrm{acre}$, fill sand backfill is present, drift diameter $=5.5 \mathrm{~m}$, and ambient percolation flux is $0.3 \mathrm{~mm} / \mathrm{yr}$. Emplacement drifts are parallel to the axial distance axis.

Refer to the tables in Section 4.4, below, for a list of cross references to Volume II, which considered many other parameters that can affect temperatures at the WP and drift wall.

\subsection{Water (Liquid and Vapor) Fluxes in the NFE}

From the list of priorities identified in Section 1, a key consideration for nuclear waste isolation is whether (more precisely, when and how) water contacts a WP. The manner in which decay heat influences the distribution of liquid saturation and liquid-phase flux in the NFE is the focus of this section.

Water may contact a WP either by liquid-phase (advective or diffusive) flow or by condensation of water vapor that forms a liquid film on the WP (function of RH). Water contact may arise in the following three ways:

- Drift seepage. Advective liquid-phase flow of water that enters the drift (and flows through the backfill if present) as a result of ambient percolation or decay-heat-driven condensate flow. This seepage can include episodic, nonequilibrium fracture flow or steady weep.

- Wicking. Transport of moisture driven by matric potential gradients (i.e., capillary pressure gradients). This is considered to be primarily an advective liquid-phase transport process called imbibition; however, binary gas-phase diffusion can also play a role. Because wicking can occur as two-phase flow, it does not necessarily require a continuous liquid phase.

- Cold-trap effect. Axial water-vapor flow and condensation within the drift is driven by axial variations in temperature $(T)$ and vapor pressure $\left(P_{v}\right)$ along the drift. Water vapor is transported by gas-phase advection and diffusion from areas of higher $T$ and $P_{\mathrm{v}}$ to areas of lower $T$ and $P_{\mathrm{v}}$ where it condenses, which causes $R H$ to increase (to as high as $100 \%$ ). Large condensation rates can arise in the cooler areas if three conditions are met: (1) high $R H$ in the rock at the drift wall, (2) WP heat output varies substantially from WP to WP, and (3) WPs are thermally isolated from one another. It is important to note that this mechanism does not require liquid water to enter the drift.

For all three of these effects, the most important thermal-management design factor is the WP layout rather than the overall AML of the repository itself (i.e., high versus low AML).

Liquid-phase flux that may enter a drift is the result of ambient percolation flux and decayheat-mobilized vapor and condensate flow. One of the issues that will be discussed in this report is whether (or under what conditions) decay heat decreases or increases the magnitude (or probability) of liquid-phase flux entering a drift. Depending on the AML, decay heat is capable of generating a zone of counter-current, two-phase flow above the repository, which is sometimes called the refluxing zone or the heat-pipe zone (Nitao, 1988; Pruess et al., 1990; Buscheck and Nitao, 1994). This zone is associated with liquid-phase fluxes that are much larger than ambient. 

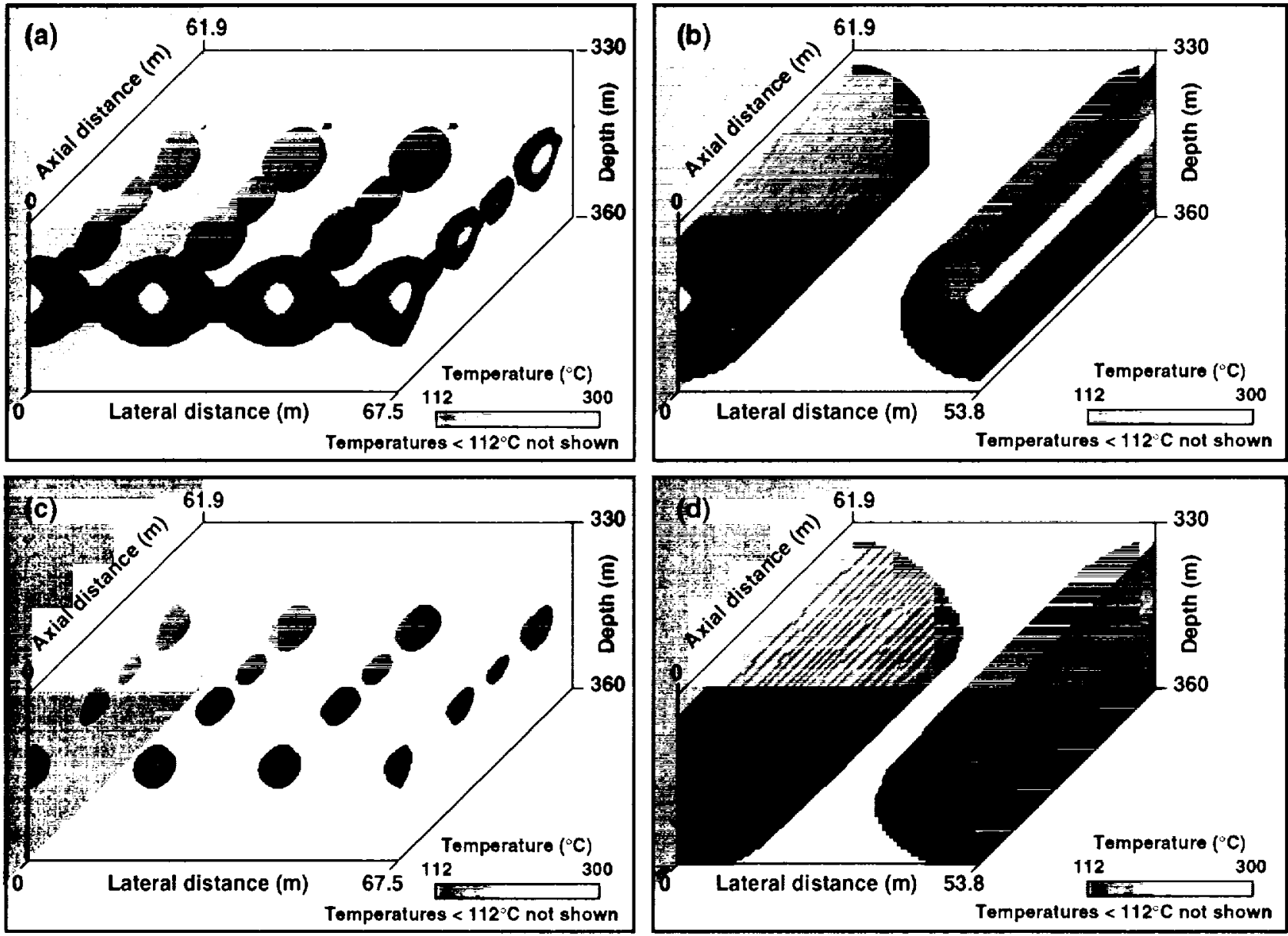

Figure 4-5. 
If the AML is large enough, this zone can be displaced well above the repository horizon by the superheated (above-boiling-temperature) zone. If the AML is not large enough or the ambient percolation flux is too large, it is possible for the heat-pipe zone to remain at the repository horizon. A heterogeneous permeability distribution can also cause the heat-pipe zone to remain at the repository horizon in regions where condensate flow is focused (see Volume II, Sec. 1.10.2.5).

Whether liquid-phase flux, arising from ambient percolation flux and decay-heat-mobilized condensate flux, may enter emplacement drifts depends on the magnitudes of the fluxes. As noted earlier, this report considers ambient fluxes in the range between 0 to $5 \mathrm{~mm} / \mathrm{yr}$, with 0.3 $\mathrm{mm} / \mathrm{yr}$ as the most likely. Current estimates, although not universally accepted, are much higher, in the range of 10 to $15 \mathrm{~mm} / \mathrm{yr}$. The overall magnitude of the condensate flux depends on AML, not layout configuration. As shown in Fig. 4-6, the total flux at the repository level that results from $83.4 \mathrm{MTU} /$ acre for percolation fluxes of $0.3 \mathrm{~mm} / \mathrm{yr}$ and $0.05 \mathrm{~mm} / \mathrm{yr}$ is less than $1 \mathrm{~mm} / \mathrm{yr}$, except between 3,000 to $6,000 \mathrm{yr}$, when fluxes peak at about $1.6 \mathrm{~mm} / \mathrm{yr}$ (at approximately 4,000 years). Moreover, liquid-phase flux in the vicinity of an 83.4-MTU/acre repository is dominated by condensate flux for 2000 to $5000 \mathrm{yr}$ (see Buscheck, 1996, in Sec. 1.10, Vol. II). Thus, there is a potential total percolation/condensate flux of about $1 \mathrm{~mm} / \mathrm{yr}$ that theoretically could enter the drifts.

Figure 4-6. Liquid-phase flux at the repository horizon at a location midway between the repository center and the outer perimeter. $\mathrm{AML}=83.4 \mathrm{MTU} / \mathrm{acre}$, and repository area $=3.06$ $\mathbf{k m}^{2}$.

Whether this amount of flux can actually enter the drifts depends on several factors. The first is how much of the condensate flux will be available to flow into the drifts and how much will be diverted away from drifts. As noted by Wilder (1990), condensate will be driven away from the drifts in all directions (radially) and will tend to be deposited in the greatest volumes over the pillars between drifts rather than above the drifts. (Although this analysis was made for the borehole emplacement case, the geometric conditions apply to current designs, so that this conclusion remains valid.) Thus, unless flow in pillars is restricted by processes such as fracture healing (see Section 5), it is not appropriate to combine both the average percolation and condensate fluxes to determine the potential flux into the drifts. How large a percentage of the condensate would be deposited over the drifts will depend on the repository design or configuration-specifically drift spacing. The assumption of uniform condensate buildup in the rock above the drifts gives an upper bound, since the condensate flux would be independent of location, and all of the focusing mechanisms would tend to focus condensate away from drifts rather than over them.

A second factor is whether condensate will leave the system before it can return to the drifts. This depends on whether the condensate will be thermally perched so that it can reside in fractures/matrix in the condensate zone rather than flowing through the fractures and away from the condensate zone. Laboratory studies by Roberts and Lin (1997) indicate that for a $25-\mu \mathrm{m}$ fracture, thermal perching is overcome once the condensate builds up a head exceeding $29 \mathrm{~m}$. At that point, the condensate would drain through fractures. Of course, how far it can flow along the fracture is a function of length of flow path in the superheated zone, the heat flux, and the quantity of condensate available to continue to feed water into the fracture (Buscheck and Nitao, 1994). Because the heat flux is much higher near the drifts, the condensate would tend to drain preferentially through pillar areas. If the condensate is thermally perched, the fractures have a very small storage volume for water to reside in. Analyses of the relative volumes of available storage versus volumes of condensate generated indicate that more than $90 \%$ of the condensate generated will have to either flow laterally away from the repository drifts and/or down fractures to the saturated zone, or fill up the matrix pores, which would result in a thick zone of nearly saturated rock, or leave the system entirely. 


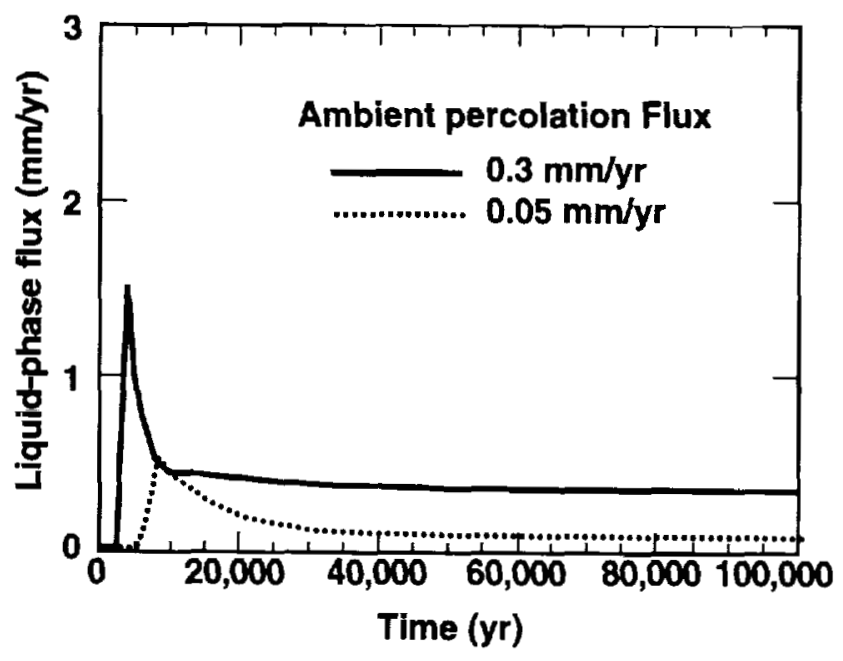

Figure 4-6. 
A third factor is whether the local heat flux, $q_{\mathrm{h}}$ is large enough to evaporate the local incoming liquid-phase mass flux $q_{\text {liq. }}$. Spatial variability can result in local regions where $q_{\text {liq }}$ will prevail. Because $q_{n}$ increases with proximity to the drift, it is more likely for $q_{\text {liq }}$ to prevail in the rock farther away from the drifts. Near the drifts, $q_{h}$ will be 2.4 times greater, on average, for the line-load design than for the point-load design.

Superheated conditions in the repository rock will occur as long as the local heat flux $q_{h}$ is enough to evaporate the local incoming liquid-phase mass flux qliq. The extent or rapidity at which the water that is within the pores of the matrix will be vaporized depends on the extent that $q_{h}>q_{\text {liq. }}$. If $q_{\text {liq }}$ is too large, then $q_{h}$ is insufficient to generate superheated conditions. Spatial variability can result in local regions where $q_{\text {liq }}$ will prevail. Because $q_{\mathrm{h}}$ increases with proximity to the drift, it is more likely for $q$ liq to prevail in the rock farther away from the drifts. Near the drifts, $q_{h}$ will be 2.4 times greater, on average, for the line-load design than for the point-load design.

Fourth, studies by Nitao (1997) indicate that for total percolation fluxes below $10 \mathrm{~mm} / \mathrm{yr}$, the water will not enter the drifts. If the ambient percolation flux approaches $10 \mathrm{~mm} / \mathrm{yr}$, then during the thermal regime the issues of $q_{h}$ versus $q_{k q}$, as well as condensate drainage become very important. After the waste and surrounding rock cools down $(2,000$ to $6,000 \mathrm{yr})$, then the condensate will not be added to the ambient percolation flux. It will have either drained away or have been imbibed into the matrix. Thus, for the longer time frames, the ambient percolation flux can be used to determine the water entry into drifts. During this time, unless the percolation flux exceeds the $10-\mathrm{mm} / \mathrm{yr}$ value that is currently envisioned as the maximum value, then water would not enter the drifts.

The above discussion assumes that there are no drift liners or other ground support systems to hinder water flow into the drifts. The current design calls for emplacement of pre-cast concrete liner as ground support. The liner will not be sealed at the joints but will interlock segments. This will provide some additional resistance to flow into the drifts but will not be entirely tight. Where fractures intersect the drift opening, the water would tend to be diverted around the liner segments, and if open fractures were available, much of the water would flow into those fractures. This would not divert all of the water from the drift ,but it would result in reductions so that assessments based on the unrestricted flow into the drifts would be a conservative estimate. Recent estimates of potential for flow into drifts from the ambient percolation flux have concluded that no flow will enter the drifts (Bodvarsson and Bandurraga, 1996).

\subsection{Relative Humidity Conditions in the Drift and NFE}

One of the performance issues related to the NFE is the relation between relative humidity $(\mathrm{RH})$ and corrosion rates of candidate metals for the WP containers. It has been observed that corrosion rates initiate, and kinetics become increased, at $R H$ values that are higher than about 70\% (McCright, 1997; see Van et al., 1994). Buscheck (1996) noted that one of the results of the heat output of the WPs is the lowering of the $R H$ on the surface of the WPs. A temperature difference or gradient in the drift will result in lowering of the $R H$ in the drift, or more specifically, on the WP surface, to values below what they would be if the $R H$ was entirely determined by equilibrium with the humidity or water/moisture conditions in the rock. Without a difference in temperature between the rock wall surface and the drift air or WP surfaces, the $R H$ in the drift would be in equilibrium with humidity conditions in the rock, which are a function of saturation of the rock. Except for very low rock saturations, this would mean that the $R H$ within the drifts would be very high. Analyses have indicated that $R H$ within the drifts will exceed $70 \%$ for rock saturation above $20 \%$. Thus, the rock would need to be reduced in saturation from its ambient state, currently estimated to be around $90 \%$ saturation, to below $20 \%$ saturation before 
there would be a sufficient reduction in $R H$ to be out of the high-corrosion-potential regime of $R H$ equal to or exceeding $70 \%$. In contrast, the thermal gradient is highly effective at lowering the $R H$.

Table 4-3 shows the calculated $R H$ conditions on the WP surface and on the emplacement drift wall (for average repository conditions) that would result from the two repository designs/layouts considered, i.e., the ACD and LL 0.1-m-gap cases. Because backfill has a strong influence on temperature gradients, the information is shown for both backfilled and open drifts.

Table 4-3. Relative humidity in rock at the upper drift wall and on the WP surface for ACD and line-load designs, assuming percolation flux $=0.3 \mathrm{~mm} / \mathrm{yr}$ and backfilling occurs at $100 \mathrm{yr}$.

\begin{tabular}{|l|l|l|l|l|}
\hline & \multicolumn{2}{|c|}{ ACD Rev 00 } & \multicolumn{2}{c|}{ Line-load design } \\
\hline Time of $R H$ & $\begin{array}{l}\text { Without } \\
\text { backfill }\end{array}$ & With backfill & $\begin{array}{l}\text { Without } \\
\text { backfill }\end{array}$ & With backfill \\
\hline WP surface & & & & \\
\hline$R H(t<100 \mathrm{yr})$ & $25-86 \%$ & Same & $16-21 \%$ & Same \\
\hline$R H(t=120 \mathrm{yr})$ & $29-85 \%$ & $1-57 \%$ & $18-23 \%$ & $1-4 \%$ \\
\hline$R H(t=2000 \mathrm{yr})$ & $86-97 \%$ & $43-98 \%$ & $72-76 \%$ & $44-57 \%$ \\
\hline$R H(t=10,000 \mathrm{yr})$ & $92-99.9 \%$ & $60-99.7 \%$ & $94-98 \%$ & $68-81 \%$ \\
\hline Rock Surface & & & & \\
\hline$R H(t<100 \mathrm{yr})$ & $36-98 \%$ & Same & $21-25 \%$ & Same \\
\hline$R H(t=120 \mathrm{yr})$ & $36-97 \%$ & $45-99 \%$ & $23-27 \%$ & $31 \%$ \\
\hline$R H(t=2000 \mathrm{yr})$ & $90-97 \%$ & $92-99 \%$ & $76-77 \%$ & $78 \%$ \\
\hline$R H(t=10,000 \mathrm{yr})$ & $99.8-99.8 \%$ & $99.8-99.8 \%$ & $99.1-99.1 \%$ & $99.1 \%$ \\
\hline
\end{tabular}

${ }^{2}$ Backfill is emplaced at $100 \mathrm{yr}$; therefore, there is no difference at $\mathrm{t}<100 \mathrm{yr}$ between backfilled and nonbackfilled cases.

Comparison of the values in Table 4-3 shows that there is a reduction in $R H$ that results from emplacement of waste for both the WP and the drift wall. The reductions are greater for the WP surfaces because the temperatures are higher there than on the drift walls. Regardless of the design option considered, the RHs are considerably lower than the values of nearly 98 to $99 \%$ that are representative of the ambient conditions (the values for $t=10,000 \mathrm{yr}$ are essentially ambient).

A significant difference between the $R H$ reductions resulting from the ACD and the LL designs arises because the axial WP spacing in the ACD design is large enough to thermally isolate WPs from each other. However, the reductions are much more dramatic for the WPs when backfill is emplaced and the LL design option is used. In this case, the humidities remain below the critical values for several thousand years. Even after $10,000 \mathrm{yr}$, they are in the 70 to $80 \%$ range. The difference between the ACD and LL case is not merely in the magnitude of the reduction, but also in the variability or range of the reduction. This can be seen by comparing average values. In the ACD case at $120 \mathrm{yr}$, the average $R H=29 \%$ and the range of values is $\pm 28 \%$ of the average; whereas for the LL case at $120 \mathrm{yr}$, the average $R H=2.5 \%$ and the range is only $\pm 1.5 \%$ of the average. Likewise at $2,000 \mathrm{yr}$, the $\mathrm{ACD} R H=70.5 \%$ and the range is $\pm 27.5 \%$ of the average; whereas the $L L$ case $R H=50.5 \%$ and the range is only $\pm 6.5 \%$ of the average. The range in $R H$ for the ACD case represents $\pm 97 \%$ and $\pm 39 \%$ of the average values at 120 and $2000 \mathrm{yr}$, respectively. In contrast, the range of $R H$ s for the LL case represents $\pm 60 \%$ and $\pm 13 \%$ of the average values at 120 and $2000 \mathrm{yr}$, respectively. The reductions in $R H$ for the wall rock are not as significant for the backfill case as for the nonbackfilled case. This reflects the temperature gradient that results when backfill is emplaced, which causes a much reduced WP relative humidity, but a less reduced wall-rock relative humidity. 
The preceding discussions were for average conditions. Table 4-4 shows the $R H$ conditions for individual WPs by waste type based on the ACD and LL cases. This table shows that repository design can cause significant differences in the RHs that develop on the WP surfaces, particularly when the drifts are backfilled. One way to consider this impact is to look at the range of $R H$ conditions that develop. Prior to backfilling, the range of $R H s$ for the ACD case is from 25 to $86 \%$. The average $R H$ is $55 \%$, and the range is equivalent to $111 \%$ of the average value. In contrast, the range of $R H s$ for the LL case is from 16 to $21 \%$, the average is $20 \%$, and the range is equivalent to $25 \%$ of the average value. Thus, the $R H$ environment is much more uniform for the LL case prior to backfill.

At $120 \mathrm{yr}$ ( $20 \mathrm{yr}$ after backfill is emplaced), the $R H$ range is from 1 to $57 \%$ for the ACD case, the average $R H$ is $19 \%$, and the magnitude of the range of $R H s$ is $300 \%$ of the average value. For the LL case, the $R H$ range is from 2 to $3 \%$, the average $R H$ is $3 \%$, and the range is equivalent to $35 \%$ of the average. Similar differences are seen at $2,000 \mathrm{yr}$, where the ACD average value is $70 \%$, and the range is equivalent to $78 \%$ of the average value. For the LL case, the average $R H$ is $50 \%$, and the range is equivalent to only $6 \%$ of the average. Similar differences are seen for the time at which the $R H$ returns to a value of $65 \%$.

Table 4-4. Relative humidity on the upper WP surface by waste type for the ACD versus LL design with $0.1-\mathrm{m}$ spacing. Full sand backfill is used with $K_{\mathrm{th}}=0.6 \mathrm{~W} / \mathrm{m}^{\circ} \mathrm{C}$, and percolation flux $=0.3 \mathrm{~mm} / \mathrm{yr}$.

\begin{tabular}{|c|c|c|c|c|c|c|}
\hline Time of $R H$ & \begin{tabular}{|l} 
Hanford \\
DHLW
\end{tabular} & $\begin{array}{l}\text { Savannah } \\
\text { DHLW }\end{array}$ & $\begin{array}{l}\text { 40-yr-old } \\
\text { PWR MPC }\end{array}$ & $\begin{array}{l}\text { 26-yr-old } \\
\text { BWR MPC }\end{array}$ & $\begin{array}{l}\text { 26-yr-old } \\
\text { PWR MPC }\end{array}$ & $\begin{array}{l}\text { 10-yr-old } \\
\text { PWR MPC }\end{array}$ \\
\hline \multicolumn{7}{|l|}{ ACD } \\
\hline$R H_{\max }(t<100 \mathrm{yr})$ & $86 \%$ & $61 \%$ & $65 \%$ & $50 \%$ & $42 \%$ & $25 \%$ \\
\hline$R H_{\max }(t=120 y r)$ & $57 \%$ & $34 \%$ & $13 \%$ & $5 \%$ & $2 \%$ & $1 \%$ \\
\hline$R H(t=2000 \mathrm{yr})$ & $98 \%$ & $97 \%$ & $71 \%$ & $62 \%$ & $50 \%$ & $43 \%$ \\
\hline$t(R H=65 \%)^{b}$ & $160 \mathrm{yr}^{2}$ & $210 \mathrm{yr}^{\mathrm{a}}$ & 1590 y & $2250 \mathrm{yr}$ & 8480 yr & $13,660 \mathrm{yr}$ \\
\hline$t(R H=90 \%)^{b}$ & $950 \mathrm{yr}$ & $860 \mathrm{yr}$ & $25,870 \mathrm{yr}$ & $35,690 \mathrm{yr}$ & 54,680 & $62,670 \mathrm{yr}$ \\
\hline \multicolumn{7}{|l|}{ Line load } \\
\hline$R H_{\max }(t<100 y r)$ & $21 \%$ & $21 \%$ & $21 \%$ & $21 \%$ & $19 \%$ & $16 \%$ \\
\hline$R H_{\max }(t=120 y r)$ & $3 \%$ & $3 \%$ & $3 \%$ & $3 \%$ & $3 \%$ & $2 \%$ \\
\hline$R H(t=2000 \mathrm{yr})$ & $51 \%$ & $52 \%$ & $50 \%$ & $51 \%$ & $49 \%$ & $49 \%$ \\
\hline$t(R H=65 \%)^{b}$ & $3930 \mathrm{yr}$ & $3730 \mathrm{yr}$ & $4250 \mathrm{yT}$ & $3960 \mathrm{yr}$ & $5430 \mathrm{yr}$ & $4600 \mathrm{yr}$ \\
\hline$t(R H=90 \%)^{b}$ & $33,320 \mathrm{yr}$ & 30,480 yr & $36,800 \mathrm{yr}$ & $34,890 \mathrm{yr}$ & $39,920 \mathrm{yr}$ & $39,820 \mathrm{yr}$ \\
\hline
\end{tabular}

RH is never less than $65 \%$ prior to backfill.

bTime at which relative humidity reaches this value.

Figures 4-7 and 4-8 show the relative humidities over time extending to 10,000 years. The very early time responses are not well defined in these plots, and those beyond 10,000 years are not shown. The humidity data for these times can be found in Volume II (see Figs. 1.10.5.1.3, 1.10.5.1.6, 1.10.5.1.9, and 1.10.5.1.13). Beyond about 2000 years, the WP RH is maintained at about $95 \%$, whereas the rock $R H$ returns to 99 to $100 \%$. The reason for this difference is that the decay heat flux is nearly constant, so that there is a sufficient difference in temperature between WP and rock wall to depress the WP RH by about $5 \%$.

Figure 4-7. Calculated relative humidities on upper drift wall for the ACD design, LL design with 1.0-m spacing, and LL design with $0.1-\mathrm{m}$ spacing (no backfill). The calculations shown here are specific to WP placement and use WPs with 21 assemblies of 26-yr-old PWR SNF. 


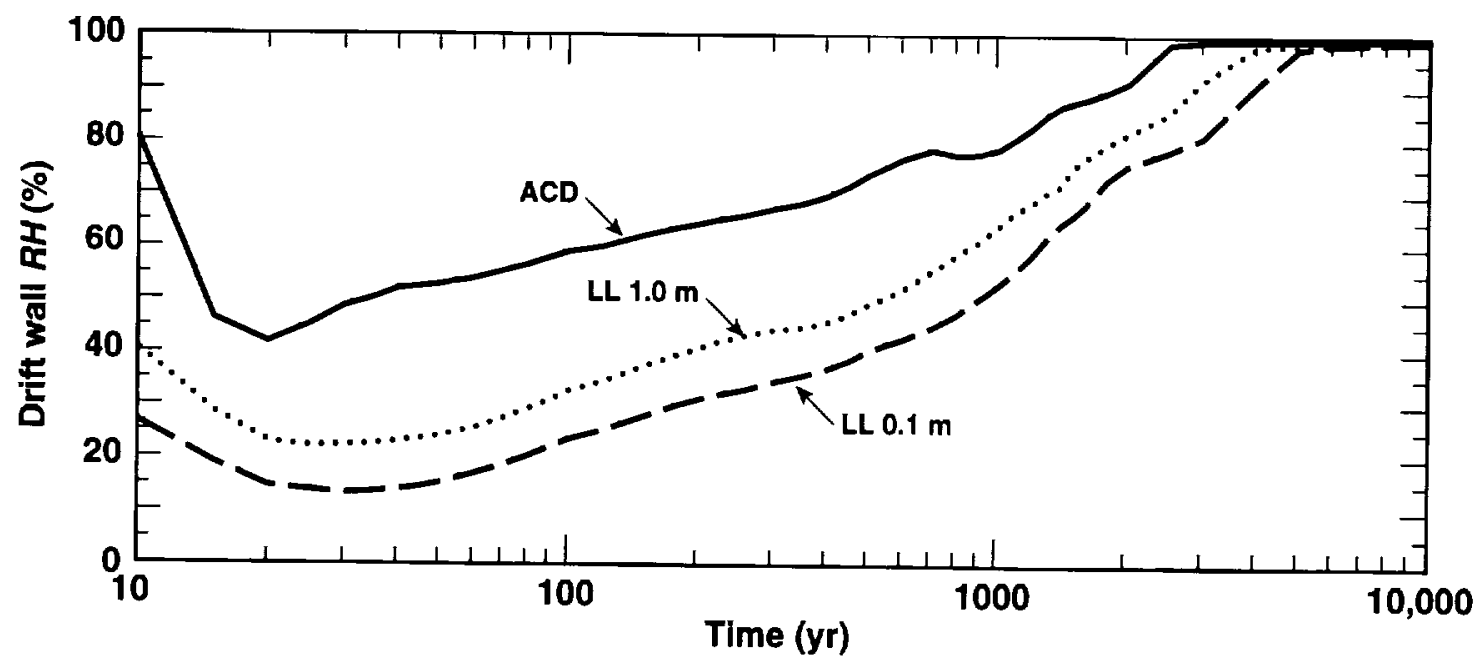

Figure 4-7. 
Figure 4-8. Calculated relative humidities on the WP surface for the ACD design, LL design with 1.0-m spacing, and LL design with $0.1-\mathrm{m}$ spacing (no backfill). The calculations shown here are specific to WP placement and use WPs with 21 assemblies of 26-yr-old PWR SNF.

The forgoing discussion of $R H$ primarily considered a percolation flux of $0.3 \mathrm{~mm} / \mathrm{yr}$, consistent with Volume II. However, the estimates of flux have been more recently revised to greater values, with $5 \mathrm{~mm} / \mathrm{yr}$ as the value that is recommended (Bodvarsson and Bandurraga, 1996). Values as high as 10 to $15 \mathrm{~mm} / \mathrm{yr}$ have been suggested. The effects of higher percolation were analyzed in Section 1.10 .6 of Volume 2 and are merely summarized here. The relationship between relative humidity on the WP $\left(R H_{w p}\right)$ and percolation flux $\left(q_{\text {perc }}\right)$ was found to fall into three ranges. For $q_{\text {perc }}<0.3 \mathrm{~mm} / \mathrm{yr}$, the duration of reduced $R H_{\text {wp }}$ increases strongly with decreasing $q_{\text {perc }}$. For $0.3<q_{\text {perc }}<1.0 \mathrm{~mm} / \mathrm{yr}$, the duration of reduced $R H_{\text {wp }}$ is relatively insensitive to $q_{\text {perc }}$. For $q_{\text {perc }}>1.0 \mathrm{~mm} / \mathrm{yr}$, the duration of reduced $R H_{\mathrm{wp}}$ decreases with increasing $q_{\text {perc }}$. Increasing $q_{\text {perc }}$ from 1 to $5 \mathrm{~mm} / \mathrm{yr}$, reduces the period during which $R H_{\mathrm{wp}}$ is less than $65 \%$ from 1660 to 1200 yr. Because the decay-heat-driven liquid-phase flux is much greater than $q_{\text {perc }}$ for the first $1000 \mathrm{yr}$, it is not surprising that $R H_{\mathrm{wp}}$ was found to be only moderately sensitive to $q_{\text {per }}$ for $0.3<q_{\text {perc }}<5 \mathrm{~mm} / \mathrm{yr}$. Even if $q_{\mathrm{per}}$ is as large as 10 to $20 \mathrm{~mm} / \mathrm{yr}$, the decay-heat-driven liquidphase flux is much larger than $q_{\text {perc }}$ during the first $500 \mathrm{yr}$.

Other studies (e.g., Bodvarsson and Bandurraga, 1996) suggest that much less reduction of $R H_{\text {wp }}$ would occur at higher $q_{\text {perc }}$ (such as $5 \mathrm{~mm} / \mathrm{yr}$ ). However, those studies used hydrological properties that result in much stronger capillary-driven rewetting of the dryout zone (both the fracture and matrix continua) than are predicted using the hydrological properties in Volume II of this report. An important distinction between the percolation-flux sensitivity study conducted in Volume II and the other sensitivity studies is whether the intrinsic hydrological properties of the rock were simultaneously varied along with percolation flux. In Volume II, the hydrological properties of the fracture and matrix continua were held constant while percolation flux was varied. Other studies (e.g., Bodvarsson et al. 1996) simultaneously varied percolation flux and the intrinsic hydrological properties, which makes it difficult to discern the influence of individual factors.

Post-test analyses of the Single-Heater Test (Buscheck et al., 1997) show that the use of recent hydrological property sets calibrated to percolation fluxes of 3.6 and $6.2 \mathrm{~mm} / \mathrm{yr}$ predicted much lower temperatures than those measured in the superheated zone surrounding the heater. The $3.6-$ and $6.2-\mathrm{mm} / \mathrm{yr}$ property sets resulted in unreasonably high rates of capillary-driven rewetting of the dryout zone around the heater, preventing the temperatures at many of the thermocouple locations around the heater from rising above the nominal boiling point. This calculated temperature behavior differed markedly from the observed behavior, which rose sharply past the nominal boiling temperatures. An important finding was that the 3.6- and 6.2$\mathrm{mm} / \mathrm{yr}$ property sets hampered the predicted dryout for the Single-Heater Test more as a result of the extremely high rates of capillary-driven rewetting than as a result of high percolation flux. Similarly, the greatly hampered dryout around emplacement drifts that has been attributed to high percolation flux is more the result of extremely high (and probably unrealistic) capillarydriven rewetting than high percolation flux itself. This finding illustrates the importance of using thermal tests to calibrate hydrological properties that are required for drift-scale thermalhydrological modeling. 


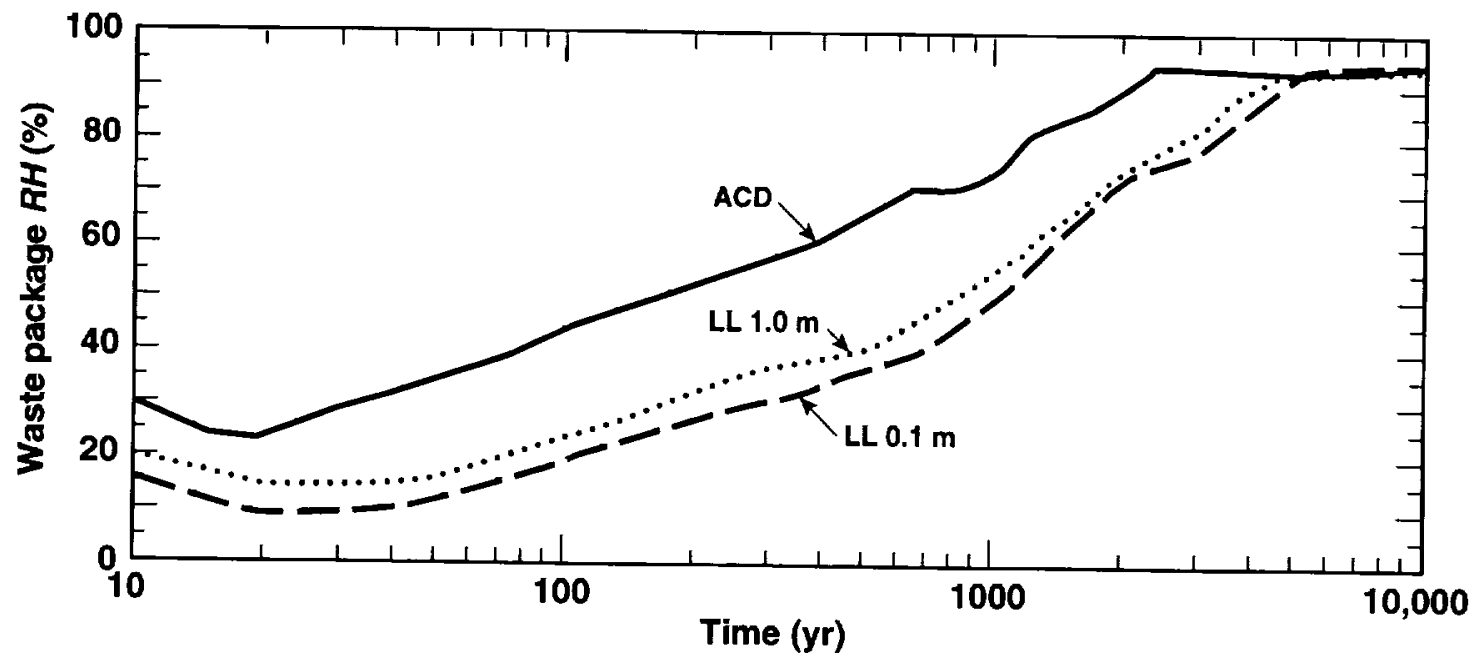

Figure 4-8. 


\subsection{Guide to Temperature and $R H$ Data in Volume II}

Volume II considers many design details that can affect temperature and relative humidity, in addition to the ones discussed in this report. The variations assessed include different values for WP spacing, drift diameter, percolation flux, emissivity, and backfill thermal conductivity. As an aid to the reader, the following tables contain cross references, by topic, to the appropriate sections, tables, and illustrations in Volume II.

Table 4-5. Guide to temperature and relative humidity data in Volume $I, R e v .1$ by section number.

Abbreviations:

$\mathrm{WP}=$ effects on waste package upper surface $\mathrm{dw}=$ effects at drift wall

$T=$ temperature

$\mathrm{AML}=$ areal mass loading expressed in MTU/acre

$R H=$ relative humidity

percolation flux expressed in $\mathrm{mm} /$ year

$\mathrm{ACD}=$ Advanced Conceptual Design Rev 00

$\mathrm{LL}=$ line-load design (LLNL comparison case)

\begin{tabular}{|c|c|c|c|c|c|}
\hline Design type & $T_{\mathbf{W P}}$ & $T_{\text {drift wall }}$ & $R H_{\mathrm{WP}}$ & $R H_{\text {drift wal }}$ & AML \\
\hline \multicolumn{6}{|l|}{ ACD no backnill } \\
\hline Flux $=0.3$ & $\begin{array}{l}1.10 .5 .1 \\
1.10 .5 .3 \\
1.10 .5 .7 \\
\end{array}$ & $\begin{array}{l}1.10 .5 .1 \\
1.10 .5 .3 \\
1.10 .5 .7\end{array}$ & $\begin{array}{l}1.10 .5 .1 \\
1.10 .5 .3 \\
1.10 .5 .7\end{array}$ & $\begin{array}{l}1.10 .5 .1 \\
1.10 .5 .3 \\
1.10 .5 .7\end{array}$ & 83.4 \\
\hline Flux $=0$ & 1.10 .6 & 1.10 .6 & 1.10 .6 & 1.10 .6 & 83.4 \\
\hline \multicolumn{6}{|l|}{ LL no backfill } \\
\hline Flux $=0.3$ to 5 & 1.10 .6 & 1.10 .6 & 1.10 .6 & 1.10 .6 & 83.4 \\
\hline Flux $=0.3$ & $\begin{array}{l}1.10 .5 .1 \\
1.10 .5 .3 \\
1.10 .5 .6 \\
1.10 .5 .7 \\
1.10 .6 \\
\end{array}$ & $\begin{array}{l}1.10 .5 .1 \\
1.10 .5 .3 \\
1.10 .5 .6 \\
1.10 .5 .7\end{array}$ & $\begin{array}{l}1.10 .5 .1 \\
1.10 .5 .3 \\
1.10 .5 .6 \\
1.10 .5 .7 \\
1.10 .6 \\
\end{array}$ & $\begin{array}{l}1.10 .5 .1 \\
1.10 .5 .3 \\
1.10 .5 .6 \\
1.10 .5 .7\end{array}$ & 83.4 \\
\hline Flux $=0$ & 1.10 .6 & 1.10 .6 & 1.10 .6 & 1.10 .6 & 83.4 \\
\hline \multicolumn{6}{|l|}{ ACD with backnill } \\
\hline Flux $=0.3$ & $\begin{array}{l}1.10 .5 .2 \\
1.10 .5 .3 \\
1.10 .5 .4 \\
1.10 .5 .5 \\
1.10 .5 .7 \\
\end{array}$ & $\begin{array}{l}1.10 .5 .2 \\
1.10 .5 .3 \\
1.10 .5 .7\end{array}$ & $\begin{array}{l}1.10 .5 .2 \\
1.10 .5 .3 \\
1.10 .5 .4 \\
1.10 .5 .5 \\
1.10 .5 .7 \\
\end{array}$ & $\begin{array}{l}1.10 .5 .2 \\
1.10 .5 .3 \\
1.10 .5 .7\end{array}$ & 83.4 \\
\hline Flux $=0$ & 1.10 .6 & 1.10 .6 & 1.10 .6 & 1.10 .6 & 83.4 \\
\hline \multicolumn{6}{|l|}{ LL with backfill } \\
\hline Flux $=0.3$ to 5 & 1.10 .6 & 1.10 .6 & 1.10 .6 & 1.10 .6 & 83.4 \\
\hline Flux $=0.3$ & \begin{tabular}{|l}
1.10 .5 .2 \\
1.10 .5 .3 \\
1.10 .5 .4 \\
1.10 .5 .5 \\
1.10 .5 .6 \\
1.10 .5 .7 \\
1.10 .6 \\
\end{tabular} & $\begin{array}{l}1.10 .5 .2 \\
1.10 .5 .3 \\
1.10 .5 .6 \\
1.10 .5 .7\end{array}$ & $\begin{array}{l}1.10 .5 .2 \\
1.10 .5 .3 \\
1.10 .5 .4 \\
1.10 .5 .5 \\
1.10 .5 .6 \\
1.10 .5 .7 \\
1.10 .6 \\
\end{array}$ & $\begin{array}{l}1.10 .5 .2 \\
1.10 .5 .3 \\
1.10 .5 .6 \\
1.10 .5 .7\end{array}$ & 83.4 \\
\hline Flux $=0$ & 1.10 .6 & 1.10 .6 & 1.10 .6 & 1.10 .6 & 83.4 \\
\hline AML variations & 1.10 .5 .7 & 1.10 .5 .7 & 1.10 .5 .7 & 1.10 .5 .7 & 25 to 120 \\
\hline
\end{tabular}


Table 4-6. Guide to Figures and Tables in Volume II, Rev. 1, Section 1-10.

Abbreviations:

WP = effects on waste package upper surface

AML $=$ areal mass loading expressed in MTU/acre

$\mathrm{dw}=$ effects at drift wall

LML = lineal mass loading expressed in MTU/m (WP spacing)

$T=$ temperature

RH $=$ relative humidity

$\Delta \mathrm{T}_{\text {drift }}=$ temp difference between WP and $\mathrm{dw}$

$\mathrm{RH}_{\mathrm{wp} / \mathrm{dw}}=$ relative humidity difference

percolation flux expressed in $\mathrm{mm} /$ year

thermal conductivity $K_{\text {th }}$ expressed in $\mathrm{W} / \mathrm{m}^{\circ} \mathrm{C}$

TSPA95 $=$ Total Systems Performance Assessment (Andrews, 95)

$\mathrm{ACD}=$ Advanced Conceptual Design rev 00 (Reference case)

for waste package and drift wall

$\mathrm{LL}=$ line-load design (LLNL comparison case)

\begin{tabular}{|c|c|c|c|c|c|c|c|c|c|c|}
\hline $\begin{array}{l}\text { Figure or } \\
\text { Table No. }\end{array}$ & $\begin{array}{l}\text { Variable } \\
\text { studied }\end{array}$ & Where & $\begin{array}{l}\text { When } \\
\text { (years) }\end{array}$ & $\begin{array}{l}\text { Design } \\
\text { type }\end{array}$ & AML & $\mathbf{L M L}$ & $\begin{array}{l}\text { Perc. } \\
\text { nux }\end{array}$ & \multicolumn{3}{|c|}{$\begin{array}{l}\text { Emiss. Backfill } \\
\text { (or explanatory notes) }\end{array}$} \\
\hline \multicolumn{11}{|c|}{ 1.10.2 Localized and extended dryout regimes } \\
\hline F1.10.2.1 & Dryout, T & \multicolumn{2}{|c|}{ for various WP ages } & varies & 0 to 100 & $0.63,1.25$ & & & no & \\
\hline F1.10.2.2 & AML & \multicolumn{2}{|c|}{ for various WP ages } & varies & varies & $0.63,1.25$ & & & no & \\
\hline F1.10.2.3 & T, RH & WP & 10,000 & varies & 40 & $0.26-1.25$ & & & no & \\
\hline \multicolumn{11}{|c|}{ 1.10.3 Performance of engineered backfill } \\
\hline $\mathrm{T} 1.10 .3 .1$ & T, RH & WP, dw & 100,000 & varies & 24,80 & 0.63 & $\mathbf{0}$ & 0.3 & yes & $K_{\mathrm{th}}=0.3$ \\
\hline F1.10.3.1 & T, RH & WP, dw & 10,000 & varies & 24,80 & 0.63 & 0 & 0.3 & \multicolumn{2}{|c|}{ yes vs no } \\
\hline \multicolumn{11}{|c|}{ 1.10.4 Engineered backfill scenarios } \\
\hline $\mathrm{T} 1.10 .4 .1$ & RH calc & & & TSPA95 & & $0.47-0.53$ & & \multicolumn{3}{|c|}{ various model assumptions } \\
\hline F1.10.4.1 & $T, \Delta T_{\text {drift }}$ & WP & 10,000 & TSPA95 & 83.4 & 0.47 & & \multicolumn{3}{|c|}{ rectangular vs circular drift } \\
\hline F1.10.4.2 & $\mathrm{RH}_{\mathrm{wp} / \mathrm{dw}}$ & & 10,000 & TSPA95 & 83.4 & varies & & \multicolumn{3}{|c|}{ varies backfill, LML, drift dian } \\
\hline F1.10.4.3 & \multicolumn{2}{|c|}{$T, R H, \Delta T_{\text {drif }}$} & 10,000 & & 80 & 0.63 & 0 to 0.3 & & \multicolumn{2}{|c|}{ yes, $K_{\mathrm{th}}=0.3$ to 0.4} \\
\hline F1.10.4.4 & \multicolumn{2}{|c|}{$T, R H, \Delta T_{\text {drif }}$} & 10,000 & & 24 & 0.63 & 0 to 0.3 & & \multicolumn{2}{|c|}{ yes, $K_{\mathrm{th}}=0.3$ to 0.4} \\
\hline F1.10.4.5 & $\mathrm{RH}_{\mathrm{wp} / \mathrm{dw}}$ & $\mathrm{WP} / \mathrm{dw}$ & 10,000 & & 80 & 0.63 & 0 to 0.3 & & \multicolumn{2}{|c|}{ yes, $K_{\mathrm{th}}=0.3$ to 0.4} \\
\hline F1.10.4.6 & $\mathrm{RH}_{\mathrm{wp} / \mathrm{dw}}$ & WP/dw & 100,000 & & 24 & 0.63 & 0 to 0.3 & & \multicolumn{2}{|c|}{ yes, $K_{\mathrm{th}}=0.3$ to 0.4} \\
\hline \multicolumn{11}{|c|}{ 1.105.I Influence of axial WP spacing and drift spacing } \\
\hline T1.10.5.1.1 & T, RH & drift wall & varies & $\mathrm{ACD}, \mathrm{LL}$ & 83.4 & varies & 0.3 & 0.8 & no & \\
\hline T1.10.5.1.2 & T, RH & WP & varies & $\mathrm{ACD}, \mathrm{LL}$ & 83.4 & varies & 0.3 & 0.8 & no & \\
\hline T1.10.5.1.3 & T, RH & \multicolumn{2}{|c|}{ different waste types } & LL & 83.4 & 1.11 & 0 & 0.8 & no & \\
\hline T1.10.5.1.4 & T, RH & \multicolumn{2}{|c|}{ different waste types } & LL & 83.4 & 1.11 & 0.3 & 0.8 & no & \\
\hline T1.10.5.1.5 & T, RH & \multicolumn{2}{|c|}{ different waste types } & LL & 83.4 & 0.94 & 0.3 & 0.8 & no & \\
\hline F1.10.5.1.1 & $T$ & 3D view & $100 \mathrm{vs} 500$ & $\mathrm{ACD}, \mathrm{LL}$ & 83.4 & varies & 0.3 & 0.8 & no & \\
\hline F1.10.5.1.2 & Liq. flux & $d w$ & 100,000 & $\mathrm{ACD}$ & 83.4 & 0.46 & 0.3 & 0.8 & no & \\
\hline F1.10.5.1.3 & T, RH & $d w$ & 100 & ACD, LL & 83.4 & $.46,1.11$ & 0.3 & 0.8 & no & \\
\hline F1.10.5.1.4 & $\mathrm{T}, \mathrm{RH}$ & $\mathrm{dw}$ & 2000 & $\mathrm{ACD}, \mathrm{LL}$ & 83.4 & $.46,1.11$ & 0.3 & 0.8 & no & \\
\hline F1.10.5.1.5 & T, RH & $d w$ & 10,000 & $\mathrm{ACD}, \mathrm{LL}$ & 83.4. & $.46,1.11$ & 0.3 & 0.8 & no & \\
\hline F1.10.5.1.6 & T, RH & WP & 100 & $\mathrm{ACD}, \mathrm{LL}$ & 83.4 & $.46,1.11$ & 0.3 & 0.8 & no & \\
\hline F1.10.5.1.8 & T, RH & WP & 2000 & $\mathrm{ACD}, \mathrm{LL}$ & 83.4 & $.46,1.11$ & 0.3 & 0.8 & no & \\
\hline F1.10.5.1.9 & T, RH & WP & 10,000 & $\mathrm{ACD}, \mathrm{LL}$ & 83.4 & $.46,1.11$ & 0.3 & 0.8 & no & \\
\hline 1.10 .5 .1 .10 & T, RH & WP & 100,000 & $\mathrm{ACD}, \mathrm{LL}$ & 83.4 & $.46,1.11$ & 0.3 & 0.8 & no & \\
\hline 1.10 .5 .1 .11 & T, RH & WP, dw & 2000 & LL & 83.4 & 0.94 & 0.3 & 0.8 & no & \\
\hline 1.10 .5 .1 .12 & T, RH & WP, dw & 10,000 & LL & 83.4 & 0.94 & 0.3 & 0.8 & no & \\
\hline 1.10 .5 .1 .13 & T, RH & WP, dw & 100,000 & $\mathrm{LL}$ & 83.4 & 0.94 & 0.3 & 0.8 & no & \\
\hline
\end{tabular}


Table 4-6. Guide to Figures and Tables in Volume II, Rev. 1, Section 1-10-continued.

Abbreviations:

WP $=$ effects on waste package upper surface

$d w=$ effects at drift wall

$T=$ temperature

$\mathrm{RH}=$ relative humidity

thermal conductivity $K_{\text {th }}$ expressed in $\mathrm{W} / \mathrm{m}^{\circ} \mathrm{C}$
AML = areal mass loading expressed in MTU/acre

LML = lineal mass loading expressed in MTU/m (WP spacing)

percolation flux expressed in $\mathrm{mm} /$ year

$A C D=$ Advanced Conceptual Design rev 00 (Reference case)

$\mathrm{LL}=$ line-load design (LLNL comparison case)

\begin{tabular}{|c|c|c|c|c|c|c|c|c|c|c|}
\hline $\begin{array}{l}\text { Figure or } \\
\text { Table No. }\end{array}$ & \begin{tabular}{|l|} 
Variable \\
studied
\end{tabular} & Where & $\begin{array}{l}\text { When } \\
\text { (years) }\end{array}$ & $\begin{array}{c}\text { Design } \\
\text { type }\end{array}$ & AML & LML & $\begin{array}{l}\text { Perc. } \\
\text { flux }\end{array}$ & Emiss. & Backrill & Notes \\
\hline \multicolumn{11}{|c|}{ 1.10.5.2 Influence of engineered backfill } \\
\hline $\mathrm{T} 1.10 .5 .2 .1$ & T, RH & $\mathrm{dw}$ & varies & ACD, LL & 83.4 & varies & 0.3 & 0.8 & yes & $K_{\mathrm{th}}=0.6$ \\
\hline $\mathrm{T} 1.10 .5 .2 .2$ & T, RH & WP & varies & $A C D, L L$ & 83.4 & varies & 0.3 & 0.8 & yes & $K_{\text {th }}=0.6$ \\
\hline T1.10.5.2.3 & $\mathrm{T}, \mathbf{R H}$ & \multicolumn{2}{|c|}{ different waste types } & ACD & 83.4 & 0.46 & 0.3 & 0.8 & yes & $K_{\mathrm{th}}=0.6$ \\
\hline $\mathrm{T} 1.10 .5 .2 .4$ & T, RH & \multicolumn{2}{|c|}{ different waste types } & LL & 83.4 & 1.11 & 0.3 & 0.8 & yes & $K_{\mathrm{th}}=0.6$ \\
\hline $\mathrm{T} 1.10 .5 .2 .5$ & T, RH & \multicolumn{2}{|c|}{ different waste types } & LL & 83.4 & 1.11 & 0.3 & 0.8 & \multicolumn{2}{|c|}{ yes, also fills WP gap } \\
\hline F1.10.5.2.1 & $\mathrm{T}$ & $3 \mathrm{D}$ view & 100,500 & ACD, LL & 83.4 & $.46,1.11$ & 0.3 & 0.8 & yes & \\
\hline F1.10.5.2.2 & T, RH & WP, dw & 10,000 & LL & 83.4 & 1.11 & 0.3 & 0.8 & no vs yes & varies $K_{\mathrm{th}}$ \\
\hline F1.10.5.2.3 & T, RH & $d w$ & 2000 & ACD, LL & 83.4 & $.46,1.11$ & 0.3 & 0.8 & yes & varies WP \\
\hline F1.10.5.2.4 & T, RH & $d w$ & 10,000 & $\mathrm{ACD}, \mathrm{LL}$ & 83.4 & $.46,1.11$ & 0.3 & 0.8 & yes & varies WP \\
\hline F1.10.5.2.5 & $T, R H$ & WP & 2000 & $\mathrm{ACD}, \mathrm{LL}$ & 83.4 & $.46,1.11$ & 0.3 & 0.8 & yes & varies WP \\
\hline F1.10.5.2.6 & T, RH & WP & 10,000 & $\mathrm{ACD}, \mathrm{LL}$ & 83.4 & $.46,1.11$ & 0.3 & 0.8 & yes & varies WP \\
\hline F1.10.5.2.7 & T, RH & WP & 100,000 & $\mathrm{ACD}, \mathrm{LL}$ & 83.4 & $.46,1.11$ & 0.3 & 0.8 & yes & varies WP \\
\hline F1.10.5.2.8 & T, RH & WP, dw & 2000 & $\mathrm{LL}$ & 83.4 & 1.11 & 0.3 & 0.8 & yes & varies WP \\
\hline F1.10.5.2.9 & $\mathrm{T}, \mathrm{RH}$ & WP, dw & 10,000 & $\mathrm{LL}$ & 83.4 & 1.11 & 0.3 & 0.8 & yes & varies WP \\
\hline 1.10 .5 .2 .10 & T, RH & WP, dw & 100,000 & $\mathbf{L L}$ & 83.4 & 1.11 & 0.3 & 0.8 & yes & varies WP \\
\hline 1.10 .5 .2 .11 & T, RH & WP, dw & 2000 & LL & 83.4 & 0.94 & 0.3 & 0.8 & yes & varies WP \\
\hline 1.10 .5 .2 .12 & T, RH & WP, $d w$ & 10,000 & LL & 83.4 & 0.94 & $\overline{0.3}$ & 0.8 & yes & varies WP \\
\hline 1.10 .5 .2 .13 & T, RH & WP, dw & 100,000 & LL & 83.4 & 0.94 & 0.3 & 0.8 & yes & varies WP \\
\hline \multicolumn{11}{|c|}{ 1.105.3 Influence of waste package emissivity } \\
\hline T1.10.5.3.1 & T, RH & $d w$ & varies & ACD, LL & 83.4 & 3 values & 0.3 & 0.3 & no & \\
\hline T1.10.5.3.2 & T, RH & WP & varies & ACD, LL & 83.4 & 3 values & 0.3 & 0.3 & no & \\
\hline $\mathrm{T} 1.10 .5 .3 .3$ & T, RH & WP & varies & $\mathrm{ACD}$ & $\overline{83.4}$ & 0.46 & 0.3 & 0.3 & no & varies WP \\
\hline T1.10.5.3.4 & T, RH & WP & varies & $\mathrm{LL}$ & 83.4 & 1.11 & 0.3 & 0.3 & no & varies WP \\
\hline $\mathrm{T} 1.10 .5 .3 .5$ & T, RH & $\mathbf{W P}$ & varies & $\mathbf{L L}$ & 83.4 & 0.94 & 0.3 & 0.3 & no & varies WP \\
\hline $\mathrm{T} 1.10 .5 .3 .6$ & T, RH & $\mathrm{dw}$ & varies & $\mathrm{ACD}, \mathrm{LL}$ & 83.4 & 3 values & 0.3 & 0.3 & yes & \\
\hline$T 1,10.5 .3 .7$ & T, RH & WP & varies & $\overline{\mathrm{ACD}}, \mathrm{LL}$ & 83.4 & 3 values & 0.3 & 0.3 & yes & \\
\hline T1.10.5.3.8 & T, RH & WP & varies & $\mathrm{ACD}$ & 83.4 & 0.46 & 0.3 & 0.3 & yes & varies WP \\
\hline T1.10.5.3.9 & T, RH & WP & varies & $\overline{L L}$ & 83.4 & 1.11 & 0.3 & 0.3 & yes & varies WP \\
\hline 1.10 .5 .3 .10 & T, RH & WP & varies & $\overline{\mathrm{LL}}$ & 83.4 & 0.94 & 0.3 & 0.3 & yes & varies WP \\
\hline F1.10.5.3.1 & $T$ & WP, dw & & varies & 83.4 & 0.4 to 1.2 & 0.3 & & no & \\
\hline
\end{tabular}


Table 4-6. Guide to Figures and Tables in Volume II, Rev. 1, Section 1-10-continued.

Abbreviations:

WP $=$ effects on waste package upper surface

AML $=$ areal mass loading expressed in MTU/acre

$\mathrm{dw}=$ effects at drift wall

$T=$ temperature

$\mathrm{LML}=$ lineal mass loading expressed in MTU/m (WP spacing)

percolation flux expressed in $\mathrm{mm} / \mathrm{year}$

$\mathrm{RH}=$ relative humidity

emissivity expressed in $\mathrm{mm}$ /year

$\mathrm{ACD}=$ Advanced Conceptual Design rev 00 (Reference case)

thermal conductivity $K_{\mathrm{th}}$ expressed in $\mathrm{W} / \mathrm{m}^{\circ} \mathrm{C}$

\begin{tabular}{|c|c|c|c|c|c|c|c|c|c|c|}
\hline $\begin{array}{l}\text { Figure or } \\
\text { Table No. }\end{array}$ & \begin{tabular}{|l|} 
Variable \\
studied
\end{tabular} & Where & $\begin{array}{l}\text { When } \\
\text { (years) }\end{array}$ & $\begin{array}{c}\text { Design } \\
\text { type }\end{array}$ & AML & LML & $\begin{array}{l}\text { Perc. } \\
\text { flux }\end{array}$ & Emiss. & Backfill & Notes \\
\hline \multicolumn{11}{|c|}{ 1.105.4 Influence of waste package and backfill } \\
\hline $\mathrm{T} 1.10 .5 .4 .1$ & \multicolumn{2}{|c|}{$\%$ drift occupied } & & varies & 83.4 & & & & varies & \\
\hline $\mathrm{T} 1.10 .5 .4 .2$ & T, RH & WP & varies & $\mathrm{ACD}$ & 83.4 & 0.47 & 0.3 & 0.3 & varies & \\
\hline T1.10.5.4.3 & T, RH & WP & varies & LL & 83.4 & 0.94 & 0.3 & 0.3 & varies & \\
\hline $\mathrm{T} 1.10 .5 .4 .4$ & T, RH & WP & varies & ACD & 83.4 & $\overline{0.46}$ & 0.3 & 0.8 & yes & varies WP \\
\hline $\mathrm{T} 1.10 .5 .4 .5$ & $T, \mathbf{R H}$ & WP & varies & LL & 83.4 & 1.11 & 0.3 & 0.8 & yes & varies WP \\
\hline F1.10.5.4.1 & \multicolumn{2}{|c|}{ 2D RH distribution } & 120 & $\mathrm{ACD}$ & 83.4 & 0.46 & 0.3 & 0.3 & varies & \\
\hline F1.10.5.4.2 & \multicolumn{2}{|c|}{ 2D RH distribution } & 120 & LL & 83.4 & 0.94 & 0.3 & 0.3 & varies & \\
\hline F1.10.5.4.3 & T, RH & WP & 10,000 & LL & 83.4 & 0.94 & 0.3 & 0.3 & varies & off-center \\
\hline F1.10.5.4.4 & T, RH & WP & 10,000 & LL & 83.4 & 0.94 & $\overline{0.3}$ & 0.3 & yes & center \\
\hline F1.10.5.4.5 & RH & WP & 100,000 & ACD & 83.4 & 0.47 & 0.3 & 0.3 & yes & \\
\hline F1.10.5.4.6 & RH & WP & 100,000 & $\mathrm{ACD}$ & 83.4 & 0.47 & 0.3 & 0.3 & \multicolumn{2}{|c|}{ partial sloping backfil } \\
\hline F1.10.5.4.7 & RH & WP & 100,000 & $\mathrm{ACD}$ & 83.4 & 0.47 & 0.3 & 0.3 & \multicolumn{2}{|l|}{\begin{tabular}{|l} 
no backfill \\
\end{tabular}} \\
\hline \multicolumn{11}{|c|}{1.10 .5 .5 Influence of engineered backfill thermal conductivity } \\
\hline $\mathrm{T} 1.10 .5 .5 .1$ & T, RH & $\mathrm{dw}$ & varies & $\mathrm{ACD}, \mathrm{LL}$ & 83.4 & 3 values & 0.3 & 0.8 & yes & $K_{\mathrm{th}}=0.3$ \\
\hline $\mathrm{T} 1.10 .5 .5 .2$ & T, RH & WP & varies & $\mathrm{ACD}, \mathrm{LL}$ & 83.4 & 3 values & 0.3 & $\overline{0.8}$ & yes & $K_{\mathrm{th}}=0.3$ \\
\hline $\mathrm{T} 1.10 .5 .5 .3$ & T, RH & \multicolumn{2}{|c|}{ different waste types } & $\mathrm{ACD}$ & 83.4 & 0.46 & 0.3 & 0.8 & yes & $K_{\mathrm{th}}=0.3$ \\
\hline T1.10.5.5.4 & T, RH & \multicolumn{2}{|c|}{ different waste types } & $\overline{L L}$ & 83.4 & 1.11 & 0.3 & 0.8 & yes & $K_{\mathrm{th}}=0.3$ \\
\hline $\mathrm{T} 1.10 .5 .5 .5$ & T. RH & \multicolumn{2}{|c|}{ different waste types } & LL & 83.4 & 0.94 & 0.3 & 0.8 & yes & $K_{\mathrm{th}}=0.3$ \\
\hline F1.10.5.5.1 & T, RH & WP & 2000 & $\mathrm{ACD}, \mathrm{LL}$ & 83.4 & $.46,1.11$ & 0.3 & 0.8 & yes & $K_{\mathrm{h}}=0.3$ \\
\hline F1.10.5.5.2 & T, RH & WP & 10,000 & $\mathrm{ACD}, \mathrm{LL}$ & $\overline{83.4}$ & $.46,1.11$ & 0.3 & 0.8 & yes & $K_{\mathrm{th}}=0.3$ \\
\hline F1.10.5.5.3 & T, RH & WP & 100,000 & $\mathrm{ACD}, \mathrm{LL}$ & $\overline{83.4}$ & $.46,1.11$ & 0.3 & 0.8 & yes & $K_{\mathrm{th}}=0.3$ \\
\hline \multicolumn{11}{|c|}{ 1.105.6 Influence of drift diameter } \\
\hline $\mathrm{T} 1.10 .5 .6 .1$ & T, RH & $d w$ & & $\mathrm{LL}$ & 83.4 & 1.11 & 0.3 & 0.8 & no & diam 3-6.5 \\
\hline $\mathrm{T} 1.10 .5 .6 .2$ & T, RH & WP & & $\mathrm{LL}$ & 83.4 & 1.11 & $\overline{0.3}$ & 0.8 & nо & $\operatorname{diam} 3-6.5$ \\
\hline $\mathrm{T} 1.10 .5 .6 .3$ & $\mathrm{~T}, \mathrm{RH}$ & $d w$ & & $\mathrm{LL}$ & 83.4 & 1.11 & 0.3 & 0.8 & yes & $\operatorname{diam} 3-6.5$ \\
\hline $\mathrm{T} 1.10 .5 .6 .4$ & $T, R H$ & WP & & LL & 83.4 & 1.11 & 0.3 & 0.8 & yes & diam 3-6.5 \\
\hline $\mathrm{T} 1.10 .5 .6 .5$ & T, RH & \multicolumn{2}{|c|}{ different waste types } & LL & $83.4^{\prime}$ & 1.11 & 0.3 & 0.8 & yes & $\operatorname{diam} 3 m$ \\
\hline $\mathrm{T} 1.10 .5 .6 .6$ & T, RH & \multicolumn{2}{|c|}{ different waste types } & $\mathrm{LL}$ & 83.4 & 1.11 & 0.3 & 0.8 & yes & $\operatorname{diam} 4 \mathrm{~m}$ \\
\hline $\mathrm{T} 1.10 .5 .6 .7$ & T, RH & \multicolumn{2}{|c|}{ different waste types } & $\mathrm{LL}$ & 83.4 & 1.11 & 0.3 & 0.8 & yes & $\operatorname{diam} 6.5 \mathrm{~m}$ \\
\hline F1.10.5.6.1 & peak $T$ & $W P, d w$ & & LL & 83.4 & 1.11 & 0.3 & 0.8 & no & diam 3-6.5 \\
\hline
\end{tabular}


Table 4-6. Guide to Figures and Tables in Volume II, Rev. 1, Section 1-10-continued.

Abbreviations:

WP $=$ effects on waste package upper surface

AML $=$ areal mass loading expressed in MTU/acre

$\mathrm{dw}=$ effects at drift wall

$T=$ temperature

LML = lineal mass loading expressed in MTU/m (WP spacing)

percolation flux expressed in $\mathrm{mm} /$ year

RH $=$ relative humidity

emissivity expressed in $\mathrm{mm} / \mathrm{year}$

$\Delta \mathrm{T}_{\text {drift }}=$ temp difference between WP and dw $\quad \mathrm{ACD}=$ Advanced Conceptual Design rev 00 (Reference case)

$\Delta \mathrm{T}_{\text {pillar }}=$ temp difference, $d w$ vs rock centerline $\mathrm{LL}=$ line-load design (LLNL comparison case)

\begin{tabular}{|c|c|c|c|c|c|c|c|c|c|c|}
\hline $\begin{array}{l}\text { Figure or } \\
\text { Table No. }\end{array}$ & $\begin{array}{l}\text { Variable } \\
\text { studied }\end{array}$ & Where & $\begin{array}{l}\text { When } \\
\text { (years) }\end{array}$ & $\begin{array}{c}\text { Design } \\
\text { type }\end{array}$ & AML & LML & $\begin{array}{l}\text { Perc. } \\
\text { nux }\end{array}$ & Emiss. & Backfill & Notes \\
\hline \multicolumn{11}{|c|}{ 1.105.7 Influence of areal mass loading } \\
\hline $\mathrm{T} 1.10 .5 .7 .1$ & T, RH & $d w$ & varies & $\overline{\mathrm{ACD}}$ & \begin{tabular}{|l|}
$25-83.4$ \\
\end{tabular} & 0.46 & 0.3 & $\overline{0.8}$ & no & diam 5.5 \\
\hline $\mathrm{T} 1.10 .5 .7 .2$ & $\mathrm{~T}, \mathrm{RH}$ & WP & varies & $\overline{A C D}$ & $25-83.4$ & 0.46 & 0.3 & 0.8 & no & $\operatorname{diam} 5.5$ \\
\hline $\mathrm{T} 1.10 .5 .7 .3$ & T, RH & WP & varies & $\mathrm{ACD}$ & 25 & 0.46 & 0.3 & 0.8 & no & $\operatorname{diam} 5.5$ \\
\hline T1.10.5.7.4 & $\mathrm{T}, \mathrm{RH}$ & WP & varies & ACD & 45 & 0.46 & 0.3 & 0.8 & no & $\operatorname{diam} 5.5$ \\
\hline $\mathrm{T} 1.10 .5 .7 .5$ & $\mathrm{~T}, \mathrm{RH}$ & $\mathrm{dw}$ & varies & $\mathrm{LL}$ & $25-120$ & 1.11 & 0.3 & 0.8 & no & diam 5.5 \\
\hline $\mathrm{T} 1.10 .5 .7 .6$ & $\mathrm{~T}, \mathrm{RH}$ & WP & varies & LL & $25-120$ & 1.11 & 0.3 & 0.8 & no & $\operatorname{diam} 5.5$ \\
\hline $\mathrm{T} 1.10 .5 .7 .7$ & T. RH & WP & varies & LL & 25 & 1.11 & 0.3 & 0.8 & no & diam 5.5 \\
\hline $\mathrm{T} 1.10 .5 .7 .8$ & T, RH & WP & varies & LL & 45 & 1.11 & 0.3 & 0.8 & no & $\operatorname{dian} 5.5$ \\
\hline T1.10.5.7.9 & T, RH & WP & varies & $\mathrm{LL}$ & 100 & 1.11 & 0.3 & 0.8 & no & $\operatorname{diam} 5.5$ \\
\hline 1.10 .5 .7 .10 & $\mathrm{~T}, \mathrm{RH}$ & WP & varies & LL & 120 & 1.11 & 0.3 & 0.8 & no & diam 5.5 \\
\hline 1.10 .5 .7 .11 & T, RH & $\mathrm{dw}$ & varies & $\mathrm{ACD}$ & $25-83.4$ & 0.46 & 0.3 & 0.8 & yes & $K_{\mathrm{th}}=0.6$ \\
\hline 1.10 .5 .7 .12 & $\mathrm{~T}, \mathrm{RH}$ & WP & varies & $\mathrm{ACD}$ & $25-83.4$ & 0.46 & 0.3 & 0.8 & yes & $K_{\mathrm{th}}=0.6$ \\
\hline 1.10 .5 .7 .13 & $\mathrm{~T}, \mathrm{RH}$ & WP & varies & $\mathrm{ACD}$ & 25 & 0.46 & 0.3 & 0.8 & yes & $K_{\mathrm{th}}=0.6$ \\
\hline 1.10 .5 .7 .14 & $\mathrm{~T}, \mathrm{RH}$ & WP & varies & $\mathrm{ACD}$ & 45 & 0.46 & 0.3 & 0.8 & yes & $K_{\text {th }}=0.6$ \\
\hline 1.10 .5 .7 .15 & T, RH & $\mathrm{dw}$ & varies & $\overline{\mathrm{LL}}$ & $25-120$ & 1.11 & 0.3 & 0.8 & yes & $K_{\mathrm{th}}=0.6$ \\
\hline 1.10 .5 .7 .16 & T, RH & WP & varies & LL & $25-120$ & 1.11 & 0.3 & 0.8 & yes & $K_{\mathrm{th}_{1}}=0.6$ \\
\hline 1.10 .5 .7 .17 & $\mathrm{~T}, \mathrm{RH}$ & WP & varies & $\mathrm{LL}$ & 25 & 1.11 & 0.3 & 0.8 & yes & $K_{\mathrm{th}}=0.6$ \\
\hline 1.10 .5 .7 .18 & T, RH & WP & varies & $\mathrm{LL}$ & 45 & 1.11 & 0.3 & 0.8 & yes & $K_{\mathrm{th}}=0.6$ \\
\hline 1.10 .5 .7 .19 & T, RH & WP & varies & $\mathrm{LL}$ & 100 & 1.11 & 0.3 & 0.8 & yes & $K_{\mathrm{th}}=0.6$ \\
\hline 1.10 .5 .7 .20 & T, RH & WP & varies & $\mathrm{LL}$ & 120 & 1.11 & 0.3 & 0.8 & yes & $K_{\mathrm{th}}=0.6$ \\
\hline F1.10.5.7.1 & Liquid flux & \multicolumn{2}{|c|}{ different waste types } & $\mathrm{ACD}, \mathrm{LL}$ & 83.4 & $.46,1.11$ & 0.3 & 0.8 & no & \\
\hline F1.10.5.7.2 & Liquid flux & \multicolumn{2}{|c|}{ different waste types } & $\mathrm{ACD}, \mathrm{LL}$ & 25 & $46,1.11$ & 0.3 & 0.8 & no & \\
\hline F1.10.5.7.3 & $\Delta T_{\text {drift }}$ & \multicolumn{2}{|c|}{ differenl waste types } & LL & $25-120$ & 1.11 & 0.3 & 0.8 & no & \\
\hline F1.10.5.7.4 & $\Delta T_{\text {drift }}$ & \multicolumn{2}{|c|}{ different waste types } & LL & 25,834 & 1.11 & 0.3 & 0.8 & no & \\
\hline F1.10.5.7.5 & RH & WP & varies & $\mathrm{LL}$ & $25-120$ & 1.11 & 0.3 & 0.8 & no & \\
\hline F1.10.5.7.6 & RH & WP & varies & LL & $25-120$ & 1.11 & 0.3 & 0.8 & yes & $K_{\mathrm{th}}=0.6$ \\
\hline F1.10.5.7.7 & $\Delta T_{\text {pillar }}$ & \begin{tabular}{|l|} 
Pwr WP \\
\end{tabular} & varies & $\mathrm{LL}$ & $25-120$ & 1.11 & 0.3 & 0.8 & yes & $K_{\mathrm{th}}=0.6$ \\
\hline F1.10.5.7.8 & $\Delta T_{\text {pillar }}$ & DHLW & varies & LL & $25-120$ & 1.11 & 0.3 & 0.8 & yes & $K_{\mathrm{th}}=0.6$ \\
\hline F1.10.5.7.9 & $\Delta \mathrm{T}_{\text {drif }}$ & WP, dw & varies & LL & $25 \cdot 120$ & 1.11 & 0.3 & 0.8 & yes & $K_{\mathrm{th}}=0.6$ \\
\hline 1.10 .5 .7 .10 & $\Delta T_{\text {drif }}$ & \multicolumn{2}{|c|}{ different waste types } & LL & 25,834 & 1.11 & 0.3 & 0.8 & yes & $K_{\mathrm{th}}=0.6$ \\
\hline
\end{tabular}


Table 4-6. Guide to Figures and Tables in Volume II, Rev. 1, Section 1-10-continued.

Abbreviations:

WP $=$ effects on waste package upper surface

$\mathrm{dw}=$ effects at drift wall

$T=$ temperature

RH $=$ relative humidity

emissivity expressed in $\mathrm{mm} /$ year

thermal conductivity $K_{\text {th }}$ expressed in $\mathrm{W} / \mathrm{m}^{\circ} \mathrm{C}$
AML $=$ areal mass loading expressed in MTU/acre

LML = lineal mass loading expressed in MTU/m (WP spacing)

percolation flux expressed in $\mathrm{mm} /$ year

$\mathrm{ACD}=$ Advanced Conceptual Design rev 00 (Reference case)

$\mathrm{LL}=$ line-load design (LLNL comparison case)

\begin{tabular}{|c|c|c|c|c|c|c|c|c|c|c|}
\hline $\begin{array}{l}\text { Figure or } \\
\text { Table No. }\end{array}$ & $\begin{array}{l}\text { Variable } \\
\text { studied }\end{array}$ & Where & $\begin{array}{l}\text { When } \\
\text { (years) }\end{array}$ & $\begin{array}{c}\text { Design } \\
\text { type }\end{array}$ & AML & LML & $\begin{array}{c}\text { Perc. } \\
\text { flux }\end{array}$ & Emiss. & Backfril & Notes \\
\hline \multicolumn{11}{|c|}{ 1.10.6 Influence of ambient percolation flux and edge effects on $T-H$ behavior } \\
\hline T1.10.6.1 & Liquid flux & $d w$ & 100,000 & $\mathrm{ACD}, \mathrm{LL}$ & 83.4 & $.46,1.11$ & 0.3 & 0.8 & nо & \\
\hline $\mathrm{T} 1.10 .6 .2$ & Liquid flux & $d w$ & 100,000 & $A C D, L L$ & 83.4 & $.46,1.11$ & 0.05 & 0.8 & no & \\
\hline $\mathrm{T} 1.10 .6 .3$ & $\mathrm{~T}, \mathrm{RH}$ & $\mathrm{dw}$ & varies & $\mathrm{ACD}$ & 83.4 & 0.46 & $0-0.3$ & 0.8 & no & \\
\hline $\mathrm{T} 1.10 .6 .4$ & T, RH & WP & varies & $\mathrm{ACD}$ & 83.4 & 0.46 & $0-0.3$ & 0.8 & no & \\
\hline $\mathrm{T} 1.10 .6 .5$ & $\mathrm{~T}, \mathrm{RH}$ & \multicolumn{2}{|c|}{ different waste types } & ACD & 83.4 & 0.46 & $\mathbf{0}$ & 0.8 & no & \\
\hline $\mathrm{T} 1.10 .6 .6$ & T, RH & \multicolumn{2}{|c|}{ different waste types } & ACD & 83.4 & 0.46 & 0.05 & 0.8 & no & \\
\hline $\mathrm{T} 1.10 .6 .7$ & T, RH & \multicolumn{2}{|c|}{ different waste types } & $\mathrm{ACD}$ & 83.4 & 0.46 & 0.3 & 0.8 & no & \\
\hline T1.10.6.8 & T, RH & $d w$ & varies & $\mathrm{LL}$ & 83.4 & 1.11 & $0-5$ & 0.8 & no & \\
\hline $\mathrm{T} 1.10 .6 .9$ & T, RH & WP & varies & $\mathrm{LL}$ & 83.4 & 1.11 & $0-5$ & 0.8 & no & \\
\hline $\mathrm{T} 1.10 .6 .10$ & $\mathrm{~T}, \mathrm{RH}$ & \multicolumn{2}{|c|}{ different waste types } & LL & 83.4 & 1.11 & 0 & 0.8 & no & \\
\hline $\mathrm{T} 1.10 .6 .11$ & T, RH & \multicolumn{2}{|c|}{ different waste types } & $\mathrm{LL}$ & 83.4 & 1.11 & 0.05 & 0.8 & no & \\
\hline $\mathrm{T} 1.10 .6 .12$ & $\mathrm{~T}, \mathrm{RH}$ & \multicolumn{2}{|c|}{ different waste types } & $\overline{L L}$ & 83.4 & 1.11 & 0.3 & 0.8 & no & \\
\hline $\mathrm{T} 1.10 .6 .13$ & T, RH & \multicolumn{2}{|c|}{ different waste types } & LL & 83.4 & 1.11 & 1.0 & 0.8 & no & \\
\hline $\mathrm{T} 1.10 .6 .14$ & T. RH & \multicolumn{2}{|c|}{ different waste types } & LL & 83.4 & 1.11 & 5.0 & 0.8 & no & \\
\hline $\mathrm{T} 1.10 .6 .15$ & T, RH & $\mathrm{dw}$ & varies & $\mathrm{ACD}$ & 83.4 & 0.46 & $0-0.3$ & 0.8 & yes & $K_{\text {th }}=0.6$ \\
\hline $\mathrm{T} 1.10 .6 .16$ & T, RH & WP & varies & $\mathrm{ACD}$ & 83.4 & 0.46 & $0-0.3$ & 0.8 & yes & $K_{\mathrm{th}}=0.6$ \\
\hline T1.10.6.17 & T, RH & \multicolumn{2}{|c|}{\begin{tabular}{|l|} 
different waste types \\
\end{tabular}} & $\mathrm{ACD}$ & 83.4 & 0.46 & 0 & 0.8 & yes & $K_{\mathrm{th}}=0.6$ \\
\hline T1.10.6.18 & T, RH & \multirow{2}{*}{\multicolumn{2}{|c|}{ different waste types }} & $\mathrm{ACD}$ & 83.4 & 0.46 & 0.05 & 0.8 & yes & $K_{\mathrm{th}}=0.6$ \\
\hline T1.10.6.19 & T, RH & different waste types & & ACD & 83.4 & 0.46 & 0.3 & 0.8 & yes & $K_{\mathrm{th}}=0.6$ \\
\hline T1.10.6.20 & T, RH & $\mathrm{dw}$ & varies & LL & 83.4 & 1.11 & $0-5$ & 0.8 & yes & $K_{\mathrm{Lh}}=0.6$ \\
\hline T1.10.6.21 & T, RH & WP & varies & LL & 83.4 & 1.11 & $0-5$ & 0.8 & yes & $K_{\mathrm{th}}=0.6$ \\
\hline $\mathrm{T} 1.10 .6 .22$ & T, RH & \multicolumn{2}{|c|}{ different waste types } & LL & 83.4 & 1.11 & 0 & 0.8 & yes & $K_{\mathrm{th}}=0.6$ \\
\hline T1.10.6.23 & T, RH & \multirow{2}{*}{\multicolumn{2}{|c|}{\begin{tabular}{|l|} 
different waste types \\
different waste tynes
\end{tabular}}} & LL & 83.4 & 1.11 & 0.05 & 0.8 & yes & $K_{\mathrm{th}}=0.6$ \\
\hline T1.10.6.24 & $\mathrm{T}, \mathrm{RH}$ & & & LL & 83.4 & 1.11 & 0.3 & 0.8 & yes & $K_{\mathrm{th}}=0.6$ \\
\hline$T 1.10 .6 .25$ & $T, R H$ & \multicolumn{2}{|c|}{ different waste types } & LL & 83.4 & 1.11 & 1.0 & 0.8 & yes & $K_{\text {th }}=0.6$ \\
\hline T1.10.6.26 & T, RH & \multicolumn{2}{|c|}{ different waste types } & $\mathrm{LL}$ & 83.4 & 1.11 & 5.0 & 0.8 & yes & $K_{\mathrm{th}}=0.6$ \\
\hline $\mathrm{T} 1.10 .6 .27$ & T, RH & \multicolumn{2}{|c|}{ different waste types } & LL & 83.4 & 1.11 & 0.3 & 0.8 & no & near center \\
\hline $\mathrm{T} 1.10 .6 .28$ & T, RH & \multicolumn{2}{|c|}{ different waste types } & $\mathrm{LL}$ & 83.4 & 1.11 & 0.3 & 0.8 & no & outer edge \\
\hline T1.10.6.29 & T, RH & \multicolumn{2}{|c|}{ different waste types } & $\overline{L L}$ & 83.4 & 1.11 & 0.3 & 0.8 & yes & near cente \\
\hline $\mathrm{T} 1.10 .6 .30$ & T, RH & \multicolumn{2}{|c|}{ different waste types } & LL & 83.4 & 1.11 & 0.3 & 0.8 & yes & outer edge \\
\hline
\end{tabular}


Table 4-6. Guide to Figures and Tables in Volume II, Rev. 1, Section 1-10-continued.

Abbreviations:

WP $=$ effects on waste package upper surface

AML $=$ areal mass loading expressed in MTU/acre

$\mathrm{dw}=$ effects at drift wall

$\mathrm{T}=$ temperature

$\mathrm{LML}=$ lineal mass loading expressed in MTU/m (WP line spacing)

RH = relative humidity

percolation flux expressed in $\mathrm{mm} /$ year

percolation flux expressed in $\mathrm{mm} /$ year

$\mathrm{ACD}=$ Advanced Conceptual Design rev 00 (Reference case)

$\mathrm{LL}=$ line-load design (LLNL comparison case)

bulk permeability $k_{\mathrm{b}}$ expressed in millidarcy thermal conductivity $K_{\text {th }}$ expressed in W/m $/ \mathrm{m}^{\circ} \mathrm{C}$

\begin{tabular}{|c|c|c|c|c|c|c|c|c|c|c|}
\hline $\begin{array}{l}\text { Figure or } \\
\text { Table No. }\end{array}$ & $\begin{array}{c}\text { Variable } \\
\text { studied }\end{array}$ & Where & $\begin{array}{l}\text { When } \\
\text { (years) }\end{array}$ & $\begin{array}{l}\text { Design } \\
\text { type }\end{array}$ & AML & $\mathbf{L M L}$ & $\begin{array}{l}\text { Perc. } \\
\text { fux }\end{array}$ & Emiss. & Backfill & Notes \\
\hline \multicolumn{11}{|c|}{ 1.10.6 Influence of ambient percolation flux and edge effects on $T-H$ behavior } \\
\hline F1.10.6.1 & Liquid flux & \multicolumn{2}{|c|}{$51 \mathrm{~m}$ above drift } & $\mathrm{ACD}, \mathrm{LL}$ & 83.4 & $046,1.11$ & varies & 0.8 & no & \\
\hline F1.10.6.2 & flux, RH & \multicolumn{2}{|c|}{$51 \mathrm{~m}$ above drift } & LL & 83.4 & 1.11 & $0-5$ & 0.8 & no & \\
\hline F1.10.6.3 & Liquid flux & varies & 100,000 & mtn scale & 83.4 & & $0.3-0.5$ & & & \\
\hline F1.10.6.4 & Liquid flux & varies & 2000 & mtn scale & 83.4 & & $0.3-0.5$ & & & \\
\hline F1.10.6.5 & RH & varies & 10,000 & mtn scale & 83.4 & & $0-0.3$ & & & \\
\hline F1.10.6.6 & RH & varies & 100,000 & mtn scale & 83.4 & & $0 \cdot 0.3$ & & & \\
\hline F1.10.6.7 & RH & WP & 100,000 & ACD & 83.4 & 0.46 & $0-0.3$ & 0.8 & no & \\
\hline F1.10.6.8 & $\overline{\mathrm{RH}}$ & WP & 100,000 & LL & 83.4 & 1.11 & 0.5 & 0.8 & no & \\
\hline F1.10.6.9 & $\overline{\mathrm{RH}}$ & WP & 100,000 & $\mathrm{ACD}$ & 83.4 & 0.46 & 0.0 .3 & 0.8 & yes & $K_{\mathrm{th}}=0.6$ \\
\hline F1.10.6.10 & RH & WP & 100,000 & LL & 83.4 & 1.11 & $0-5$ & 0.8 & yes & $K_{\mathrm{th}}=0.6$ \\
\hline F1.10.6.11 & T, RH & WP & 100 & $\mathrm{LL}$ & 83.4 & 1.11 & 0.3 & 0.8 & no & \\
\hline F1.10.6.12 & T, RH & WP & 2000 & $\mathrm{LL}$ & 83.4 & 1.11 & 0.3 & 0.8 & no & \\
\hline F1.10.6.13 & T, RH & WP & 10,000 & LL & 83.4 & 1.11 & 0.3 & 0.8 & no & \\
\hline F1.10.6.14 & T, RH & WP & 100,000 & LL & 83.4 & 1.11 & 0.3 & 0.8 & no & \\
\hline F1.10.6.15 & T, RH & WP & 2000 & LL & 83.4 & 1.11 & 0.3 & 0.8 & yes & $K_{\mathrm{th}}=0.6$ \\
\hline F1.10.6.16 & T, RH & WP & 10,000 & LL & $\overline{83.4}$ & 1.11 & 0.3 & 0.8 & yes & $K_{\mathrm{th}}=0.6$ \\
\hline F1.10.6.17 & T, RH & WP & 100,000 & LL & 83.4 & 1.11 & 0.3 & 0.8 & yes & $K_{\mathrm{th}}=0.6$ \\
\hline \multicolumn{11}{|c|}{ 1.10.7 Comparison of discrete-fracture model with equivalent continuum model } \\
\hline F1.10.7.1 & \multicolumn{3}{|c|}{ Liq. saturation at 50 and 500 yrs } & & 48 & & & & & $k_{b}=280$ \\
\hline F1.10.7.2 & \multicolumn{3}{|c|}{ Liq. saturation at 100 to 1000 yrs } & & 48 & & & & & $k_{\mathrm{b}}=280$ \\
\hline
\end{tabular}




\subsection{Geochemistry of the NFE}

The chemistry of water entering drifts and contacting WPs will depend not only on the chemistry of water as it moves through the rock mass and interacts with the rock, but also on the chemical interactions of that water with introduced materials and microbial communities that exist within the drifts. These topics are discussed separately. In addition, performance of the system will depend on the mineralogy of zones within the natural system that are perturbed as a result of the emplacement of waste, specifically the thermal pulse that results from emplacement. Mineralogy is discussed in Section 5 of this report.

Figure 4-9 is a matrix showing the main components of the NFE associated with water chemistry on the diagonal and the coupled processes off-diagonal.

Figure 4-9. Matrix of coupled processes in the NFE related to water chemistry.

To determine the composition of water that might contact the WPs, the evolution of water compositions over a range of scenarios must be determined. The chemistry of the initial water is probably only of concem during the early time prior to the thermal pulse within the rock exceeding the boiling point of water. After boiling, the water is mobilized, and any water that returns into the drifts subsequently will be a combination of meteoric and condensate water. The condensate would be very dilute, essentially distilled, water but would have strong interaction with the rock because it would be condensing at elevated temperatures. The extent of rock-water interaction will be a function of the temperatures, the duration of contact, whether the rock is unaltered, or whether it had already interacted with other water (typical of the more stable condensate zone of later time frames). The meteoroic waters may have been exposed to elevated temperatures, but such would only be the case for the first few thousand years after emplacement. The mixture of meteoric and condensate waters would then interact strongly with the materials within the drift that had been introduced into the system. Such materials will include significant volumes of cementitious materials, irons or steel, and various constructionrelated materials. An exhaustive list of these materials is available in Volume II, Sec. 6.

Water contacting the EBS would also interact with any minerals or salts left by the water that had been removed from the NFE during the thermal pulse. The likely result will be that between the introduced material interactions, dissolution of precipitated minerals, as well as the microbial interactions. The water chemistry will be largely determined by interactions in the very near field regardless of what the water chemistry might have been in the condensate or meteoric waters. Therefore, water chemistry within the $\mathrm{AZ}$ is not discussed here (see Volume II for more information), and is only discussed in Section 5.0 (AZ) as it determines the chemistry of reactions.

As noted, water might drip into the drifts and contact the WPs in the period prior to water removal by boiling. Such contact is less likely because this is also the period during which the ground-support system should be essentially intact and would tend to inhibit water influx into the drifts. This is especially the case if continuous concrete liners are used as ground support. However, the liner segments are not intended to be sealed, and water can enter through the joints between segments. During early elevated temperatures prior to boiling, evaporation of water is an important consideration in determining the water chemistry as well as in establishing the nature of secondary precipitates that may be deposited along fracture surfaces or rock pores. In such regions, secondary precipitates could be dissolved later by the percolation of meteoric and condensate waters. It is also important to determine the nature of precipitates deposited on the WPs directly as water is evaporated or boiled, thus leaving behind the mineral salts. The deposition on WPs is important not only in determining future water chemistries but also in relative humidity corrosion interactions because salt depositions can facilitate corrosion at much lower $R H$. The specific precipitates that may develop will reflect the initial water composition and that which evolves as evaporation takes place. 


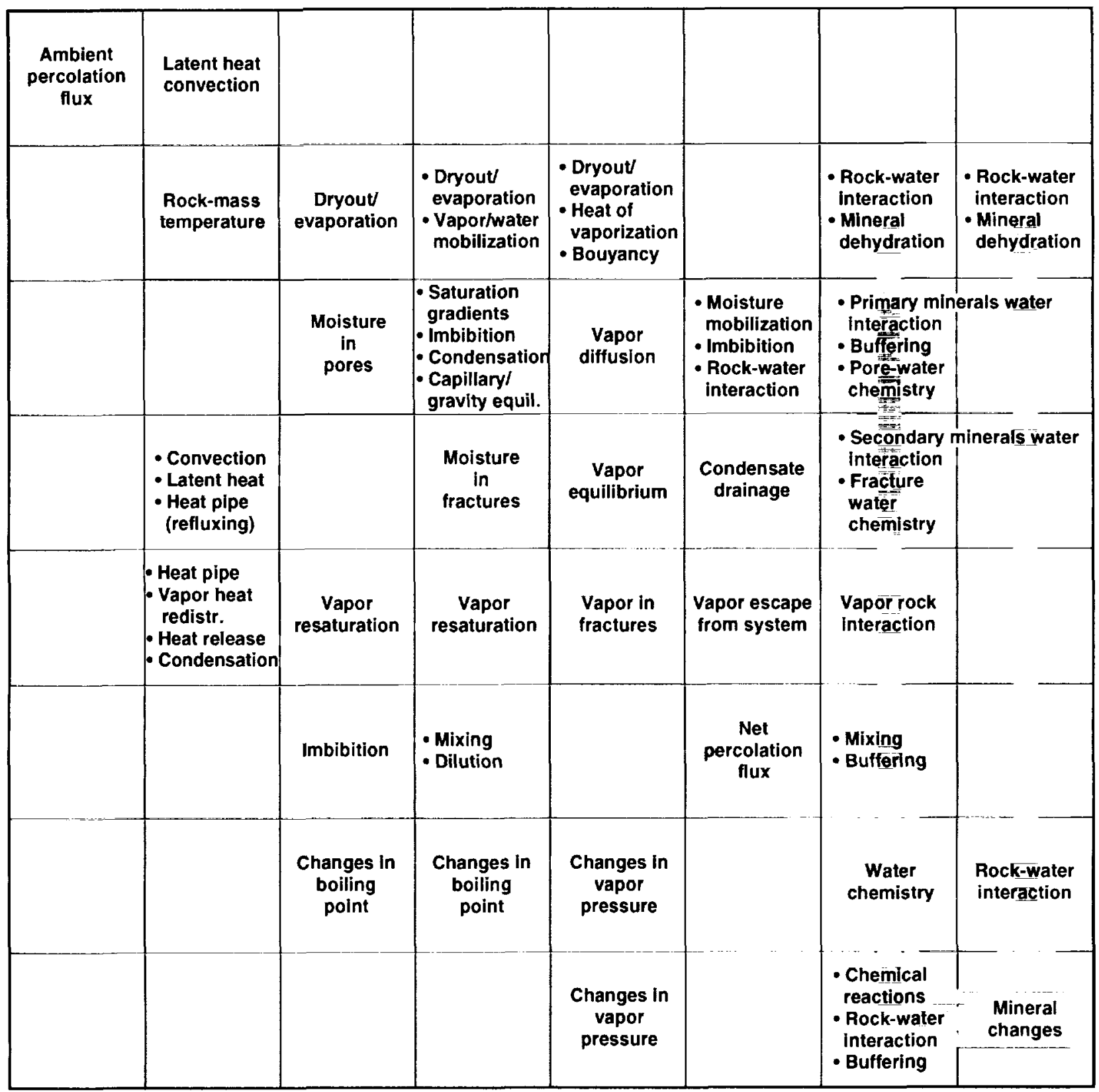

Figure 4-9. 
The chemical consequences of evaporation are distinct from those of boiling. The distinction arises from the contrast in behavior of dissolved gases during evaporation and boiling. The material reported here does not consider the role of rock-water interaction, or the role of boiling in development of water compositions. Rock-water interactions are discussed in Section 5 of this volume and are reported in detail in Volume II. Boiling impacts have been discussed in TSPA workshops, but the impacts have not been reported elsewhere and were not available at the time this volume was prepared.

\subsubsection{Results}

Simulations of the evolving water chemistry due to evaporation were reported in Volume II. There, it was noted that results are sensitive to whether limits were placed on gas-phase control or on mineral availabilities. As shown in Fig. 4-10, the $\mathrm{pH}$ that evolves as temperature increases will tend towards slightly acidic ( $\mathrm{pH}=6.5$ ) for an open system or towards moderately alkaline ( $\mathrm{pH}=9.5$ ) if $\mathrm{CO}_{2}$ and $\mathrm{O}_{2}$ were held at atmospheric levels. In Fig. 4-10 and all subsequent illustrations in this section, square symbols are used to denote cases in which gas-phase controls were implemented $\left(\mathrm{CO}_{2}\right.$ and $\mathrm{O}_{2}$ fugacities were fixed at atmospheric values throughout the runs); circles denote values computed with no gas-phase controls. Filled symbols denote runs in which precipitation of solids was not restricted; open symbols denote runs in which quartz, tridymite, and talc were suppressed.

Figure 4-10. Evolving $\mathrm{pH}$ as a function of temperature.

Because of the overall gas exchange in the mountain (e.g., breathing wells), it might be assumed that the $\mathrm{CO}_{2}$ and $\mathrm{O}_{2}$ would always approach atmospheric values. However, several factors may create a limit on these compounds. First, barometric pressure responses in the Topopah Spring unit were suppressed until the tunnel was opened into this unit. This suppression would indicate that the gas exchange is restricted to the overlying units. Second, during the heatup and particularly when boiling is active, water vapor will displace the oxygen. However, the evaporation chemistry is only of concern when temperatures are below boiling and probably occur during emplacement operations when ventilation would replenish the oxygen. If ventilation is maintained beyond the time of emplacement, then the atmospheric $\mathrm{CO}_{2}$ and $\mathrm{O}_{2}$ fixed conditions would probably be the more appropriate.

Figure 4-11 shows the simulation results for Eh. Evaporation that occurs in the absence of controls on coexisting gases results in water compositions that remain near neutral, and the Eh slightly oxidizing.

Figures 4-12 through 4-15 show that $\mathrm{Na}, \mathrm{S}, \mathrm{Cl}$, and $\mathrm{F}$ concentrations, respectively, increase linearly as the activity of $\mathrm{H}_{2} \mathrm{O}$ decreases (as temperature increases). Figures 4-16 through 4-22 show the results for $\mathrm{Ca}, \mathrm{P}, \mathrm{Si}$, calcite, dolomite, saponite, and stilbite, respectively.

Insert Figures 6-2 through 6-13. Change $x$ axis on all to temperature scale from 30 to $100^{\circ} \mathrm{C}$.

Figure 4-11. Eh, in volts, as a function of temperature.

Figure 4-12. Total $\mathrm{Na}$ in solution, in $\mathrm{mg} / \mathrm{kg}$, as a function of temperature. Figure 4-13. Total $\mathrm{S}$ in solution, in $\mathrm{mg} / \mathrm{kg}$, as a function of temperature. Figure 4-14. Total $\mathrm{Cl}$ in solution, in $\mathrm{mg} / \mathrm{kg}$, as a function of temperature. Figure 4-15. Total $\mathrm{F}$ in solution, in $\mathrm{mg} / \mathrm{kg}$, as a function of temperature. Figure 4-16. Total $\mathrm{Ca}$ in solution, in $\mathrm{mg} / \mathrm{kg}$, as a function of temperature. Peak concentration for the uncontrolled $\mathrm{CO}_{2}$ and $\mathrm{O}_{2}$ case corresponds to calcite saturation. Figure 4-17. Total $P$ in solution, in $\mathrm{mg} / \mathrm{kg}$, as a function of temperature. Figure 4-18. Total $\mathrm{Si}$ in solution, in $\mathrm{mg} / \mathrm{kg}$, as a function of temperature. 


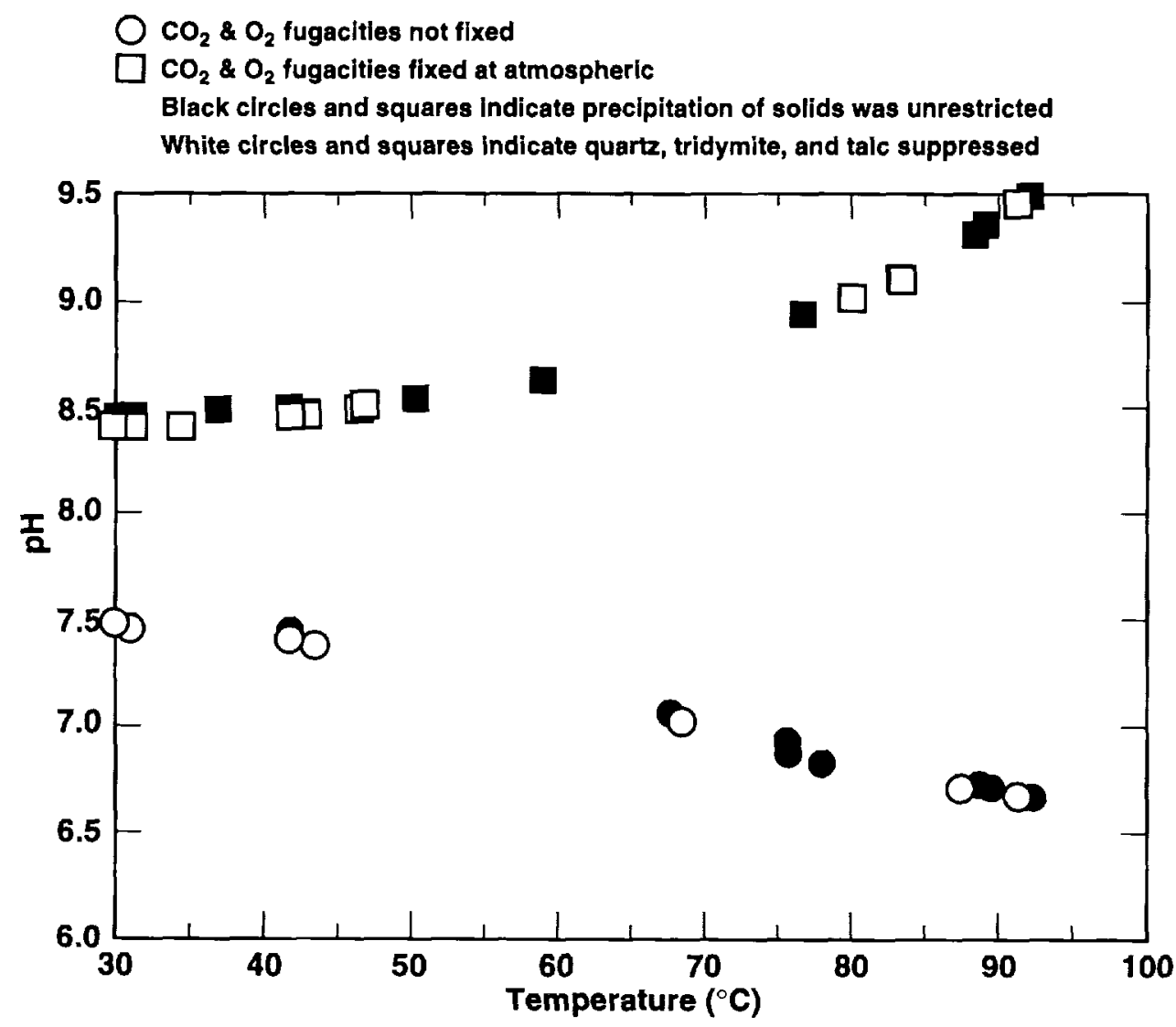

Figure 4-10. 


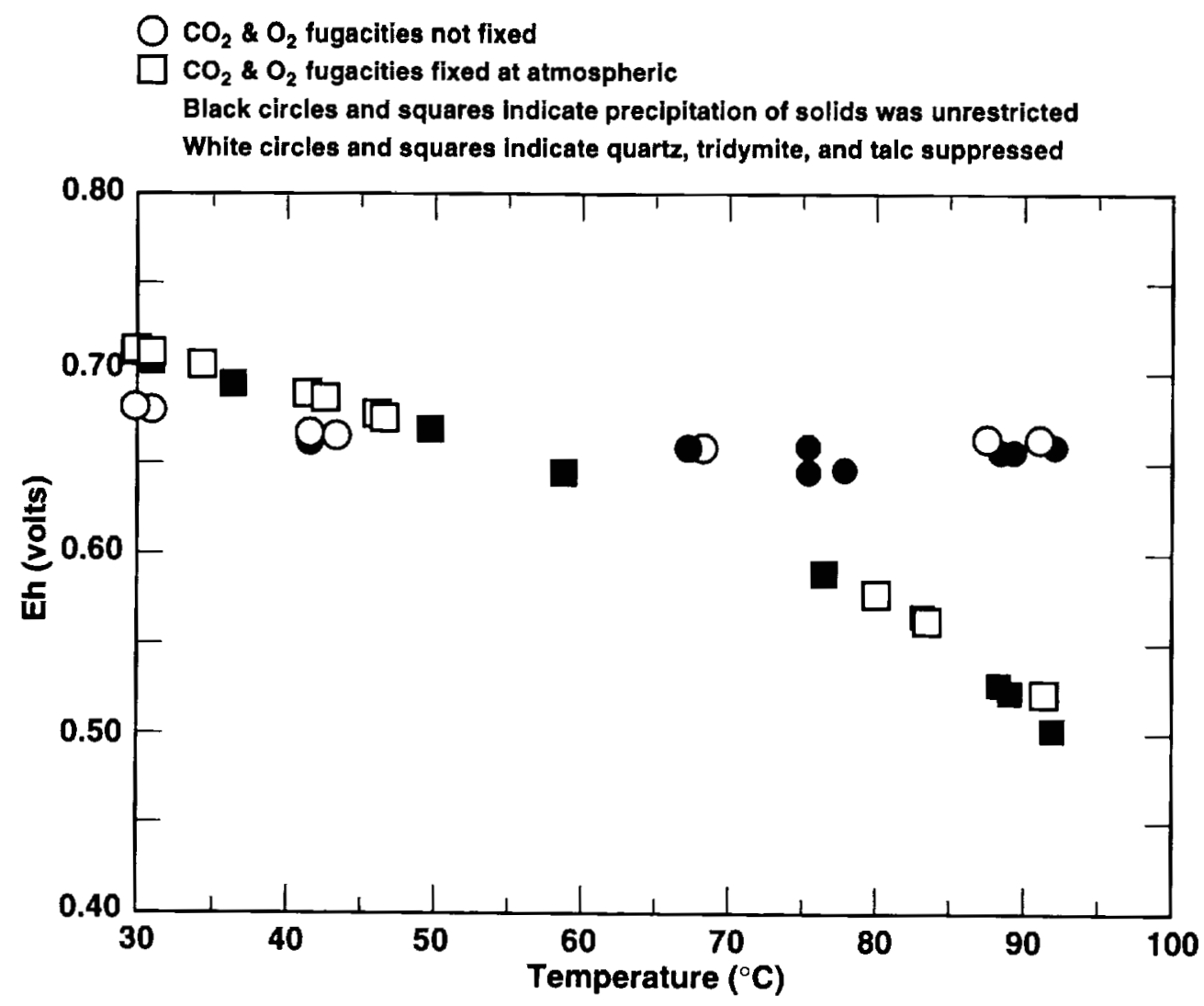

Figure 4-11. 


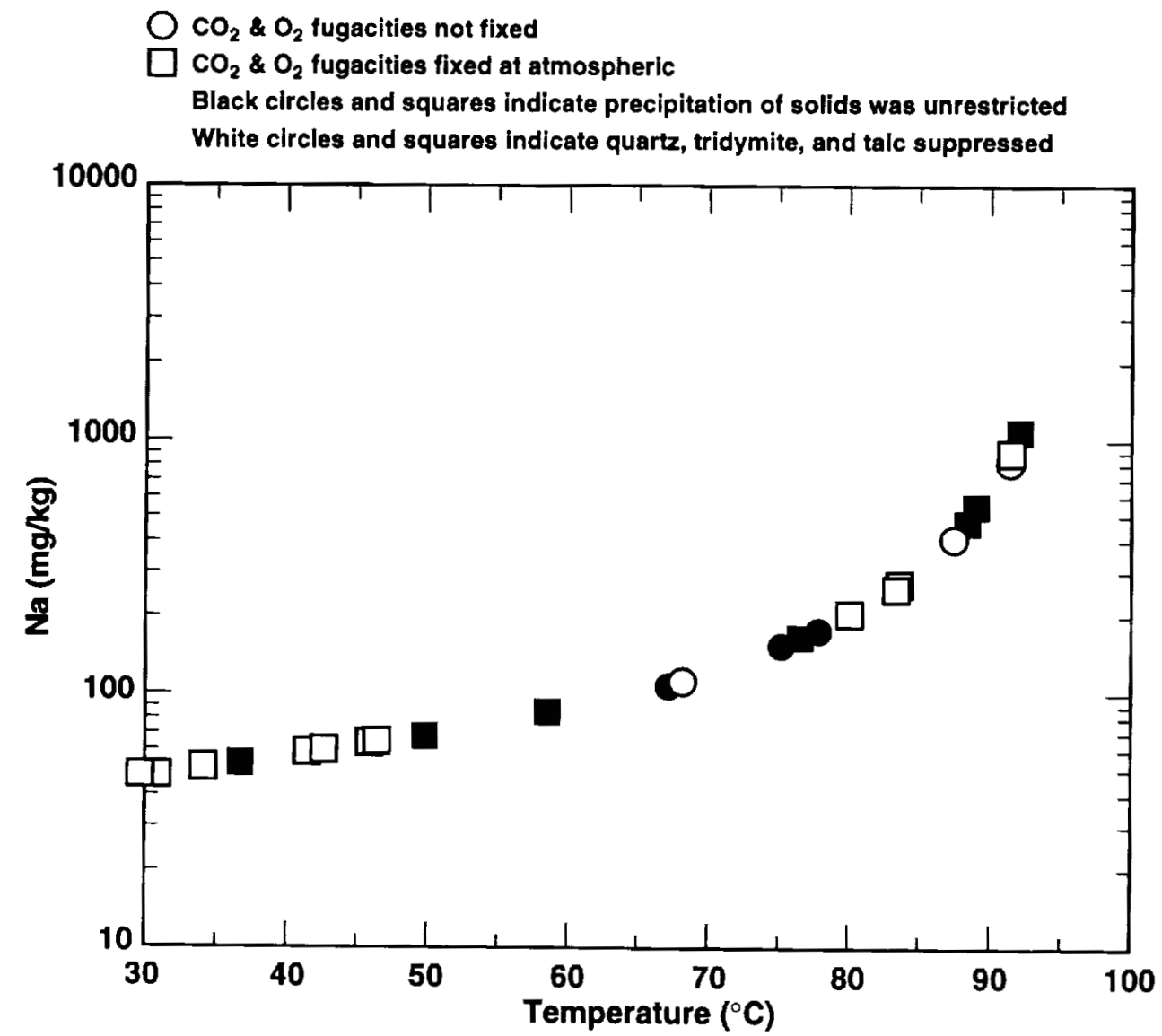

Figure 4-12. 




Figure 4-13. 


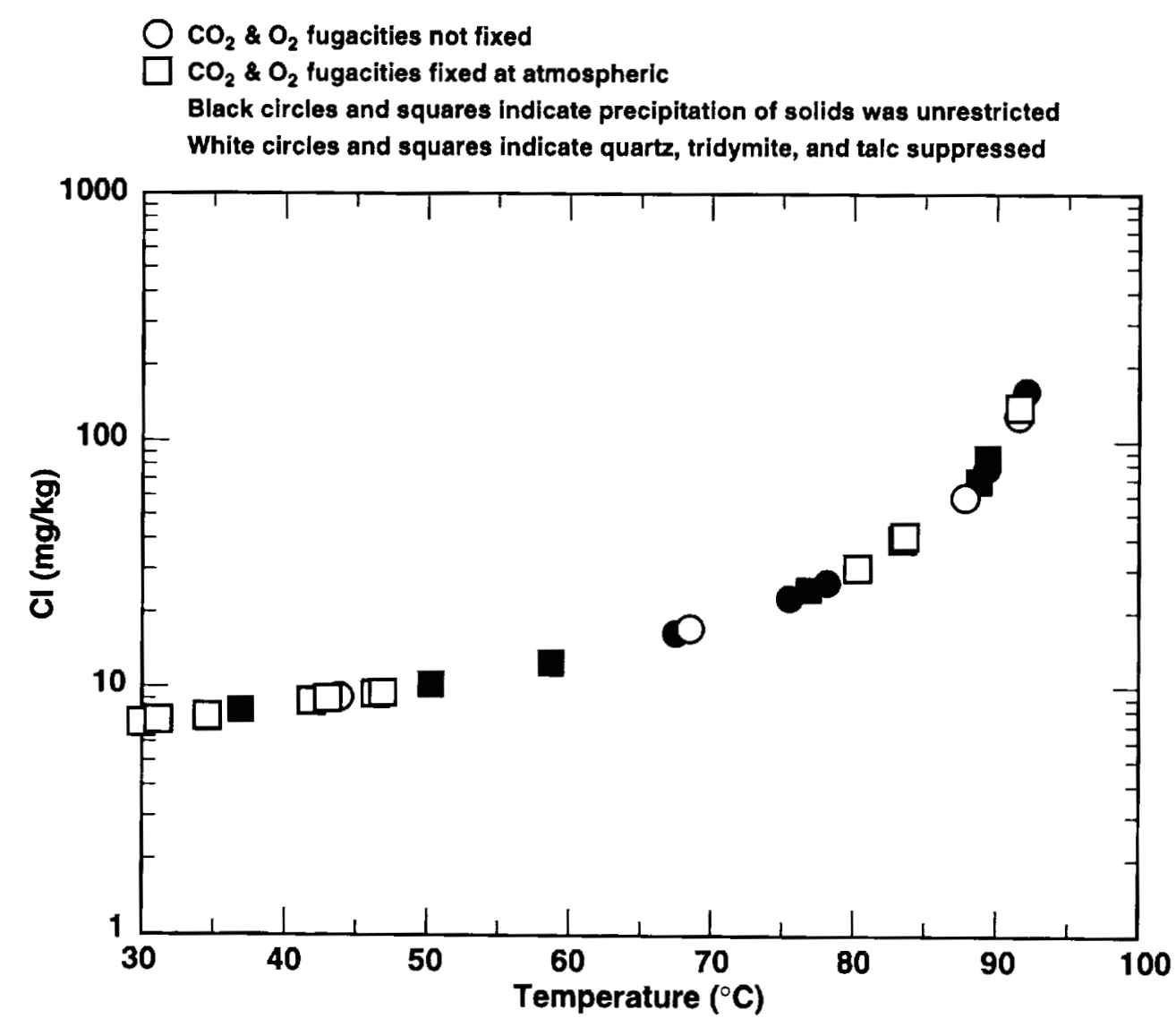

Figure 4-14. 


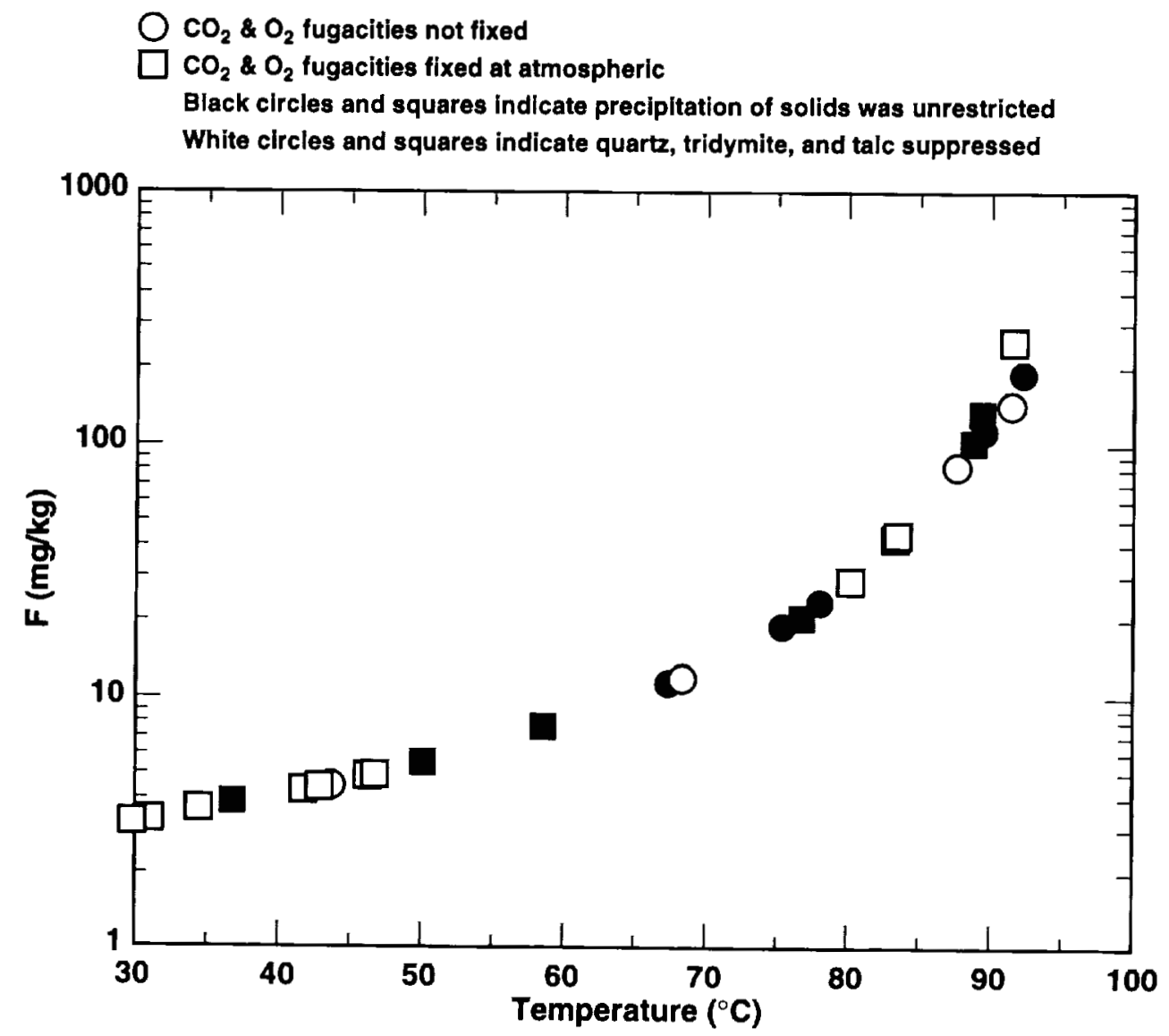

Figure 4-15. 


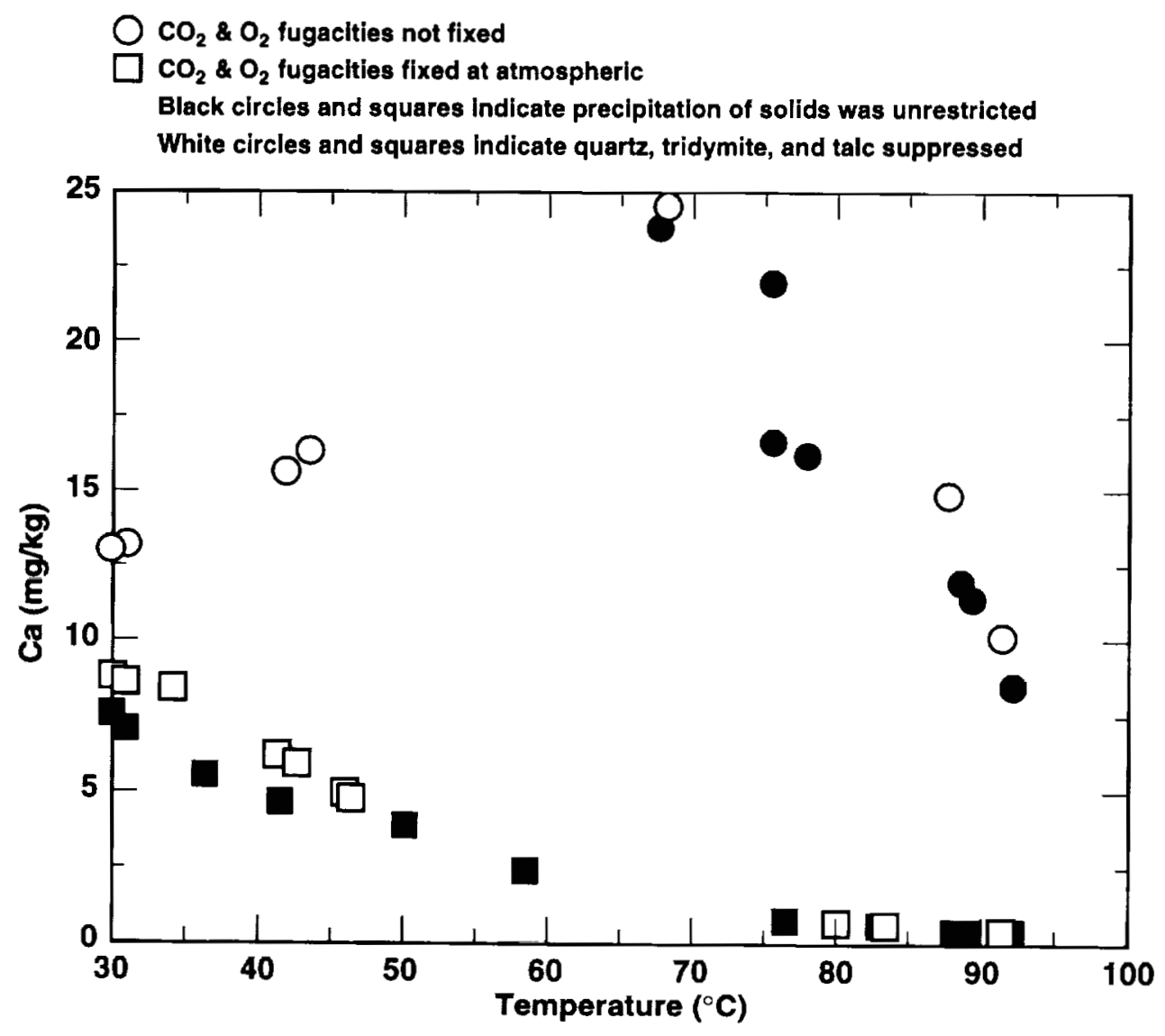

Figure 4-16. 


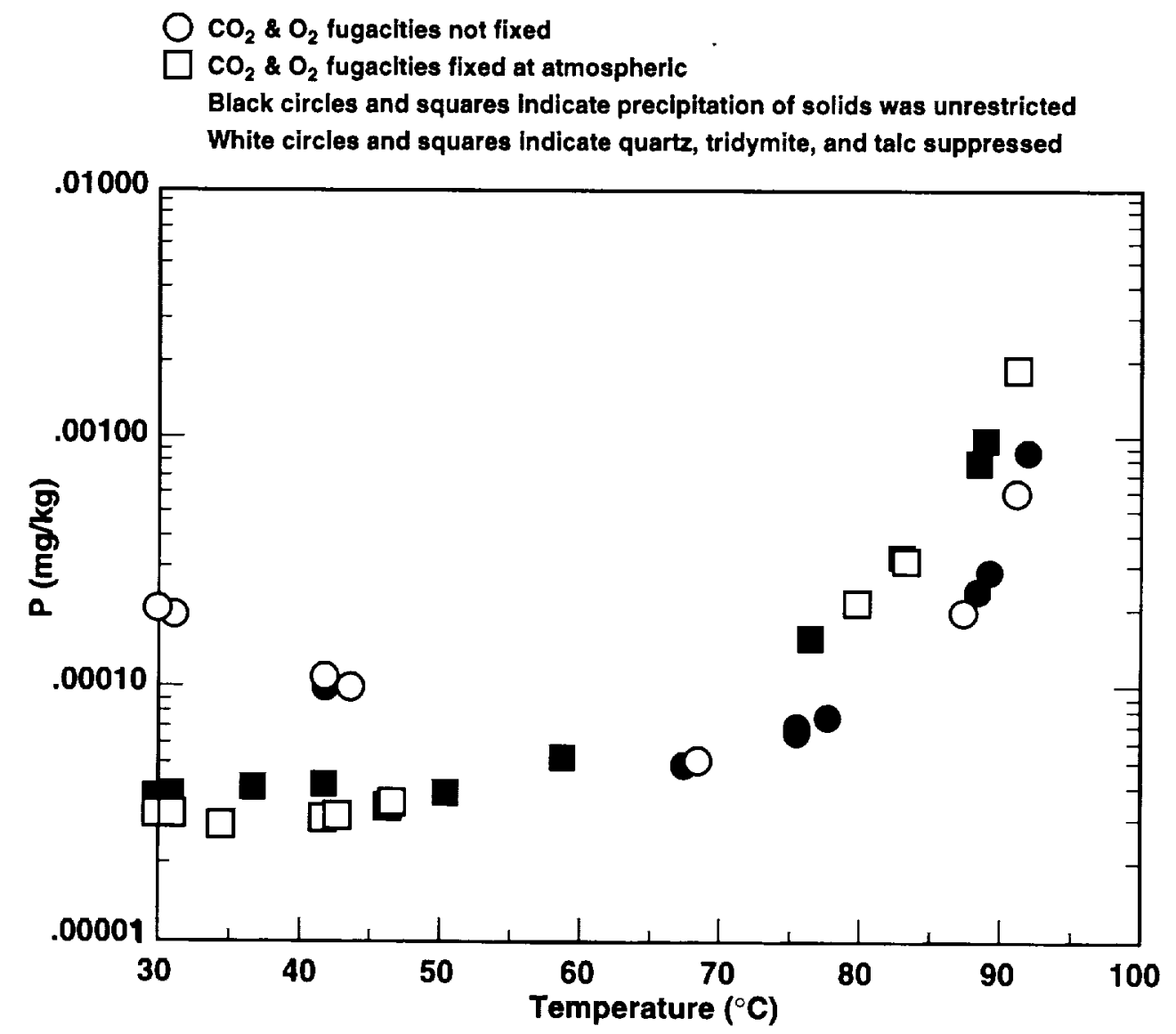

Figure 4-17. 
$\mathrm{O} \mathrm{CO}_{2} \& \mathrm{O}_{2}$ fugacities not fixed

$\mathrm{CO}_{2} \& \mathrm{O}_{2}$ fugacities fixed at atmospheric

Black clrcles and squares indicate precipitation of solids was unrestricted

White circles and squares indicate quartz, tridymite, and talc suppressed

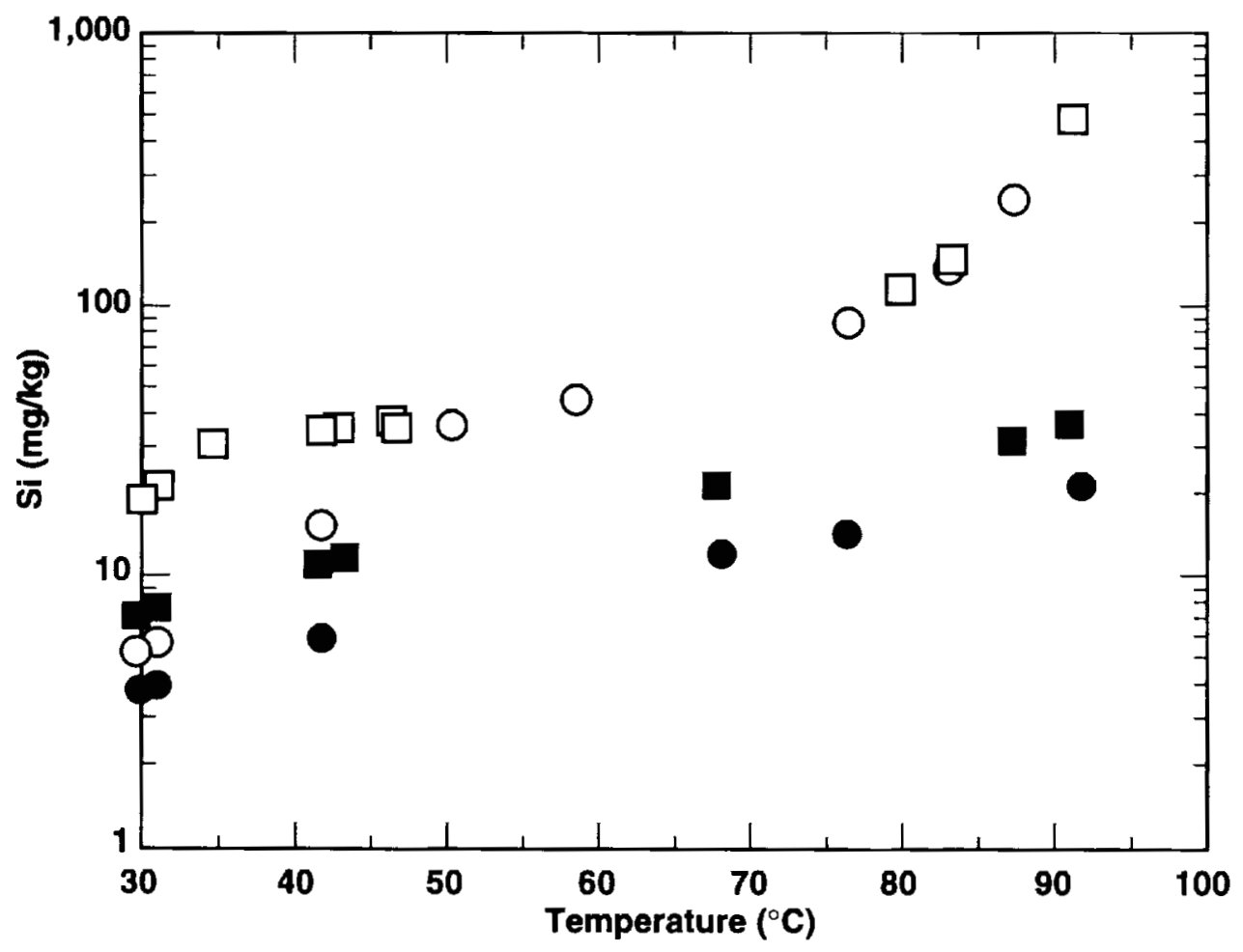

Figure 4-18. 
Figure 4-19. Log of the number of moles of calcite precipitated as a function of temperature. Figure 4-20. Log of the number of moles of dolomite precipitated as a function of temperature. Figure 4-21. Log of the number of moles of saponite precipitated as a function of temperature. Figure 4-22. Log of the number of moles of stilbite precipitated as a function of temperature.

The type of salt deposits, as well as their volumes, can be estimated from the amount of water estimated to enter the drift prior to moisture displacement by the thermal pulse and the temperature of the drift wall, which would determine the chemistry of the water based on the amount of evaporation that would have taken place at that temperature. Such estimates are highly dependent on the designs selected.

However, regardless of the design, water will begin to evaporate in response to heat as the waste is emplaced. Initially, water in the NFE will be similar in composition to water in the pores and fractures, although it may also include water used in construction, e.g., excess water in concrete. The composition within the rock is not determined in detail at present but will be somewhat similar to that from J-13. As noted earlier, evaluations of the chemical evolution of water as it evaporates indicate that water compositions will change as the water evaporates such that the composition will be near neutral $\mathrm{pH}$, slightly oxidizing, with increased $\mathrm{Na}, \mathrm{S}, \mathrm{Cl}$, and $\mathrm{F}$. Sodium approaches $1,000 \mathrm{mg} / \mathrm{kg}$ at temperatures of about $95^{\circ} \mathrm{C}$; extrapolation to near total evaporation is not accurate but would indicate in excess of $10,000 \mathrm{mg} / \mathrm{kg}$ water. Similar increases are seen for $\mathrm{S}, \mathrm{Cl}$, and $\mathrm{F}$, from about 6,8 , and $3 \mathrm{mg} / \mathrm{kg}$, respectively, for ambient conditions to about 100,150 , and $200 \mathrm{mg} / \mathrm{kg}$, respectively, at 90 to $95^{\circ} \mathrm{C}$. In contrast, Ca nearly disappears, whereas Si increases from about $20 \mathrm{mg} / \mathrm{kg}$ to in excess of $500 \mathrm{mg} / \mathrm{kg}$ at about $90^{\circ} \mathrm{C}$. As water is evaporated and boiled in the region of rock that exceeds the boiling point, the salts will be left behind, and the vapor will migrate to cooler portions of the rock mass, where it will condense. The water chemistry of the condensate will approach that of distilled water.

After temperatures exceed the boiling point, water will not enter the drift until the temperatures decay, or if the combined volume of meteoric and condensate fluxes exceed the capacity for the heat flux to drive off that water. After the thermal pulse decays, the chemistry of the condensate will likely be dominated by rock-water interactions because of the long residence times at elevated temperatures so that the water would tend to be in equilibrium with the rock. Thus, the initial chemistry of water entering the drift will be a combination of meteoric and dilute water. If the fluxes exceed the heat-flux capacity, then it is likely that the percolation fluxes will be high so that initial water chemistry of water entering the drifts will be dominated by the fastfracture flow of meteoric water with some condensate that has not come into equilibrium with the rock.

Any water entering the drifts will flow through the $\mathrm{AZ}$ and through the dried zone, where it can pick up the residual salts that had been left when the water was driven out of the dried zone. Water initially entering the near-field will contain relatively elevated concentrations of a variety of salts and other highly soluble species, which will be present because of evaporation of water during heating and dryout of the rock near emplacement drifts. With time, if flow of water continues along the same pathway, the concentrations of these species will decrease as the salts are dissolved. These relatively high-ionic-strength solutions will then interact with emplaced materials that have been altered in response to repository conditions. The alteration is expected to evolve over time. It is anticipated that the result of these interactions will be a solution of moderately high pH (9 to 11), with an ionic strength greater than that of the present ambient pore waters. Regardless of the starting chemistry, the final chemistry of water that contacts the waste during this time will be strongly, if not dominantly, influenced by the interactions with materials within the drifts themselves, including the rock support system. 


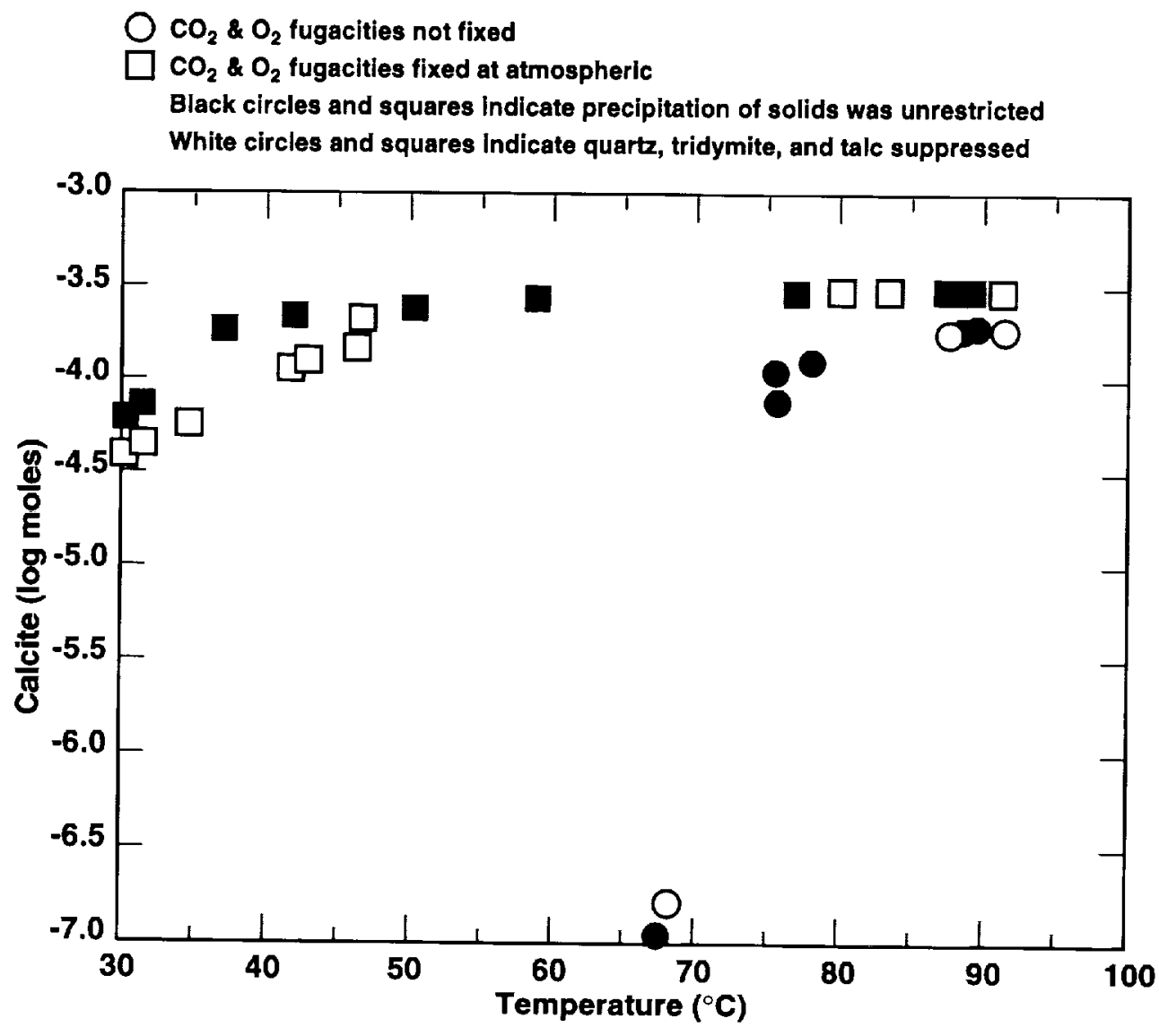

Figure 4-19. 


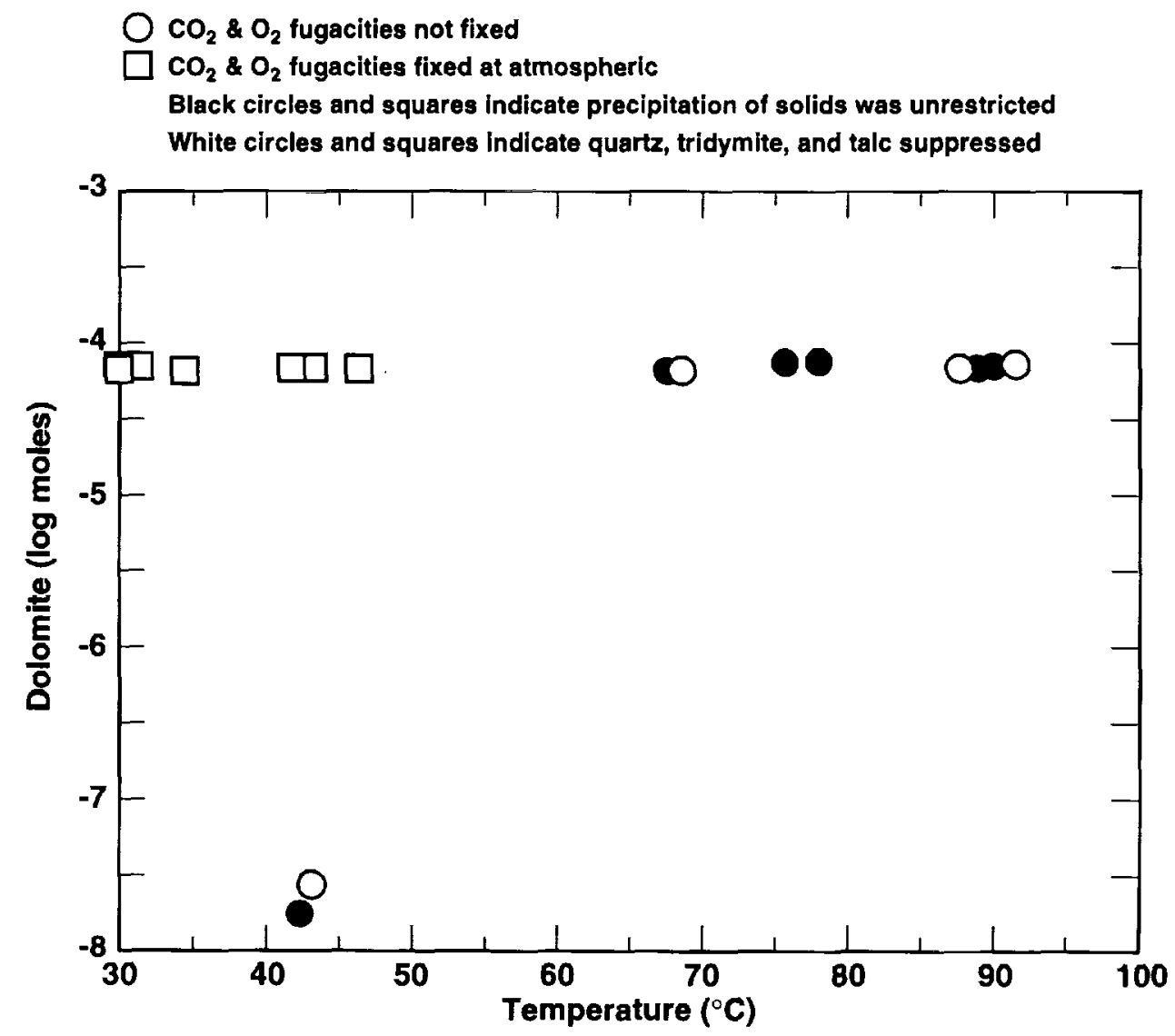

Figure 4-20. 


\section{$\mathrm{O} \mathrm{CO}_{2} \& \mathrm{O}_{2}$ fugacities not fixed}

$\square \mathrm{CO}_{2} \& \mathrm{O}_{2}$ fugacities fixed at atmospheric

Black circles and squares indicate precipitation of solids was unrestricted

White circles and squares indicate quartz, tridymite, and talc suppressed



Figure 4-21. 


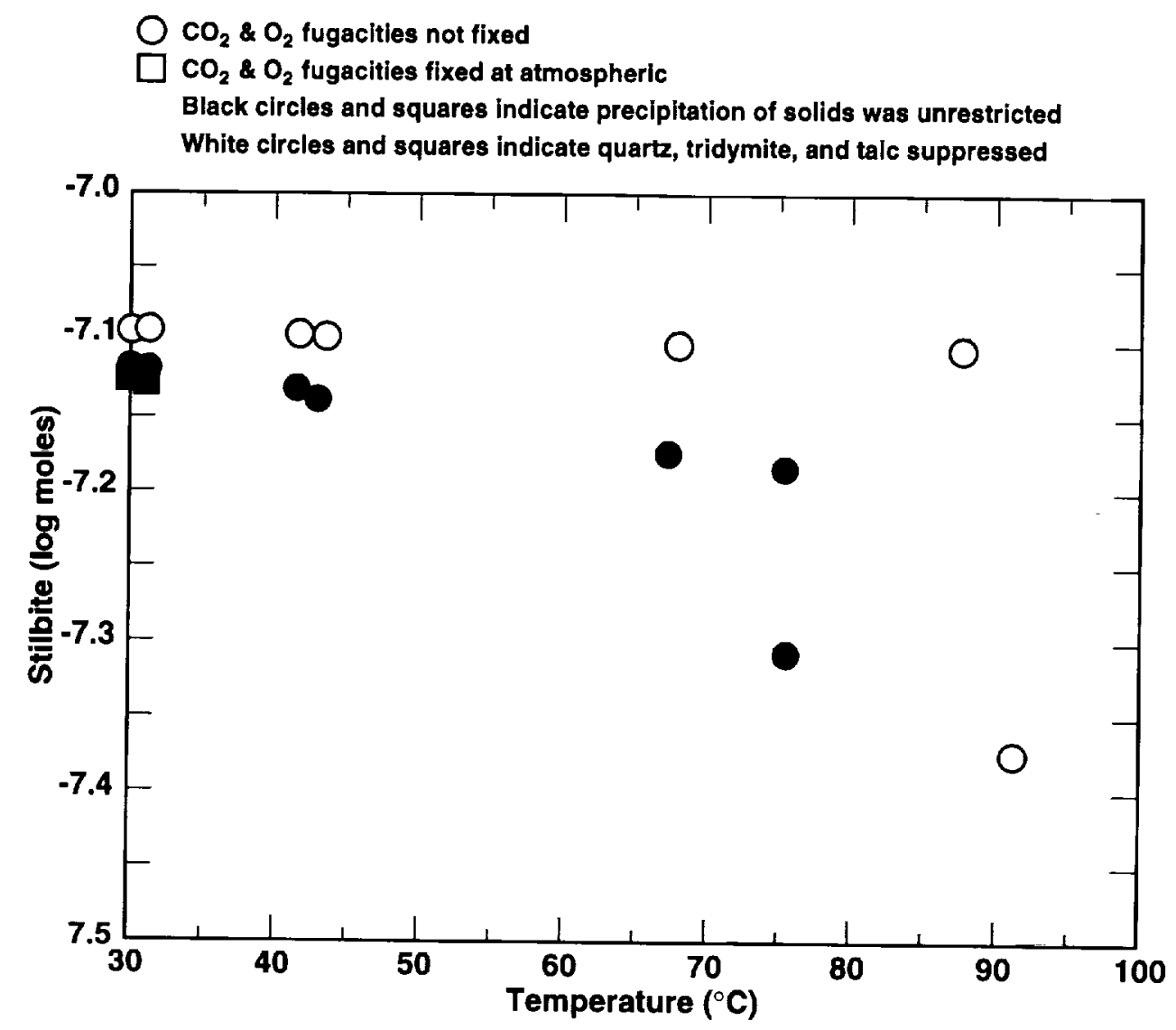

Figure 4-22. 


\subsubsection{Introduced Materials}

Volume II provides extensive accountings of possible materials and volumes that will be used during construction. However, considerable uncertainty remains as to the materials that will be used. In addition, the design is evolving, and at the time of publication of Volume II, the most likely ground support system (other than steel sets, which are still being evaluated) was considered to be pre-cast concrete or cast-in-place concrete or shotcrete. The techniques to make a detailed analysis are in development. Therefore, determination of likely water chemistry remains for subsequent revisions of this report. Once the materials are emplaced, the chemical and mineralogical evolution of the repository would be fixed to a specific path and would be hypothetically predictable. One of the uncertainties at present in making such determinations is the role of chemical processes that are biotic, or mediated by living organisms, in contrast to those that are abiotic. At present, the abiotic processes are more easily determined, as is discussed below.

4.5.2.1 Abiotic Chemistry. One of the first evaluations of the impact of introduced materials on chemistry considered the impacts of diesel fuels. Although a decision was made not to use diesel underground, the results remain applicable because the experiments that incorporated other materials (tuff and shotcrete) were performed both with and without diesel fuels. The results of these experiments also underscored the potential significance of microbial activity because it is clear that in an abiotic environment, diesel fuel would remain indefinitely under repository conditions. We know from experience, however, that organic compounds, such as diesel fuel, do degrade far more quickly than that, because of microbial activity. The interactions measured were between water and Fibercrete ${ }^{T M}$. The results indicated that, although some components of diesel fuel are soluble or volatile, most of the inorganic abiotic interactions were independent of the presence of diesel fuel. That is, diesel components do not degrade and do not affect the inorganic species in solution. As shown in Figs. 6-6 through 6-8 of Volume II, solution $\mathrm{pH}$ at $200^{\circ} \mathrm{C}$ decreases from approximately 8.8 to 8.4 and was approaching a steady state. Similarly, total sulfur concentrations increased to approximately $15 \mathrm{mM}$, and initial inorganic carbon decreased to near the detection limit. Aqueous Si concentrations increased to about $5 \mathrm{mM}$, and aqueous $\mathrm{Al}$ concentrations decreased to $1 \mathrm{mM}$. Concentrations of $\mathrm{Ca}$ increased with time without diesel present. Aqueous Fe and $\mathrm{Mg}$ concentrations hovered around $1 \mathrm{mM}$ (near detection limits). At $200^{\circ} \mathrm{C}$, the system quickly reached an equilibrium that is stable over the lifetime of the repository. The cementitious material used in these experiments was Fibercrete ${ }^{\mathrm{TM}}$, which may be analogous to the cast-in-place design option for mechanical support.

Insight into the long-term performance of cements (a likely component of ground support systems) has been gained from rocks containing minerals that are expected in concrete exposed to elevated temperatures. Water with $\mathrm{pH}$ as high as 12.5 has been collected from these rocks. These data are consistent with preliminary calculations of phases in equilibrium with water (Atkins et al., 1992, 1994). It is concluded that the presence of cementitious material may greatly alter the chemistry of water moving through the repository by providing a large reservoir of unstable Casilicate phases, which will affect the corrosion of the WP, the dissolution of the waste form, and the solubility of repository rock.

At YM, the impact of temperature must be considered in these chemical interactions. Clearly, temperature will cause an evolution in the construction materials so that water returning to the post-thermal repository will contact significantly altered materials. However, it is also likely that the cementitious materials will have dehydrated and transformed to a more crystalline mineral assemblage. As a consequence, chemical reactions can affect not only water chemistry, but the relative humidity of the repository if there are large volumes of cement present. This coupling was not considered in the earlier discussion of relative humidity (Section 4.3). An iteration with the analyses in Section 4.3 will be included in a subsequent revision of this report when the design has matured and the amount of cement is better determined. 
Recent results from the Single Heater Test (SHT) raise the issue of excess $\mathrm{CO}_{2}$, which not only impacts the rock-water interaction results, but also the evolutionary history of cement. As noted in Volume II, at partial pressures of $\mathrm{CO}_{2}$ greater than ambient, compositional and microstructural changes are expected in the cement phases. The data from the SHT indicate that excess $\mathrm{CO}_{2}$ is generated by rock-water interaction and release from water. Thus, much of the cementitious material could evolve into $\mathrm{CaCO}_{3}$ phases plus $\mathrm{SiO}_{2}$ phases. The consequences to the $\mathrm{pH}$ are significant in that a calcite-water-dominated system would have a significantly lower $\mathrm{pH}$ than that of the cement-water systems discussed, which have $\mathrm{pH}$ values of 11 to 12 . As discussed in Volume II, water in contact with portland cement can attain extremely high pHs. However, the effects of microbes, heating, $\mathrm{pCO}_{2}$ above ambient, and other factors can all impact those $\mathrm{pHs}$ and tend to lower them. In addition to the influence on chemistry, cementitious materials may contain zeolites as aggregate or pozzolana, which would also contribute to sorbing radionuclides.

4.5.2.2 Biotic Chemistry. The impact of biotic chemistry cannot be ignored. There is a growing awareness that biotic factors could affect the integrity of the repository by several processes. They include microbially induced corrosion (MIC) of the WP, degradation of construction materials (including concrete), and alteration of the chemical environment. Evaluations of microbial populations at YM indicate that microbes are both present and capable of growth under repository conditions (see Volume II). Some microbes are capable of producing slime under low nutrient conditions and could therefore play a role in corrosion of WP materials. Some of the microbes can produce acids, and some may alter the pore water chemistry (Horn et al., 1996). The impacts of biotic factors on chemistry will be included in subsequent revisions of this report.

Microbial activities are subject to bounds. To a certain extent, heat will promote microbial activity, but at temperatures greater than $130^{\circ} \mathrm{C}$, microbial activity is expected to cease (and to reinitiate when temperatures drop below $130^{\circ} \mathrm{C}$ ). Similarly, we expect relative humidity to limit microbial activity. The exact bounds will be discussed in subsequent revisions of this report. For further discussion of this topic, see Horn and Meike (1996).

\subsubsection{Conclusions}

Chemistry within the near-field will be dominated by the interaction of emplaced materials with the repository atmosphere and liquid water. The emplaced materials, in turn, are affected by heat and relative humidity. Hence, the chemical conditions that develop within the near field will be dominated by the alteration products of cementitious materials and metals, which appear to be the majority of introduced materials, and how these materials affect the composition of incoming water. It is expected that the water chemistry interactions will occur in a solution of moderately high pH (9 to 11) with an ionic strength greater than that of present ambient pore water.

One of the impacts of introduced materials that needs to be considered during repository design is that chemical potentials, concentrations, and temperatures can be extremely heterogeneous. This heterogeneity is the basis for gradients in factors that influence chemical interactions. The gradients are the basis of thermodynamic driving forces and, as such, cause substances to dissolve and precipitate in a manner that is not predicted by using average values. Thus, those design options that tend toward more homogeneous conditions (e.g., end-to-end emplacement, uniform ground support systems, etc.) will be more desirable when making performance assessments.

In addition to the physical-chemical processes, it is also likely that microbial activity will play a role in establishing the near-field conditions, given the ability of microbes to adapt to extreme environments, to sporulate, migrate, and become dormant. Microbial activity can alter local chemistry significantly, plug fractures to modify hydrology, and create a vehicle for radionuclide 
sorption. Once sorbed, radionuclide transport depends on the attachment and detachment characteristics of the microbes. Work is currently underway to bound the conditions under which microbial activity may be significant, and to define those locations and times for which microbial activity is likely to have no significant influence on near-field conditions.

\subsection{Geomechanics}

\subsubsection{Ambient Mechanical Rock Properties}

To properly characterize the mechanical behavior of the NFE, it is necessary to know the mechanical properties of the rock mass forming the NFE. The mechanical properties of a rock mass are difficult to measure directly and depend on the properties of both intact rock and the fractures making up the rock mass. The information presented here includes rock mass properties measured in situ to the extent such data are available; however, if not available, properties of intact rock samples are discussed. Because most of the intact properties are available in the YMP Reference Information Base (RIB) (DOE, 1995) and are discussed in Section 2, that information is not duplicated here. This section focuses only on rock properties when either the thermal influence or the rock mass variability in those properties is known.

Information on physical properties is available in the RIB (refer also to Sec. 4.2.1.1 and Table 4-4 of Volume II). Information on thermal properties, including conduction and expansion, is also included in the RIB (refer to Sec. 4.2.1.2 of Volume II for additional data on changes in properties . due to temperature and confinement and to Sec. 4.4.4 of Volume II for more discussion).

\subsubsection{Ambient Joint/Fracture Properties}

Mapping of the Exploratory Studies Facility (ESF) at Yucca Mountain, which is within the Topopah Spring tuff, identified three major fracture sets. Two are subvertical, while the third is subhorizontal. These fractures will dominate much of the geomechanical behavior of the rock in the NFE, and it is important to have a basic knowledge of the properties of the fractures. MacDougall et al. (1987) reported joint cohesion $=0.1 \mathrm{MPa}$ and joint friction angle $=28.4^{\circ}$. Olsson $(1987,1988)$ found that the strength of a joint may increase with the time of stationary contact and that joint properties are dependent on stress history. These findings need to be considered for the long-term repository analyses since the stress history will include a thermal pulse followed by cooldown. The times of stationary contact will be much longer after the thermal pulse and major portions of cooldown are completed.

The constitutive properties of fractures and joints in the potential repository horizon are also important for assessment of the thermal-mechanical and thermal-hydrologic behavior of the rock. Olsson and Brown (1994) measured constitutive properties of seven fractures from drill holes NRG-4 and NRG-6 using a rotary shear apparatus. They found that the peak friction ranged from 0.89 to 1.11 , and residual friction ranged from 0.76 to 1.00 . They also reported that dilation angle ranged from 5.29 to $11.28^{\circ}$ and that the roughness characteristics for the fracture surfaces are in qualitative agreement with the mathematical model of Brown (1994). Olsson examined the effect of sliding velocity on the mechanical response of an artificial joint in Topopah Spring tuff to determine the velocity dependence of shear strength. Olsson found that different initial conditions affected the character of the stress-slip curve. In particular, slide-hold-slide tests exhibited time-dependent strengthening, whereas hold-slide tests produced slip weakening. No joint creep was observed in these tests.

Blair and Berge (1996) found that imposing low levels of compressive stress on 0.5-m-scale blocks caused time-dependent, nonrepeatable behavior to occur for existing cracks. Under longterm loading, cracks/vugs oriented perpendicular to the applied stress showed significant closure, and pre-existing hairline cracks oriented parallel to the applied stress opened. Based on 
their observations Blair and Berge postulated that some properties of the rock mass may become increasingly anisotropic with time. Additional data are currently being collected from the ESF; however, the data were not available at the time this report was prepared.

\subsubsection{Ambient Rock Mass Properties}

A major issue associated with measuring physical properties is scale effects. One of the reasons for this is the ability, or lack thereof, to test fractures. Blair and Berge (1996) monitored deformation of a fracture zone in a 0.5-m block of Topopah Spring tuff and found that deformation is nonlinear with increasing stress, and modulus increases as normal stress increases above $4 \mathrm{MPa}$. They determined the modulus value to be $\sim 4 \mathrm{GPa}$ below 4-MPa normal stress, and $-6 \mathrm{GPa}$ above 4-MPa confinement. These values are considerably lower than measured values on core samples. They interpreted the increase in modulus to above $4 \mathrm{MPa}$ to be due to closure of fractures and vugs. Based on hysteretic behavior, they postulate that during the cool-down period, when stresses are released, opening of fractures will increase permeability of the NF region.

Uncracked samples exhibited quite high uniaxial strength of about $155 \mathrm{MPa}$ for Topopah Spring tuff. However, as expected, samples with cracks exhibit nonlinear stress-strain behavior when stress is above $50 \%$ of the failure stress (see Fig. 4-2 of Volume II for stress-strain curves). The implications for the rock mass is that, except in localized areas without fractures present, the use of linearly elastic models must be used with caution. Furthermore, work of Martin et al. (1993, 1994, 1995a) reported in Volume II (p. 4-6) indicates that the Topopah Spring tuff is quite heterogeneous in porosities and in strength-some tested samples were much weaker than would be indicated by the values shown in the RIB, having failed at pressures well below 100 MPa. Brechtel et al. (1995) analyzed the rock-mass strength based on empirical methods (see p. 4-11, Volume II) and found that the estimated rock-mass strengths are substantially lower than those determined from intact rock samples. They estimated that the compressive strength for TSw2 is $18.8 \mathrm{MPa}$, which is about $10 \%$ of the value determined from intact core samples.

Tests performed on one $0.5-\mathrm{m}$ block that contained fractures indicate that the Young's modulus is about 6 GPA (Blair and Berge, 1996). This is approximately $16 \%$ of the modulus determined from intact rock. Therefore, the values of Young's modulus reported in Table 4-4 (Volume II) may be unrealistically high for application to repository conditions. This lower modulus may serve to decrease stress levels predicted for the NFE.

\subsubsection{Time-Dependent Rock Properties}

The thermal properties of rock samples from the proposed repository horizon have been the subject of several laboratory and field studies. Results, as reported in the RIB and included in the Preliminary NFER, indicate that the dry matrix thermal conductivity is $2.51 \pm 0.17\left(\mathrm{~W} / \mathrm{m} \cdot{ }^{\circ} \mathrm{K}\right)$. The in situ thermal conductivity has been measured both dry $\left(2.1 \pm 0.2 \mathrm{~W} / \mathrm{m} \cdot{ }^{\circ} \mathrm{K}\right)$ and at a saturation of $0.65\left(2.1 \pm 0.2 \mathrm{~W} / \mathrm{m} \cdot{ }^{\circ} \mathrm{K}\right)$. Brodsky et al. (1997) indicate that recent data are consistent with previous values reported by Nimick (1989). However, they found that saturation had an effect. For unit TSw2, the thermal conductivity for dry samples was $1.50 \pm 0.44 \mathrm{~W} / \mathrm{m} \cdot{ }^{\circ} \mathrm{K}$, and for saturated samples, the value was $2.29 \pm 0.42 \mathrm{~W} / \mathrm{m} \cdot{ }^{\circ} \mathrm{K}$.

The effect of temperature on the strength of near-field rock is not well defined at this time. Rock strength, however, generally decreases with increasing temperature. Price et al. (1987) report that for samples from the potential repository horizon, Young's modulus decreases an average of $16 \%$ as temperature is raised from 22 to $150^{\circ} \mathrm{C}$. The mean ultimate strength also decreases $16 \%$ as temperature is raised from 22 to $150^{\circ} \mathrm{C}$ at both 0 - and 5-MPa confining pressures. 
Measurements of linear thermal expansion have been made on samples from unit TSw2 and are reported in the RIB (see summary Table 4-2 in Volume II). At temperatures below $100^{\circ} \mathrm{C}$, the coefficient of thermal expansion was in the range of 7.7 to $10.8 \times 10^{-60} \mathrm{C}^{-1}$. As temperature was increased to near $250^{\circ} \mathrm{C}$, the values increased to between 14.2 and $20.6 \times 10^{-6 \circ} \mathrm{C}^{-1}$. Cautions in the Preliminary NFER regarding the use of these values to estimate processes in the very near field and for simulation of cooling still apply. Recent measurements (Brodsky et al., 1997) indicate that the coefficients are highly temperature-dependent and that there is a hysteresis between heating and cooling. Furthermore, they observed some permanent elongations. Because the coefficients are strongly temperature-dependent, single ranges are not useful. Table 4-7 gives the coefficient of thermal expansion at different temperatures. Whereas the values for $T<100^{\circ} \mathrm{C}$ are similar to those reported in the Preliminary NFER, the values for higher temperatures are significantly different.

Table 4-7. Coefficient of thermal expansion in TSw2 unit at different temperatures, from Brodsky et al. (1997).

\begin{tabular}{|c|c|c|c|c|c|c|c|c|c|c|c|c|}
\hline \multicolumn{13}{|c|}{ Mean coefficient of thermal expansion $\left(\times 10^{-6}\right.$ per $\left.{ }^{\circ} \mathrm{C}\right)$ during heatup } \\
\hline $\begin{array}{l}\text { Saturation } \\
\text { state }\end{array}$ & Statistic & $\begin{array}{l}25- \\
50^{\circ} \mathrm{C}\end{array}$ & $\begin{array}{l}50- \\
75^{\circ} \mathrm{C}\end{array}$ & $\begin{array}{l}75- \\
100^{\circ}\end{array}$ & $\begin{array}{l}100- \\
125^{\circ}\end{array}$ & $\begin{array}{l}125- \\
175^{\circ}\end{array}$ & $\begin{array}{l}150- \\
175^{\circ}\end{array}$ & $\begin{array}{l}175- \\
200^{\circ}\end{array}$ & $200-$ & $\begin{array}{l}225- \\
250^{\circ}\end{array}$ & $\begin{array}{l}250- \\
275^{\circ}\end{array}$ & $\begin{array}{l}275- \\
300^{\circ}\end{array}$ \\
\hline Saturated & Mean & 7.14 & $\mathbf{7 . 4 7}$ & 7.46 & 9.07 & 9.98 & 11.74 & 13.09 & 15.47 & 19.03 & 25.28 & 37.13 \\
\hline Saturated & Std. dev. ${ }^{\mathrm{a}}$ & 0.65 & 151 & 1.21 & 241 & 0.77 & 1.28 & 1.40 & 1.75 & 3.09 & 6.87 & 14.27 \\
\hline Saturated & Count & 19 & 19 & 19 & 19 & 19 & 19 & 19 & 16 & 16 & 16 & 16 \\
\hline Dry & Mean & 6.67 & 8.31 & 8.87 & 9.37 & 10.10 & 10.96 & 12.22 & 14.54 & 20.79 & 25.13 & 35.13 \\
\hline Dry & Std. dev. & 1.20 & 0.42 & 0.40 & 0.55 & 0.88 & 1.16 & 1.50 & 2.57 & 17.03 & 10.07 & 14.56 \\
\hline Dry & Count & 40 & 40 & 40 & 40 & 40 & 38 & 38 & 35 & 35 & 35 & 35 \\
\hline & & & & & & & & & & & & \\
\hline \multicolumn{13}{|c|}{ Mean coefficient of thermal expansion $\left(\times 10^{-6}\right.$ per $\left.{ }^{\circ} \mathrm{C}\right)$ during cool-down } \\
\hline Saturated & Mean & 21.89 & 27.83 & 26.55 & 21.38 & 17.31 & 14.06 & 12.49 & 11.52 & 10.27 & 9.48 & 8.81 \\
\hline Saturated & Std. dev. & 6.16 & 10.36 & 10.01 & 5.70 & 3.07 & 1.38 & 1.32 & 2.00 & 0.62 & 0.63 & 0.62 \\
\hline Saturated & Count & 16 & 16 & 16 & 16 & 19 & 19 & 19 & 19 & 19 & 19 & 19 \\
\hline Dry & Mean & 20.57 & 24.31 & 24.20 & 21.16 & 18.45 & 14.34 & 11.74 & 10.51 & 9.54 & 8.87 & 7.48 \\
\hline Dry & Std. dev. & 4.88 & 7.55 & 8.08 & 6.24 & 9.36 & 4.23 & 3.03 & 2.26 & 1.79 & 1.56 & 1.99 \\
\hline Dry & Count & 35 & 35 & 35 & 35 & 38 & 38 & 40 & 40 & 40 & 40 & 40 \\
\hline
\end{tabular}

Standard deviation.

In general, the coefficient of thermal expansion increases with increasing temperature. Work by Martin et al. (1996) indicated that confining pressure has little effect on the coefficient of thermal expansion. The increase with temperature is attributed to local distortions and formation of microcracks due to mismatch of expansion coefficient of constituent grains. Brodsky et al. (1997) attributed the hysteresis observed at temperatures near $200^{\circ} \mathrm{C}$ to phase changes in trydimite and cristobalite. Phase changes in some minerals can cause step changes in the rock volume. Cristobalite exhibits a few percent volume increase in transition from alpha to beta phase at temperatures around $200^{\circ} \mathrm{C}$. However, cristobalite is expected to represent only about $30 \%$ of rock mass volume, and depending on design, a small percentage of the rock volume will be elevated to temperatures approaching $200^{\circ} \mathrm{C}$. The phase change, if it does occur, is reversible so that a volume decrease may occur upon cooling below $200^{\circ} \mathrm{C}$.

\subsubsection{Time-Dependent Joint $/$ Rock Mass Properties}

Microcracking and subcritical growth in the near-field rock over long time periods is of concern because the formation, growth, and coalescence of microcracks in the rock at or near excavations could lead to excavation damage and the formation of rock chips or blocks. The chips 
or blocks might passively load the container and form transport pathways. The formation of microcracks may also change the physical and geochemical properties of rock in the NFE. Little work has been done in this area. Kemeny and Cook (1990) however used a probabilistic approach that included time-dependent crack growth to examine borehole emplacement. They estimated that, over the lifetime of the repository, slabbing would be likely to occur in a significant portion of emplacement boreholes, were they to be used.

\subsubsection{Mechanical Loading Conditions on WPs}

4.6.6.1 Block Failures. The rock-mass failure mechanisms that could lead to loading of the container include:

1. Block failures. Blocks could fall into open spaces left by a collapsed ground support system. Block failures are the most credible loading scenario.

2. Rock burst failures. Such failures are unlikely, even if ground support fails.

3. Creep. Openings close, forcing ground support segments onto the package or backfill.

4. Sloughing of rock materials into openings created by failed ground support systems.

The type of loadings that would result from these failures will be different and are assessed separately in the following sections. Thermal loading is the most likely cause of ground support failures and associated loading of the WPs.

Two types of loading are possible: point loads and uniform loads. The type of loading that is most likely is strongly influenced by engineering design. For instance, nonuniform loading of WPs can be mitigated by engineered alternatives, such as backfilling the drifts at the time of closure. Drift backfill should remain effective against drift collapse indefinitely. Even if settlement of backfill occurred, the amount of rock motion would be limited. Therefore, loading conditions must be discussed relative to design assumptions.

Under assumed conditions, rock loading on the WPs by block failures or by sloughing can be bounded. The rock support system currently envisioned consists of pre-cast segmental liner, which will be emplaced immediately behind the tunnel boring machine (TBM). If this support system maintains its integrity, there will be no rock loading on WPs. The issue of mechanical loading on the rock support system is beyond the scope of the NFER. If the drift collapses with time, then the WPs can be loaded by contact with the failed concrete support system that, in turn, would be loaded by either blocks of rock or bulked rock rubble. If backfill is used, the contact would not be directly with the concrete, and the potential for point loading would disappear. Presumably smaller blocks of rock would be able to mobilize because of the smaller open volume for the rock to move into. Unless a different ground support system is used than that currently envisioned, there is no likelihood that blocks could fall directly onto WPs. More likely, the liner segments, if the wedging or keyblock failed, could fall onto the WPs, and then blocks of rock could fall into the opening left by the liner segments. Unless the liner segments failed by crumbling, they would not occupy the space in a densely packed fashion, and, therefore, there would be a limit on the magnitude of rock movement that would occur.

A probabilistic approach could be used to estimate the stability of drifts over time. Kemeny and Cook (1990) used this approach to evaluate the stability of boreholes over time in conjunction with a repository design that employed borehole emplacement. They estimated that, over the lifetime of such a repository, slabbing would be likely to occur in a significant portion of the emplacement boreholes. This analysis, although performed for boreholes, could be applied to drifts. It should be recognized that other processes might apply to drifts, and furthermore, that in a rock mass where vertical fractures dominate, the potential for slabbing or for block failures into a large horizontal opening may be significantly greater than into a vertically oriented borehole such as was used by Kemeny and Cook. Slabs could place either uniform or point loading on the 
ground support system liners, etc., but would not likely impact directly on WPs except through failed support system components.

4.6.6.2 Uniform Loading. Without backfill, uniform loading of the WPs could only result from creep closure of openings being imposed on a uniformly failed and completely crumbled support system. This, in turn, would impose the loading on the WPs. In the case of backfill, creep closure could be imposed through the backfill. If sufficient long-term creep takes place to entirely close the openings around the WPs, then the full lithostatic load might be imposed. Whereas data are not available to address creep over long time frames $(10,000 \mathrm{yr})$, there is no indication that full lithostatic loading is likely to be imposed. Natural openings in other rock types have remained open over long periods (e.g., limestone caves and lava tubes), but no study has been made as to whether these natural analogs apply to Yucca Mountain.

A third mechanism for uniform loading is hydrostatic loading. No hydrostatic loading is anticipated because the repository horizon is unsaturated. Any water that might be introduced inadvertently into the system will likely drain away before any appreciable head can develop. Therefore, no hydrostatic loads need be provided for.

4.6.6.3. Point Loading. If pre-cast liners are used for ground support, the only means of creating point loadings on WPs would be from the concrete liner itself. The rock load could be imposed on a failed, but not crumbled ground-support system, which in turn transferred that load to WPs, or by rock blocks directly if portions of the ground-support system fell to the sides of the WPs. The rock loading could be from block failures behind the liner or from creep closure.

The size of blocks that could enter the space left by a collapsed liner depend on the fracture spacing and, ultimately, the opening dimensions that result from the ground support failure. The ultimate bound on this opening dimension would be the full drift diameter, but the actual dimension should be somewhat smaller because total failure of the ground support is unlikely. In the Preliminary NFER, it was noted that for horizontal emplacement, it is conceivable that vertical_joints with different orientations could form a block with about $1 \mathrm{~m}^{2}$ horizontal dimension that could extend for a considerable distance vertically. Given the dry bulk density of $2.22 \mathrm{~g} / \mathrm{cm}^{3}$, this would be equivalent to $2000 \mathrm{~kg} / \mathrm{vertical} \mathrm{ft}$ of block. A reasonable estimate for point loadings by a tabular block can be made by using a ratio of $10: 1$ vertical to horizontal dimensions for the block. (At vertical dimensions greater than 10:1, an estimate of the locking into the overall fracture/block system needs to be made.)

An estimate for a tabular block was based on constraining the horizontal dimension of blocks by the borehole diameter and by fracture spacing (see Table 4-8). A similar approach can be taken for the drift emplacement. Given the orientation of fracture Set 1 (about $18^{\circ}$ to drift orientation), theoretically tabular blocks with dimensions up to $16 \mathrm{~m}$ long (the length of the fracture trace in a 5-m-diameter drift) could fall with the drift. However, a more realistic value can be estimated by using the average fracture spacing of the three prominent Sets 1,2, and 3 (realizing that when fracture spacing is different, blocks of quite different dimensions can form). These sets would intersect to form blocks with one side oriented approximately $120^{\circ}\left(300^{\circ}\right)$ with a length of about 2 to $4 \mathrm{~m}$ (that is, $2 \mathrm{~m}$ in domain 4 , and $4.4 \mathrm{~m}$ in domain 3 ) and width ranging from about $0.3 \mathrm{~m}$ to $1.1 \mathrm{~m}$ for domains 3 and 1 , respectively. The vertical extent of the blocks would be roughly the spacing of Set 3 , which varies from about $10 \mathrm{~m}$ in domains 1 and 2 to about $45 \mathrm{~m}$ in domain 3 (see Table 4-8). Domain 3 will represent a large portion of the repository. Therefore, if a single block were to fall into the drift, it could range in weight from 360,000 to $20,000 \mathrm{~kg}$ for domains 3 and 1, respectively. It is less likely that a single block $45 \mathrm{~m}$ high would fail; therefore, the $360,000-\mathrm{kg}$ block represents a bounding value that is unlikely. If multiple blocks fell into the drift, then a block of this dimension would be more plausible. 
Table 4-8. Fracture spacing by domain.

\begin{tabular}{|l|c|c|c|c|}
\hline & Domain 1 & Domain 2 & Domain 3 & Domain 4 \\
\hline Set 1 & & & & \\
\hline Fractures & 798 & 540 & 2851 & 428 \\
\hline Drift length (m) & 900 & 500 & 950 & 350 \\
\hline Fractures/m & 0.89 & 1.08 & 3.11 & 1.22 \\
\hline Spacing between fractures (m) & 1.13 & 0.93 & 0.32 & 0.82 \\
\hline & & & & \\
\hline Set 2 & & & & \\
\hline Fractures & 230 & 134 & 215 & 168 \\
\hline Drift length $(\mathrm{m})$ & 900 & 500 & 950 & 350 \\
\hline Fractures/m & 0.26 & 0.27 & 0.23 & 0.48 \\
\hline Spacing between fractures (m) & 3.91 & 3.73 & 4.42 & 2.08 \\
\hline & & & & \\
\hline Set 3 & & & & \\
\hline Fractures & 86 & 51 & 21 & 26 \\
\hline Drift length (m) & 900 & 500 & 950 & 350 \\
\hline Fractures/m & 0.10 & 0.10 & 0.02 & 0.07 \\
\hline Spacingbetween fractures (m) & 10.5 & 9.80 & 45.2 & 13.5 \\
\hline & & & & \\
\hline Set 4 & & & & 0 \\
\hline Fractures & 62 & 0 & 0 & 0 \\
\hline Drift length (m) & 900 & 500 & 950 & 350 \\
\hline Fractures $/ \mathrm{m}$ & 0.07 & 0 & 0 & 0 \\
\hline Spacing between fractures $(\mathrm{m})$ & 14.5 & NA & NA & NA \\
\hline
\end{tabular}

4.6.6.4 Seismic Loading. Information contained in Rev 0 of the Preliminary NFER remains relevant (refer to Sec. 4.1.3 of that document). An earthquake with focus at Little Skull Mountain has been studied, and damage to underground structures was evaluated. This information is available in (note: Ref. to come).

The current design with large WPs emplaced within drifts and resting on pedestals results in different potential seismic impacts. Specifically, the thick packages within a large opening to allow for fault creep without loading the WPs should protect the WPs from shearing or large deformations due to fault offsets. Even the very large offsets associated with major earthquake events (usually less than $8 \mathrm{~m}$ ) should not break an individual package because the WP can rotate within the drift. Furthermore, the WPs are sufficiently strong that the rock in a sheared zone associated with faulting should break around the WP rather than shearing the WP itself.

However, the WP could be dislodged from the pedestals and could be thrown against the rib of the drift.

\subsubsection{Predictive Modeling}

No predictions of the geomechanical component of the NFE are currently available. Analyses of stresses resulting from waste heat generation have been made and are included in the Design Review Document (Repository Ground Support Analysis for Viability Assessment), which is in review. However, predictive modeling for heater tests compare favorably with deformation responses measured by Finley et al., 1997. Thus, macroscopic geomechanical behavior can probably be modeled by existing techniques. However, the real focus of geomechanics for the NFE involve how it back couples with hydrology and geochemistry. The major issues involve: 
1. Modification of hydrologic pathways due to opening and closing of existing fractures as well as creation of new fractures (microcracking). It should be noted that deformations of the rock mass can have a strong influence on permeability, and these deformation effects may be permanent (Wilder, 1986).

2. Creation of newly exposed surfaces for geochemical rock-water interactions.

3. Long-term creep or crack propagation that could alter the coupling.

All of these issues will be address in subsequent revisions of the NFER based on models, testing, and technique development that are the focus of current work.

The focus of LLNL's geomechanics work in the past was to evaluate subcritical crack growth over long time frames as it would produce deformations equivalent to long-term creep. Model development to address the potential for crack propagation has been the focus of geomechanical studies. Crack growth as a mechanism of long-term creep behavior has been studied and reported by Martin et al. (1997) and Yang and Daemen (1997). This work will be reported in the forthcoming Synthesis Report on Thermally Driven Coupled Processes (Hardin and Chesnut, 1997). Martin et al. (1997) report that there is not only similarity between the creep curve and that of time-dependent crack growth, but also that there is a theoretical basis for relating creep to crack growth. They note that data for crack growth in single-crystal quartz is similar to that observed in creep experiments. Whereas the focus of their work was on drift stability, it also has application to the NFE in that crack growth provides the surface exposure as well as modified hydrologic paths and stress concentrations for increased rock-water interactions. Yang and Daemen (1997) observed that creep of tuff increases with temperature; thus, this issue will have direct application to the NFE. 


\subsection{Altered Zone Environment}

\subsection{Introduction}

\subsubsection{Definitions and Organization}

At Yucca Mountain, many processes or interactions can potentially cause significant property changes extending for considerable distances into the rock mass or natural system. The altered zone (AZ) is defined as the region of the natural system wherein fundamental changes to hydrologic, mineralogical, or chemical conditions take place. The changes are generally a result of increased temperature in the presence of water or water vapor. Alteration can also take place with increased temperature in the dryout zone where water exists as vapor rather than liquid phase. However, the alterations are greatest where both liquid water and elevated temperatures exist. The $\mathrm{AZ}$ conditions do not interact directly with the waste packages; rather, they interact with the NFE. The $A Z$, with associated conditions, differs from the FFE, where ambient conditions tend to prevail. Many of the same processes occur in the NFE, AZ, and to some extent FFE. However, the processes that dominate the system in the AZ are not necessarily the same as the ones that dominate either the NFE or the FFE. Except for the coupling with introduced materials that occurs in the NFE, the AZ processes are the most fully coupled.

The fact that coupled processes dominate the $\mathrm{AZ}$, and that the processes are coupled in complex ways, makes understanding difficult. To facilitate explanations, the multiply coupled processes are discussed in this report as being singly or, where necessary, multiply coupled but without evaluating all the interactions at the same time. Thus, the fully coupled processes are broken down into component parts. Figure 5-1 is the basis for organizing the discussion. The way to read this chart is discussed in Section 1. Simply put, components of the NFE and AZ environments are identified on the diagonal, and processes are shown off-diagonal. Forward coupling is shown to the right, and backward coupling is shown to the left.

Figure 5-1. Model of coupled processes in the AZ. Entries on the diagonal denote components of the environment. Arrows to the right denote forward coupling; arrows to the left denote backward coupling.

For example, when thermal-mechanical unit TSw2 is exposed to water at elevated temperatures, the rock-water interaction will form new mineral assemblages, including carbonates and silica depositions. These, in turn, will heal fractures and plug the original pore spaces resulting in an overall reduction in permeability. This example of coupling is shown in Fig. 5-1, where the arrows extending to the right from temperatures and moisture conditions to processes of kinetics, rock-water interactions, mineral dissolution, and so forth, indicate the interaction leading to a change in development of mineral assemblages. Moreover, once the mineralogy changes, the permeability changes, the coefficient of thermal conduction is modified, moisture conditions (involved in reactions) change, and the convection within the system is hindered. This type of back-coupling is indicated by the arrows pointing to the left from changed mineralogy and upward to changed hydrologic properties, and through the back-coupling of those processes to the thermal regime. As is apparent, the coupling can be quite complex. However, such forward and backward coupling is important to repository performance. In this example, the changes in heat flow due to changed conduction and convection conditions could lead to vastly different temperatures within the NFE and drifts. Each main topic in Section 5 is organized by identifying on a similar chart the coupling that is most dominant. The multiple back-coupling will be implied on the matrix. However, the multiple coupling pathways are not fully identified at this time and will be included in future revisions of this report. 


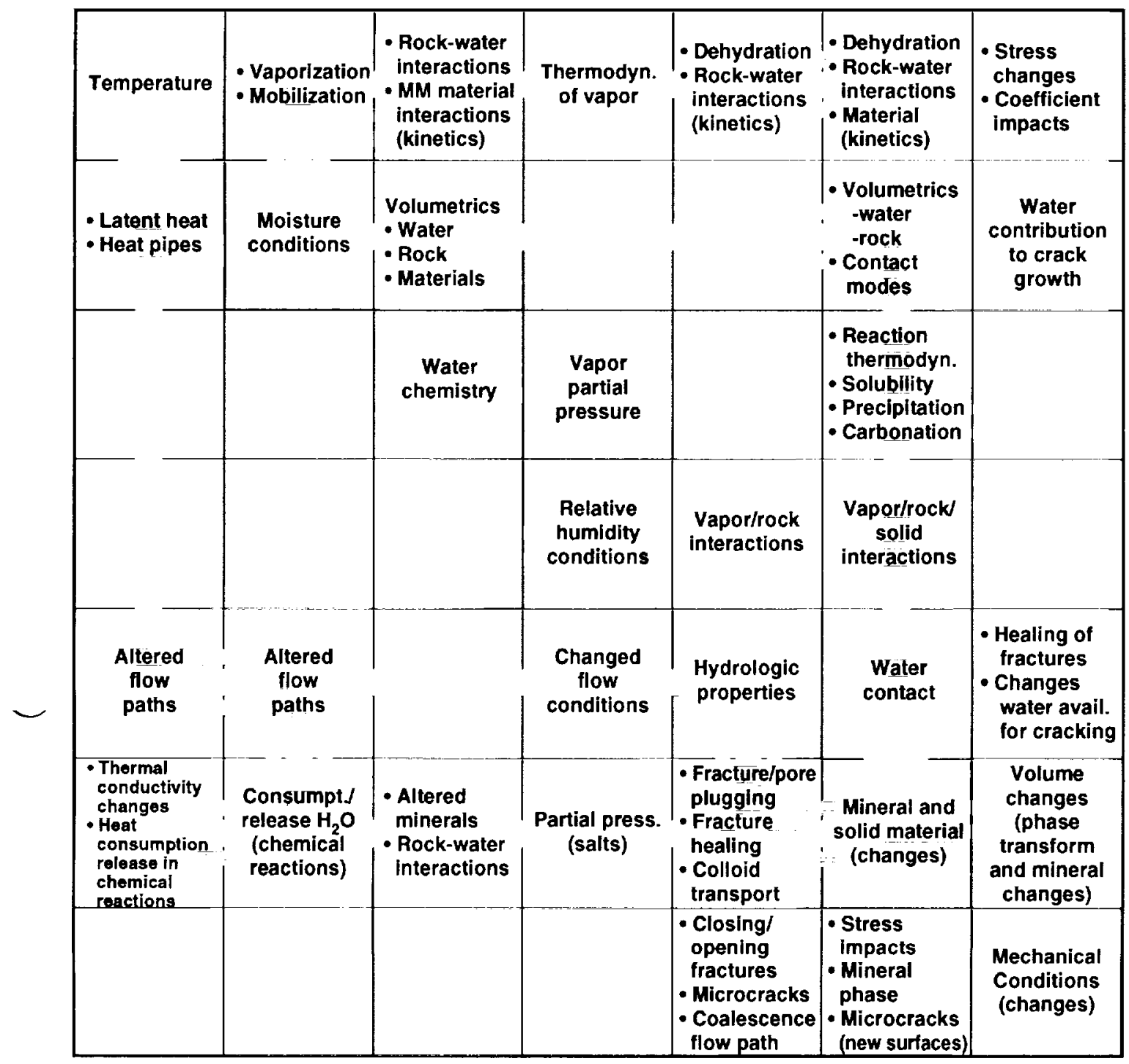

Figure 5-1 


\subsubsection{Background}

The environmental conditions that impact WPs and radionuclides will be strongly perturbed by the heat of decay from the waste for many hundreds or thousands of years. As the thermal pulse moves further into the rock mass, the rapidity of movement of the thermal isotherms slows down, and equilibrium conditions begin to dominate. Thus, to some degree, the distinction between the NFE and AZ is the transition from dominance of kinetics to equilibrium, although both processes will occur to some degree in each zone. For any given emplacement scenario, the rate at which temperature changes occur depends, in general, on the distance from the heat source: the greater the distance, the slower the change of temperature. This temperature behavior provides one basis for defining or distinguishing the NFE from the AZ.

In the near-field region, strong thermal gradients will exist for the first $1000 \mathrm{yr}$. These regions will be dominated by kinetic effects, and hydrological processes will be dominated by water vaporization, water movement by means of gas-phase transport, and condensation in those outer regions of the NFE where temperatures are below the boiling point. Geochemical processes will be dominated by evaporation and boiling, mineral dehydration, and solid-vapor interactions. The system will be a highly dynamic one in which the dryout regions will continue to increase in size and therefore incorporate what had been zones of condensation. Because of the dynamics, coupling between hydrology and geochemistry may not be well developed (water removed before geochemical reactions change the system in significant or fundamental ways).

In the $\mathrm{AZ}$, hydrologic processes will be dominated by an increase in water availability and increased saturation, associated with vapor condensation. There will be a general elevation of temperatures by several tens of degrees centigrade. The geochemical processes will be dominated by fluid-rock interactions and reactive transport. The $\mathrm{AZ}$ will tend to be less dynamic than the NFE in that the residence times for water will be much longer, and the dryout zone will not incorporate the condensation zones until long after geochemical/mineralogic changes have occurred, if at all. Within the AZ, these interactions will result in significant coupling between hydrological and geochemical processes, such that fluid pathways and geochemical conditions will evolve in a synergistic way.

Although the geochemical processes (e.g., recrystallization, hydration/dehydration of mineral phases, dissolution/precipitation, rock-water interaction involving water in pores and fractures, cation exchange, sorption, etc.) in both regions are the same, their impact on rock properties will be different. The differences are due to contrasts in heating and cooling rates, in the abundance and temperature of liquid water, in whether kinetics or equilibrium dominate, and in the duration of reactions. These differences will be expressed as differences in the magnitude and nature of chemical and mineralogical changes. As a result, repository performance will be affected differently in the two regions because of water-mineral interactions. In this report, the NFE is considered to be those regions that achieve temperatures well above the boiling point, and the $\mathrm{AZ}$ is considered to be those regions that maintain temperatures low enough to allow liquid water to exist in pores and fractures. This distinction has the advantage of focusing attention on the dominant processes that may affect performance in different regions of the repository.

Because hydrothermal conditions are strongly coupled with geochemical processes, the hydrothermal conditions will be determined first, then coupling with geochemical processes will be discussed. Figure 52 shows the various decay-heat-driven hydrological processes and ambient site conditions that may significantly affect moisture balance in and development of the AZ. In general, decay heat will result in regions of dryout and condensate buildup in the unsaturated zone (UZ). Modeling studies (Buscheck and Nitao, 1993a; Buscheck and Nitao, 1993b; Buscheck and Nitao, 1994a; Buscheck et al., 1994) have indicated that decay-heat-driven changes in the saturation distribution can persist for more than 100,000 years. These effects, along with temperature changes, can alter the hydrological, geochemical, and geomechanical properties that influence fluid flow and radionuclide transport. 
Figure 5-2. Moisture balance in the UZ (and above the repository) is affected by both ambient and decay-heat-driven processes. The two processes labeled with an asterisk are applicable only to aboveboiling conditions. All other processes can occur under both sub-boiling and above-boiling conditions.

\subsection{Thermal-Hydrology in the Unsaturated Zone}

This discussion focuses on those thermal-hydrologic processes shown within the shaded areas of Fig. 5-2 and as the off-diagonal process in Fig. 5-3, which essentially define the AZ. The processes are dryout/boiling-driven vapor flow, condensate buildup and flow (including downward drainage), vapor diffusion, and buoyancy-driven vapor flow. Refluxing or gravity-driven heat pipes are included in these processes but are mentioned specifically because of their significance.

Figure 5-3. Thermal-hydrologic coupling matrix.

Fluid flow in the UZ at Yucca Mountain involves liquid- and gas-phase flow through the fractures and through the rock matrix. Under ambient conditions, the gas phase contains about $98.5 \%$ air and $1.5 \%$ water vapor. Except for regions with a perched water table or during transient recharge episodes, capillary/gravity forces cause most fractures to be drained of liquid water. Matrix permeability is extremely low for most of the hydrostratigraphic units in the UZ, so liquid-phase flow will primarily occur in fractures rather than in the matrix. Liquid-phase flow in fractures may arise from three origins:

1. Ambient infiltration and percolation of rainfall and snowmelt.

2. Condensate generated under boiling conditions.

3. Condensate generated under sub-boiling conditions.

The first source arises from the ambient system; the second and third are generated by radioactive decay heat. Decay-heat-driven, buoyant vapor flow may play an important role in generating the second and third sources of liquid water. Decay-heat-driven binary diffusion of water vapor and air may also play important roles in condensate generation (Buscheck and Nitao, 1994a).

Because of the large bulk permeability of fracture networks, gas-phase pressures in the fractures remain very close to atmospheric, even during boiling. Consequently, as temperatures reach the nominal boiling point $\left(\sim 96^{\circ} \mathrm{C}\right)$, boiling first occurs along fractures (Fig. 5-4) and proceeds into the matrix blocks. Accordingly, dry-out due to boiling is more suppressed in sparsely fractured regions (with large matrix blocks) and less suppressed in intensely fractured regions.

Figure 5-4. Schematic of hydrothermal flow near the emplacement drift. Rock dryout occurs as boiling drives water vapor out of the rock matrix (arrows). On reaching the fracture network, vapor is driven away from the boiling zone to where cooler temperatures cause it to condense along fracture walls. Because the small matric permeability limits the rate of matrix imbibition, condensate drainage can persist for considerable distances down fractures.

Most of the water vapor reaching the fracture network is eventually driven away from the emplacement drift by higher gas-phase pressures in the boiling zone to where cooler temperatures cause it to condense along fracture walls (Fig. 5-4). Buoyant, gas-phase convection can cause more of the vapor flow to be driven upward to where it condenses above the dry-out zone. In general, regardless of where the condensate is generated, three things can happen to it:

1. It can drain away from the boiling zone.

2. It can drain back toward the boiling zone.

3. It can be imbibed by the matrix. 


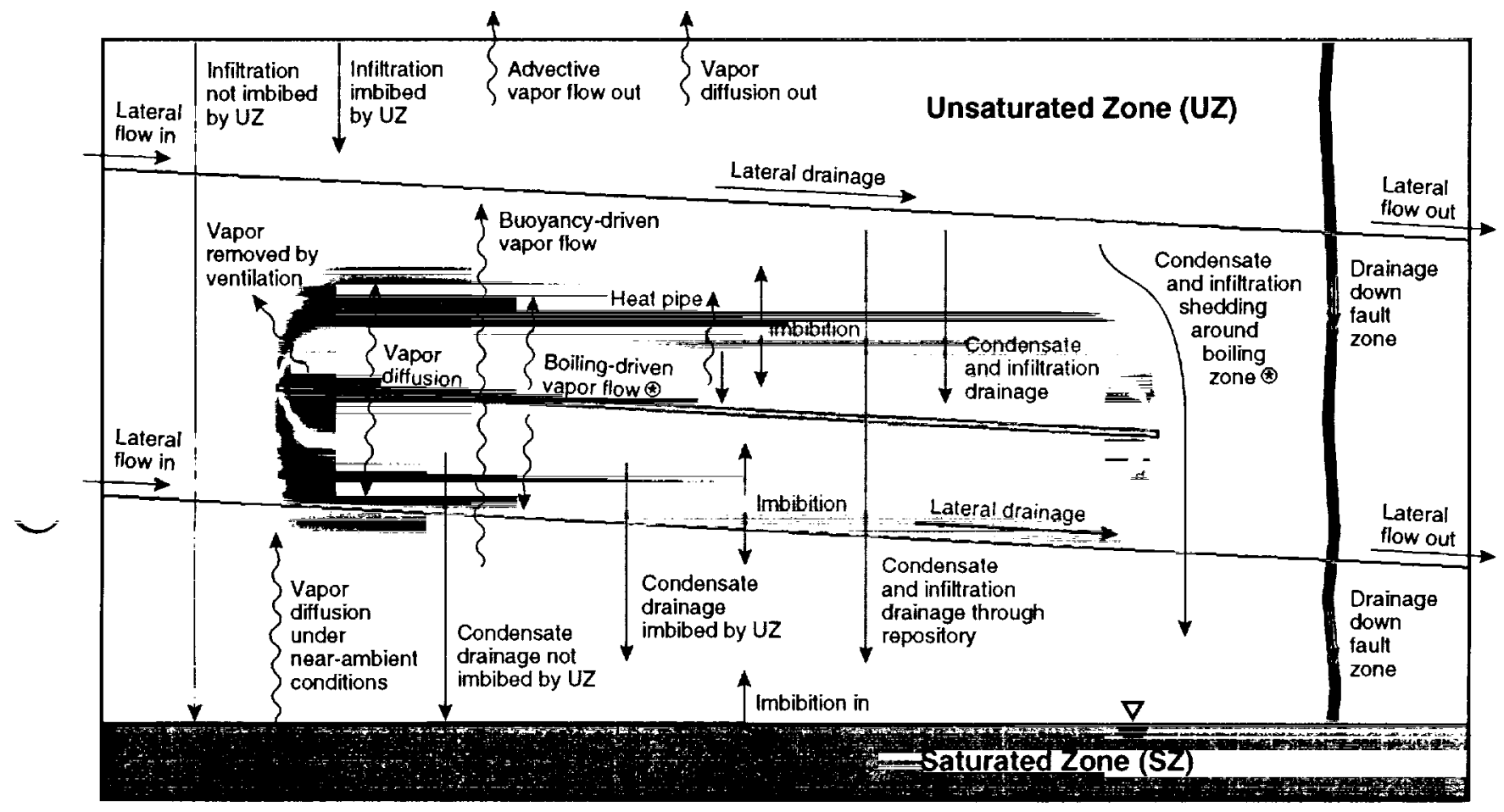

Figure 5-2. 


\begin{tabular}{|c|c|c|c|c|c|}
\hline \multirow[t]{6}{*}{$\begin{array}{c}\text { Meteoric } \\
\text { percolation } \\
\text { flux }\end{array}$} & $\begin{array}{l}\text { Latent heat } \\
\text { convection }\end{array}$ & & & & \\
\hline & $\begin{array}{l}\text { Rock-mass } \\
\text { temperature }\end{array}$ & $\begin{array}{c}\text { Dryout/ } \\
\text { evaporation }\end{array}$ & $\begin{array}{l}\text { - Dryout } \\
\text { evaporation } \\
\text { - Vapor/water } \\
\text { mobilization }\end{array}$ & $\begin{array}{l}\text { - Dryout } \\
\text { evaporation } \\
\text { - Heat of } \\
\text { vaporization } \\
\text { - Bouyancy }\end{array}$ & $\begin{array}{l}\text { - Boiling } \\
\text { driven } \\
\text { vapor flow } \\
\text { - Buoyancy } \\
\text { driven vapor } \\
\text { flow } \\
\end{array}$ \\
\hline & & $\begin{array}{c}\text { Moisture } \\
\text { in } \\
\text { pores }\end{array}$ & \begin{tabular}{|l|} 
- Saturation \\
gradients \\
- Imbibition \\
- Condensation \\
- Capillary/ \\
gravity equil.
\end{tabular} & $\begin{array}{l}\text { Vapor } \\
\text { diffusion }\end{array}$ & $\begin{array}{c}\text { Vapor } \\
\text { diffusion }\end{array}$ \\
\hline & $\begin{array}{l}\text { - Convection } \\
\text { - Latent heat } \\
\text { - Heat pipe } \\
\text { (refluxing) }\end{array}$ & & $\begin{array}{l}\text { Moisture } \\
\text { in } \\
\text { fractures }\end{array}$ & $\begin{array}{c}\text { Vapor } \\
\text { equilibrium }\end{array}$ & \multirow{3}{*}{$\begin{array}{c}\begin{array}{c}\text { Condensate } \\
\text { buildup/ } \\
\text { drainage }\end{array} \\
\text { Buoyancy } \\
\text { driven vapor } \\
\text { flow } \\
\\
\text { Total or net } \\
\text { percolation } \\
\text { flux }\end{array}$} \\
\hline & \begin{tabular}{|l|} 
- Heat pipe \\
- Vapor heat \\
redistr. \\
- Heat release \\
- Condensation
\end{tabular} & $\begin{array}{c}\text { Vapor } \\
\text { resaturation }\end{array}$ & $\begin{array}{c}\text { Vapor } \\
\text { resaturation }\end{array}$ & $\begin{array}{l}\text { Vapor } \\
\text { in } \\
\text { fractures }\end{array}$ & \\
\hline & & & & & \\
\hline
\end{tabular}

Figure 5-3 


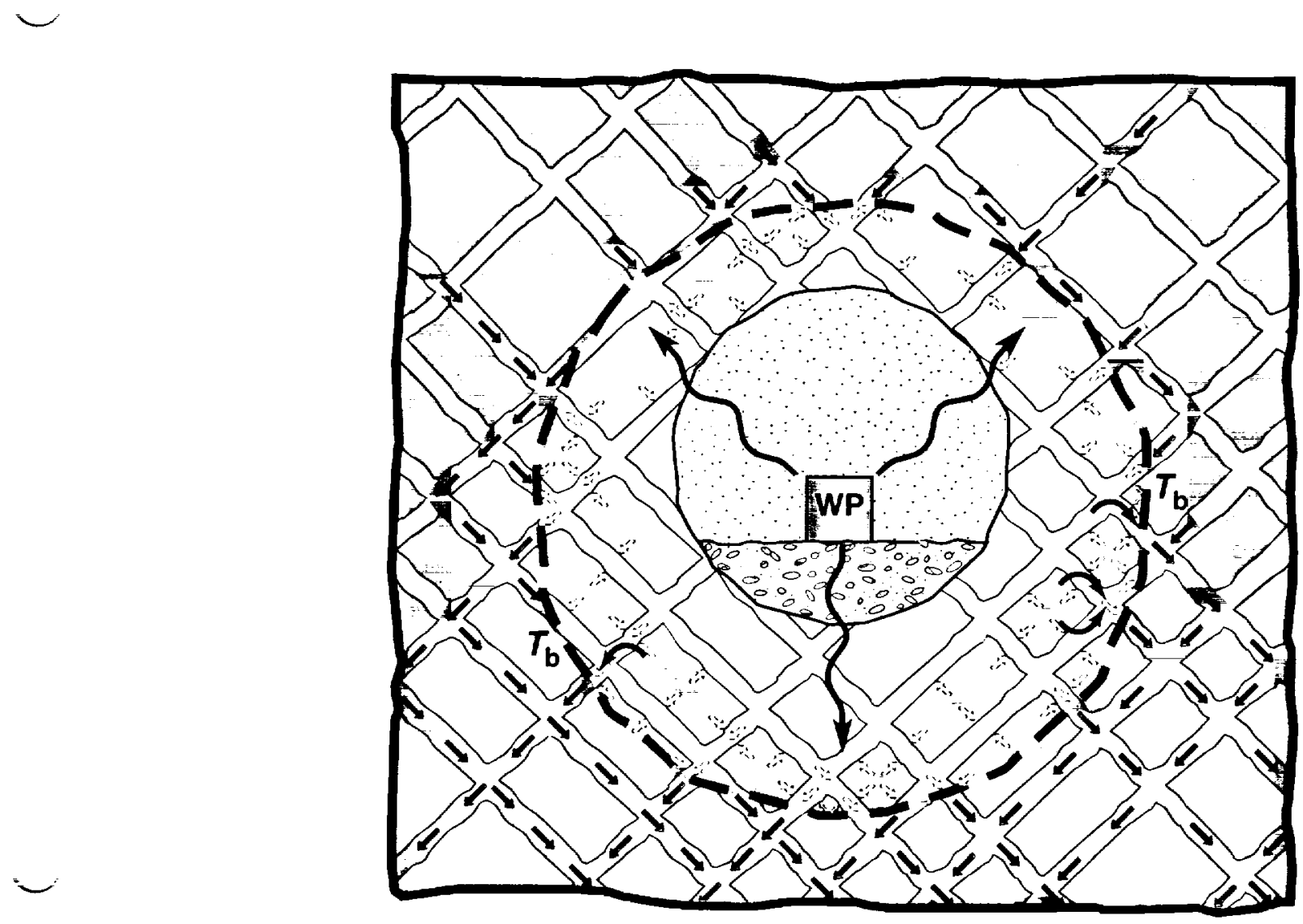

Figure 5-4. 
Because the small matrix permeability limits the rate at which the matrix can imbibe condensate by capillary suction, condensate can drain for considerable distances down fractures before being completely imbibed. Below the boiling zone, condensate drainage is away from the boiling zone (Fig. 5-4), enhancing the dry-out rate. Above the boiling zone, condensate tends to drain back toward the boiling zone, where it reboils, creating a gravity-driven heat pipe. This creates asymmetry in the boiling zone around the drift, as is illustrated in Fig. 5-4, where the dryout or elevated temperature zone is larger below the drift. This effect has been observed in field experiments at G-Tunnel (Ramirez et al., 1991), at the Exploratory Studies Facility (Lin, 1997), and at the Large Block Test at Fran Ridge.

Refluxing does not require boiling conditions (Buscheck and Nitao, 1994a). Heat-driven, buoyant gasphase flow can drive refluxing under sub-boiling conditions; however, the heat transfer is greater under boiling conditions. Refluxing results in a heat transfer mechanism (driven by the convection of latent heat) called the heat-pipe effect. Heat pipes are capable of sustaining a given heat flux with a much flatter temperature gradient than is associated with heat conduction. Consequently, heat pipes are manifested by a flat temperature profile, with temperatures close to the nominal boiling point.

The zone of two-phase refluxing overlying the boiling zone (the heat-pipe zone) is of particular interest because the liquid saturation and relative humidity $R H$ remain high in this zone, increasing the likelihood of aqueous reactions and aqueous-transport processes occurring. Refluxing can also generate a very high liquid-phase flux in fractures, which can result in significant dissolution and precipitation of minerals along the fracture walls. The heat-pipe zone is typically manifested by temperatures that are very close to the nominal boiling point of water at the repository elevation $\left(96^{\circ} \mathrm{C}\right)$ and a liquid saturation that is very close to $100 \%$.

Figure 5-5 summarizes the time and length scales involved in how repository heat influences the three major sources of fracture flow. Mountain-scale effects depend on the overall heating conditions for the entire repository. The most useful macroscopic thermal loading parameter quantifying the timeintegrated heat content of the waste in the repository is the areal mass loading (AML, expressed in metric tons of uranium per acre, MTU/acre). Mountain-scale effects depend primarily on the AML of the entire repository, and they are insensitive to the details of WP emplacement, such as WP size and spacing, and spent nuclear fuel (SNF) age.

Figure 5-5. Various time and length scales involved in how decay heat influences the three major sources of liquid water flow.

\subsubsection{Assumptions and Calculations}

For a detailed discussion of the property values and boundary conditions used in the calculations reported here, refer to Secs. 10.1.1.3 and 10.1.1.4 of Volume II. All major hydrostratigraphic units in the UZ at Yucca Mountain were included in the models. The wet and dry thermal conductivity $\left(K_{t h}\right)$ data were obtained from the Reference Information Base (RIB) (DOE, 1990). A steady-state liquid saturation profile obtained for a net percolation flux of $0 \mathrm{~mm} / \mathrm{yr}$, yielding a repository horizon saturation of $68 \%$ was used in calculations. Other studies (Buscheck and Nitao, 1992; Buscheck and Nitao, 1993a; Buscheck and Nitao, 1993c) also considered the steady-state saturation profile obtained for percolation fluxes of 0.045 and $0.132 \mathrm{~mm} / \mathrm{yr}$, resulting in repository horizon saturations of 85 and $95 \%$, respectively. For the reference case, we used the matrix hydrological properties given in the RIB and in Klavetter and Peters (1986). Updated physical properties are currently being incorporated and will be included in subsequent revisions of this report. We also considered the impact of more recent matrix hydrological properties reported by Pruess and Tsang (1994).

The reference case assumed a bulk permeability $k_{\mathrm{b}}$ of $2.8 \times 10^{-13} \mathrm{~m}^{2}$ ( 280 millidarcy), equivalent to three $100-\mu \mathrm{m}$ fractures per meter. The sensitivity of buoyant, gas-phase convection, boiling and dryout behavior to $k_{\mathrm{b}}$ was examined (see Sec. 10.1.1.3, Volume II) 

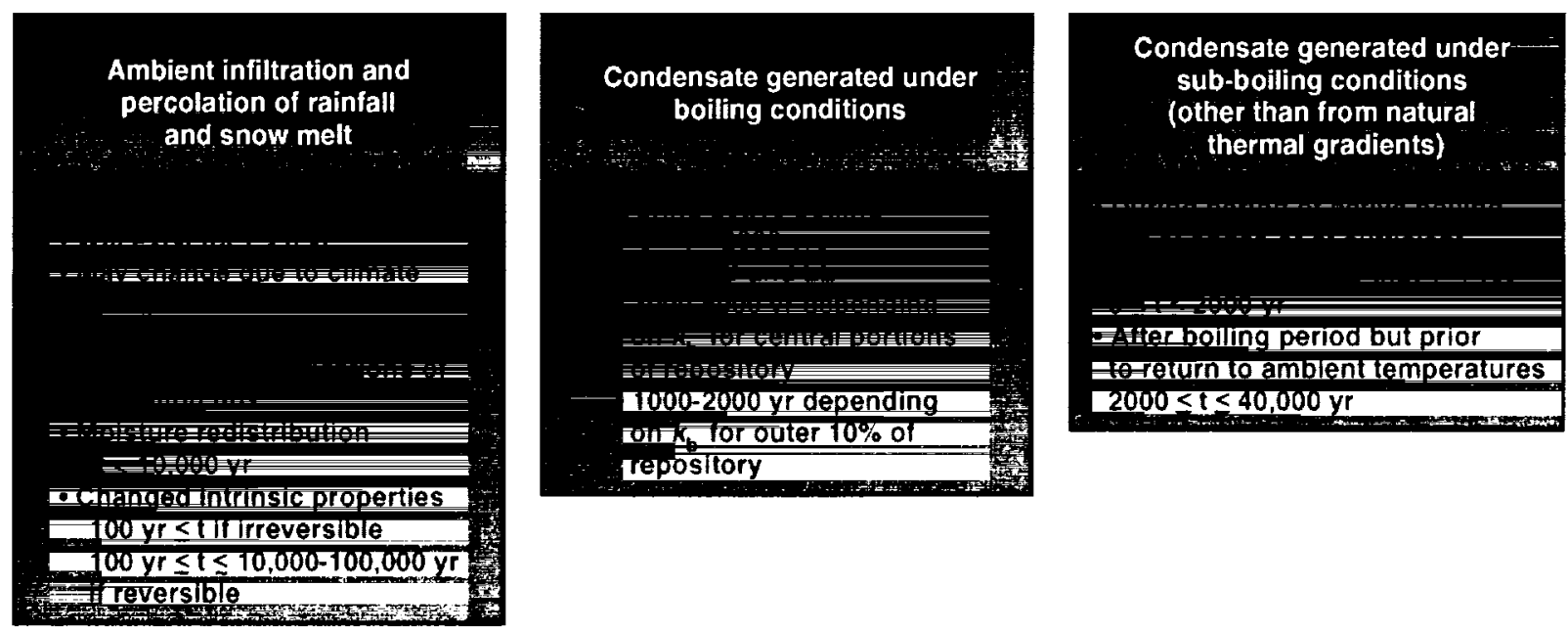

Figure 5-5. 
The initial vertical temperature distribution $T$ in the models corresponded to the nominal geothermal gradient in the region. The initial temperature and saturation at the repository horizon in the UZ model are $23.3^{\circ} \mathrm{C}$ and $68 \%$, respectively. The atmosphere at the ground surface was represented by a constantproperty boundary, with $T$ and gas-phase pressure fixed at $13^{\circ} \mathrm{C}$ and $0.86 \mathrm{~atm}$, respectively. The relative humidity $R H$ at the ground surface was also fixed at $100 \%$. Therefore, under initial (ambient) saturation and temperature conditions, there is no mass flux of water vapor between the atmosphere and upper $\mathrm{TCw}$. We also assumed that the water table has a fixed depth $(z=568.1 \mathrm{~m})$ and a constant temperature $\left(31^{\circ} \mathrm{C}\right)$; this causes the water table to act as a heat sink. For the first 1000 years, repository temperatures are insensitive to the treatment of heat flow at the water table (Buscheck and Nitao, 1993; Buscheck and Nitao, 1993c).

Calculations that use a fixed-depth constant-temperature boundary at the water table substantially underpredict mountain-scale temperature rise as well as the overall magnitude of decay-heat-altered $\mathrm{T}-\mathrm{H}$ effects in the UZ (see Sec. 10.2.1, Volume II). We assumed that the PPw data were applicable to the upper $1000 \mathrm{~m}$ of the SZ (down to the lower boundary of the UZ-SZ model). The lower boundary of the UZ-SZ model has a constant temperature of $53.5^{\circ} \mathrm{C}$ and a fixed pressure corresponding to the hydrostatic pressure and temperature profile of the upper $1000 \mathrm{~m}$ of the SZ. The repository was assumed to be at a depth of $343.1 \mathrm{~m}$.

Because it areally averages the thermal load and represents the repository as a planar heat source, the mountain-scale model cannot represent differences in temperature and saturation behavior within the pillars, the emplacement drifts, or the WPs themselves. The drift-scale model is useful in representing details of thermal-hydrological behavior at the drift scale and, thus, AZ scale.

Heterogeneity that occurs at a larger scale was represented by a third model, called the crosssectional uniform heat flow (CSUHF) model. Like the drift-scale model, the CSUHF model assumes an infinite repository, thereby enabling it to take advantage of symmetry. The CSUHF model represents an infinite series of vertical, uniformly spaced, $1.0 \mathrm{~m}$-wide, high- $k_{\mathrm{b}}$ zones. We considered high- $k_{\mathrm{b}}$ zone spacings of 100 and $1000 \mathrm{~m}$. For the high- $k_{b}$ zones, we considered $10,84,414$, and 840 darcy.

\subsubsection{Influence of Fracture Permeability Distribution}

5.2.2.1 Temperature and Liquid Saturation Distribution. The vertical temperature and saturation profiles in Sec. 10.1.2.1 of Volume II are given for three different repository locations: (1) the center of the repository, (2) the perimeter that encloses the central $50 \%$ of the repository area (representative of "average" conditions because half of the WPs are inside this area), and (3) the perimeter that encloses $95 \%$ of the repository area (representative of the repository edge). The following discussion focuses on the repository average conditions.

Figure 5-6 shows the vertical temperature and saturation profiles at a radial distance enclosing 50\% of the repository for the 83.4-MTU/acre case at various times after emplacement. The thermal and dryout behavior are very similar for the center and average repository locations for the first thousand years. (The percentage of the repository that is influenced by edge-cooling effects increases with time.) The flattening of the temperature profile at the nominal boiling temperature $T_{\mathrm{b}}\left(\sim 96^{\circ} \mathrm{C}\right)$, corresponds to the two-phase flow refluxing zone (the heat-pipe zone). This zone is of particular interest because the liquid saturation and $R H$ remain high, increasing the likelihood of aqueous reactions and aqueous-transport processes. Refluxing also generates a very high liquid-phase flux in fractures, which can result in significant dissolution and precipitation of minerals along the fracture walls. This is the zone where significant coupling with geochemistry takes place and where conditions are maintained for sufficient times to allow reactions to achieve equilibrium.

Figure 5-6 shows significant zones wherein the saturation remains above $60 \%$ (blue color) and temperatures are between $60^{\circ}$ and $96^{\circ} \mathrm{C}$ (pink color). The zones where both conditions are present, shown as yellow bands, represent where coupling will be strong, thus forming the $\mathrm{AZ}$. As shown, the $\mathrm{AZ}$ will be maintained for thousands of years (still operating at 10,000 yr) for the case shown here. Factors such as 
higher percolation flux could modify the spatial and temporal extent of the $A Z$, but it will nonetheless be substantial. In actuality, the $A Z$ encompasses the entire region of rock extending from the repository to the highlighted regions in Fig. 5-6. However, once water is removed from the system, the coupling processes are greatly reduced. Thus, the $\mathrm{AZ}$ analyses and discussions are focused on the highlighted zones.

Figure 5-6. Vertical temperature profiles at a radial distance enclosing 50\% of the repository for $A M L=$ 83.4 MYU/acre at (a) $100 \mathrm{yr}$, (b) $1000 \mathrm{yr}$, and (c) $10,000 \mathrm{yr}$. Vertical liquid saturation profiles for the same times are shown in (d) through ( $f$ ). The $A Z$, defined as the regions where temperature ranges from $60^{\circ}$ to $96^{\circ} \mathrm{C}$ and saturation is $>60 \%$, is identified by the yellow bands at the three time periods.

Boiling results in a 150 - to $200-\mathrm{m}$-thick dryout zone for the inner $50 \%$ of the repository. The low liquid saturation in the dryout zone decreases the likelihood of aqueous reactions and aqueous-transport processes altering the flow and transport properties in this zone. However, as noted earlier, the regions closer to the drifts are highly dynamic, and, as shown in Fig. 5-6, approximately $100 \mathrm{~m}$ of this 150 - to 200$\mathrm{m}$ dryout zone is part of the $\mathrm{AZ}$ at 100 years. Depending on the kinetics, it is possible that part of this zone would experience chemical/mineralogical alterations that would then be exposed to further alteration (at a minimum, dehydration) as the thermal pulse envelopes this region above boiling temperatures.

Refer to Volume II, Sec. 10.1.2 for nonreference case calculations (other AMLs) as well as discussion of edge effects. Volume II (Fig. 10.1.2.1.1) indicates that edge-cooling effects substantially reduce the vertical extent of dryout in the outer region of the repository. Temperatures in the outer edge of the repository only rise to $98^{\circ} \mathrm{C}$, while at the center of the repository, $T_{\text {peak }}=146^{\circ} \mathrm{C}$. Temperatures decline to below $T_{b}$ within $5000 \mathrm{yr}$; however, a zone of less-than-ambient saturations persists after that. The outer $5 \%$ of the repository rewets back to ambient saturation within $10,000 \mathrm{yr}$, whereas the repository center remains below ambient saturation for more than 30,000 yr. Edge-cooling/rewetting/shedding effects will probably have less of an impact on the edge of a high-AML repository. Wide drift spacing will encourage more drift-scale condensate shedding, which will decrease the amount of condensate that can be displaced to the edge of the repository. This would lessen the contribution of edge-shedding to the liquidphase flux at the edge of the repository, thereby lessening the impact of heat pipes at the repository edge.

If the bulk permeability, $k_{\mathrm{b}}$, of the fractured rock mass is large enough, repository heat can lead to the development of large-scale, buoyant convection cells transporting water vapor from regions below the repository to regions above. These cells also have the potential to redistribute heat within the mountain and reduce temperatures in the repository as well as in the altered zone.

Mountain-scale, buoyant, gas-phase convection occurs within fracture networks having a connectivity with length scale comparable to the UZ thickness and repository width. As repository heat propagates into the rock, a column of warmer, less-dense gas develops that encompasses the repository area (Fig. 5-7). The result is that gas from outside the repository footprint is drawn into the region below the repository and flows upward through the repository, in a fashion similar to the updraft in a chimney. Buoyant, gas-phase convection cells develop as the warmer, less-dense column of gas within the repository footprint is displaced by the cooler, denser gas from outside the repository footprint. As the initially cooler gas is heated, its relative humidity is lowered, causing it to evaporate water from the rock matrix below the repository. This warm moist air is convected upward to where it cools above the repository, generating condensate that drains down fractures back toward the repository and/or is imbibed by the matrix, causing a saturation buildup above the repository. Because water removed below the repository may be replenished by water imbibed from the SZ, this process can result in a net buildup of liquid water in the UZ. For sufficiently large $k_{\mathrm{b}}$, mountain-scale, buoyant, vapor flow can dominate moisture movement on the order of $100,000 \mathrm{yr}$ (see Fig. 5-5). The analyses indicate that if $k_{\mathrm{b}}$ is sufficiently large (greater than 10 darcy) and well connected over a sufficiently large volume, then the fluxes are large enough to alter the saturation distribution for thousands of years - well beyond the thermal period. This indicates that the magnitude would be greater than the natural percolation flux. 

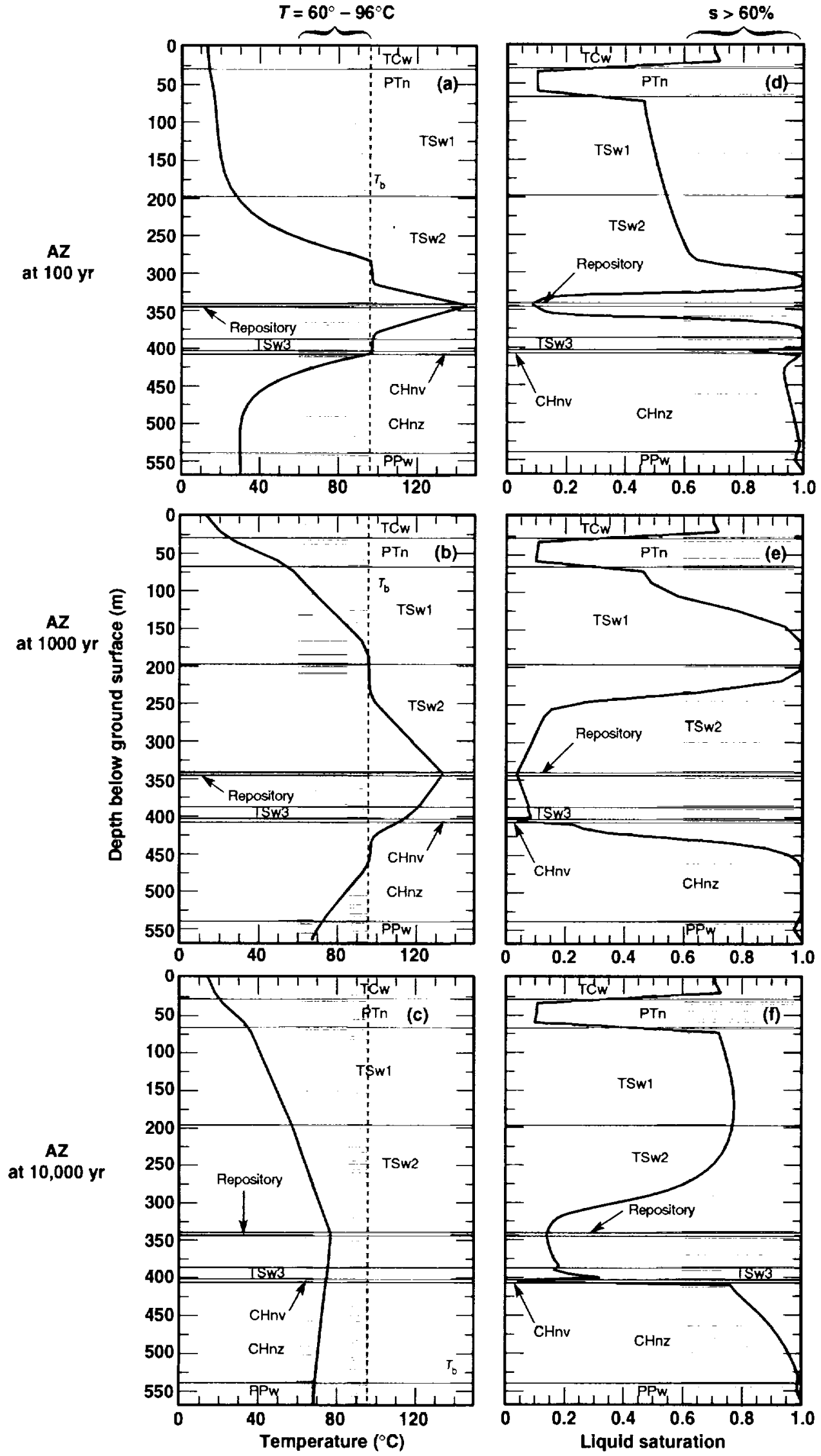

Figure 5-6. 
Under sub-boiling conditions, this phenomenon always occurs and is significant unless the $k_{\mathrm{b}}$ is very small. Under boiling conditions, steam generation causes a gas pressure buildup that can dominate the buoyancy forces, thereby suppressing large-scale buoyant convection cells.

Figure 5-7. Illustration of model calculations of repository-heat-driven vapor and condensate flow. Buoyant vapor flow occurring on the (a) near-repository or (b) mountain scale moves moisture from below to above the repository. (c) Zones of contrasting bulk permeability result in gas-phase pressure differentials that drive vapor flow into a hypothetical high-bulk-permeability zone, where it condenses and drains, possibly causing persistent two-phase refluxing (heat pipes) near WPs.

Figure 5-8 shows the duration of the boiling period, $t_{\mathrm{bp}}$, as a function of the percentage of the repository included within the calculations and bulk permeability for the 83.4-MTU/acre case. The influence of edge cooling is evident. Mountain-scale, buoyant, gas-phase convection begins to significantly reduce repository temperatures for $k_{\mathrm{b}}>1$ darcy. For $k_{\mathrm{b}} \leq 1$ darcy, duration of boiling is less sensitive to $k_{\mathrm{b}}$ as illustrated by the similar durations for 1 darcy and for 280 millidarcy ( 0.28 darcy).

Figure 5-8. Duration of boiling period versus percentage of repository area enclosed, for different bulk permeabilities.

For $k_{\mathrm{b}} \geq 10$ darcy, a very early peak in the net buildup of liquid water $\Delta V$ occurs at 500 to $800 \mathrm{yr}$ Fig. 5-9(c-e), coinciding with the maximum extent of boiling conditions. After the initial peak, $\Delta V$ declines for the high- $k_{\mathrm{b}}$ cases, with a trough occurring at $3000 \mathrm{yr}$, coinciding with the maximum vertical extent of dryout. The trough is less pronounced as $\Delta V$ stays well above zero. After the trough occurs, the increase in $\Delta V$ resumes until a second peak in $\Delta V$ occurs at around 20,000 to $30,000 \mathrm{yr}$.

Figure 5-9. Net buildup of liquid water above the repository vs time for an AML of 83.4 MTU/acre and $k_{\mathrm{b}}$ values of (a) 280 millidarcy, (b) 1, (c) 10, (d) 40 , and (e) 84 darcy.

If the large-scale connected $k_{\mathrm{b}}$ is small enough, mountain-scale, buoyant, gas-phase convection does not result in a liquid water buildup above the repository. For intermediate $k_{\mathrm{b}}\left(k_{\mathrm{b}}<1-10\right.$ darcy), for which buoyant gas-phase convection does not dominate vapor flow, the cumulative effects of vapor flow and condensate buildup depend on the magnitude of boiling effects.

It is likely that the $k_{\mathrm{b}}$ distribution at Yucca Mountain will be highly variable. Some of that variability will be random, while some may be correlated with discrete hydrological features such as fault zones or hydrostratigraphic units like the nonwelded vitric tuff units (PTn). If the $k_{\mathrm{b}}$ distribution spans a significant fraction of the range shown in Fig. 5-10 (including regions in which $k_{\mathrm{b}}>10$ darcy), then mountain-scale hydrothermal behavior will be more variable for low-to-intermediate AMLs than for high AMLs. If the $k_{\mathrm{b}}$ distribution only spans the lower end of the $k_{\mathrm{b}}$ range $\left(k_{\mathrm{b}}<1\right.$ darcy), then mountain-scale hydrothermal behavior will be less variable for all AMLs. The ECM cannot represent nonequilibrium fracture-matrix flow. It underpredicts the condensate drainage flux and, consequently, overpredicts $\Delta V_{1}$.

Figure 5-10. Maximum net buildup of liquid water above the repository as a function of bulk permeability for an AML of 83.4 MTU/acre.

5.2.2.2 Heat-Pipe Behavior. Refluxing, or the heat-pipe effect, is important to consider because it can affect coupled T-H-M-C processes (that may alter flow and transport properties) in two ways. First, refluxing maintains local temperatures near the boiling point, making it more difficult to dry the rock out. Consequently, the liquid saturation and relative humidity $R H$ remain high, increasing the likelihood of 



(b)

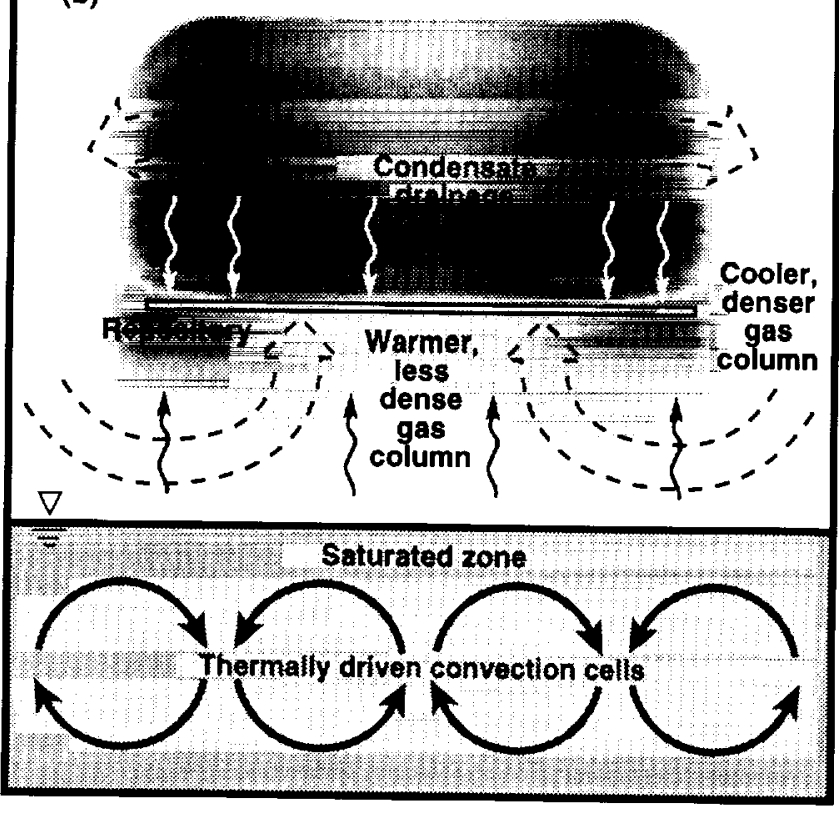

Figure 5-7. 


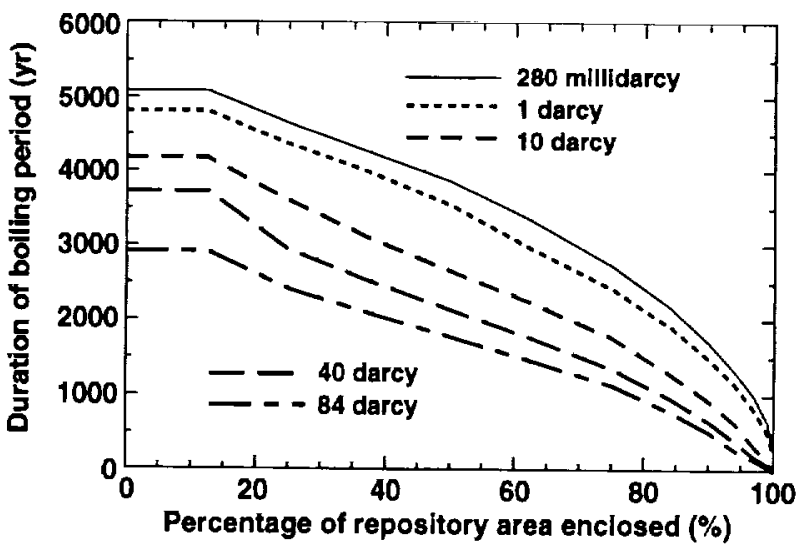

Figure 5-8. 


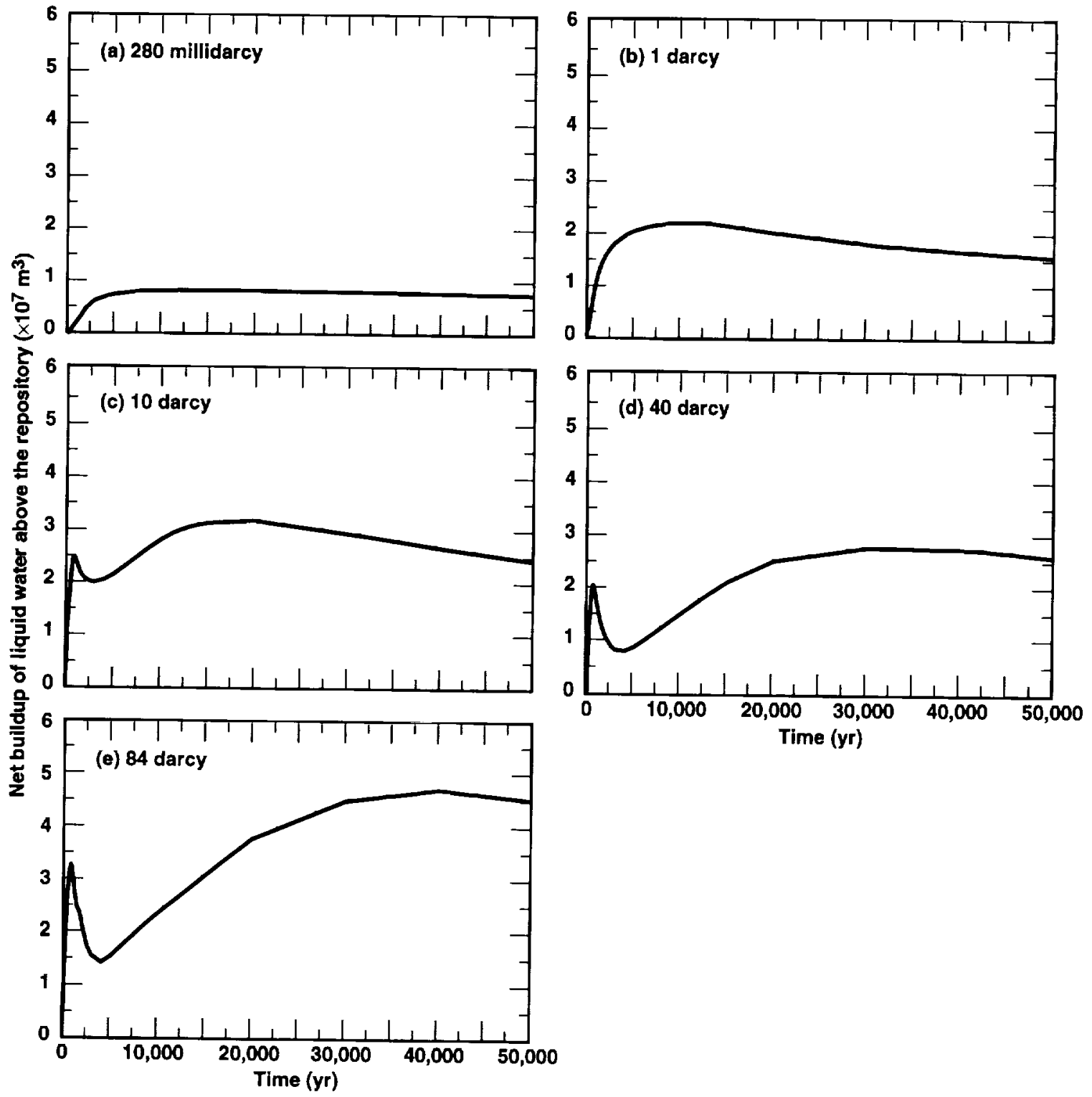

Figure 5-9. 


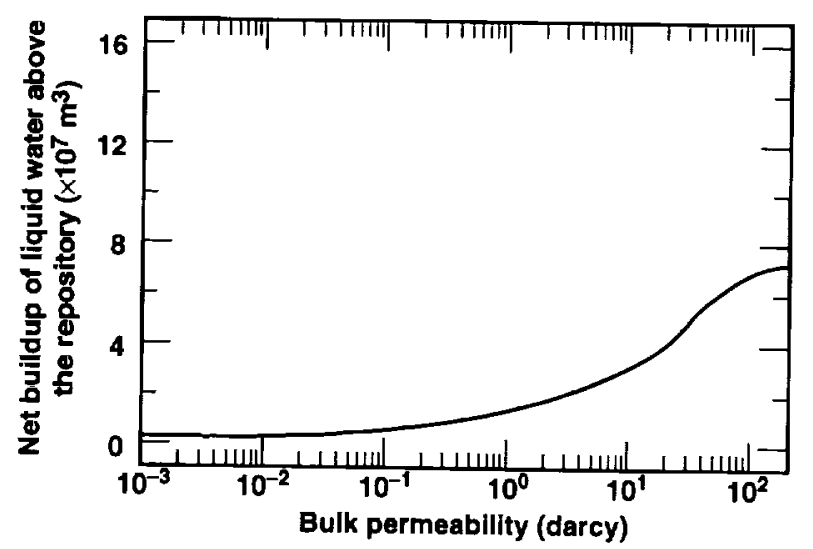

Figure 5-10. 
coupled processes, specifically rock-water interactions. Second, refluxing can generate a very high liquidphase flux in fractures, which can result in significant dissolution and precipitation of minerals along the fracture walls.

The magnitude and duration of refluxing depend on four factors.

- First, there must be a fracture or set of fractures that allow vapor from boiling to move above the boiling zone Ithe classical heat pipe involving porous media will not develop at YM because the $K_{\text {matrix }}$ is so small that 1 ) flow will preferentially occur in fractures, 2) the time scale for flow through the matrix would exceed that of the boiling process, and 3) imbibition rates are too low.] Therefore, saturation-gradient-induced flow that would be required for flow through the boiling zone, except as driven by gravity, would not allow for development of a heat pipe. This report uses the term gravity-driven heat pipe to make this distinction. Thus, the only potential heat-pipe zone is above the boiling zone.

- Second, $k_{\mathrm{b}}$ in the nominally fractured zone must be large enough not to significantly throttle the rate of vapor generation due to boiling (or due to evaporation under sub-boiling conditions).

- Third, a large contrast in $k_{\mathrm{b}}$ between the high- and nominal- $k_{\mathrm{b}}$ zones results in a gas-phase pressure differential between these zones that preferentially drives vapor flow into the high- $k_{b}$ zone [Fig. 5-7(c)]. This is based on the observation that the rock mass contains ubiquitous fractures that are open to vapor flow, but would not support significant liquid flow (Chesnut, 1992). It has been observed that the spacing of the more permeable fractures is greater than that of the smaller and tighter fractures. Thus, it would be necessary for a fracture or fractures to exist that would allow vapor to preferentially collect and flow in them so that condensate could return as fracture flow.

- Fourth, there must be sufficient spacing between the high- $k_{b}$ zones to drive enough water vapor into these zones to result in the local condensate drainage flux being substantially greater than the mean condensate flux. Effectively, the high- $k_{\mathrm{b}}$ zones are competing for a finite quantity of vapor flow and condensate generation. Consequently, there is a trade-off between the duration of refluxing and the number of locations where it can occur in the repository. If there are too many such zones, there will be insufficient condensate focusing to cause persistent refluxing at the repository horizon. The degree of focusing necessary to cause persistent refluxing limits the number of locations where it can occur. Therefore, it is unlikely that refluxing can dominate the overall thermal behavior in the repository (or throughout the AZ). See Volume II, Sec. 10.1.2.5 for a more detailed discussion.

Heat pipes farther away from the WP heat sources are more likely to persist longer than heat pipes that are closer. The reason is that close in, the heat is more influenced by single WP; farther out, the heat is contributed from many WPs. Similarly, heat pipes closer to cold WPs in a thermal design in which the WPs are thermally isolated from one another (such as in the ACD design) will be more persistent than those close to hot WPs. This variability in the likelihood or duration of heat pipes could lead to a highly heterogeneous distribution of decay-heat-driven alteration in the near field and AZ. At $200 \mathrm{yr}$, the manifestation of focused vapor and condensate flow on the dryout zone is no longer evident, and the two design cases have nearly identical dryout zones (see Fig. 10.1.2.5.1, Volume II).

Because heat pipes are manifestations of heterogeneities, they are influenced by the repository design. Figure 5-11 shows the total flux calculated to be present in the zone $51 \mathrm{~m}$ above the repository where heat pipes can exist. Heat pipes are more likely to exist at early times, as shown in this figure by the shortduration peak in total fluid flux that occurs at about $100 \mathrm{yr}$. Furthermore, the volume of liquid flux for the ACD case is approximately $103 \mathrm{~mm} / \mathrm{yr}$, whereas for the LL case, it is approximately $57 \mathrm{~mm} / \mathrm{yr}$. Thus, there is a potential for significant fluid flux to be present in the reflux zone. Figure 5-12 shows the impact of percolation flux for the LL case. There is very little impact on the peak fluxes at $100 \mathrm{yr}$. Beyond about $200 \mathrm{yr}$, except for zero ambient percolation flux, there is no real difference between total flux for percolation fluxes from 0.5 to $5.0 \mathrm{~mm} / \mathrm{yr}$ other than the magnitude of the percolation flux itself. 
Figure 5-11. Liquid-phase flux $51 \mathrm{~m}$ directly above the emplacement drift for an AML of 83.4 MTU/acre. Curves are shown for Hanford DHLW waste packages.

Figure 5-12. (a) Liquid-phase flux $51 \mathrm{~m}$ above the repository horizon and (b) relative humidity in rock at the upper drift wall for the LL design with an AML of 83.4 MTU/acre. Curves are shown for conditions above Hanford DHLW waste packages.

Based on experience with geothermal reservoirs, some have suggested that heat-pipe zones, spaced every $100 \mathrm{~m}$, have the potential of convecting enough heat away from the repository to prevent its temperature from rising above the boiling point. However, we found for a wide range of AMLs, that the heat-pipe zone could not prevent the temperature exceeding the boiling point beyond about $2.8 \mathrm{~m}$ from the heat pipe. Convection-dominated heat flow occurs in the heat-pipe zone, whereas in the neighboring rock, heat flow primarily occurs as heat conduction. Heat must be conducted from the heat sources (the WPs) to the heat-pipe zone for that zone to significantly influence repository temperatures. Heat cannot be conducted in relatively low-thermal-conductivity rock unless a significant temperature gradient is established. Such a thermal gradient would cause temperatures away from the heat-pipe zone to be elevated above the boiling point.

\subsubsection{Influence of Water Vapor and Relative Humidity}

Coupled processes in the $\mathrm{AZ}$ do not require liquid water; they can also occur if water vapor is present. A measure of the availability of water is the relative humidity in the rock mass. As noted in Section 10.2, under ambient conditions, the gas phase in fractures consists of about $98.5 \%$ air and $1.5 \%$ water vapor. The mole fraction $n_{v}$ of water vapor under conditions of local thermodynamic equilibrium within the rock is a function of liquid saturation $S_{l}$, absolute temperature, $T$, and gas-phase pressure, $P_{g}$. The mole fraction of water vapor is considerably greater at the repository in response to higher temperatures there.

As temperatures rise in the repository, the equilibrium amount of water vapor in the gas phase increases because of the increase in $\mathrm{P}_{\text {sat }}(T)$. As temperatures reach the boiling point of water, $P_{\text {sat }}$ approaches $P_{\mathrm{g}}$ and the mole fraction of water vapor approaches unity (i.e., the gas phase becomes $100 \%$ water vapor). Gas-phase advection (advective transport of water vapor will occur as long as steam is generated) is likely to be the dominant mechanism transporting water vapor from the boiling zone to the condensation zone except for a rock mass where $k_{\mathrm{b}}$ is sufficiently small $k_{\mathrm{b}}<1-10$ millidarcy) to substantially throttle gas-phase advection and the rate of boiling. Beyond the condensation zone, vapor diffusion is the dominant mechanism of vapor movement except where $k_{\mathrm{b}}$ is sufficiently large $\left(k_{\mathrm{b}}>1-10\right.$ darcy) for buoyant gas-phase convection to dominate. Because temperatures in the vicinity of the condensation zone are close to the boiling point, the water vapor mole fraction is nearly unity, whereas beyond the condensation zone, the temperatures are cooler and the mole fractions are much less (approximately $2 \%$ at ambient conditions). This gradient in mole fraction leads to diffusive fluxes that transport water vapor away from the condensation zone. Diffusive vapor fluxes can dominate over convective vapor fluxes around the repository if the vapor generation rate is very low or if temperatures are close to, but below, the boiling point.

As the repository heat generation decays, water vapor continues to diffuse away from the repository because of the higher temperatures there. This diffusion of water vapor contributes to latent heat transport. In general, water vapor diffuses away from the repository until repository temperatures have decreased to the point that the temperature effect (that drives water vapor away from the repository) can no longer overcompensate for the vapor-pressure lowering effect. This "vapor-pressure lowering" effect is significant only at $S_{1}<20-30 \%$. Consequently, vapor diffusion will only significantly contribute to rewetting the dryout zone for $S_{1}<20-30 \%$. For $S_{1}>20-30 \%$, rewetting of the dryout zone will be 


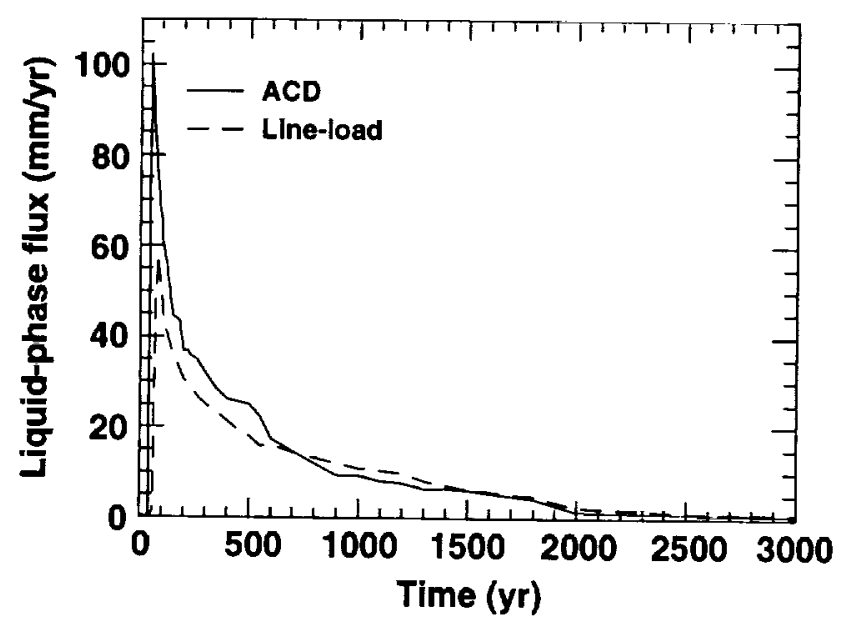

Figure 5-11 

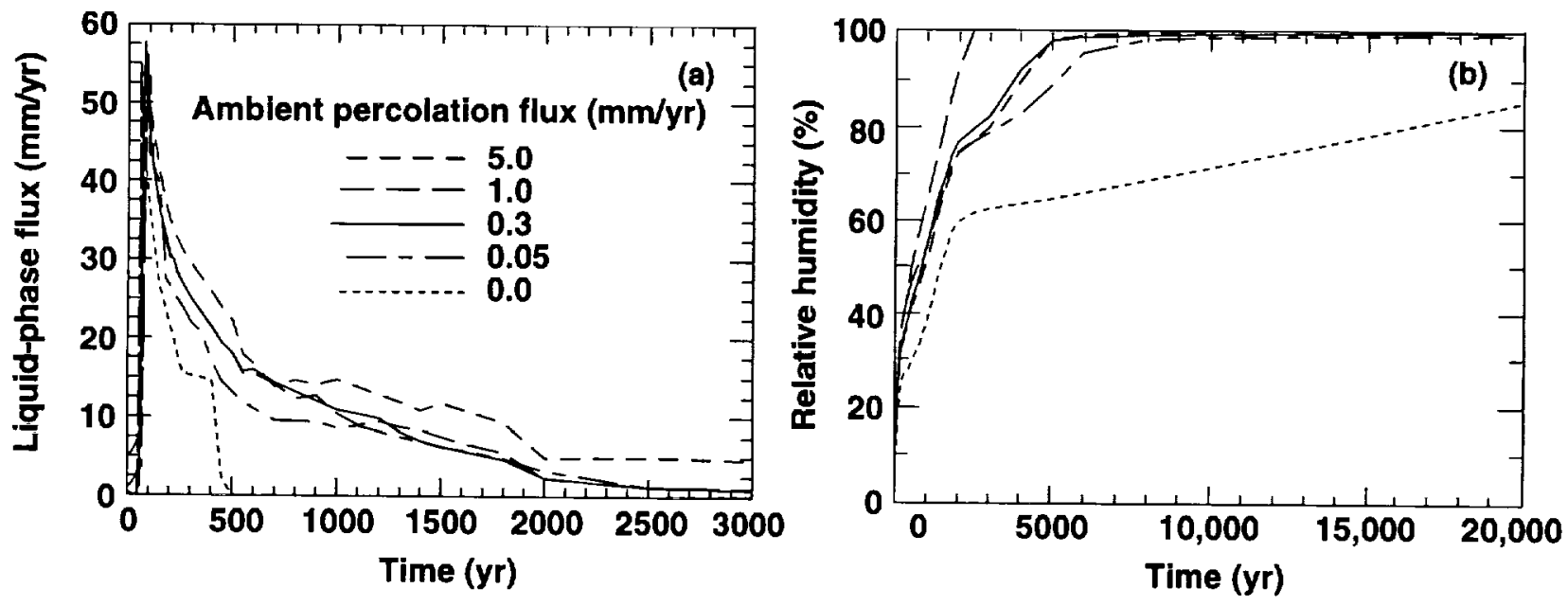

Figure 5-12 
dominated by liquid-phase advection driven by matric potential gradients and gravity. The length of time during which diffusive vapor transport dominates rewetting behavior depends on:

- How dry the dryout zone becomes.

- The range of $S_{1}$ that is associated with high matric potential.

- How quickly repository rock temperatures decline.

The longer that the dryout zone remains dry, the higher the value of $S_{1}$ limit for which vapor-pressure lowering dominates rewetting behavior. The faster repository temperatures decrease while still in the high-matric-potential (i.e., dry) regime, the longer the duration of significant gas-phase diffusion of water vapor back to the dryout zone.

\subsubsection{Overburden Thickness}

For a discussion of the effects of overburden, refer to Sec. 10.1.4 of Volume II.

\subsection{Thermal-Hydrology in the Saturated Zone}

For $t>1000 \mathrm{yr}$ (after repository temperatures have peaked), the saturated zone (SZ) begins to heat up significantly, as shown in Fig. 5-13. Consequently, the duration of boiling $t_{\mathrm{bp}}$ substantially increases, particularly for higher AMLs $\left(t_{\mathrm{bp}}\right.$ " $\left.1000 \mathrm{yr}\right)$. More importantly for AZ considerations, the temperatures are sufficiently elevated above ambient that issues of rock-water interactions arise. As noted, the duration of the elevated temperatures is long.

Because water has been present for long periods, and the water mobilized by emplacement will not necessarily elevate the water table, the rock-water interactions that have been occurring in the past represent those that will occur in the future. Heat affects the kinetics, not the reactions themselves, at the temperatures shown in Fig. 5-13. To date, the analyses of coupling in the $A Z$ have not considered the saturated zone to any real extent. Preliminary results indicate that, in general, changes are small, but there could be significant changes (up to $30 \%$ ) in porosity in some units. Analyses of $A Z$ effects in the saturated zone will be incorporated in subsequent revisions of this report.

Figure 5-13. Temperature history at locations below the center of the repository (a) at the water table and (b) $250 \mathrm{~m}$ below the water table. AML $=83.4 \mathrm{MTU} / \mathrm{acre}$.

Although, after $1000 \mathrm{yr}$, convection no longer dominates heat flow in the SZ, heat flow continues to dominate fluid flow. This dominant influence of decay-heat-driven flow was found to occur for all AMLs investigated. As the SZ temperatures (below the repository footprint) rise, the accompanying decrease in mass density results in significant upward component of flow from considerable depth, generating buoyant convection cells. This, of course, depends on the hydrologic continuity with depth. If the strata prevent continuity, then convection will not occur to the same depth or extent, and smaller convection cells will result.

Decay-heat-driven convection cells in the SZ require tens of thousands of years to fully develop. As the thermal pulse from the repository propagates both vertically and radially into the $S Z$, the region over which decay-heat-driven convection occurs continues to expand during at least the first 20,000 yr (Fig. 514). As this region expands, additional parallel convection cells are added to the convective system. After $1000 \mathrm{yr}$, multiple (two distinct) convection cells (one on each side of the symmetry axis) have developed (in cross section), extending radially $\sim 2$ to $3 \mathrm{~km}$ from the repository center. After $5000 \mathrm{yr}$, the radial extent of repository-heat-driven convection is $\sim 5 \mathrm{~km}$ [Fig. 5-14(a)]. After 10,000 yr, the radial extent of the convection cells is $\sim 8$ to $10 \mathrm{~km}$. After $20,000 \mathrm{yr}$, the radial extent of the convection cells exceeds $10 \mathrm{~km}$ 




Figure 5-13. 
from the repository center [Fig. 5-14(b)]. Because the matrix permeability of the SZ is presumably quite small, these large-scale, buoyant convection cells require large-scale connectivity within the fracture system. Because the temperatures will be elevated, significant alteration is possible through rock-water interactions. This could impact the connectivity and interrupt convection. In addition, the convection shown is based on uniform hydrologic properties with depth below the water table. In reality, the YM system is dominated by strata with greatly differing hydrologic properties, including strata-determined fracture patterns and extent. Therefore, the more likely case will be a series of smaller convection cells. However, the temperature increases will be significant, and convection will not dominate heat flow in the SZ, thus the temperatures shown in Fig. 5-14 would be representative regardless of the convection patterns.

Figure 5-14. Contours of temperature rise above ambient and velocity vectors for liquid-phase flow in fractures in the SZ for AML = 77.4 MTU/acre, 30-yr-old SNF, 1118-acre repository area, and ambient percolation flux $=0 \mathrm{~mm} / \mathrm{yr}$ at (a) 5000 and (b) $20,000 \mathrm{yr}$. Temperature contour interval is $5^{\circ} \mathrm{C}$. Liquidphase velocity vectors are scaled logarithmically from 0.03 to $1600 \mathrm{~m} / \mathrm{yr}$. Larger arrows in (a) denote the convection cells described in text.

\subsection{Altered Zone Geochemistry and Mineralogy}

The purpose of the research summarized in this section is to establish the accuracy of long-term simulations of geochemical processes expected to take place in the AZ. The approach has been to evaluate the parameters that influence uncertainty in simulations, which are primarily error in reaction rate constants and thermodynamic properties. This has been done by conducting simulations using the extreme values for rates of dissolution of certain minerals, by comparing field- and laboratory-based measurements of precipitation rates for silica polymorphs, and by conducting plug flow reactor experiments and comparing the results with simulations using the reactive transport simulator GIMRT.

The results of the rate studies indicate that the uncertainty in dissolution kinetics will have a more significant affect on numerical simulation results than will the much faster precipitation rates. This conclusion assumes that nucleation effects are not rate limiting.

Given knowledge of the uncertainty in reaction rate constants, it is then possible to conduct simulations that are constrained to use rates that fall within these uncertainty envelopes. The results of this effort demonstrate an excellent correspondence between experiments and simulations, indicating that the conceptual models of reaction process are accurate.

On this basis, it is then possible to develop with some confidence first-generation descriptions of the long-term mineralogical evolution of the AZ. The accuracy of these results is directly dependent on numerical representation of the thermal-hydrological regime. Further refinements of these simulations will be developed as the ability to couple thermal-hydrological models with reactive transport models improves.

Geochemical processes that will occur as a result of emplacement of waste will depend on the heat transferred into the rock surrounding the emplacement drifts and the hydrological regime associated with that heat. As shown in Fig. 5-15, elevated temperatures couple (see yellow arrows) to mineralogy and solid material conditions by several geochemical processes. The processes include dehydration, rockwater and material interactions, and changes in the volume and chemistry of water that is available for geochemical reactions. The consequences of geochemical effects will depend on the rate of temperature change, the maximum temperature reached, and the flux of water and vapor through the rock. For any given emplacement scenario, the rate at which temperature changes occur depends, in general, on the distance from the heat source. The further the distance, the slower the heating rate. Such temperature behavior has led to the conceptual model in which NFE effects are distinguished from AZ effects by whether dominant processes are kinetic or equilibrium reactions. 



Figure 5-14. 
Figure 5-15. Matrix of coupled geochemical and mineralogical processes.

\subsubsection{Summary of Recent Studies}

This section summarizes four studies that considered the geochemical and mineralogical evolution of the AZ. More detailed information is provided at the end of the summary.

- Hydrothermal alteration of vitric tuff. Vitric material typical of the Tsw3 unit and the vitric Calico Hills lithology, as a function of time, is sensitive to temperature (as expected from well-established models of reaction kinetics), and to the extent of prior alteration.

- Amorphous silica precipitation. Rate measurements show that the field-based rates are 10 to 300 times faster than those measured in the laboratory. Observations suggest that these differences are sensitive to temperature, and may be influenced by the presence of other chemical species in solution. The precipitation mechanism in the field may be controlled by surface defects.

- Preliminary bounds on the water composition and secondary mineral development. This study considered the effect of temperature and uncertainty in reaction kinetics to place limits on fluid composition for devitrified and vitric tuffs interacting with a J-13-like water over a range of temperatures. The simulations assumed that fluid was in equilibrium with atmospheric gases. The results indicate that water compositions remain mildly oxidizing and slightly to mildly alkaline (pH between 7.5 and 8.8 ) for most conditions. The exception was that in which very large water volumes interacted with small volumes of vitric material. In that case, the buffering effect of atmospheric gases was overwhelmed, and the solution became acidic. This may be the case for large volumes of condensate draining; however, the only way for condensate to drain is by fast fracture flow. Thus, the large volumes of water relative to rock volumes would not remain within the UZ and could only exist in SZ or ponded areas if imbibed into the matrix. The fracture volume is too small relative to the rock. However, on a local basis, the water volume in fractures versus the fracture coating volume might be considered high. Secondary minerals that formed were sensitive to the extent of reaction and temperature. In most cases, zeolites and clays were formed, with minor to trace amounts of other minerals. Uncertainty in the time at which secondary minerals form can be as great as hundreds to thousands of years.

- Reactive transport simulations. Porosity modification was monitored during dissolution and precipitation of a wide range of silicates along a flow path similar to that expected for water condensed from steam generated in the NFE. The results show that porosity may more than double in devitrified and welded tuff, due to the dissolution of cristobalite in the regions immediately adjacent to the condensation front. As these waters migrate along and across isotherms, the dissolved constituents eventually precipitate as complex silicates, reducing porosity, and forming altered regions composed of zeolites, clays, and hydrated alumino-silicates. The complex coupling of fluid flow and reactive chemical transport demonstrates that large changes in bulk rock hydrological properties may occur within a few hundred years of repository operation. As was noted in Section 5.2.2.1 and on Fig. 5-6, the condensation zone may remain in place for thousands of years, therefore this change in hydrologic properties may be quite significant.

These results are expected to be the foundation upon which refined estimates of mineral facies would be developed for specific repository scenarios of waste emplacement strategies, infiltration fluxes, and rock properties. These scenarios have yet to be developed. Future work will focus on developing these mineralogical and chemical scenarios, and on reducing the uncertainties in key thermodynamic and kinetic data to better bound the behavior of the repository.

\subsubsection{Hydrothermal Alteration of Vitric Tuff}

Alteration of the basal vitrophyre of the Topopah Spring tuff (Tsw3 unit) represents a potentially profound modification of the lithologic units that compose the potential repository block at Yucca 


\begin{tabular}{|c|c|c|c|c|c|c|}
\hline Temperature & $\begin{array}{l}\text { - Vaporization } \\
\text { - Mobilization }\end{array}$ & $\begin{array}{l}\text { - Rock-water } \\
\text { interactions } \\
\text { - MM material } \\
\text { interactions } \\
\text { (kinetics) }\end{array}$ & $\begin{array}{c}\text { Thermodyn. } \\
\text { of vapor }\end{array}$ & $\begin{array}{l}\text { - Dehydration } \\
\text { - Rock-water } \\
\text { interactions } \\
\text { (kinetics) }\end{array}$ & $\begin{array}{l}\text { - Dehydration } \\
\text { - Rock-water } \\
\text { interactions } \\
\text { - Material } \\
\text { (kinetics) }\end{array}$ & $\begin{array}{l}\text { - Stress } \\
\text { changes } \\
\text { - Coefficient } \\
\text { impacts }\end{array}$ \\
\hline \multirow[t]{3}{*}{$\begin{array}{l}\text { - Latent heat } \\
\text { - Heat pipes }\end{array}$} & $\begin{array}{l}\text { Moisture } \\
\text { conditions }\end{array}$ & $\begin{array}{l}\text { Volumetrics } \\
\text { - Water } \\
\text { - Rock } \\
\text { - Materials }\end{array}$ & & & $\begin{array}{l}\text { 1. Volumetrics } \\
\text {-water } \\
\text {-rock } \\
\text { Contact } \\
\text { modes }\end{array}$ & $\begin{array}{l}\text { Water } \\
\text { contribution } \\
\text { to crack } \\
\text { growth }\end{array}$ \\
\hline & & $\begin{array}{l}\text { Water } \\
\text { chemistry }\end{array}$ & $\begin{array}{c}\text { Vapor } \\
\text { partial } \\
\text { pressure }\end{array}$ & & $\begin{array}{l}\text { - Reaction } \\
\text { thermodyn. } \\
\text { - Solubility } \\
\text { - Precipitation } \\
\text { - Carbonation }\end{array}$ & \\
\hline & & & $\begin{array}{l}\text { Relative } \\
\text { humidity } \\
\text { conditions }\end{array}$ & $\begin{array}{c}\text { Vapor/rock } \\
\text { interactions }\end{array}$ & \multicolumn{2}{|l|}{$\begin{array}{l}\text { Vapor/rock' } \\
\text { solid } \\
\text { interātions }\end{array}$} \\
\hline $\begin{array}{c}\text { Altered } \\
\text { flow } \\
\text { paths }\end{array}$ & $\begin{array}{c}\text { Altered } \\
\text { flow } \\
\text { paths }\end{array}$ & & $\begin{array}{l}\text { Changed } \\
\text { flow } \\
\text { conditions }\end{array}$ & $\begin{array}{l}\text { Hydrologic } \\
\text { properties }\end{array}$ & $\begin{array}{l}\text { Water } \\
\text { contact }\end{array}$ & $\begin{array}{l}\text { - Healing of } \\
\text { fractures } \\
\text { - Changes } \\
\text { water avail. } \\
\text { for cracking }\end{array}$ \\
\hline \multirow[t]{2}{*}{$\begin{array}{l}\text { - Thermal } \\
\text { conductivity } \\
\text { changes } \\
\text { - Heat } \\
\text { consumption } \\
\text { rolease in } \\
\text { chemical } \\
\text { reactions }\end{array}$} & $\begin{array}{c}\text { Consumpt } / \\
\text { release } \mathrm{H}_{2} \mathrm{O} \\
\text { (chemical } \\
\text { reactions) }\end{array}$ & \multirow[t]{2}{*}{$\begin{array}{l}\text { - Altered } \\
\text { minerals } \\
\text { - Rock-water } \\
\text { interactions }\end{array}$} & $\begin{array}{l}\text { Partial press. } \\
\text { (salts) }\end{array}$ & $\begin{array}{l}\text { - Fracture/pore } \\
\text { plugging } \\
\text { - Fracture } \\
\text { healing } \\
\text { - Colloid } \\
\text { transport }\end{array}$ & $\begin{array}{c}\text { Mineral and } \\
\text { solid material } \\
\text { (changes) }\end{array}$ & $\begin{array}{l}\text { Volume } \\
\text { changes } \\
\text { (phase } \\
\text { transform } \\
\text { and mineral } \\
\text { changes) }\end{array}$ \\
\hline & & & & $\begin{array}{l}\text { - Closing/ } \\
\text { opening } \\
\text { fractures } \\
\text { - Microcracks } \\
\text { - Coalescence } \\
\text { flow path }\end{array}$ & \begin{tabular}{|l|} 
- Stress \\
impacts \\
- Mineral \\
phase \\
- Microcracks \\
(new surfaces)
\end{tabular} & $\begin{array}{l}\text { Mechanical } \\
\text { Conditions } \\
\text { (changes) }\end{array}$ \\
\hline
\end{tabular}

Figure 5-15 
Mountain. The results of earlier hydrothermal alteration experiments, in which the devitrified (repository-equivalent) Tpt was reacted with well J-13 water at $150^{\circ}$ and $250^{\circ} \mathrm{C}$, showed that the primary alteration products were the Ca-rich, mordenite-type zeolite, dachiardite, and mordenite itself (Knauss et al., 1987). Aqueous $\mathrm{SiO}_{2}$ activity was controlled by cristobalite saturation. Fluid chemistry was in accord with the production of these zeolites. In contrast, results of earlier hydrothermal alteration experiments, in which the vitric airfall/ashflow at the base of the Tpt was reacted with well J-13 water at $250^{\circ} \mathrm{C}$, showed production of the zeolite clinoptilolite, exclusively (Knauss, 1987).

Knauss continued the series of runs using vitric airfall/ashflow from the base of the Tpt and found that even after 6 months at $150^{\circ} \mathrm{C}$, the $\mathrm{SiO}_{2}$ activity remained below amorphous silica saturation, and no zeolites precipitated. However, at $350^{\circ} \mathrm{C}$, amorphous silica saturation was quickly reached, and the glass was completely consumed by the end of the run. Because the temperatures generated by waste disposal are well below $250^{\circ} \mathrm{C}$, this would imply that zeolites and clays would be formed at the base of the Tpt, but their exact compositions remain to be established.

Hydrothermal alteration of Tpt vitrophyre in well J-13 water was also studied(Knauss, 1987). Although compositionally identical to the vitric basal airfall/ashflow material, the vitrophyre has a much smaller specific surface area. At $250^{\circ} \mathrm{C}$, it is clear from SEM/EMP analyses that early in the run the dominant product was a clay, but as the run progressed, the zeolite clinoptilolite became the major product. Given sufficient time and reaction progress, one would expect the vitrophyre to result in mostly zeolite alteration.

Knauss also studied hydrothermal alteration of naturally zeolitized Tpt in well J-13 water at $90^{\circ}$ and $150^{\circ}$. No new run products were identified in either run, and there was no obvious evidence of dissolution.

Preliminary results from the three experiments to study the hydrothermal alteration of vitric Calico Hills tuff (Tchnv) at $90^{\circ}, 150^{\circ}$, and $250^{\circ} \mathrm{C}$ contrast with those from the other experiments. Whereas the basal airfall/ashflow and vitrophyric Tpt samples were largely fresh (unaltered) glass, the vitric Tch material contained a significant amount of smectite. The smectite was observed to coat the matrix shards and pumice lapilli. These results demonstrate that the presence of secondary minerals in the vitric tuffs may accelerate, relative to rates of formation in "pristine" vitric materials, the formation of a new generation of minerals under repository conditions. By implication, this leads to the conclusion that alteration of the underlying vitric material will not be rate limited by nucleation effects or alteration minerals.

\subsubsection{Amorphous Silica Precipitation}

Dissolution of silica in response to water movement at elevated temperatures and subsequent precipitation of silica on cooling may affect local porosity and permeability. Changes in porosity and permeability will, in turn, affect flow pathways, imbibition, and heat transfer. A study was conducted to measure rates of precipitation in natural and laboratory settings as the first stage of an effort to place bounds on kinetic effects over a range of humidities (Carroll et al., 1996, in Sec. 10.4.2, Vol. II; Johnson and Glassley, 1996, in Sec. 10.4.4, Vol. II).

This study confirmed the need of complementary laboratory and field studies to determine the factors that control mineral-water interactions in tuff. Amorphous silica precipitation rates appear to be controlled by distinct mechanisms in laboratory versus field studies. Rates from a field study are 10 to 300 times higher than those predicted from laboratory experiments. The deviation in rates increases as temperature decreases and solution composition increases, and may be influenced by the presence of other chemical species in solution. The precipitation mechanism in the field may be controlled by surface defects, such as dislocation or impurities.

These results indicate that laboratory measurements of precipitation rates may significantly underestimate the rates at which alteration minerals will form in the natural system when perturbed by 
repository heat. Mineral precipitation rates may be considered instantaneous for modeling purposes, and the primary rate-limiting step in alteration processes will be the dissolution kinetics of mineral phases.

\subsubsection{Bounds on Water Composition and Secondary Mineral Development in the AZ}

Heat-driven evaporation, boiling, and condensation processes will lead to movement of water vapor away from the repository, resulting in increased saturation of some rocks within some parts of the repository block (Nitao, 1988; Buscheck and Nitao, 1992, 1993). The saturation may approach $100 \%$ under some operation scenarios after waste is emplaced. During cool down, or as a result of fracture flow or dehydration of hydrous minerals, it is possible that liquid water may retum to or enter the NFE, or may affect rock units bounding the repository horizon. Most of the minerals currently present in the rock making up the potential repository horizon are not in thermodynamic equilibrium with water at elevated temperatures, nor is the glassy material preserved within the PTn or the TSw3 units. As a result, water will interact with existing minerals and glass, causing new minerals to form, existing minerals to change their compositions or dissolve, and modifying the water chemistry in the process.

The extent to which reactions will progress in the near-field and $A Z$ systems may be limited by water availability. In such cases, the natural systems will only progress part way along the reaction paths suggested by the modeling described here. In these studies, the initial water composition reacting with the rock materials was assumed to be that of J-13 water. The composition used was the average composition reported in Harrar et al. (1990).

5.4.4.1 Results. The water compositions and secondary mineralogies obtained at steady-state conditions, at a given temperature, for the tuffs are constrained by the fixed composition of the starting material, and the solubilities of the starting phases. For vitric material, however, dissolution is treated as though it is congruent; hence, the amount of material dissolved (or, in other words, the extent of reaction progress) will determine the mineralogical products and water chemistry. In this case, therefore, a steadystate composition will not be achieved, except under extreme conditions in which very high absolute amounts of glass are dissolved.

The mineral suites described here must be considered representative "facies" of the assemblage of minerals that may form, and not absolute descriptions of the specific identities of minerals that will be present. In particular, the occurrence of zeolites, such as mesolite, clinoptilolite, and stilbite, or the occurrence of muscovite in simulations must be taken to indicate that a zeolite(s) and a sheet silicate are expected to form, but the specific composition of those phases will depend on local effects that cannot be accounted for a priori.

Throughout reaction progress, saponite (a clay), carbonate, and fluorapatite are present at low abundances at all temperatures. These phases are joined by clays (celadonite and smectite), authigenic feldspar (microcline), and zeolites (clinoptilolite at low temperature, stilbite at $50^{\circ}$ and $75^{\circ} \mathrm{C}$, with mesolite present throughout the temperature range), relatively early in the reaction progress period, and they persist to steady-state conditions. The actual time of appearance of specific phases depends on temperature. At $40^{\circ} \mathrm{C}$, important secondary alumino-silicate phases do not appear until after approximately 100 days of reaction progress. At temperatures greater than $50^{\circ} \mathrm{C}$, important aluminosilicates appear within a few days. However, in all cases, steady-state conditions with relatively high abundances of secondary minerals are not approached until thousands of days have elapsed. In all cases, one of the last phases to appear is a silica polymorph (in this case, chalcedony), but it quickly becomes the most abundant secondary phase. At high temperatures $\left(90^{\circ} \mathrm{C}\right)$, garnet and tremolite appear in the secondary mineral assemblage. These phases probably would not be the stable phases that would form under these conditions, given evidence from metamorphic petrology in low-temperature systems. Their presence in the simulations attests to the limitations of the thermodynamic data currently available.

The initial water composition reflects equilibration of J-13 water at the temperature of the simulation. At all temperatures, this initial composition is moderately alkaline ( $\mathrm{pH}$ of $\sim 8.5$ ), oxidizing (Eh between 
580 and 680 millivolts), and has a low ionic strength ( $\sim 0.0028$ molal). Concentrations of the dissolved elements are low.

Water composition remains relatively constant at a given temperature, until reaction progress reaches approximately 100 days. At that point, the composition changes significantly due to formation of secondary mineral phases, and dissolution of significant quantities of the rock components. Calcium and magnesium are both largely removed from solution due to precipitation of carbonates and, to a lesser extent, a variety of silicates. Thus, as long as the system is changing and dynamic, we would not expect significant changes in secondary mineral phases; however, once conditions become stable (e.g., 50 yr after emplacement), it will only take a few years to experience significant changes.

$\mathrm{Na}, \mathrm{Si}$, and $\mathrm{Al}$ increase significantly, because the amount added to solution by dissolution of the solids is much greater than the amount removed by precipitation. Nevertheless, the final concentration reached for these elements is controlled by the solubilities of the major secondary phases. Silica, for example, is buffered at chalcedony saturation, at steady-state conditions. Therefore, in the AZ, where temperature and saturation remain relatively stable for long times, it is expected that silica will be in equilibrium with chalcedony saturation.

The redox state is effectively determined by the assumption that the solution is in equilibrium with atmospheric gases. Although this may not be the case within the drifts at early times, it is most likely to be the case in the AZ. Hence, total oxygen is assumed to be maintained at approximately $20 \%$ of the coexisting gas phase.

Variation in $\mathrm{pH}$ is strongly controlled by the fact that $\mathrm{CO}_{2}$ fugacity is fixed in these simulations. These results differ somewhat from those described in Sec. 3.4.1 of Volume II, where water evaporation was modeled. In the latter study, the effect of including rock interaction with the water was not considered. The $\mathrm{pH}$ remains relatively alkaline when $\mathrm{CO}_{2}$ is controlled by atmospheric gases. Results of the single heater test (SHT) indicate that within the active boiling regime, excess $\mathrm{CO}_{2}$ is generated by rock-water interactions. This would change the $\mathrm{pH}$ conclusions. However, it is unknown whether excess $\mathrm{CO}_{2}$ will be generated within the $\mathrm{AZ}$. That generated in the boiling zone could flow into the $\mathrm{AZ}$, but after the initial thermal perturbation, the excess $\mathrm{CO}_{2}$ should decrease.

The conservative elements $\mathrm{Cl}, \mathrm{F}, \mathrm{Li}$, and $\mathrm{P}$ showed no significant variation during reaction progress because they are not incorporated into any secondary phases that form in significant quantities.

For dissolution of relatively small volumes of glass, the secondary phases that form during reaction progress are similar to those formed in the tuffs (pyrolusite, clays, and zeolites), except for the respective amounts of secondary phases. These results are qualitatively consistent with the description of glass alteration (Levy, 1984a,b) in the vicinity of Yucca Mountain. The main exception is calcite, which persists to the end point of the calculations for all temperatures except $40^{\circ} \mathrm{C}$.

Dissolution of large volumes of glass rather quickly achieves a state in which the only secondary phases that are present are pyrolusite, chalcedony, and hematite. In none of the simulations with vitric material was muscovite or microcline present as reaction products at any temperature.

Water composition in simulations involving small degrees of glass dissolution reached end points that were nearly identical to those for the tuff-water system. The simulations involving large volumes of glass ultimately achieved much higher total concentrations of all elements except $\mathrm{Si}$, which dropped to very low values controlled by large volumes of precipitated chalcedony. In addition, at high degrees of glass dissolution, $\mathrm{pH}$ drops, reaching acidic values $(-3.8)$ in the low temperature simulations and slightly alkaline $(-7.8)$ at the $90^{\circ} \mathrm{C}$ simulation. This $\mathrm{pH}$ behavior primarily reflects the effects of temperature, the glass chemistry components, and the solubility of C-bearing aqueous species (e.g., $\mathrm{HCO}_{3}{ }^{-}$) and solids on $\mathrm{pH}$. In these simulations, total dissolved elemental carbon decreased by three orders of magnitude, which will profoundly influence alkalinity.

The results shown in Fig. 5-16 for sanidine abundance demonstrate that the propagated error increases with time, until sanidine vanishes. The error bars represent uncertainty regarding the amount of the mineral present at any given time. The error in predicting when a phase appears or disappears from the model can be substantially greater than the prediction of the amount made. For example, the 
maximum uncertainty in the amount of sanidine produced is about $50 \%$, but the uncertainty of when it is consumed is from about $-60 \%$ to $+2100 \%$.

Figure 5-16. Estimates of sanidine abundance over time.

5.4.4.2 Conclusions. These simulations were designed to be preliminary for bounding water compositions that could evolve within the $\mathrm{AZ}$ and migrate into the $\mathrm{NFE}$, and for bounding the mineralogy that could evolve in the AZ. The key constraints upon which the simulations were based and details of the uncertainties are discussed in Sec. 10.4.3.4 of Volume II. The results provide bounds on secondary mineralogy and water chemistry and are a baseline from which further refinements in simulation strategies can be developed.

The results document that the timing of mineral development is most sensitive to dissolution kinetics. Precipitation kinetics are sufficiently fast that they do not significantly influence mineral development for most mineral phases. This knowledge allows uncertainty limits to be quantified for projections of mineral development based mainly on dissolution kinetics.

These results also complement studies of the thermodynamic properties of mineral phases (Bruton, 1996, in Sec. 3.4.2, Vol. II) documenting that specific types of minerals (facies) can be accurately predicted during evolution of the repository. However, the development of individual mineral compositions is less accurately predicted. The studies also provide quantitative descriptions of the uncertainty expected in simulations of the evolution of the AZ.

Retardation of radionuclides passing through the $\mathrm{AZ}$ is directly related to the identity and abundance of minerals along the flow path. These results show that an analysis of radionuclide transport must consider the effects of water chemistry as well as the impact of dissolution kinetic and thermodynamic properties on the models.

\subsubsection{Formation of Flow and Transport Barriers in the AZ}

Thermal gradients and resultant advective mass transport within the $\mathrm{AZ}$ will invariably lead to porosity evolution as a consequence of reaction-controlled mineral dissolution and precipitation both along fractures and within bounding matrix blocks (Fig. 5-17). Preliminary reactive transport modeling conducted in FY 1995 suggested that these processes might result in significant modification of flow porosity both above and below the repository (Glassley, 1995).

Figure 5-17. Matrix of coupled processes.

Reactive transport simulations can be viewed as an iterative, five-stage process, in which the steps are:

1. Precise specification of the initial chemical and hydrologic state of the fluid-rock system.

2. Translation (which of ten includes approximation) of the specifications into the analogous model parameters of the software.

3. Specification of certain system-independent numerical parameters.

4. Successful execution of the software.

5. Interpretation of calculated results.

Using this five-stage process, the approach taken in this study was to first establish the validity of the software-encoded numerical model by successfully predicting the outcome of two well-characterized, experimentally verifiable "benchmark" problems. Next, increasingly complex, yet still experimentally 




Figure 5-16. 




Figure 5-17. 
verifiable problems having some relevance to porosity evolution in the backfill zone were addressed. Finally, a critical simulation that cannot be addressed directly by physical experiment was carried out: modeling of long-term porosity evolution in the AZ. These benchmark comparisons are reported in more detail in Sec. 10.4.4.1 of Volume II and provide some confidence that the results of the verification are realistic, if not exact. Only those simulations that apply to the $A Z$ are reported here.

5.4.5.1 Compositional Specifications and Parameterization of the AZ. The composition and relative abundance of mineral phases in the potential repository host rock, the Topopah Spring Member of the Paintbrush Tuff (TSw2), have been determined experimentally by Warren et al. (1984), and translated into model compositions/abundances by Delany (1985) for use in EQ3/6 calculations. Because GIMRT, unlike $\mathrm{EQ} 3 / 6$, is not yet configured to account for solid solutions, it is necessary to further approximate Delany's (1985) model TSw 2 mineralogy by resolving its alkali feldspar and plagioclase compositions into the corresponding end-member K-feldspar, albite, and anorthite components. $\mathrm{Mg}$-beidellite and biotite compositions compose only 1.1 volume\% of the TSw2, and they represent the only $\mathrm{Mg}$ - and Fe-bearing phases in the system. In these preliminary simulations, $\mathrm{Mg}$-beidellite and biotite were eliminated from the model TSw2 composition.

The fluid phase anticipated to form within, and react with, the TSw2 in the AZ is derived from condensation of a vapor phase moving radially outward from the repository (Buscheck et al., 1993). This condensate is likely to be a highly dilute, neutral-pH fluid. The fluid was modeled to initially contain very low concentrations of aqueous ions and complexes augmented by the additional component $\mathrm{CO}_{2}$, which is necessary owing to the presence of atmospheric gases. Again, a cautionary note regarding $\mathrm{CO}_{2}$ beyond atmospheric is made. The initial fluid composition, specified as the log molal concentration of basis species and given in Table 5-1, is much more dilute than J-13, reflecting its condensation from a vapor phase.

Table 5-1. Summary of infiltrating fluid composition used in this study. In the simulations, $\mathrm{Ca}^{+2}$ and $\mathrm{HCO}_{3}{ }^{-}$represent the mass- and charge-balancing species, respectively.

\begin{tabular}{|l|c|}
\hline Basis species & Log activity \\
\hline $\mathrm{H}^{+}$ & -7 \\
\hline $\mathrm{K}^{+}$ & -10 \\
\hline $\mathrm{Na}^{+}$ & -10 \\
\hline $\mathrm{Ca}^{+2}$ & -5 \\
\hline $\mathrm{Al}^{+3}$ & -20 \\
\hline $\mathrm{SiO}_{2}(\mathrm{aq})$ & -10 \\
\hline $\mathrm{HCO}_{3}^{-}$ & -5 \\
\hline
\end{tabular}

We employed the thermodynamic data base typically used with both the original and our modified version of GIMRT, mastertemp.data, which is a reformatted version of the "composite" data base distributed with the EQ3/6 software package (Wolery, 1992). Two distinct AZ environments were addressed with GIMRT. The first was the localized, interior backfill environment. The second was the much larger-scale, relatively outlying condensation zone (Buscheck et al., 1993), where gravity-driven flow of vapor-exsolved fluid represents the most likely catalyst for significant, long-term porosity evolution in the $\mathrm{AZ}$.

5.4.5.2 Backfill Simulations. We used crushed Tpt material having an initial porosity of $40 \%$, where a constant outlet flux of $266.7 \mathrm{~m}^{3} / \mathrm{m}^{2} / \mathrm{yr}$ was maintained over six months. Because the porosity of actual backfill material and especially the in situ fluid flux are likely to be lower than the adopted values, the simulations provide an upper bound to the potential magnitude of porosity evolution. 
In the first TSw2-backfill simulation, the system was maintained in isothermal equilibrium at $90^{\circ} \mathrm{C}$. Steady-state saturation indices for all primary and potential secondary minerals were achieved within one hour. As shown in Fig. 5-18, the fluid remains undersaturated with respect to all primary and potential secondary minerals at this inlet node throughout the simulation. Hence, at this location, all primary phases will dissolve to varying degrees controlled by the encoded kinetic rate law, and no secondary minerals will precipitate. At the outlet node (Fig. 5-19), mineral saturation indices reach steady-state values in about 9 hours. Here again the fluid remains undersaturated with respect to all primary minerals, but in contrast to the initial node, several secondary phases (kaolinite, gibbsite, diaspore, boehmite, and muscovite) achieve steady-state supersaturation with the fluid.

Figure 5-18. Mineral saturation indices $(\log Q / K)$ vs time at the inlet node of a GIMRT simulation at $90^{\circ} \mathrm{C}$, where initial composition of the 31-cm, 1-D, fluid-rock system is given in Table 5-1. Solid symbols denote primary minerals; open symbols denote secondary minerals.

Figure 5-19. Mineral saturation indices $(\log Q / K)$ vs time at the outlet node of a GIMRT simulation at $90^{\circ} \mathrm{C}$.

At $90^{\circ} \mathrm{C}$, kinetic dissolution rates for the undersaturated primary phases are on the order of $-10^{-1}$ volume $\% / \mathrm{yr}$ for cristobalite and albite, $-10^{-2}$ volume\%/yr for quartz, and $<-10^{-3}$ volume\%/yr for $\mathrm{K}$ feldspar and anorthite. As a result, over six months, the aggregate dissolution of primary minerals will be $<0.25$ volume\%. Some of this minute volume loss will be filled by precipitation of secondary phases following their sequential supersaturation along the flowpath. Specifically, gibbsite will precipitate first (at node 2; nodes were located at each $\mathrm{cm}$ along the flowpath), subsequently joined by diaspore (node 4), kaolinite (node 9), boehmite (node 14), and finally muscovite (node 29). However, because maximum precipitation rates for these phases are so slow at $90^{\circ} \mathrm{C}$ (ranging from $10^{-11}$ volume\%/yr for kaolinite to $10^{-14}$ volume\%/yr for muscovite and boehmite), the aggregate precipitation of secondary minerals is $<2.5\left(10^{-3}\right)$ volume/yr throughout the domain, i.e., negligible. As a consequence, six months of reactive flow through crushed $\mathrm{Tpt}$ at $90^{\circ} \mathrm{C}$ results in a relatively uniform but minute increase in porosity (from 40 to $40.25 \%$ ) as a function of minor dissolution of primary phases and trace precipitation of alteration minerals (Figs. 5-20 and 5-21). Although the changes are very small, when considering the times of concern for repository performance $(10,000 \mathrm{yr}$ or longer), the changes can be significant. At about $3000 \mathrm{yr}$, the aggregate is 10\%; at 100,000 yr, it could be significant. It is unknown whether these rates continue or if they decrease with time.

Figure 5-20. Porosity and volume fractions of primary and secondary minerals as a function of distance at six months for a GIMRT simulation at $90^{\circ} \mathrm{C}$. Solid symbols denote primary minerals; open symbols denote secondary minerals.

Figure 5-21. Porosity and volume fractions of trace secondary minerals as a function of distance after six months for a GIMRT simulation at $90^{\circ} \mathrm{C}$.

A second GIMRT simulation was performed identical to the first except for the temperature, which was increased to $250^{\circ} \mathrm{C}$. Although this temperature exceeds the maximum likely to be attained in the near-field rock, depending on emplacement configuration, it may be realistic and is within the plausible temperature ranges in the backfill close to drifts. These temperatures are probably unrealistic for the $\mathrm{AZ}$, which will be in the temperature range closer to $100^{\circ}$ to $150^{\circ} \mathrm{C}$. Thermodynamic and kinetic considerations suggest that $250^{\circ} \mathrm{C}$ will lead to readily observable porosity evolution and alteration-phase precipitation. We know that similar changes to those observed at $250^{\circ} \mathrm{C}$ would apply to lower temperatures (especially at long time frames), but in a qualitative sense. We do not have sufficient information at present to be more quantitative. 


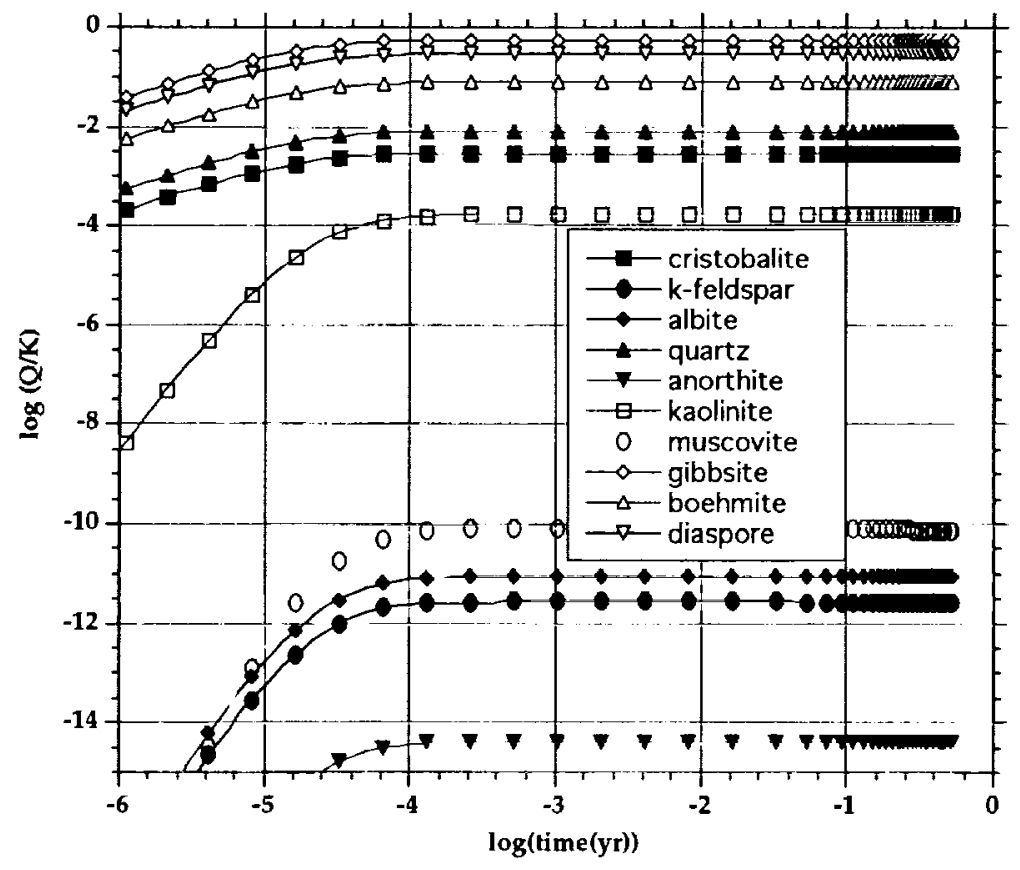

Figure 5-18. 


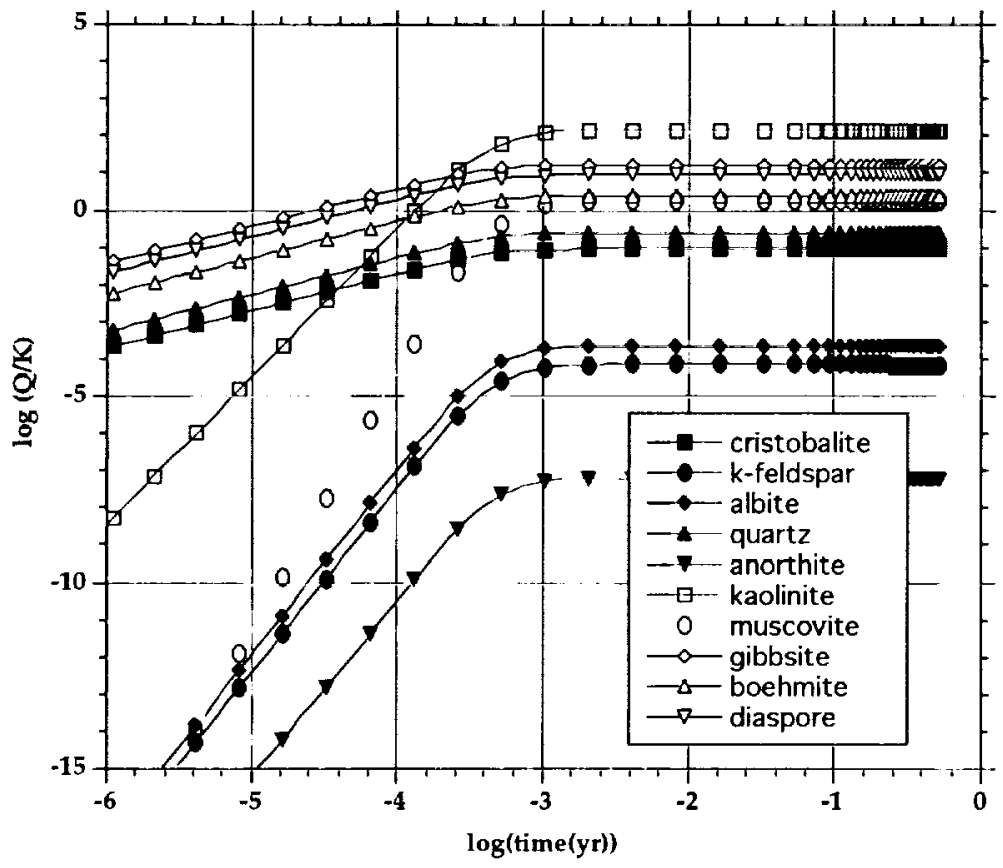

Figure 5-19. 




Figure 5-20. 




Figure 5-21. 
Although the time scale for attainment of steady-state saturation indices is similar for the $90^{\circ} \mathrm{C}$ and $250^{\circ} \mathrm{C}$ simulations, the enhanced solubilities and faster reaction rates of primary Tsw 2 minerals at the higher temperature and their effect on dissolution (and secondary phase precipitation) are readily apparent. Despite concomitant precipitation of kaolinite, whose reaction rate and volume fraction ultimately attain 50 volume\%/yr and 14 volume\%, respectively, this near-complete consumption of cristobalite, albite, and quartz causes porosity to increase from 40 to $70 \%$ at the initial node (Fig. 5-22), and, of course, results in the late marked decline in saturation indices for these and all other silica-bearing phases (Fig. 5-23). Because the differences between the $90^{\circ} \mathrm{C}$ and $250^{\circ} \mathrm{C}$ cases are impacted by reaction kinetics, except for those products that are in thermodynamic equilibrium, the long time frames of elevated temperatures expected in the $\mathrm{AZ}$ will probably result in mineralogy/chemistry similar to the $250^{\circ} \mathrm{C}$ case by the time the thermal pulse decays.

Figure 5-22. Porosity and volume fractions of primary and secondary minerals as a function of time at the inlet node of a GIMRT simulation at $250^{\circ} \mathrm{C}$.

Figure 5-23. Mineral saturation indices $(\log Q / K)$ vs time at the inlet node $(1 \mathrm{~cm})$ of a GIMRT simulation at $250^{\circ} \mathrm{C}$, where initial composition of the $31-\mathrm{cm}, 1-\mathrm{D}$, fluid-rock system is given in Table 51. Solid symbols denote primary minerals; open symbols denote secondary minerals.

As shown in Fig. 5-24, the fluid is supersaturated with not only the same six secondary minerals that characterize the inlet node, but also with albite and quartz. Primary albite ceases to dissolve, and secondary albite begins to precipitate within 20 minutes, quartz follows suit about 40 minutes later, and within nine hours the cristobalite dissolution rate has dropped to and essentially leveled off at about $20 \%$ of its original magnitude. As a result, after six months, total quartz and albite volume fractions have actually increased (Fig. 5-25), and the net volume fraction of cristobalite, albite, and quartz has only declined from $\mathbf{4 5 . 9 \%}$ to $37.2 \%$ (versus the inlet node). Hence, despite slightly reduced precipitation of secondary kaolinite relative to the inlet $(10.2 \%$ versus $15.2 \%)$, the six-month outlet porosity has actually decreased from 40 to $38.8 \%$ (Fig. 5-25).

Figure 5-24. Mineral saturation indices $(\log Q / K)$ vs time at the outlet node of a GIMRT simulation at $250^{\circ} \mathrm{C}$.

Figure 5-25. Porosity and volume fractions of primary and secondary minerals as a function of time at the outlet node of a GIMRT simulation at $250^{\circ} \mathrm{C}$.

One would expect the gradient in dissolution/precipitation behavior to be sharpest across the first few nodes, where the fluid concentration gradient is steep. This is exactly the case, as illustrated by the time-integrated spatial distribution of saturation indices and porosity/volume fractions (Figs. 5-26 and 527). Thus, gradients that develop during initial $A Z$ development close to the WP environment may not experience complete chemical reactions. However, the rapidity of growth in the dryout zone and its associated condensate zone will slow as a function of decreasing rate and increased diameter as the spherical volumes increase. In addition, the kinetics are sufficiently high that reactions can be essentially fully developed in a relatively short time. Therefore, the products of the $250^{\circ} \mathrm{C}$ case should be representative of the majority of the $\mathrm{AZ}$. Note that the region of enhanced porosity is restricted to the first few nodes and is characterized by very steep gradients, whereas the region of reduced porosity accounts for roughly $90 \%$ of the reaction domain and is characterized by much subtler variations.

Figure 5-26. Mineral saturation indices $(\log \mathrm{Q} / \mathrm{K})$ as a function of distance after six months for a GIMRT simulation at $250^{\circ} \mathrm{C}$. 


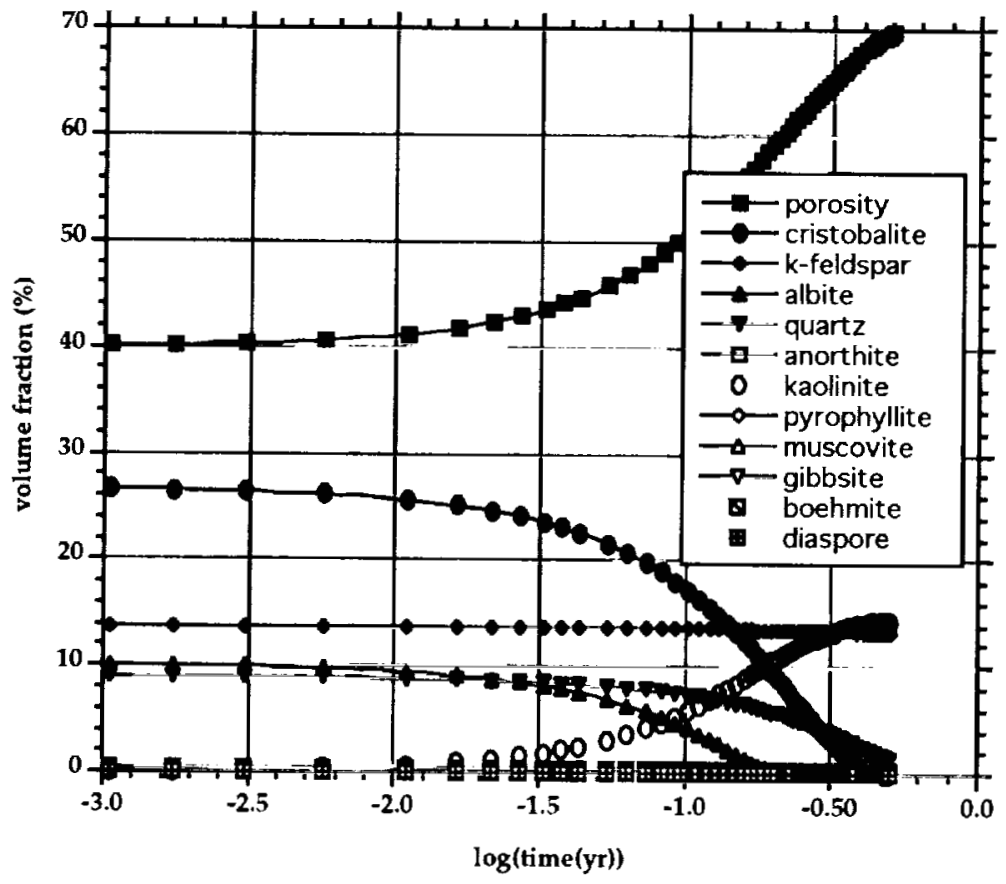

Figure 5-22. 


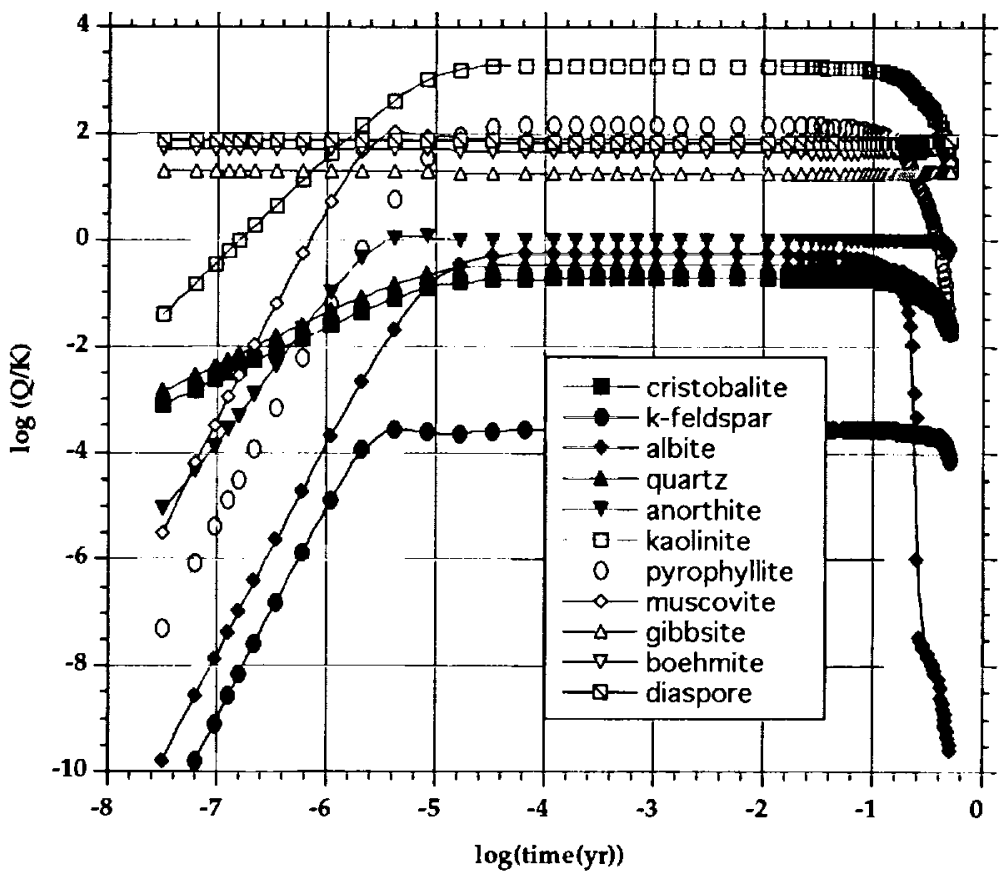

Figure. 5-23. 


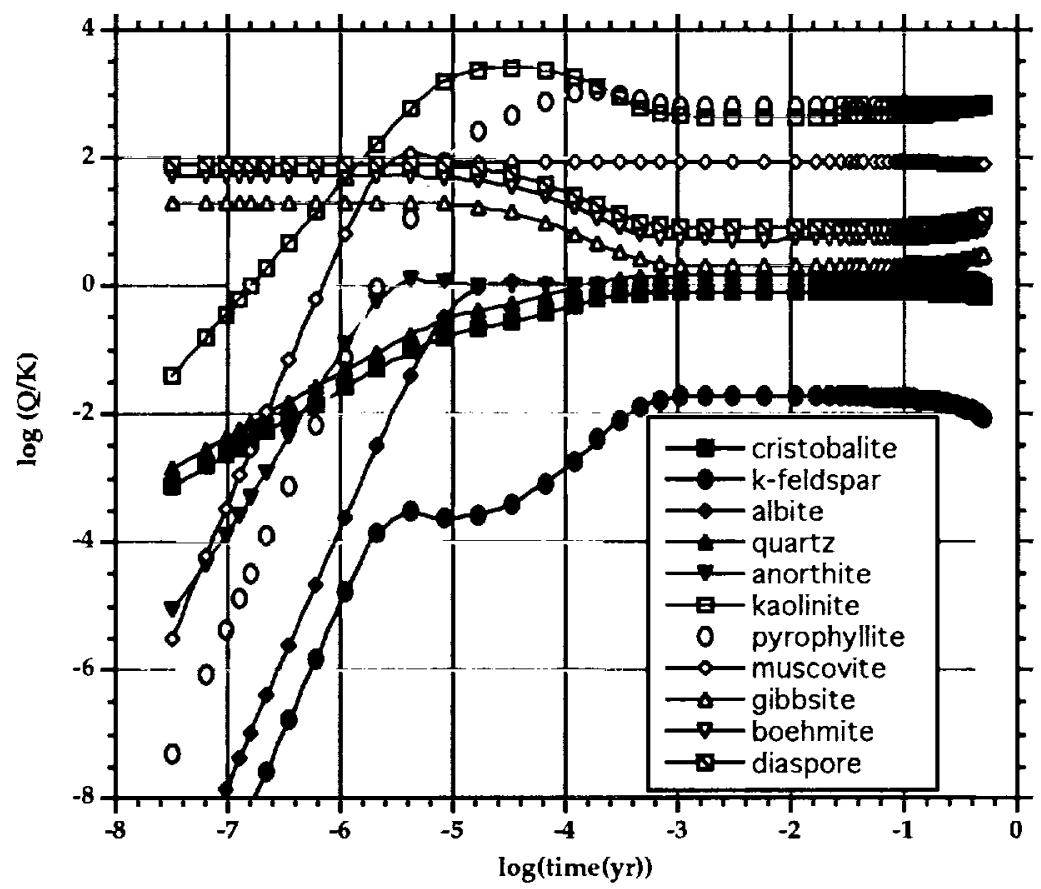

Figure 5-24. 




Figure 5-25. 


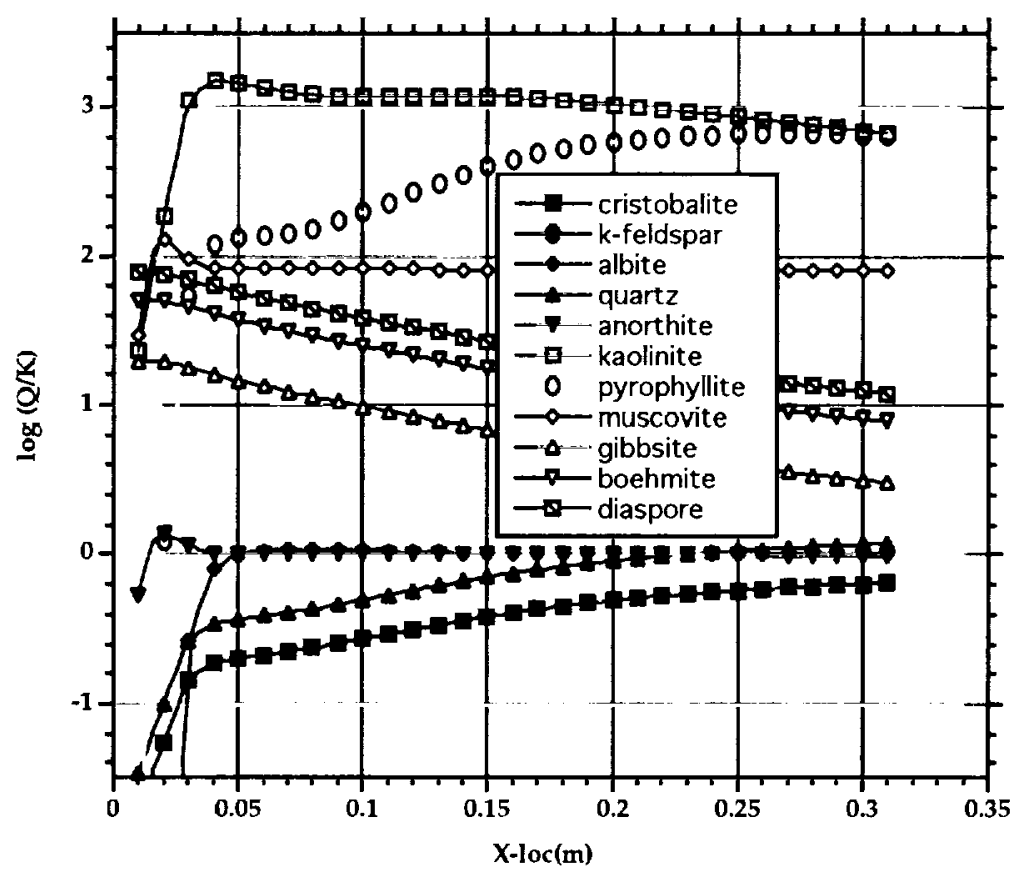

Figure 5-26. 
Figure 5-27. Porosity and volume fractions of primary and secondary minerals as a function of distance after six months for a GIMRT simulation at $250^{\circ} \mathrm{C}$.

Significant porosity evolution in the $90^{\circ} \mathrm{C}$ backfill zone will not be realized for at least $100 \mathrm{yr}$. Moreover, recalling the likely overestimation of initial porosity, this time frame must be considered extremely conservative. Because accurate values for the initial porosities and flow rates relevant to the potential crushed-TSw 2 backfill environment are currently unavailable, a more detailed, longer time-scale simulation addressing porosity evolution here cannot be pursued at this time. Current information indicates that if pre-cast or cast-in-place concrete liners are used, the water chemistries $(\mathrm{pH})$ would be affected, and the fluid would be more reactive. Therefore, the extent of alteration of the backfill would be increased. However, no quantitative studies of this topic have been performed to date.

The potential repository horizon lies well above the present-day water table within the welded, devitrified section, which is characterized by low porosity $(11 \%)$ and extremely low, fracture-controlled permeability $\left(10^{-18} \mathrm{~m}^{2}\right.$ ) (Klavetter and Peters, 1988). As described by Buscheck et al. (1993), hydrology of the post-emplacement NFE may be characterized by a boiling zone, where vapor moves radially outward from the EBS/WP and an outer but partially overlapping condensation zone, where temperaturedependent condensation of the vapor leads to primarily gravity-driven flow of a fluid phase. In the vicinity of emplacement drifts, average calculated trajectories indicate that the condensate may flow along path lines characterized by an initial isothermal segment (at $90^{\circ}$ to $100^{\circ} \mathrm{C}$ ) of several meters and subsequent cooling segment $\left(-1^{\circ}\right.$ to $\left.-3^{\circ} \mathrm{C} / \mathrm{m}\right)$, also of several meters.

The temporal evolution of mineral saturation indices at the inlet $(0.25 \mathrm{~m})$, center $(5 \mathrm{~m})$, and outlet (10 $\mathrm{m}$ ) nodes are shown in Figs. 5-28 through 5-30. Initial steady-state mineral saturation indices are attained after about 1 month, during which time the fluid obtains supersaturation with quartz and the secondary phases kaolinite and pyrophyllite, but remains undersaturated with respect to cristobalite (and the primary feldspars) throughout the reaction domain. As a result, over the entire reactive flowpath, cristobalite (and the feldspars) will dissolve, whereas quartz, kaolinite, and pyrophyllite will precipitate. Given the relatively sluggish dissolution rates of the feldspars at $90^{\circ}$ to $95^{\circ} \mathrm{C}$, dissolution of these primary aluminous phases and dependent precipitation of kaolinite and pyrophyllite will be very minor. Hence, the fundamental mechanism of porosity evolution in this environment is expected to be metasomatic replacement of cristobalite by quartz.

Figure 5-28. Mineral saturation indices $(\log \mathrm{Q} / \mathrm{K})$ as a function of time at the inlet node $(0.25 \mathrm{~m})$ of a GIMRT simulation at $95^{\circ} \mathrm{C}$, where initial composition of the $10-\mathrm{m}, 1-\mathrm{D}$, fluid-rock system is given in Table 5-1. Solid symbols denote primary minerals; open symbols denote secondary minerals.

Figure 5-29. Mineral saturation indices $(\log Q / K)$ as a function of time at the center node $(5 \mathrm{~m})$ of a GIMRT simulation at $95^{\circ} \mathrm{C}$.

Figure 5-30. Mineral saturation indices $(\log Q / K)$ as a function of time at the outlet node $(10 \mathrm{~m})$ of a GIMRT simulation at $95^{\circ} \mathrm{C}$.

As shown in Fig. 5-31, at the inlet (pure dissolution) node, behavior analogous to the center and outlet of the domain is observed until cristobalite has been completely dissolved at about $650 \mathrm{yr}$. Subsequently, the dilute inlet fluid begins to dissolve quartz, which disappears completely after $3,100 \mathrm{yr}$, and then albite.

Figure 5-31. Porosity and volume fractions of primary and secondary minerals as a function of time at the inlet node $(0.25 \mathrm{~m})$ of a GIMRT simulation at $95^{\circ} \mathrm{C}$. 


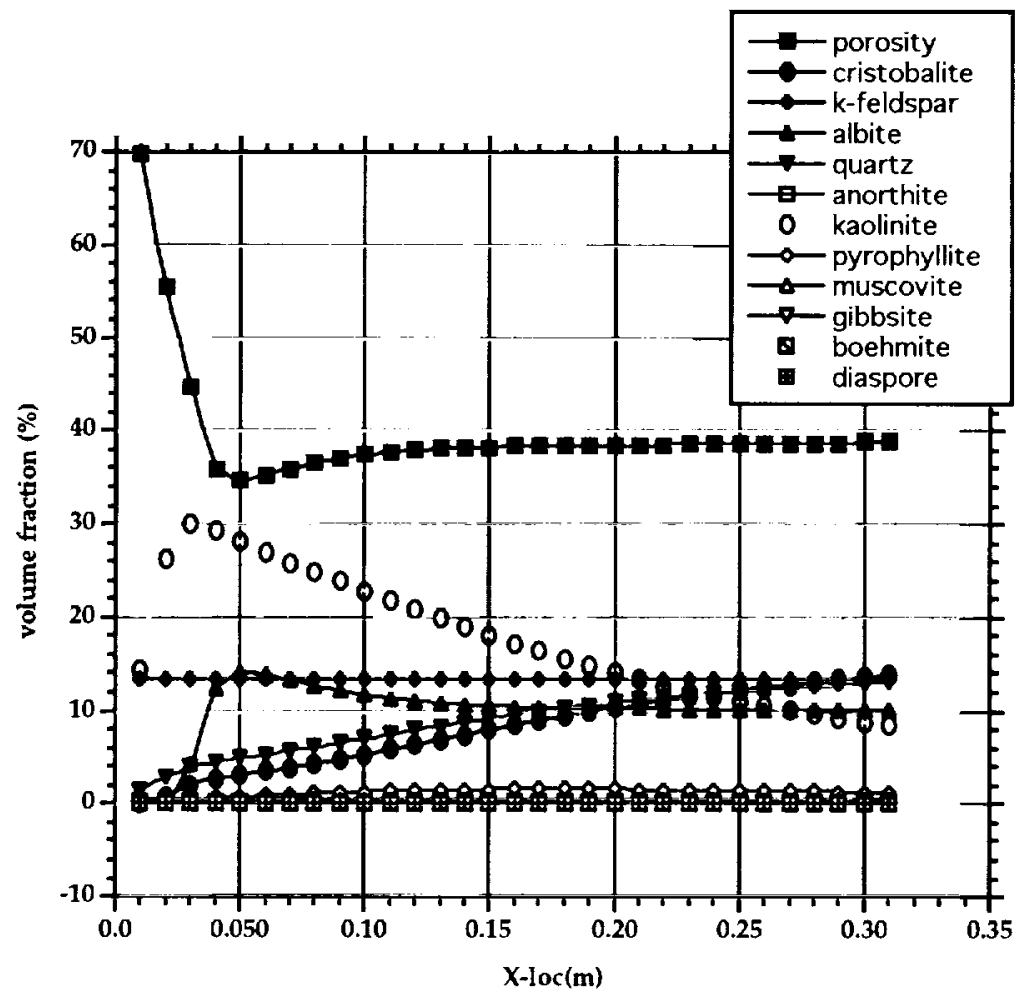

Figure 5-27. 


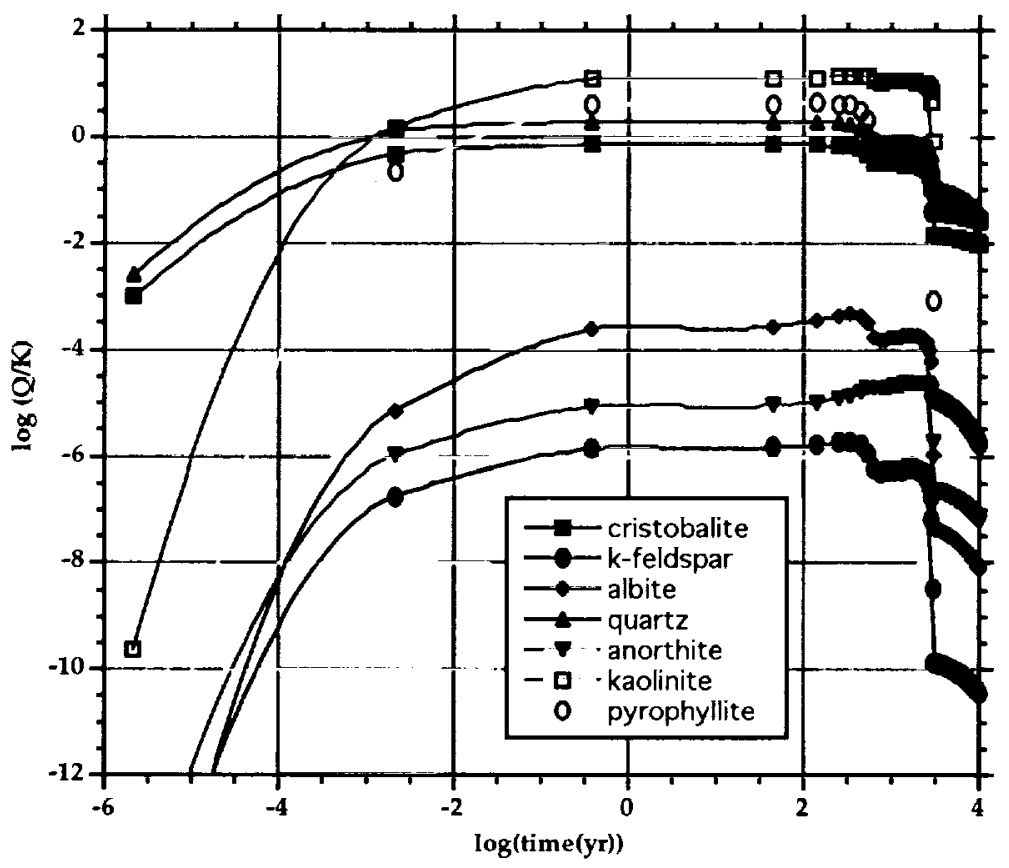

Figure 5-28 


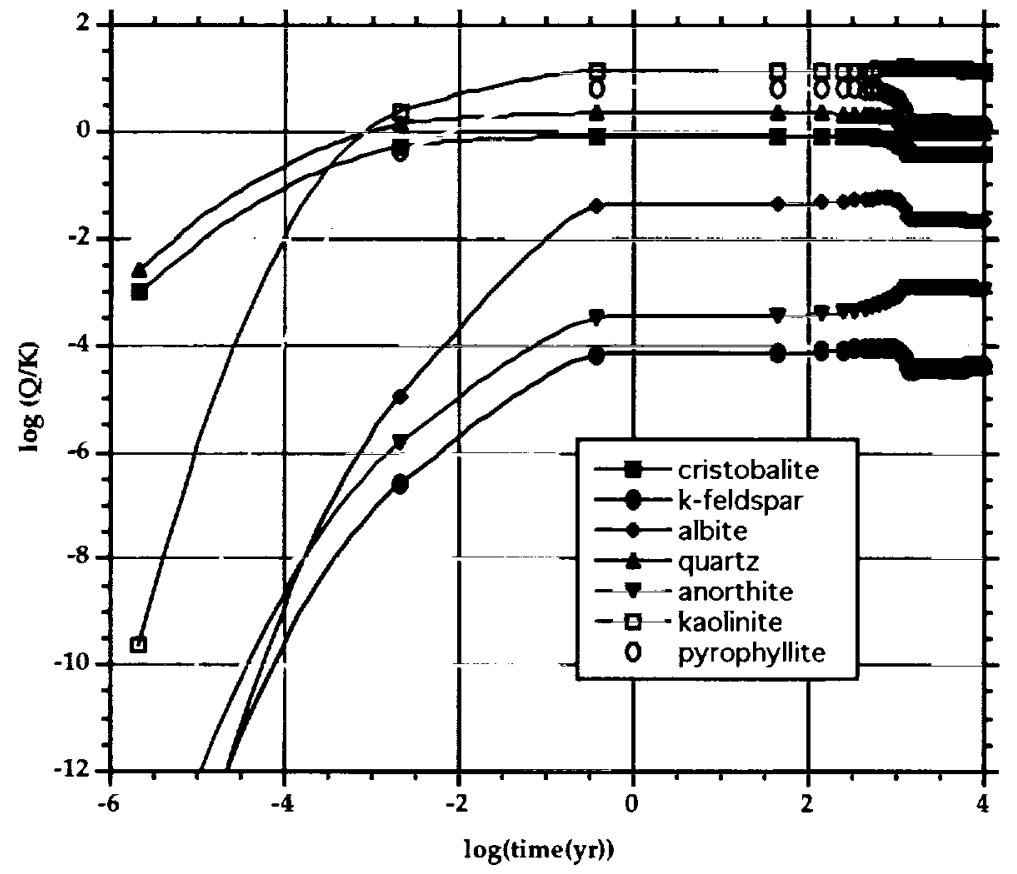

Figure 5-29. 


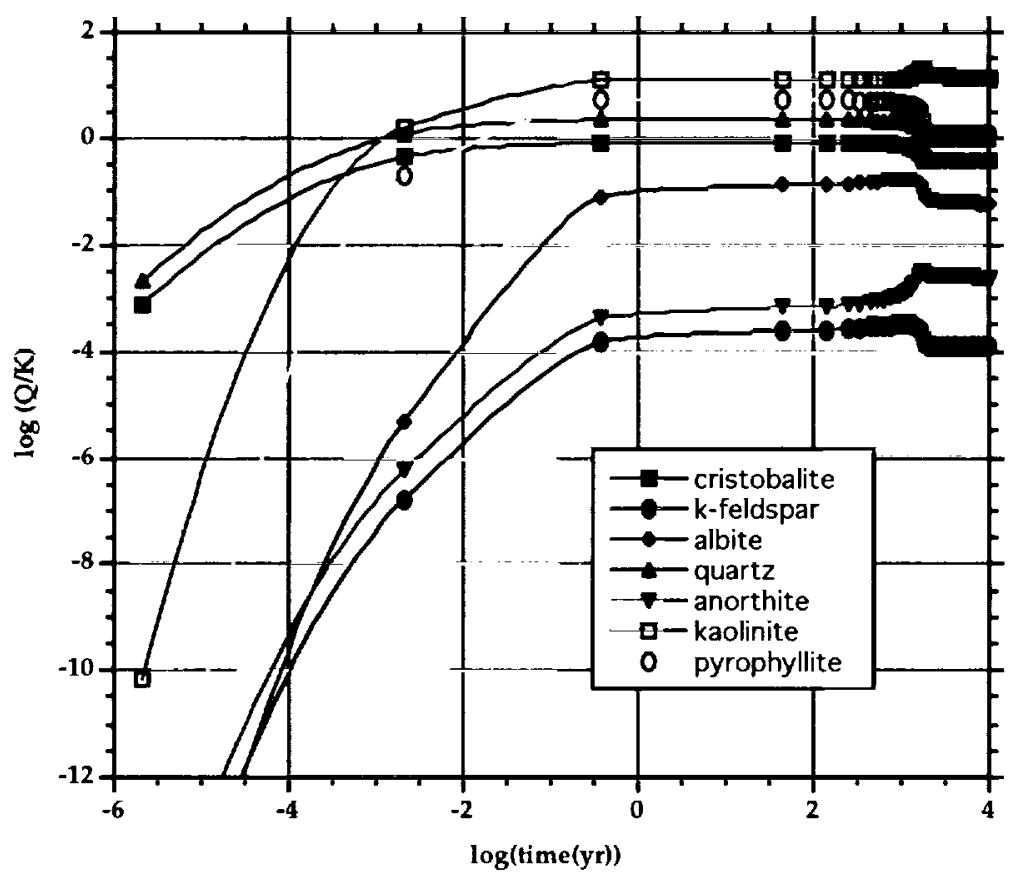

Figure 5-30. 


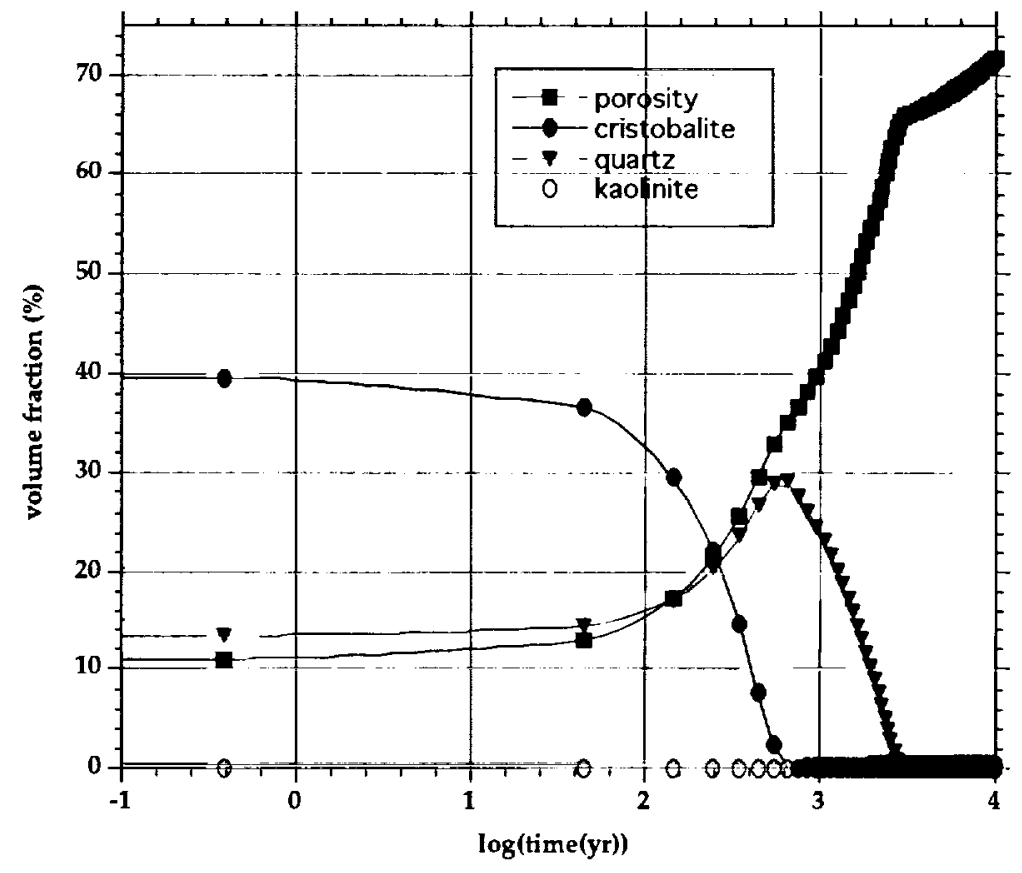

Figure 5-31. 
Figures 5-32 through 5-35 show time-integrated spatial variations in porosity and mineral volume fractions. The complete replacement of cristobalite (initial volume fraction $=39.6 \%$ ) by quartz throughout the reaction domain leads directly to a background increase in porosity from $11 \%$ to about $16 \%$ after roughly 3,100 yr (Figs. 5-34 and 5-35). Superimposed is a secondary porosity enhancement, resulting from quartz dissolution (initiated following complete cristobalite consumption) at the first few inlet nodes, beginning with the inlet node at $650 \mathrm{yr}$. Because the $90^{\circ}$ to $95^{\circ} \mathrm{C}$ dissolution rate of quartz is only about $40 \%$ that of cristobalite, it takes dilute inlet fluid roughly 2,500 years to completely dissolve the inlet-node quartz from its maximum concentration ( 29 volume\%), which coincided with cristobalite disappearance at $650 \mathrm{yr}$. This secondary quartz dissolution front advances quite slowly, and the advection of quartzderived $\mathrm{SiO}_{2}(\mathrm{aq})$ maintains nearly uniform levels of slight quartz supersaturation and resultant minor quartz precipitation over the entire downstream reaction domain. As a result, this secondary porosity enhancement is characterized by steep gradients that advance downstream quite slowly (Figs. 5-34 and 535).

Figure 5-32. Porosity and volume fractions of primary and secondary minerals as a function of distance after $100 \mathrm{yr}$ for a GIMRT simulation. Temperature for the first $5 \mathrm{~m}$ is $95^{\circ} \mathrm{C}$, then decreases by $1^{\circ} \mathrm{C} / \mathrm{m}$ over the last $5 \mathrm{~m}$.

Figure 5-33. Porosity and volume fractions of primary and secondary minerals as a function of distance after $1000 \mathrm{yr}$ for a GIMRT simulation. Temperature for the first $5 \mathrm{~m}$ is $95^{\circ} \mathrm{C}$, then decreases by $1^{\circ} \mathrm{C} / \mathrm{m}$ over the last $5 \mathrm{~m}$.

Figure 5-34. Porosity and volume fractions of primary and secondary minerals as a function of distance after 5000 yr for a GIMRT simulation. Temperature for the first $5 \mathrm{~m}$ is $95^{\circ} \mathrm{C}$, then decreases by $1^{\circ} \mathrm{C} / \mathrm{m}$ over the last $5 \mathrm{~m}$.

Figure 5-35. Porosity and volume fractions of primary and secondary minerals as a function of distance after 10,000 yr for a GIMRT simulation. Temperature for the first $5 \mathrm{~m}$ is $95^{\circ} \mathrm{C}$, then decreases by $1^{\circ} \mathrm{C} / \mathrm{m}$ over the last $5 \mathrm{~m}$.

Important implications for the post-emplacement evolution of porosity in the $\mathrm{AZ}$ can be drawn from this simulation. First, thermodynamic, kinetic, and volumetric constraints strongly suggest that long-term $(>3,000 \mathrm{yr})$, gravity-driven flow of vapor-derived dilute condensate at $90^{\circ}$ to $95^{\circ} \mathrm{C}$ will result in nearly $50 \%$ background porosity enhancement (from $11 \%$ to $16 \%$ ) as a consequence of mole-for-mole, quartz-forcristobalite replacement. Should this local "condensation" zone persist for longer time periods, the in situ porosity may further increase dramatically, albeit slowly, to more than $65 \%$ as quartz dissolution occurs. It is conceivable, if not likely, that the post-emplacement $\mathrm{AZ}$ will evolve toward extreme porosity heterogeneity, characterized by relatively large porosities in the condensation-zone "cap" above the repository and relatively low porosities (which nevertheless exceed pre-emplacement porosity) in the outlying margins of this cap. In addition, these extremes may be joined by a narrow, steep-gradient interface. All of the dissolved silica will, of course, eventually precipitate farther downstream, presuming gravity-driven flow continues down thermal gradients. Hence, it is anticipated that a zone of very low (less-than-ambient) porosity may develop at depth, perhaps below and radially outward from the repository. Above the condensate cap, there will also be porosity decreases.

5.4.5.3 Conclusions. Recognizing the abundance of compositional and hydrologic approximations, assumptions, and simplifications that are necessarily embodied in these still-preliminary models, they nevertheless serve to elucidate the fundamental time scales (thousands of years) and geochemical processes (e.g., cristobalite-for-quartz replacement) likely to govern active evolution of the AZ. They can also be used to imply the distant-future porosity distributions that are so critically important. Our initial 




Figure 5-32. 


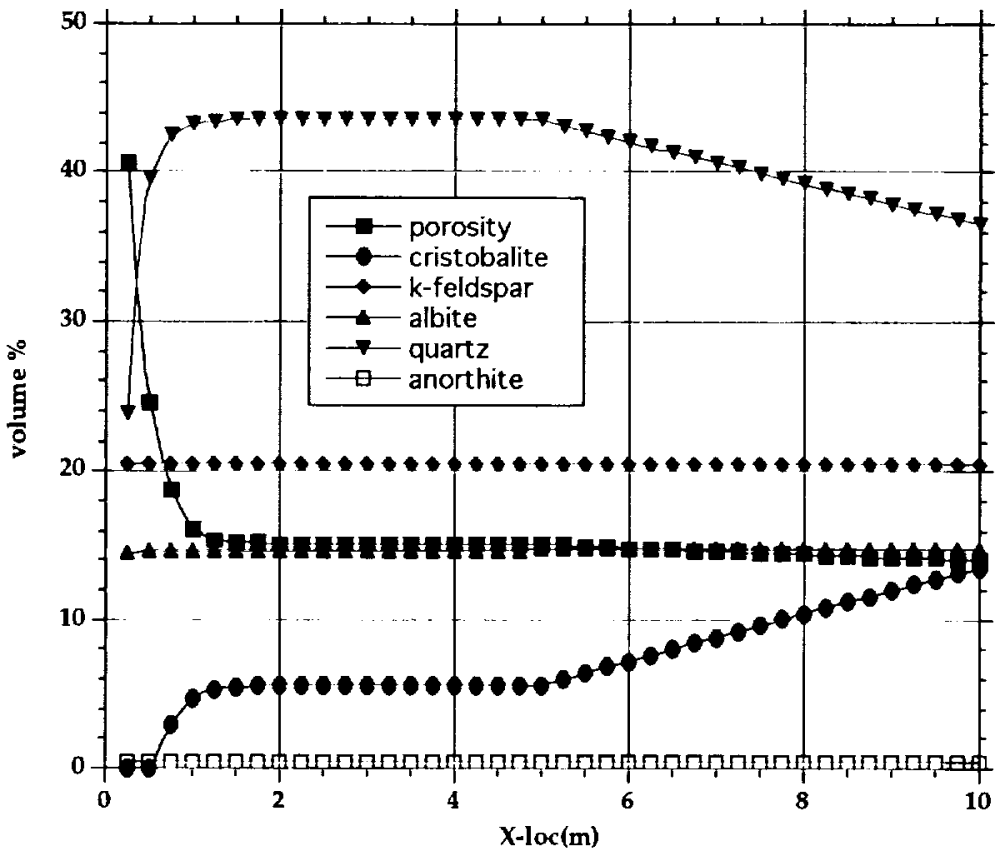

Figure 5-33. 


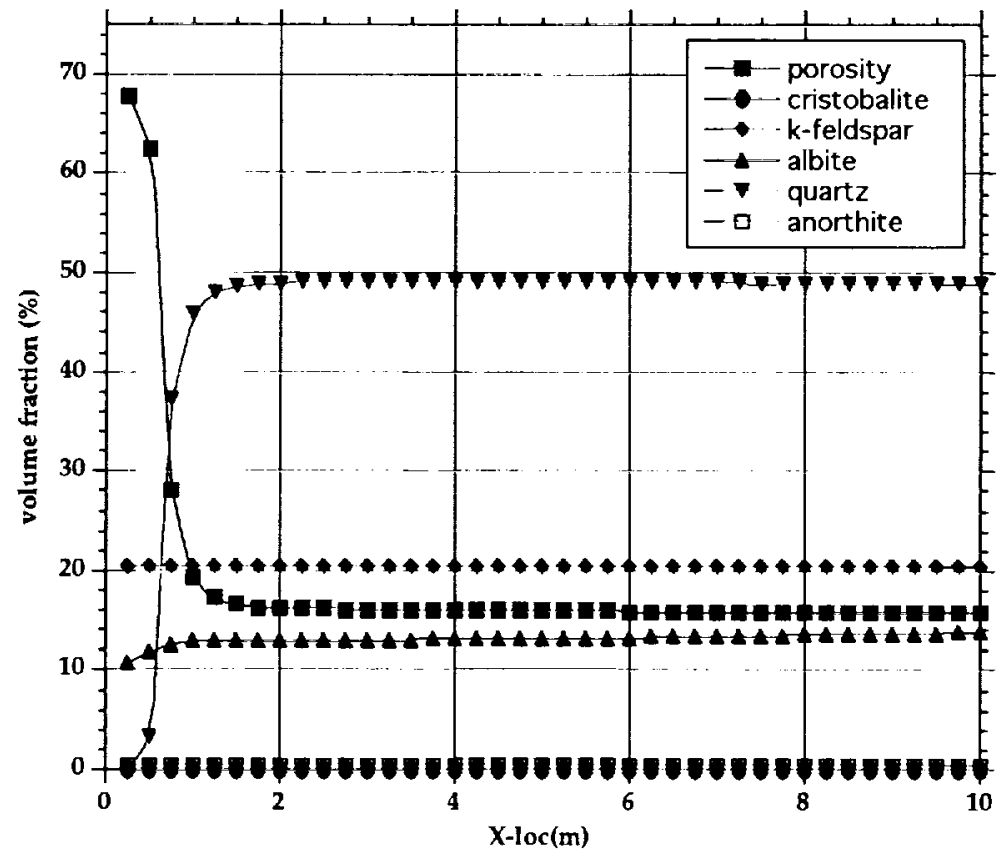

Figure 5-34. 


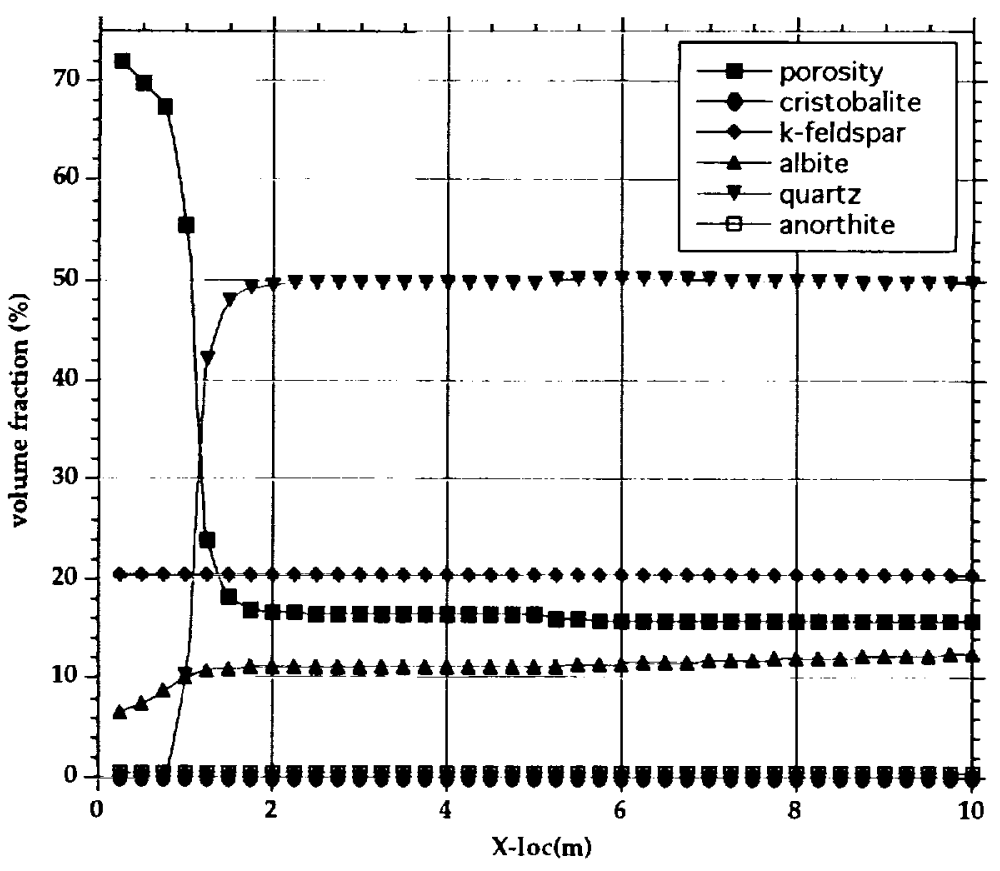

Figure 5-35. 
modeling efforts suggest that post-emplacement reactive transport will lead to porosity enhancement in the AZ, most dramatically in the condensation "cap" overlying the repository. Further modeling of fluid transport to regions below the emplacement drifts will evaluate the extent to which flow barriers may form due to porosity reduction.

Our results to date strongly suggest that significant porosity changes will occur in the postemplacement, repository-block environment. Long-term performance assessment of this environment must explicitly account for such porosity evolution and its effect on dependent geochemical and hydrologic processes. Porosity changes in the backfill would also be significant because the purpose of the backfill is to act as a hydrological barrier. Buscheck has pointed out that backfill may need to be quartz sand, not crushed tuff, to provide diversion of percolation without wicking. A further consideration is the geochemical alteration of backfill materials, particularly crushed tuff. If porosity, hence permeability and matric potential, significantly change, then the backfill may not serve its intended function. 


\subsection{Performance Implications}

The near-field and altered-zone environments impact the overall performance of the repository system in three general areas:

- Performance of the waste container materials, particularly metallic container materials.

- Dissolution/mobilization and transport of radionuclides from the waste.

- Flow fields and retardation characteristics of the natural system.

\subsection{Impacts on Waste Container Performance}

The current repository concept includes the use of metal containers that consist of outer corrosionallowance materials in concert with inner corrosion-resistant materials. Combined, the materials are intended to prevent contact of water with the waste materials and to provide for containment, thus isolation, of the waste. The length of time that these containers will function and how well they function very much depends on how much water can contact the WPs, the chemistry of the water, and the relative humidity of air surrounding the WPs.

Estimates of water volumes that can potentially contact the WPs have been based on the Project's understanding of ambient percolation fluxes and the thermohydrologic response of the system to the repository heat load as envisioned in the current design for the repository. In terms of WP water contact, this revision of the NFER has placed more emphasis on flux that is created by displaced water combining with ambient percolation flux than on the saturation conditions and timing for those conditions. This change of emphasis from that of the Preliminary NFER is due to two factors.

First, as the YMP has continued to study water flow through the mountain, it has become apparent that the flow is dominated by fracture flow more than by matrix hydrologic conditions. This was recognized at the time the Preliminary NFER was written and was the basis for the statement "...Thus, fracture flow is the only credible mechanism to bring liquid water into contact with the WPs."

The second change arises from the recent recognition that ambient percolation fluxes may be much higher than values originally considered possible. At the time the Preliminary NFER was written, the general feeling was that the total percolation flux was very low or zero. Current estimates for fluxbased, in part, on neutron logging measurements and isotopes released by atmospheric nuclear weapons tests-range as high as 10 to $15 \mathrm{~mm} / \mathrm{yr}$, with $5 \mathrm{~mm} / \mathrm{yr}$ as the most accepted value (Bodvarsson and Bandurraga, 1996). However, such estimates are based largely on analyses that used assumed hydrologic property values, the representativeness of which has not been demonstrated and is not entirely consistent with the findings of others (Buscheck, 1997).

Although it was previously recognized that periodic or episodically higher fluxes could occur, data were not available to quantify the significance of these transient fluxes. Hence, greater emphasis in the Preliminary NFER was placed on the conditions of overall saturation as an indicator of potential water contact with the waste. The current revision places much less emphasis on saturation changes and their duration as an indicator of WP performance (it is still important in AZ processes, as discussed in Section 5). Instead, more emphasis is placed on actual flux estimates, which will be dominated by fracture flow. It is difficult to relate saturation to flux directly because saturation that exists in the matrix is relatively immobile and does not contribute to flux to the same extent that the same saturation in fractures would. Because the saturation profiles shown in Figure 5-6 are based on assumptions of equilibrium between the moisture in matrix and pores, they do not relate directly to flux of water that could enter the drifts.

One possible way to assess the flux entering drifts is to account for the current or ambient percolation flux in the mountain--which is an indication of flux within fractures because the matrix will contribute such a small percentage to the overall flow-and then to assess the quantity of additional water that can 
be added to this flux by thermal mobilization or redistribution of water. In this regard, it is important to note that the total condensate flux reported in Section 4.3 represents the total amount of water that can be vaporized by the heat available, which consists of both meteoric percolation and thermally mobilized water. Thus, if the meteoric percolation flux is greater, then the amount of water that can be vaporized will be reduced. The total flux will remain constant for any given heat flux.

The influence of percolation flux on drift-scale thermal-hydrological behavior was investigated in Section 1.10 .6 of Volume II for the flux range of 0 to $5 \mathrm{~mm} / \mathrm{yr}$. It is important to realize that the decayheat-mobilized, liquid-phase flux in the condensate zone overlying the repository is much greater than this range for about $1000 \mathrm{yr}$. For the 83.4-MTU/acre repository design, the maximum decay-heatmobilized liquid-phase flux can be as large as $1000 \mathrm{~mm} / \mathrm{yr}$ during the first $100 \mathrm{yr}$. The maximum liquidphase flux declines to about $200 \mathrm{~mm} / \mathrm{yr}$ at $200 \mathrm{yr}, 100 \mathrm{~mm} / \mathrm{yr}$ at $500 \mathrm{yr}$, and $20 \mathrm{~mm} / \mathrm{yr}$ from 1000 to 3000 yr. These flux values are for homogeneous conditions; spatial variability in heating conditions or fracture properties can cause fluctuations about these averages. For example, greater fluxes can occur in regions of focused condensate flow or where the decay-heat flux is less than average. On the basis of test results from air permeability, it is likely that the fracture network within the TSw unit can easily accommodate fluxes of up to hundreds of millimeters per year.

Two significant cautions apply to this assessment. First, the same problems in defining flux based on saturation apply to estimating the ambient flux; that is, assumptions must be made to evaluate the current flux. These assumptions deal with the equilibrium between fracture and matrix flow, as well as the rock mass properties versus those determined from intact, small-scale samples. Current estimates of flux are as high as 10 to $15 \mathrm{~mm} / \mathrm{yr}$, but these values are not confirmed by direct measurements within the TSw2. Shallow infiltration flux is estimated by periodic neutron logging of shallow boreholes. Analyses of these measurements provide a lower bound estimate of the flux from the surface to the depth of measurement. This measurement will not detect water moving rapidly though the fractures because large fluxes can be handled with no measurable change in water content. Only the water actually imbibed into the matrix will be measured by the neutron log. These relatively shallow measurements do not account for diversion and other processes, and thus may not be representative of the percolation flux at the repository horizon. (See Section 4.3 for further information on flux.)

As explained in Section 4.3, the amount of water that can contact waste depends on both the meteoric water percolation flux and on the flux of water that is mobilized by being driven out of the pores of the rock. Furthermore, depending on the repository design, there can be local areas where water is more readily able to enter the drifts than others because the thermal output of waste will drive water away from the waste for many years. For the percolation flux cases analyzed in this report, up to $5 \mathrm{~mm} / \mathrm{yr}$, the estimate of how much water could contact the WPs is less than $1 \mathrm{~mm} / \mathrm{yr}$. In addition, studies by both Nitao (1997) and Bodvardsson and Bandurraga (1996) indicate that there will be very little or no flow into the drifts at the percolation fluxes that are believed to exist at YM. Even after the thermal pulse no longer restricts inflow, after thousands of years, Nitao found that unless percolation flux exceeded $10 \mathrm{~mm} / \mathrm{yr}$, there would not be influx into the drifts. Further, as noted in Section 4.5, the use of a concrete liner will moderate or inhibit any inflow that might occur during the early times when the liner remains intact. It is also recognized that inflow will not be uniform but, rather, restricted mostly to major inflow zones. The inflowing water will interact with emplaced materials that have been altered in response to repository conditions. This alteration is expected to evolve over time. It is anticipated that the result of these interactions will be a solution of moderately high pH ( 9 to 11), with an ionic strength greater than that of the present ambient pore waters. Depending on how inflow is distributed both spatially and temporally, inflow could accelerate corrosion, but inflow is not seen as a major determinant of WP lifetime. The corrosion-allowance material can be designed with thickness necessary to provide for long-lived containers if general corrosion, not pitting or microbial-induced corrosion, is the concern.

Relative humidity, on the other hand, is perhaps the most significant environmental variable affecting corrosion rate of the outer barrier, therefore survival of the WPs. As discussed in Section 4.3, both the magnitude and time distribution of $R H$ depend on the repository design/layout. The design can prevent conditions in which corrosion is most aggressive, namely when temperatures and relative humidities are high, for many thousands of years, or it can create conditions that will be adverse to container survival. 
This is especially true for individual waste containers having low heat output or those located near the edge of the repository. The ACD and LL designs have different $R H$ conditions associated with them, and the ACD design has great variability in $R H$ conditions from package to package (see Section 4.3 and Table 4-4).

The period of time during which design influences $R H$ also depends on percolation flux. The relationship between relative humidity on the WP $\left(R H_{w_{p}}\right)$ and percolation flux falls into three flux ranges. For a percolation flux of less than $0.3 \mathrm{~mm} / \mathrm{yr}$, the duration of reduced $R H_{\mathrm{wp}}$ increases strongly with decreasing flux. For the range 0.3 to $1.0 \mathrm{~mm} / \mathrm{yr}$, the duration of reduced $R H_{\mathrm{wp}}$ is relatively insensitive to percolation flux. For percolation flux greater than $1.0 \mathrm{~mm} / \mathrm{yr}$, the duration of reduced $R H_{\mathrm{wp}}$ decreases with increasing flux. Increasing the percolation flux from 1 to $5 \mathrm{~mm} / \mathrm{yr}$, reduces the period during which $R H_{\mathrm{wp}}<65 \%$ from $1660 \mathrm{yr}$ to $1200 \mathrm{yr}$. For the first $1000 \mathrm{yr}, R H_{\mathrm{wp}}$ is only moderately sensitive to flux between 0.3 and $5 \mathrm{~mm} / \mathrm{yr}$. Even if the flux is as large as 10 to $20 \mathrm{~mm} / \mathrm{yr}$, the decay-heat-driven liquidphase flux is much larger than the percolation flux during the first $500 \mathrm{yr}$. Therefore, percolation flux will only have a moderate impact on $R H$ after 500 to 1000 years. If the percolation flux is as high as $10 \mathrm{~mm} / \mathrm{yr}$, the $R H$ will essentially be ambient (close to $100 \%$ ).

Preliminary unpublished analyses of thermal variability have been made for the ACD and the 1997 modified designs (Blink and Chesnut, 1977). Figure 6-1 shows the package arrangement for the modified design that had been described earlier in Fig. 1-3, but with both the axial position and the WP heat output shown. Figure 6-2 shows the initial heat output as a function of axial position along an emplacement drift. As can be seen, there will be a very significant peak of thermal output around the 21 PWR assembly, which will result in much higher local temperatures around these packages with associated lowering of $R H$. In contrast, much cooler temperatures prevail around the $44 \mathrm{BWR}$ assemblies. This design will result in much higher $R H$ in the areas of lower heat output and possibly even condensate collection and dripping in the cooler areas.

Figure 6-1. Location of individual waste packages for the modified design.

Figure 6-2. Heat output $(\mathrm{kW} / \mathrm{m})$ as a function of the location (axial position) of individual waste packages for various averaging lengths.

Figure 6-3 shows the effect of the time-dependent (calculated) $R H$ and $T$ environment on general corrosion rate for an ACD layout but with only $24 \mathrm{MTU} /$ acre, compared with corrosion predicted for ambient (fixed) $R H$ and $T$. This was considered to be a conservative estimate of the impact of waste-heat generation on corrosion because it represents the smallest MTU/acre value that has been considered to be feasible. Even for this conservative case, the difference between ambient and thermally perturbed conditions is dramatic. The corrosion rate does not change much, compared to ambient conditions, until a few years after emplacement, then drops rapidly at closure as the $R H$ drops to very low values. For several hundred years after closure, the calculated corrosion rate is less than $10^{-10}$ microns per year. As humidity increases from the minimum value reached shortly after closure, the corrosion rate increases rapidly but does not reach the ambient corrosion rate until almost 100,000 years after closure.

Figure 6-3. Corrosion rate of the outer WP barrier at ambient conditions compared with the rate predicted for the 24-MTU/acre repository.

Figure 6-4 shows the cumulative depth of corrosion of the outer WP barrier for both an ambient (fixed) $R H$ and $T$ environment and for the predicted $R H$ and $T$ repository conditions representative of the conservative 24-MTU/acre case. The predictions show that almost 100,000 years would be required to remove half the original outer barrier thickness by general corrosion for the repository $R H$ and $T$, as contrasted with approximately 10,000 years for the ambient conditions. These predictions do not take into account localized attack. Analyses using a Monte Carlo approach, as well as analyses for the 83.4- 


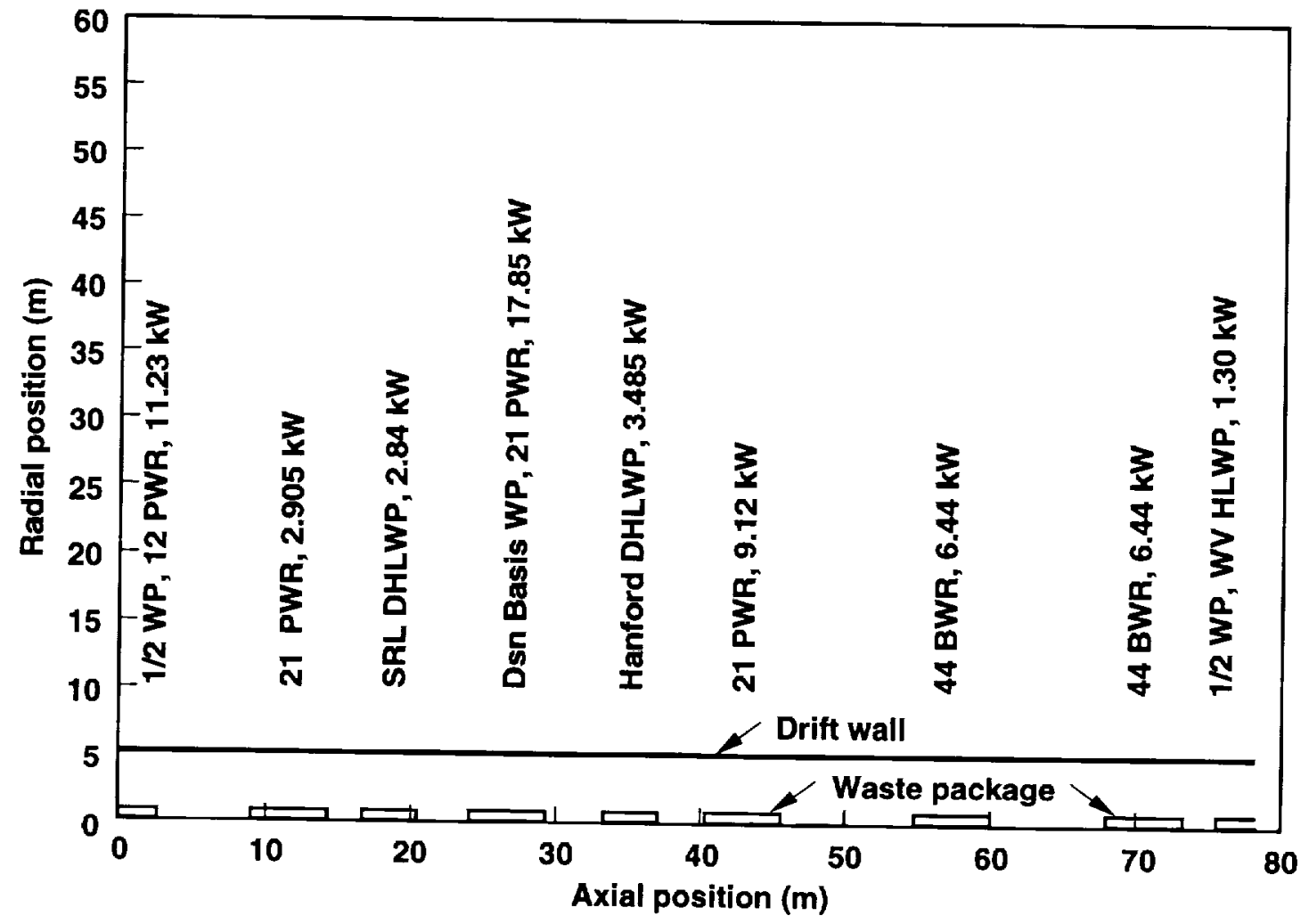

Figure 6-1 


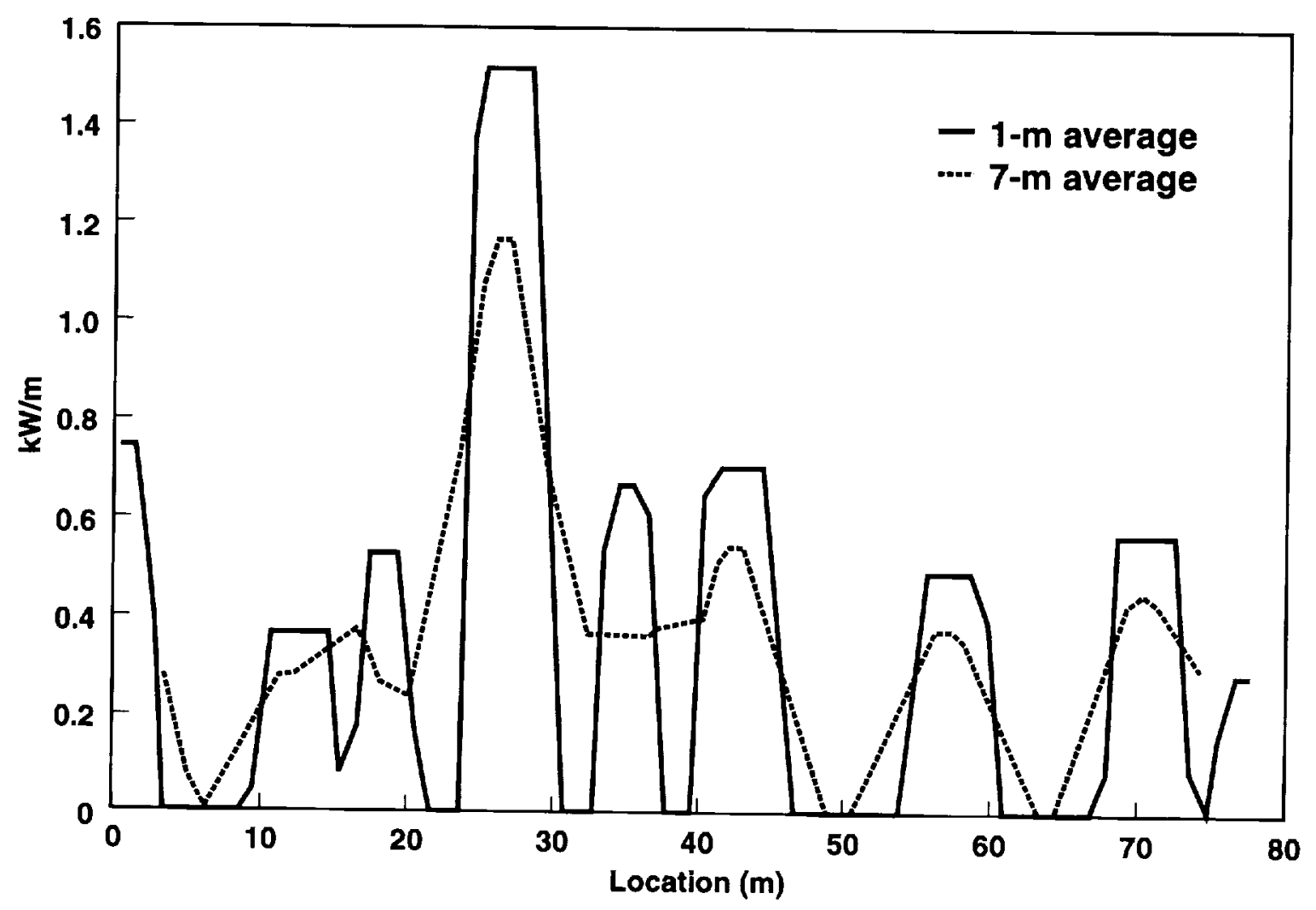

Figure 6-2 


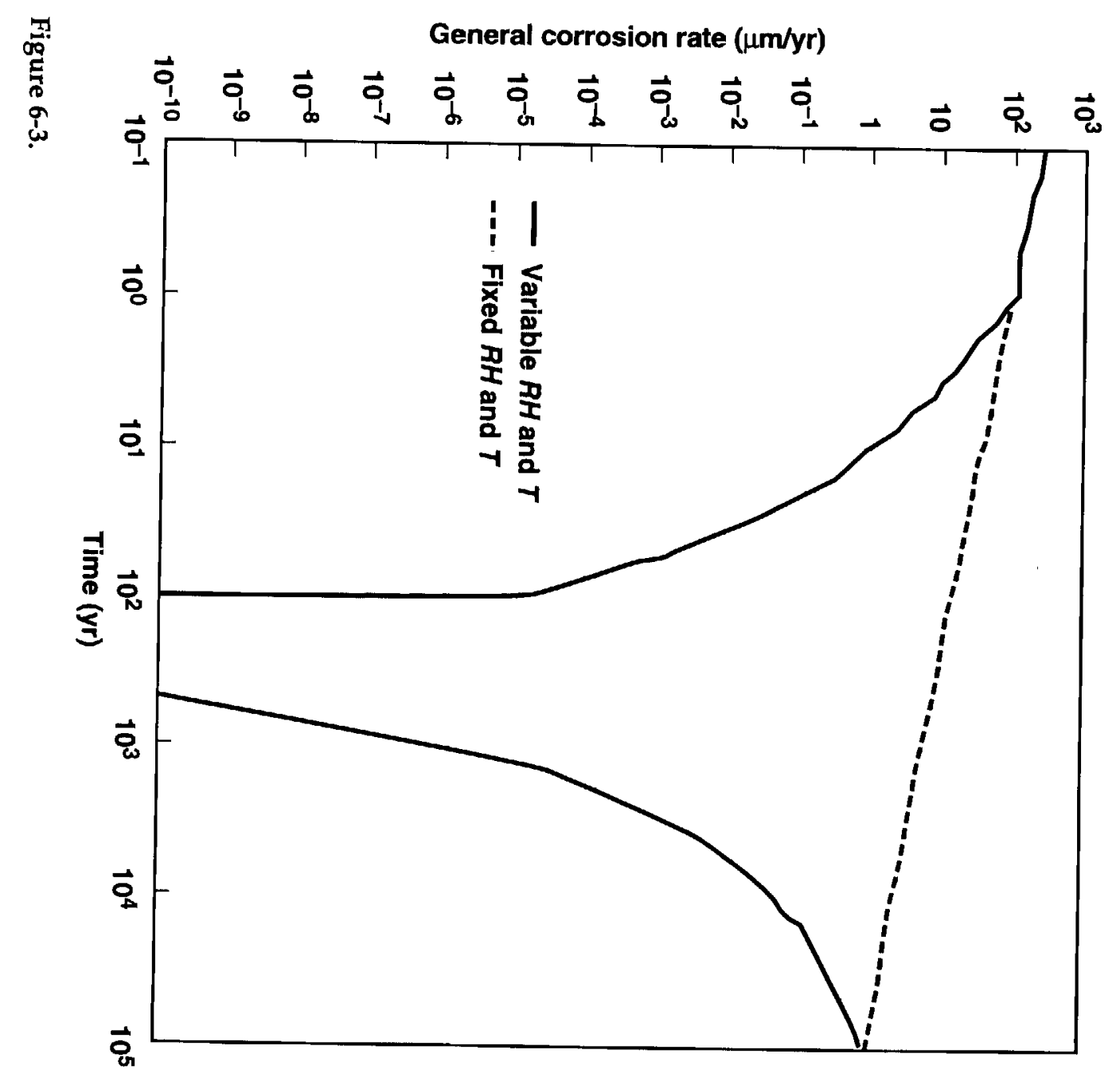




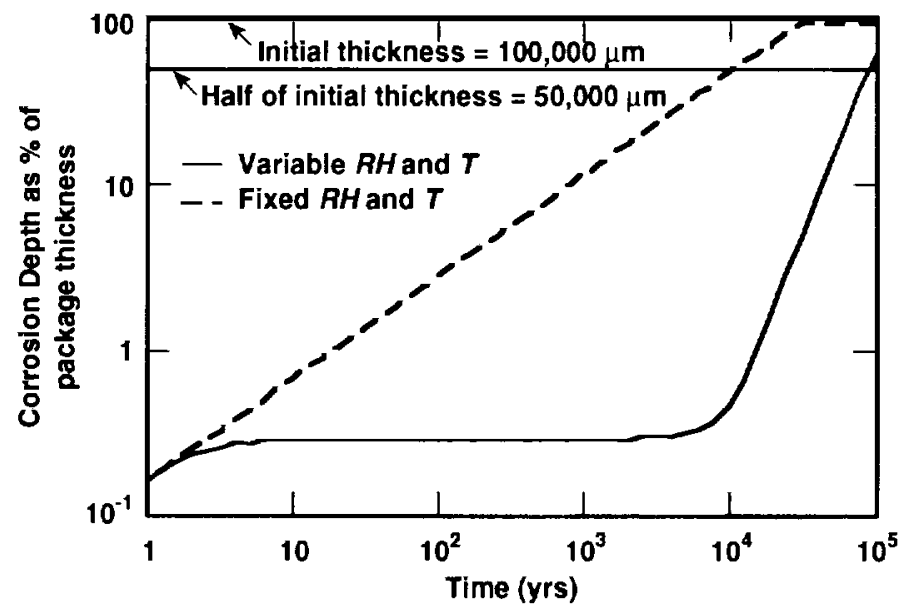

Figure 6-4. 
MTU/acre design, will be reported in the future. Such simulations of the propagation of millions of pits per WP suggest failure of the outer barrier in only a few thousand years.

Figure 6-4. Cumulative corrosion depth of the outer WP barrier at ambient conditions compared with the values predicted for the 24-MTU/acre repository.

In addition, the preliminary analyses of Blink and Chesnut (1977) have also identified the periods of time during which WPs in the ACD, 83.4-MTU/acre design will be exposed to especially adverse environments. The simultaneous occurrence of high $R H$ and $T$ promotes rapid corrosion, whereas lowering the $R H$ retards corrosion at all temperatures. Figures 6-5 and 6-6 show the conditions of corrosion susceptibility for two design options with an assumed 6-mm/yr ambient flux. Figure 6-5 shows results for the ACD design case without backfill. Fig. 6-6 shows results for the LL case with 0.1-m gaps between WPs and with sand backfill. Recall that these two designs represent the bounding cases for corrosion. For the ACD design case, both "hot" and "cool" waste packages enter the window of susceptibility - that is, the combinations of $R H$ and $T$ that cause rapid corrosion-within a few hundred years and do not exit this region until after 70,000 years. In contrast, model calculations for the LL design (Fig. 6-6) show that the "hot" packages never enter the aggressive corrosion region. The "cool' packages enter the aggressive region at about 10,000 years and exit at about 18,000 years. For the LL design with backfill, water evaporates within the backfill and is not deposited on the WPs. Therefore, the $R H$ at which corrosion starts is not lowered by the presence of salts on the WP surfaces. Other engineering options, such as drip shields, limit contact by liquid water, but they do not influence $R H$. Even continuous drift liners would only prevent such exposure if they could be designed to have lifetimes that exceed 10,000 years. Thus, the most effective engineering option that offers protection from corrosion is the simple selection of WP placement and backfill.

Figure 6-5. WP relative humidity versus surface temperature for the ACD design with an AML of $83 \mathrm{MTU} / \mathrm{acre}$, no backfill, and an ambient flux of $6.2 \mathrm{~mm} / \mathrm{yr}$ (Blink and Chesnut, 1997).

Figure 6-6. WP relative humidity versus surface temperature for the 0.1-m LL design with an AML of $83 \mathrm{MTU} / \mathrm{acre}$, sand backfill, and an ambient flux of $6.2 \mathrm{~mm} / \mathrm{yr}$ (Blink and Chesnut, 1997).

At present, the program is considering ceramic coatings or other options to make the WP lifetime less sensitive to environmental variables. However, unless $100 \%$ defect-free manufacturing and inspection can be guaranteed, the environment will still be of concern.

\subsection{Impacts on the Waste Form}

Several issues regarding waste form dissolution and radionuclide release/mobilization are related to the NFE. First, the amount and timing of dissolution or radionuclide release is directly related to the amount of water contacting the waste, its chemistry at the time of contact, and the temperature of the waste at the time of contact (which influences the kinetics or rapidity of reactions). The amount of water that contacts the waste provides an upper bound on the amount of water that contacts the WPs. This value would tend to be conservative in that the WP container would have to first fail before water could contact the waste itself. It is possible that the WP could be penetrated by humid air corrosion, exacerbated by microbes and crevice processes, before any actual flow of liquid water contacts the WPs. Another source of conservativism is introduced by assuming that all water contacting a failed WP also contacts the waste itself. Much of the water will never contact waste, especially that fraction of waste protected by cladding remaining intact after the decay of the thermal pulse. Part of the water contacting WPs will also be consumed in corrosion processes and products. Thus, depending on the design, the waste would not likely be contacted by water until well after the thermal pulse and its impact on overall flux had decayed. 


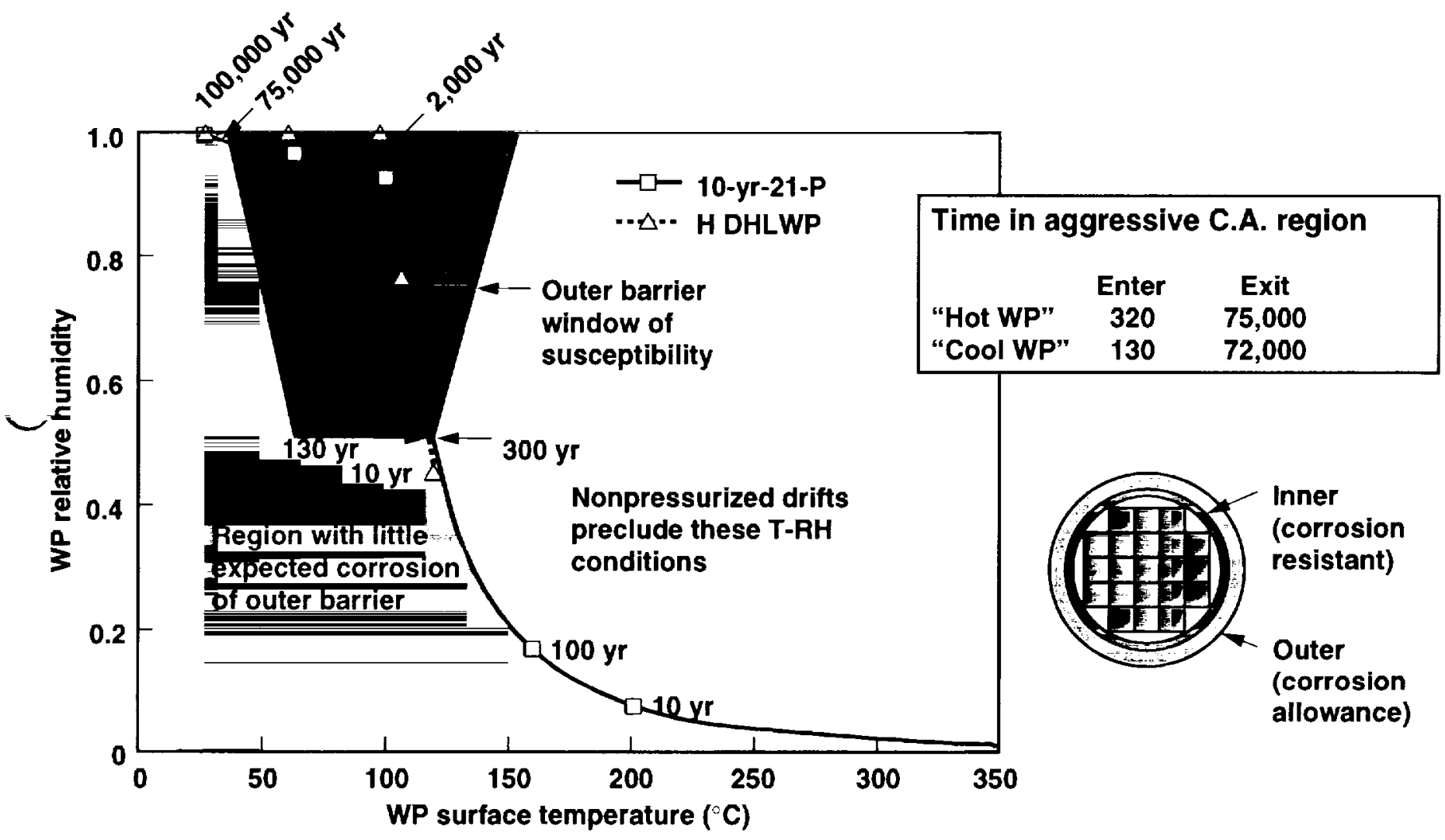

Figure 6-5. 


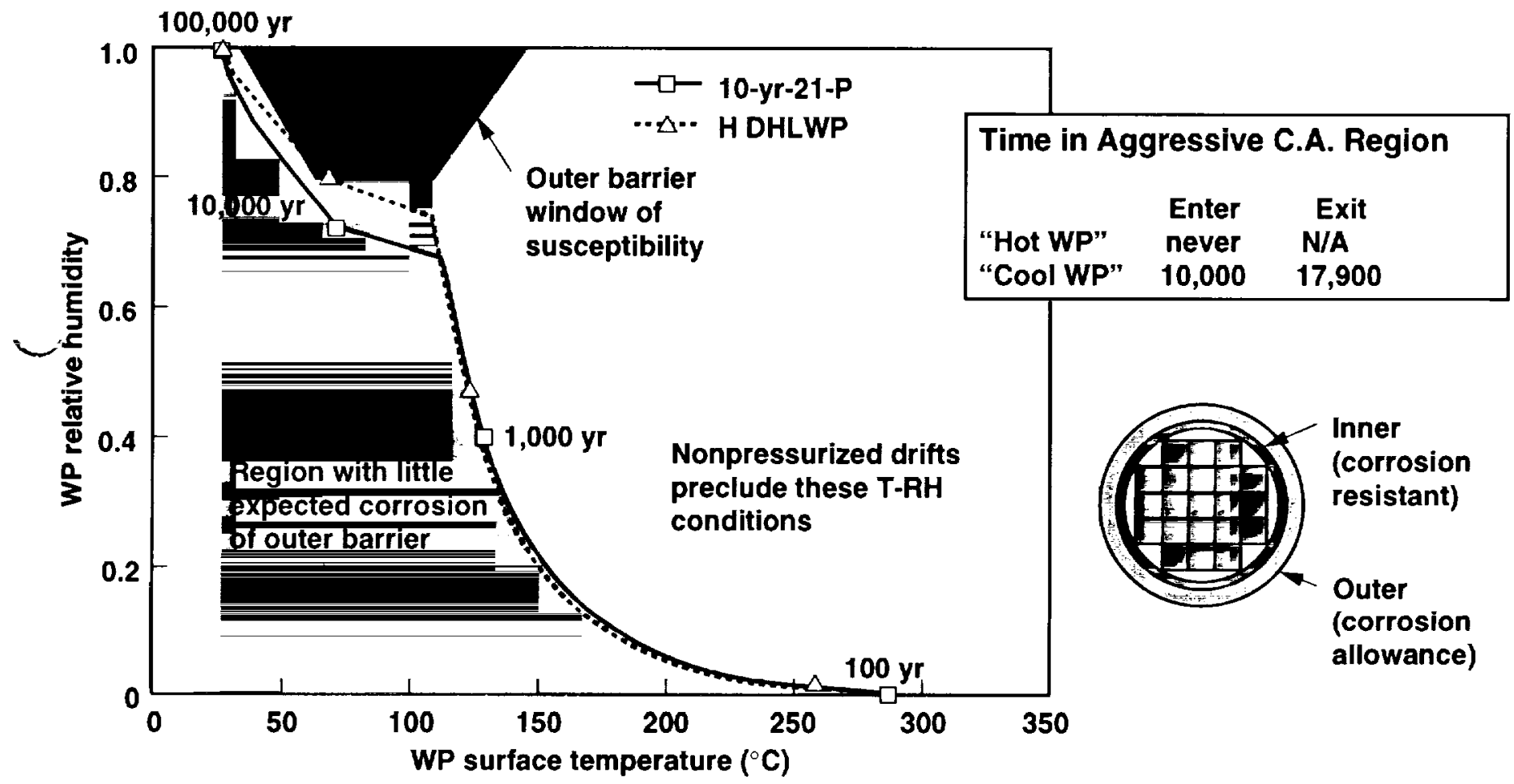

Figure 6-6. 
Water chemistry will be very much influenced by interactions with introduced materials and possibly microbes, and by the temperatures of the system at the time of those interactions. Studies are not mature in this area, but it is likely that the $\mathrm{pH}$ will be elevated by the significant amount of concrete in the system. If crushed backfill is used, the water will probably be elevated in silica. How much influence on water chemistry the corrosion products will have is not currently known. The amount of impact would depend on whether failures had occurred by general corrosion-in which case there would be large volumes of corrosion product that would both hinder water flow and also influence its chemistry-or whether the failures resulted from localized failures, such as pitting. Insufficient information is available on the design or the interaction with materials to allow definitive discussion at this time.

\subsection{Impacts on Flow Fields and Transport}

The impacts on system performance that involve flow and transport are essentially due to the $A Z$ as it develops with time. The major conclusion that can be reached at this time is that there will be a significant zone that will be exposed to both elevated temperatures and moisture (saturations). As shown in Fig. 5-6, a zone of elevated temperatures between $60^{\circ}$ and $96^{\circ} \mathrm{C}$ and saturations between 60 and $100 \%$ moves away from the repository horizon and increases in size. Below the repository is a zone from 425 to $500 \mathrm{~m}$ below surface that remains at elevated temperatures and saturations for at least 9,000 years. A similar zone is located above the repository around $250 \mathrm{~m}$ below the ground surface; however, this zone is not as longlived and extensive.

The conditions in these zones are conducive to chemical/mineralogical reactions. These zones are likely to experience equilibrium conditions. Estimates of the alteration potential show that during early times, the TSw3 unit may develop alteration products of zeolites and clays. However, the kinetics of the zones close to the repository are such that these zones may not have water present for sufficiently long periods to allow the chemical reactions to go to completion. Farther away from the repository, nearly complete chemical reactions are expected so that the mineralogy and water chemistry will be in equilibrium.

As described in Sec. 5.4.5, long-term condensate zones will allow considerable porosity enhancement (from 11 to $16 \%$ ), and the values could be even larger if the zones persist for long time periods. This would certainly be the case in the zone below the repository that is stable for many thousands of years, and for the condensate cap if condensate is able to develop above the repository. Dissolved silica would be deposited further out. Thus, a zone of enhanced porosity would develop around the repository, and a zone with reduced porosity would develop farther out. Studies of fracture healing indicate that the zones where water flows through will potentially have healing of fractures. Therefore, there is the potential to have increased porosity (and possibly permeability) around the repository with a zone of decreased porosity and permeability further out. If these zones developed, they would tend to divert percolating meteoric water away from the repository area, would restrict the downward flow of water that might have flowed through the repository (thus reducing waste transport), and create an enlarged porosity around the repository that would be able to store water so that it would not flow through the fractures. On the other hand, the zone wherein the temperatures and saturations are high is much larger and more stable (in duration) below the repository than above it. This might imply that the restrictions to flow above the repository would not develop to the same extent as below the repository. In this case, environmental conditions might develop wherein water could build up (bathtub scenario) over time. However, the development of heat-pipes in this region could cause greater rock-water interactions that would potentially cause greater changes to occur above the repository.

The $\mathrm{AZ}$ is less sensitive to repository design than is $R H$, water contact, and other parameters within the drifts and on the WPs. Therefore, it is the WP and waste form performance issues that need to be considered in design of the repository. The $\mathrm{AZ}$ is more sensitive to total mass of waste emplaced and on its density. Thus, for any given AML, the general AZ development will be similar, especially at longer time frames. Nevertheless, a zone that is part of both the AZ and NFE can be influenced by design, namely, the one that develops in the pillars between waste emplacement drifts. Condensate will tend to 
drain down the pillars during early emplacement times. Depending on the spacing of drifts, the pillars may be in the environment of elevated temperatures and saturations (between 60 and $97^{\circ} \mathrm{C}$, and greater than $60 \%$ saturation). Because condensate will be elevated in temperature, it may not require that the conduction of heat cause elevated temperatures to create conditions conducive to porosity/permeability changes. However, the larger the pillar, the longer the time for drainage to occur before the temperatures are elevated to the extent that kinetics will result in these hydrologic changes. Therefore, design options that include wider drift spacing would result in a larger percentage of the condensate draining away from the zone above the repository. This would reduce the amount of flux to re-enter the drifts and would also reduce the heat pipes that may form above the repository horizon.

An additional performance implication of the $A Z$ is the significant amounts of zeolites and secondary minerals that are likely to form below the repository. The extent of changed sorptive capacity of the overall system is not known at this time. However, preliminary indications suggest fundamental increases in both amounts of and lateral extent of these minerals.

Finally, if the thermal conditions that extend into the water table create the types of convection cells that are postulated, they might contribute to increased mixing/dilution of any radionuclides. Of course, increases in temperatures within the saturated zone may also cause the rocks to be out of thermodynamic equilibrium with the water, which could cause mineralogical changes that are unknown at present. 


\section{Acknowledgments}

The author would like to acknowledge the significant contributions that were made by W. E. Glassley, T. A. Buscheck, A. Meike, and S. Blair for their contributions and for their review of the materials of this report, which were summations of individual sections of Volume II for which they were authors. The author would also like to acknowledge the assistance of J. Blink and D. A. Chesnut for their contributions regarding the corrosion implications. A special note of appreciation is given to $R$. Kirvel for long hours in editing and in producing much of the material that is contained in this report. Appreciation is expressed to $M$. Lewis for assisting in the production of this report and to T. Carey and D. Fletcher for invaluable assistance with the illustrations contained in this report. The author would also like to express gratitude to L. Ramspott for his careful review of this report and for his insightful technical suggestions. 


\section{References}

Albin, A. L., W. L. Singleton, T. C. Moyer, A. C. Lee, R. C. Lung, G. L. W. Eatman, and D. L. Barr (1997), Geology of the Main Drift-Station 28+00 to 55+00, Exploratory Studies Facility, Yucca Mountain Project, Yucca Mountain, Nezada, Bureau of Reclamation and U.S. Geological Survey, Denver, CO.

Archambault, G., S. Gentier, J. Riss, and R. Flamand (1997), "The Evolution of Void Spaces (Permeability) in Relation with Rock Joint Shear Behavior," Int. J. Rock Mech. Min. Sci. 34:3-4, paper no. 14.

Atkins, M., D. Bennett, A. Dawes, F. Glasser, A. Kindness, and D. Read (1992), A Thermodynamic Model for Blended Cements, DOE report DOE-HMIP-92-005.

Atkins, M., F. Glasser, L. P. Moroni, and J. J. Jack (1994), Thermodynamic Modeling of Blended Cements at Elevated Temperatures $\left(50-90^{\circ} \mathrm{C}\right)$, DOE report DOE-HMIP-94-001.

Bandis, S., A. C. Lumsden, and N. R. Barton (1983), "Fundamentals of Rock Joint Deformation," Int. J. Rock Mech. Min. Sci. and Geomech. Abstr. 20, 249-268.

Barton, N. R., S. Bandis, and K. Bakhtar (1985), "Strength, Deformation, and Conductivity Coupling of Rock Joints," Int. J. Rock Mech. Min. Sci. and Geomech. Abstr. 22(3), 121-140.

Blair, S. C. and P. A. Berge (1996). "Uniaxial Compression Behavior of Small Blocks of Welded Tuff, " in Proc. 1996 Intl. High Level Radioactive Waste Management Conf., April 29-May 3, 1996, Las Vegas, NV, published by American Nuclear Society and American Society of Civil Engineers, pp. 409-411.

Blink and Chesnut (1977), personal communication.

Boitnott, G. N. (1997), "Experimental Characterization of the Nonlinear Rheology of Rock," Int. J. Rock Mech. Min. Sci. 34:3-4, paper no. 33.

Bodvarsson, G. S. and T. M. Bandurraga (1996), Development and Calibration of the Three-Dimensional SiteScale Unsaturated Zone Model of Yucca Mountain, Nevada, Lawrence Berkeley National Laboratory, Earth Sciences Division, Berkeley, CA.

Brechtel, C. E., M. Lin, E. Martin, and D. S. Kessel (1995), Geotechnical Characterization of the North Ramp of the Exploratory Studies Facility, SNAD95-0488/1 and 2, Yucca Mountain Site Characterization Project, Sandia National Laboratories, Albuquerque, NM. (MOL.19950502.0004(

Brodsky, N. S., M. Riggins, and J. Connolly (1997), "Thermal Expansion, Thermal Conductivity, and Heat Capacity Measurements at Yucca Mountain, Nevada," Int. J. Rock Mech. Min. Sci. 34:3-4, paper no. 40.

Brown, S. R. (1994), Simple Mathematical Model of a Rough Fracture, Sandia National Laboratories, Albuqueruqe, NM, SAND92-2216J. (MOL 19941106.0040)

Bruton, C. J. (1995), "Testing EQ3/6 and GEMBOCHS Using Fluid-Mineral Equilibria in the Wairakei Geothermal System: Yucca Mountain Project Letter Report, Milestone MOL206," in Chemical and Mineralogical Properties of the Waste Package Environment: Natural System Simulations, WBS Element 1.2.3.12.1, August 28, 1995.

Buscheck, T. A. (1997), personal communication.

Buscheck, T. A., D. G. Wilder, and J. J. Nitao (1993), Large-Scale In Situ Heater Tests for Hydrothermal Characterization at Yucca Mountain, Lawrence Livermore National Laboratory, Livermore, CA, UCRL-JC-112445.

Buscheck, T. A., and J. J. Nitao (1992), The Impact of Thermal Loading on Repository Performance at Yucca Mountain, Lawrence Livermore National Laboratory, Livermore, CA, UCRL-JC-109232. (NNA.920408.0008)

Buscheck, T. A., and J. J. Nitao (1993a), The Impact of Repository Heat on Thermo-Hydrological Performance at Yucca Mountain, Lawrence Livermore National Laboratory, Livermore, CA, UCRL-JC-114791.

Buscheck, T. A., and J. J. Nitao (1993b), "Repository-Heat-Driven Hydrothermal Flow at Yucca Mountain, Part I: Modeling and Analysis," Nucl. Technol. 104(3), 418-448. 
Buscheck, T. A., and J. J. Nitao (1993c), The Impact of Repository-Heat-Driven Hydrothermal Flow on Hydrological Performance at Yucca Mountain, Lawrence Livermore National Laboratory, Livermore, CA, UCRL-JC-112444.

Buscheck, T. A., and J. J. Nitao (1994a), The Importance of Thermal Loading Conditions to Waste Package Performance at Yucca Mountain, Lawrence Livermore National Laboratory, Livermore, CA, UCRL-JC116429.

Buscheck, T. A., and J. J. Nitao (1994b), The Impact of Buoyant Gas-Phase Flow and Heterogeneity on ThermoHydrological Behavior at Yucca Mountain, Lawrence Livermore National Laboratory, Livermore, CA, UCRL-JC-115351.

Buscheck, T. A., J. J. Nitao, and L. D. Ramspott (1996), Near-Field Thermal-Hydrological Behavior for Alternative Repository Designs at Yucca Mountain, Lawrence Livermore National Laboratory, Livermore, CA, UCRL-JC-124629; Materials Research Society, Proc. Mat. Res. Soc. XX Internat. Symp. Sci Basis Nuclear Waste Management, Dec. 2, 1996, Boston, MA.

Buscheck, T. A., J. J. Nitao, and S. F. Saterlie (1994), "Evaluation of Thermo-Hydrological Performance in Support of the Thermal Loading Systems Study," in Proceedings of the 5th International High Level Nuclear Waste Management Conference, Las Vegas, NV (American Nuclear Society, La Grange, IL), pp. $592-610$.

Carlos, B. (1985), Minerals in Fractures of the Unsaturated Zone from Drill Core USW-G4, Yucca Mountain, Nye County, Nevada, Los Alamos National Laboratory, Los Alamos, NM, LA-10415-MS.

(NNA.920506.0037)

Carlos, B. (1989), Fracture-Coating Minerals in the Topopah Spring Member and Upper Tuff of Calico Hills from Drill Hole J-13, Los Alamos National Laboratory, Los Alamos, NM, LA-11504-MS. (NNA.881220.0001)

Chesnut, D. A. (1992), "Characterizing the Altered Zone at Yucca Mountain: The Beginning of a Testing Strategy," Proc. Third Internat. High-Leoel Radioactive Waste Management Conf., Las Vegas, NV

Civilian Radioactive Waste Management System Management and Operation Contractor (CRWMS M\&O) (1996), Characterization of the ESF Thermal Test Area, Rev. 1 (B00000000-01717-5705-00047), pp. 5-1 to 52.

Civilian Radioactive Waste Management System Management and Operation Contractor (CRWMS M\&O) (1996), Mined Geologic Disposal System Advanced Conceptual Design Report, Vol. 2 (B00000000-017175705-00027), Rev. 00.

Daily, W., W. Lin, and T. Buscheck (1987), "Hydrological Properties of Topopah Spring Tuff-Laboratory Measurements," J. Geophys. Res. 92(B8), 7854-7864. (NNA.900123.0064)

Delany, J. M. (1985), Reaction of Topopah Spring Tuff with J-13 Water: A Geochemical Modeling Approach Using the EQ3/6 Reaction Path Modeling Code, Lawrence Livermore National Laboratory, Livermore, CA, UCRL-53631.

DOE (U.S. Department of Energy) (1988), Site Characterization Plan, Yucca Mountain Site, Nevada Research and Development Area, Nevada, Office of Civilian Radioactive Waste Management, Washington, DC, DOE/RW-0199. (HQO.881201.0002)

DOE (U.S. Department of Energy) (1995), Yucca Mountain Project Reference Information Base, Version 4, Yucca Mountain Site Characterization Project Office, Las Vegas, NV, YMP/CC-0002. (NNA.890330.0077)

DOE (U.S. Department of Energy) (1997), Quality Assurance Requirements and Description for the Civilian Radioactive Waste Management Program, Office of Civilian Radioactive Waste Management, Washington, DC, DOE/RW-0333, Rev. 7.

Dudley, Jr., W. W., W. E. Wildon, and D. T. Hoxie (1990), "Hydrologic Framework of the Yucca Mountain Area, Nevada," Proc. Int. Symp. on Unique Underground Structures, (Colorado School of Mines Press, Colorado). (NNA.900403.0205)

Elayer, R. (1997), Determination of Available Volume for Repository Siting, YMP-M\&O Design Analysis Document BCA000000-01717-0200-00007, Rev. 00. 
Finley, R. E., S. R. Sobolik, N. D. Francis, S. Ballard, J. T. George, and L. S. Costin (1997), "Preliminaty Thermomechanical Results of a Heater Test in Welded Tuff," Int. J. Rock Mech. Min. Sci. 34:3-4, paper no. 080 .

Flint, A. (1991), personal communication with Alan Flint from the U.S. Geological Survey on the topic of "Annual Precipitation Measurements at Yucca Mountain." (N/A)

Gentier, S. S. and D. L. Hopkins (1997), "Mapping Fracture Aperture as a Function of Normal Stress Using a Combination of Casting, Image Analysis and Modeling Techniques," Int. J. Rock Mech. Min. Sci. 34:3-4, paper no. 132.

Glassley, W. E. (1986), Reference Waste Package Environment Report, Lawrence Livermore National Laboratory, Livermore, CA, UCRL-53726. (NNA.920506.0035)

Glassley, W. E. (1995), "Characterization of Chemical and Mineralogical Changes in the PostEmplacement Environment," YMSCP Study Plan for SCP Section 8.3.4.2.4.1, R1, p. 69.

Glassley, W. E. (1995), Report on Near-Field Geochemistry: Water Composition Changes Due to Evaporation, Yucca Mountain Milestone MOL206.

Glassley, W. E. (in preparation), Near Field Environmental Models Report, deliverable ID: SP3100M3.

Hardin, E. L. and D. A. Chesnut (1997), Synthesis Report on Thermally Driven Coupled Processes, Lawrence Livermore National Laboratory, Livermore, CA, Milestone report SP3005M3 (in preparation).

Harrar, J. E., J. F. Carley, W. F. Isherwood, and E. Raber (1990), Report of the Committee to Review the Use of J-13 Well Water in Nevada Nuclear Waste Storage Investigations, Lawrence Livermore National Laboratory, Livermore, CA, UCID-21867. (NNA.910131.0274)

Harrison-Giesler, D. J., R. P. Morissett, and L. J. Jardine (1991), Yucca Mountain Site Characterization Project Waste Package Plan, YMP-90/62, Lawrence Livermore National Laboratory, Livermore, CA, UCRL-JC106161. (NNA.920529.0030)

Horn, J. M. and A. Meike (1996), "A Program to Assess Microbial Impacts on Nuclear Waste Containment," Proc. 1996 High-Level Radioactive Waste Meeting, Las Vegas, NV; Lawrence Livermore National Laboratory, Livermore, CA, UCRL-JC-122732.

Horn, J. M., B. Economides, A. Meike, and R. D. McCright (1996), "Initial Studies to Assess Microbial Impacts on Nuclear Waste Disposal" Proc. 1996 High-Level Radioactive Waste Meeting, Las Vegas, NV; Lawrence Livermore National Laboratory, Livermore, CA, UCRL-JC-122587.

Hudson, J. A. (1989), Rock Mechanics Principles in Engineering Practice (Butterworths, London), p. 72.

Jiao, Y., and J. A. Hudson (1995), "The Full-Coupled Model for Rock Engineering Systems," Int. J. Rock Mech. Min. Sci. Geomech. Abst. 32(5), 491-512.

Kemeny, J., and N. Cook (1990), "Rock Mechanics and Crustal Stress," Demonstration of a Risk-Based Approach to High-Leoel Waste Repository Evaluation, R. K. McGuire, Ed., Electric Power Rescarch Institute, Palo AIto, CA, EPRI NP-7057. (NNA.910813.0004)

Klavetter, E. A., and R. R. Peters (1986), Estimation of Hydrologic Properties of an Unsaturated, Fractured Rock Mass, Sandia National Laboratories, Albuquerque, NM, SAND84-2642. (NNA.870317.0738)

Klavetter, E. A., and R. R. Peters (1987), An Evaluation of the Use of Mercury Porosimetry in Calculating Hydrologic Properties of Tuffs from Yucca Mountain, Nevada, Sandia National Laboratories, Albuquerque, NM, SAND86-0286-UC-70. (NNA.890327.0056)

Klavetter, E. A., and R. R. Peters (1988), "A Continuum Model for Water Movement in an Unsaturated Fracture Rock Mass," Water Resources Research 24, 416-430. (NNA.900719.0082)

Knauss, K. G. (1987), "Zeolitization of Glassy Topopah Spring Tuff under Hydrothermal Conditions," Mat. Res. Soc. Symp. Proc. 84, 737-745. (NNA.920302.0050)

Knauss, K. G., and D. W. Peifer (1986), Reaction of Vitric Topopah Spring Tuff and J-13 Groundwater under Hydrothermal Conditions Using Dickson-Type, Gold-Bag Rocking Autoclaves, Lawrence Livermore National Laboratory, Livermore, CA, UCRL-53795. (NNA.891102.0117)

Knauss, K. G., J. M. Delany, W. J. Beiriger, and D. W. Peifer (1986), "Hydrothermal Interaction of Topopah Spring Tuff with J-13 Water as a Function of Temperature," Mat. Res. Soc. Symp. Proc., vol. 44, pp. 539-546. (NNA.870407.0364) 
Knauss, K. G., W. J. Beiriger, and D. W. Peifer (1987), Hydrothermal Interaction of Solid Wafers of Topopah Spring Tuff with J-13 Water and Distilled Water at 90 and $150^{\circ} \mathrm{C}$ Using Dickson-Type, Gold-Bag Rocking Autoclaves: Long-Term Experiments, Lawrence Livermore National Laboratory, Livermore, CA, UCRL-53722. (NNA.19870713.0081)

Levy, S. S. (1984a), "Studies of Altered Vitrophyre for the Prediction of Nuclear Waste Repository Induced Thermal Alteration at Yucca Mountain, Nevada," in Scientific Basis for Nuclear Waste Management VII, G. L. McVay, Ed. (Elsevier, New York), pp. 959-966.

Levy, S. S. (1984b), Petrology of Samples from Drill Holes USW H-3, H-4, and H-5, Yucca Mountain, Nevada, Los Alamos National Laboratory, Los Alamos, NM, LA-9706-MS.

Lin, W. (1990), Variation of Permeability with Temperature in Fractured Topopah Spring Tuff Samples, Lawrence Livermore National Laboratory, Livermore, CA, UCRL-JC-104765. (NNA.910523.0105)

Lin, W. and W. D. Daily (1989), "Laboratory Study of Fracture Healing in Topopah Spring TuffImplications for Near Field Hydrology," Proc. of the ANS Topical Mtg. on Nuclear Waste Isolation in an Unsaturated Zone, Focus '89 (American Nuclear Society, La Grange Park, IL), p. 443. (Readily available)

MacDougall, H. R., L. W. Scully, and J. R. Tillerson, (Compilers) (1987), Site Characterization Plan Conceptual Design Report, Sandia National Laboratories, Albuquerque, NM, SAND84-2641. (NNI.880902.0014)

MacIntyre, A. T., D. Chesnut, and W. J. O' Connell (1990), Disruptive Scenario Aspects Important to Source Term Performance," Lawrence Livermore National Laboratory, Livermore, CA, UCRL-JC104769. (Abstract)

Martin, R. J., J. S. Noel, P. J. Poyd, and R. H. Price (1997), "Creep and Static Fatigue of Welded Tuff from Yucca Mountain, Nevada," Int. J. Rock Mech. Min. Sci. 34:3-4, paper no. 190.

Martin, R. J., R. H. Price, P. J. Boyd, and J. S. Noel (1994), Bulk and Mechanical Properties of the Paintbrush Tuff Recovered from Borehole USW NRG-6: Data Report, Sandia National Laboratories, Albuquerque, NM, SAND93-4020. (MOL.19940811.0001)

Martin, R. J., R. H. Price, P. J. Boyd, and J. S. Noel (1995a), Bulk and Mechanical Properties of the Paintbrush Tuff Recovered from Borehole USW NRG-7/7 A: Data Report, Sandia National Laboratories, Albuquerque, NM, SAND94-1996. (MOL.19930116.0087)

Martin, R. J., R. H. Price, P. J. Boyd, and J. S. Noel (1995b), Creep in Topopah Spring Member Welded Tuff, Sandia National Laboratories, Albuquerque, NM, SAND94-2585. (MOL.19950502.0006)

Montazar, P., and W. E. Wilson (1984), Conceptual Hydrologic Model of Flow in the Unsaturated Zone, Yucca Mountain, Nevada, U. S. Geological Survey, Lakewood, CO, WRIR-84-4345. (NNA.890327.0051)

Moore, D. E., C. Morrow, and J. Byerlee (1986), "High-Temperature Permeability and Groundwater Chemistry of Some Nevada Test Site Tuffs," J. Geophys. Res. 91(B2), 2163-2171. (Readily available)

Nimick, F. G., and B. M. Schwartz (1987), Bulk, Thermal, and Mechanical Properties of the Topopah Spring Member of the Paintbrush Tuff, Yucca Mountain, Nevada, Sandia National Laboratories, Albuquerque, NM, SAND85-0762. (NNA.870723.0015)

Nitao, J. J. (1988), Numerical Modeling of the Thermal and Hydrological Environment Around a Nuclear Waste Package Using the Equivalent Continuum Approximation: Horizontal Emplacement, Lawrence Livermore National Laboratory, Livermore, CA, UCID-21444. (NNA.890317.0021)

Nitao, J. J. (1997), Preliminary Bounds for the Drift-Scale Distribution of Percolation and Seepage at the Repository Level under Pre-Emplacement Conditions, Lawrence Livermore National Laboratory, Livermore, CA. (LLYMP 9703034), letter report to CRWMS Management and Operations Contractor, Las Vegas, NV).

Nitao, J. J. and T. A. Buscheck (1995), "Discrete-Fracture Modeling of Thermal-Hydrological Processes at Yucca Mountain and the LLNL G-Tunnel Field Test," Materials Rescarch Society, Pittsburgh, PA, Proc. Mat. Res. Soc. XIX Internat. Symp. Sci Basis Nuclear Waste Management, Nov. 27-Dec. 1, 1995. 
Olsson, W. A. (1987), Rock Joint Compliance Studies, Sandia National Laboratories, Albuquerque, NM, SAND86-0177.

Olsson, W. A. (1988), Compliance and Strength of Artificial Joints in Topopah Spring Tuff, Sandia National Laboratories, Albuquerque, NM, SAND88-0660.

Olsson, W. A. and S. R. Brown (1994), Mechanical Properties of Seven Fractures from Drillholes NRG-4 and NRG-6 at Yucca Mountain, Neoada, Sandia National Laboratories, Albuquerque, NM, SAND94-1995. (MOL.19941007.0081)

Ortiz, T. S., R. L. Williams, F. B. Nimick, B. C. Whittet, and D. L. South (1985), A Three-Dimensional Model of Reference Thermal/Mechanical and Hydrologic Stratigraphy at Yucca Mountain, Southern Nevada, Sandia National Laboratories, Albuquerque, NM, SAND84-1076. (NNA.890315.0013)

Price, R. H. (1986), Effects of Sample Size on the Mechanical Behavior of Topopah Spring Tuff, Sandia National Laboratories, Albuquerque, NM, SAND85-0709. (NNA.891106.0125)

Price, R. H., J. R. Connolly, and K. Keil (1987), Petrologic and Mechanical Properties of Outcrop Samples of the Welded, Devitrified Topopah Spring Member of the Paintbrush Tuff, Sandia National Laboratories, Albuquerque, NM, SAND86-1131. (NNA.870601.0013)

Pruess, K., J. S. Y. Wang, and Y. W. Tsang (1990), "On Thermohydrologic Conditions near High-Level Nuclear Wastes Emplaced in Partially Saturated Fractured Tuff, Part I: Simulation Studies with Explicit Consideration of Fracture Effects," Water Resources Research 26(6), 1235-1248.

Pruess, K. and Y. W. Tsang (1994), Thermal Modeling for a Potential High-Level Nuclear Waste Repository at Yucca Mountain, Nezada, Lawrence Berkeley National Laboratory, Berkeley, CA, LBL-35381. (HQO.19940506.0005)

Ramirez, A., T. Buscheck, R. Carlson, W. Daily, K. Lee, W. Lin, N-H. Mao, T-S. Ueng, H. Wang, and D. Watwood (1991), Prototype Engineered Barrier System Field Tests (PEBSFT), Final Report, Lawrence Livermore National Laboratory, Livermore, CA, UCRL-ID-106159. (NNA910711.0047)

Roberts, J. J. and W. Lin (1997), "X-Ray Radiography of Fracture FLow and Matrix Imbibition in Topopah Spring Tuff Under a Thermal Gradient," Int. J. Rock Mech. Min Sci. 34(3-4), paper no. 259.

Scott, R. B., and M. Catellanos (1984), Stratigraphic and Structural Relations of Volcanic Rocks in Drill Holes USW GU-3 and USW G-3, Yucca Mountain, Nye County, Nevada, U.S. Geological Survey, Denver, CO, OFR-84-491. (NNA.870519.0095)

Stock, J. M., J. H. Healy, and S. H. Hickman (1984), Report on Televiewer Log and Stress Measurements in Core Hole USW G-2, Nevada Test Site, U.S. Geological Survey, Denver, CO, OFR-84-172. (NNA.870406.0157)

Stock, J. M., J. H. Healy, S. H. Hickman, and M. D. Zoback (1985), "Hydraulic Fracturing Stress Measurements at Yucca Mountain, Nevada, and Relationship to Regional Stress Field," I. Geophys. Res. 90(B10), 8691-8706. (Readily available)

Stout, R. B. and H. R. Leider (1997), Waste Form Characteristics Report, Revision 1, Lawrence Livermore National Laboratory, Livermore, CA, UCRL-ID-108314, rev. 1.2.

Van, K., D. McCright, A. K. Roy, and D. Jones (1994), Engineered Materials Characteristics Report, Lawrence Livermore National Laboratory, Livermore, CA, UCRL-ID-119564, 3 vols; Vol. 3, Rev. 1 in preparation, 1997.

Warren, R. S., F. M. Byers, and F. A. Caporuscio (1984), Petrography and Mineral Chemistry of Units of the Topopah Spring, Calico Hills, and Crater Flat Tuffs, and Older Volcanic Units, with Emphasis on the Samples from Drill Hole USW G-1, Yucca Mountain, Nevada Test Site, Los Alamos National Laboratory, Los Alamos, NM, LA-10003-MS. (HQS.19880517.2569)

Wilder, D. G. (1986), Inelastic Deformations of Fault and Shear Zones in Granitic Rock, Lawrence Livermore National Laboratory, Livermore, CA, UCRL-93422.

Wilder, D. G. (1987), Influence of Stress-Induced Deformations on Observed Water Flow in Fractures at the Climax Granitic Stock, Lawrence Livermore National Laboratory, Livermore, CA, UCRL-95539, Rev. 1. 
Wilder, D. G. (1990), “Engineered Barrier Systems and Canister Orientation Studies for the Yucca Mountain Project, Nevada," Proc. Int. Symp. on Unique Underground Structures, (Colorado School of Mines Press, Colorado). (NNA.910711.0041)

Wilder, D. G. (1993), Preliminary Near-Field Environment Report, Volume I: Technical Bases for EBS Design, Lawrence Livermore National Laboratory, Livermore, CA, UCRL-LR-107476 Vol. 1.

Wolery, T. J. (1992), EQ3/6, A Software Package for Geochemical Modeling of Aqueous Systems: Package Overview and Installation Guide, Lawrence Livermore National Laboratory, Livermore, CA, UCRLMA-110662.

Yang, C., and Daemen, J. J. K. (1997), "Temperature Effects on Creep of Tuff and Its Time-Dependent Damage Analysis," Int. J. Rock Mech. Min. Sci. 34:3-4, paper no. 345.

Yow, L. J., Jr. and D. G. Wilder (1983), "Planning Exploratory Drilling: The Effect of Blind Zones and Level of Logging Effort," Proc. 24th U.S. Symp. Rock Mech., College Station, TX, 807-812. 